\title{
Wilfried Stölting
}

\section{Beiträge \\ zur Geschichte des Artikels im Bulgarischen}

Verlag Otto Sagner München · Berlin - Washington D.C.

Digitalisiert im Rahmen der Kooperation mit dem DFG-Projekt „Digi20“

der Bayerischen Staatsbibliothek, München. OCR-Bearbeitung und Erstellung des eBooks durch den Verlag Otto Sagner:

http://verlag.kubon-sagner.de

() bei Verlag Otto Sagner. Eine Verwertung oder Weitergabe der Texte und Abbildungen, insbesondere durch Vervielfältigung, ist ohne vorherige schriftliche Genehmigung des Verlages unzulässig. 


\section{- Slavistische Beiträge}

Unter Mitwirkung von M. Braun, Göttingen · T P. Diels, München - J. Holthusen, München - E. Koschmieder, München - W. Lettenbauer, Freiburg/Br. J. Matl, Graz

F. W. Neumann, Mainz - K.-H. Pollok, Regensburg $\cdot$ L. Sadnik-Aitzetmüller, Graz $\cdot J$. Schütz, Erlangen

HERAUSGEGEBEN VON † A. SCHMAUS, MÜNCHEN

Technische Redaktion: P. Rehder, München

Band 44 


\author{
WILFRIED STÖLTING
}

\title{
BEITRÄGE ZUR GESCHICHTE DES ARTIKELS IM BULGARISCHEN
}

VERLAG OTTO SAGNER - MÜNCHEN

1970

P71/1557 
D 188

Copyright by Verlag Otto Sagner, München 1970 Abtellung der $\mathrm{Pa}$. Kubon \& Sagner, München Druck: Pa. W.u.I.M. Salzer

8 Mlinchen 2, Schle1Bheimerstr. 20 
Die vorliegende Arbeit wurde im Wintersemester 1968/69 von der Philosophischen Pakultät der Preien Universität Berlin als Dissertation angenommen.

Diese Untersuchung wurde von Herm Prof. Dr. A. Schmaus im Frühjahr 1965 in München angeregt und durch lange Diskussionen mit Herrn Prof. Dr. N. Reiter, Berlin, in dankenswerter Weise gefördert.

Herrn Prof. Schmaus und dem Verlag 0tto Sagner danke ich zudem für die Aufnahme der Arbeit in die "Slavistischen Beiträge". 


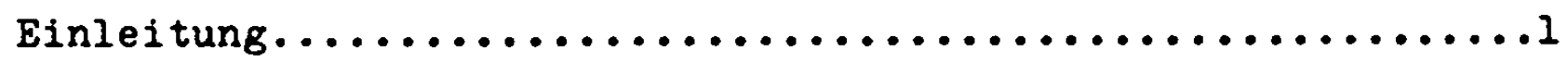

I. Iinguistischer Kontakt auf dem Balkan.............

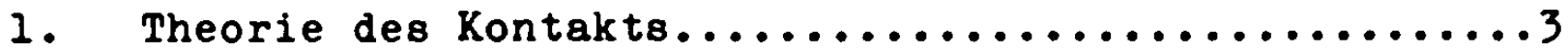

2. Phasen des balkanischen Sprachkontakto............l

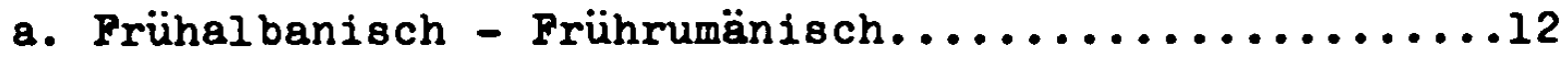

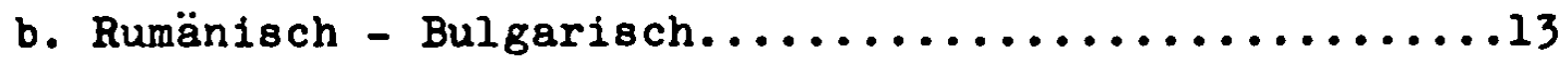

II. Die Entstehung des Artikels im Bulgarisch-

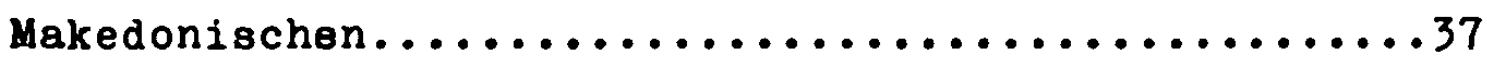

1. Theorie der Artikelflexion......................

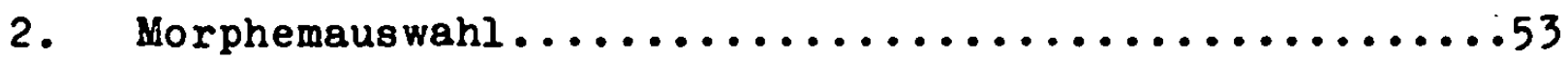

3. Morphemposition........................

8. Innerslavische Tendenzen...................

b. Artikelposition des rumänischen Substrats.........95

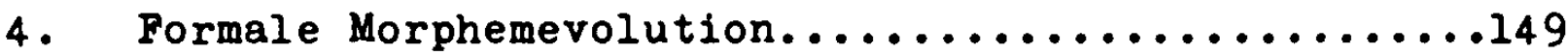

8. Veränderung des Demonstrativpronomens in

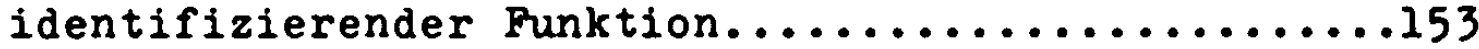

b. Veränderung des Demonstrativpronomens in

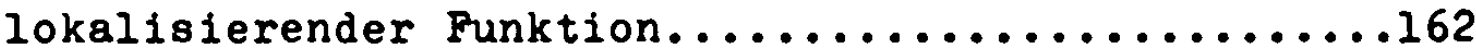

c. Entstehung des Artikelallomorphs -

d. Chronologische Einordnung der Artikelevolution.....171

III. Artikel und Kasusflexion im Bulgarisch-Makedoni-

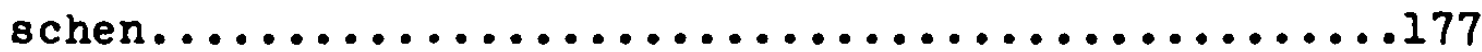

1. Plexionsparallelismus von Substantiv und Artikel...184

8. Synthetisches Directus-Obliquus-System..........184

b. Analytisches Directus-Obliquus-System...........19l

2. Flexionsdifferenz von Substantiv und Artikel......196

IV. Protoartikel im Slavischen und Albanischen.......221

Resümee...................................253

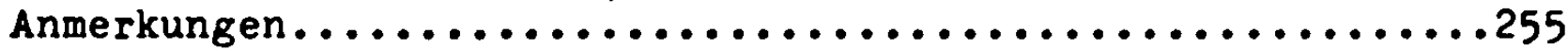

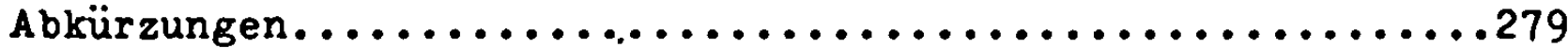

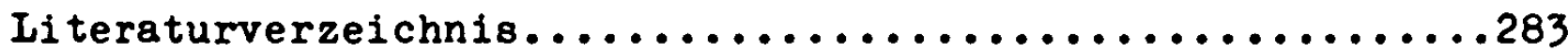


(1) if

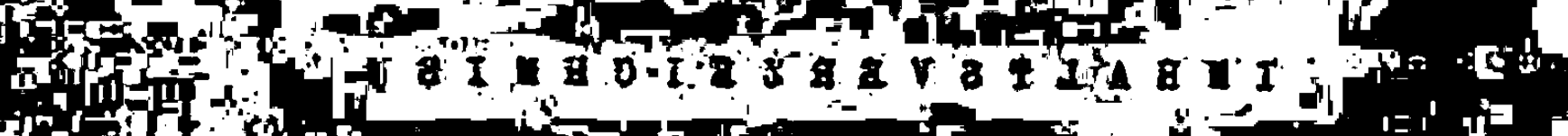
皮

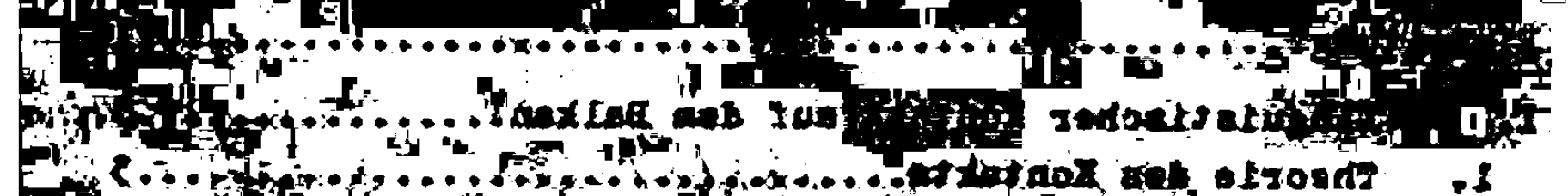

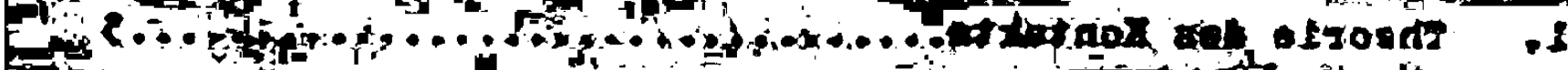

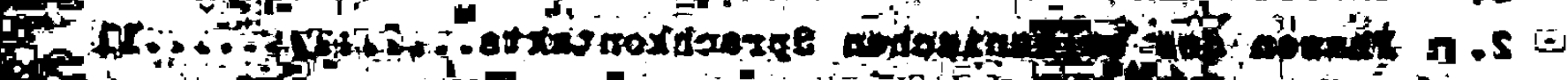

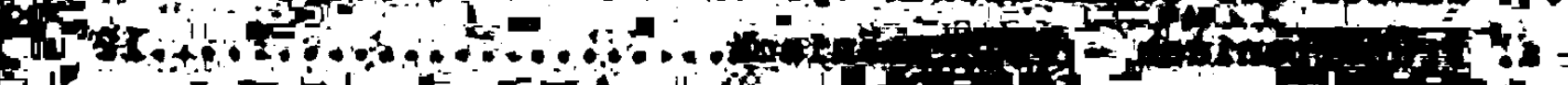

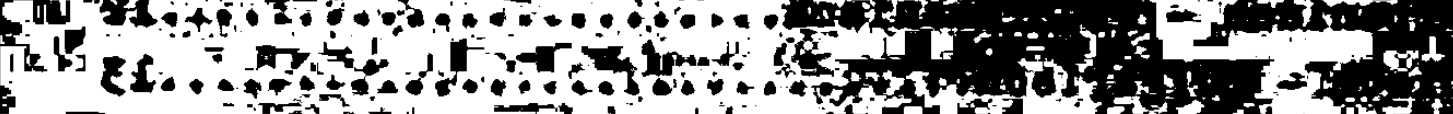

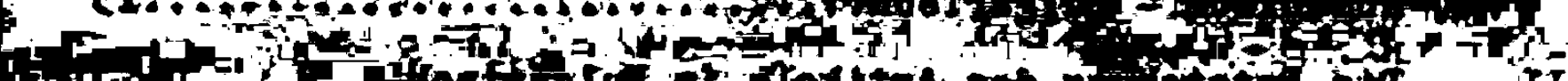

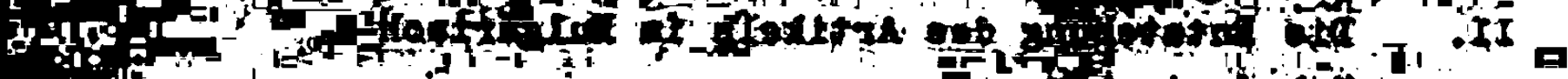

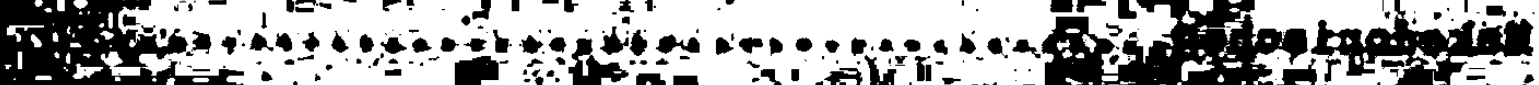
-

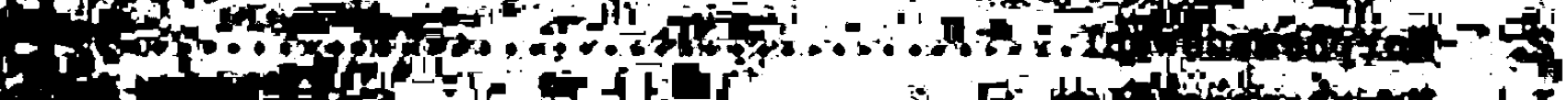
in $\Rightarrow$ ll

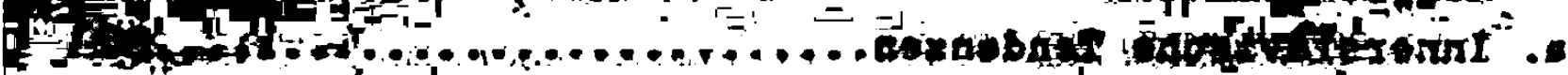
If

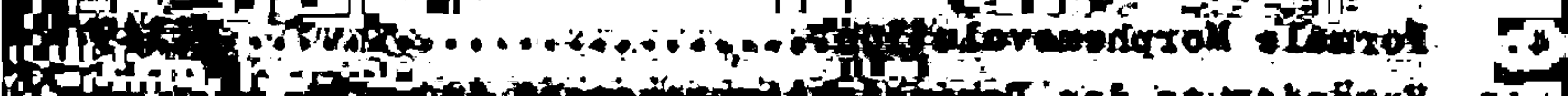

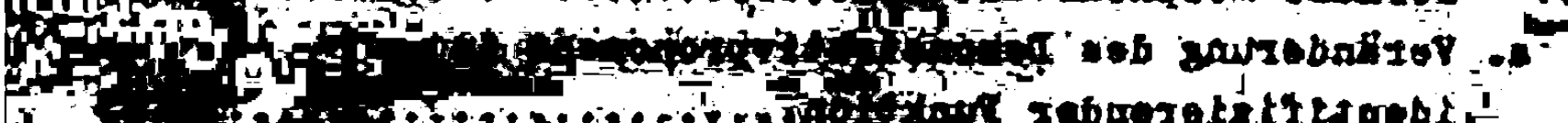
in

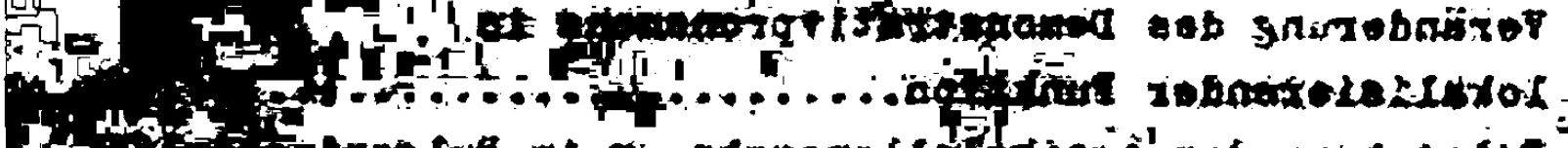

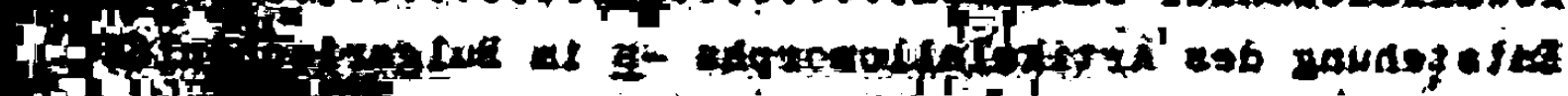
Fin

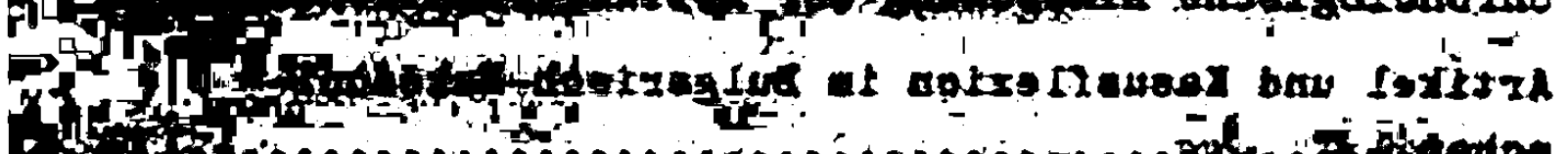

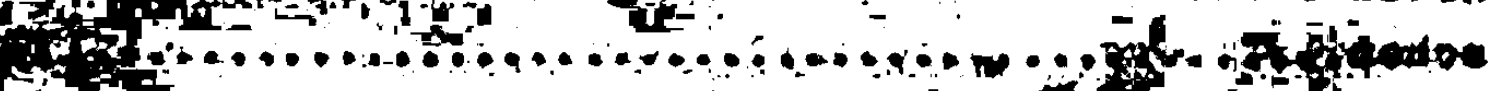

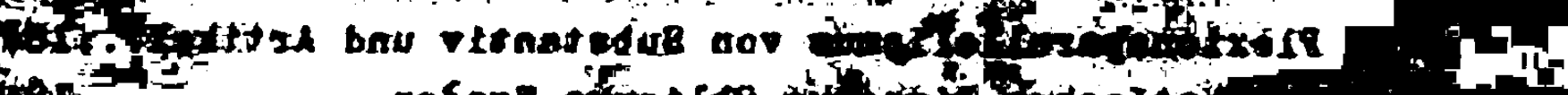
1.

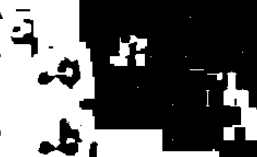

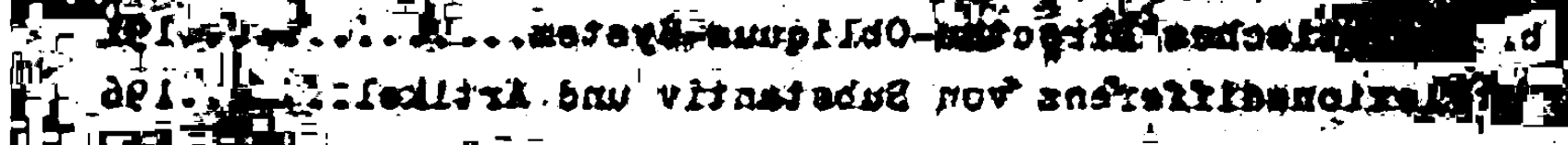

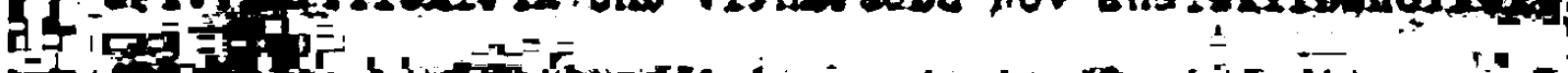

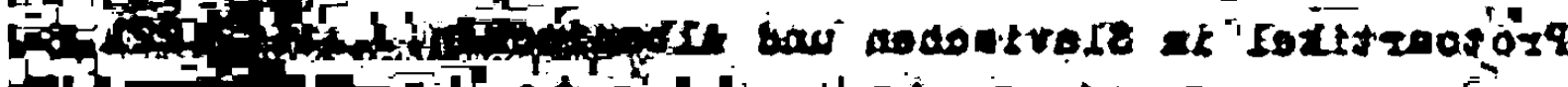

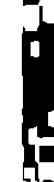

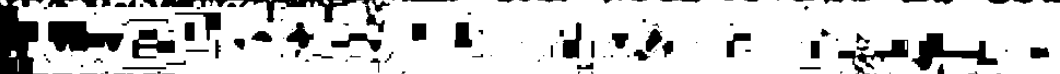

\section{$\sqrt{12}$

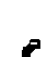
1 Tip 5 C85. 8 . 1 L 1 1 . . Astrenzidd $\vec{d}$

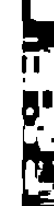
of

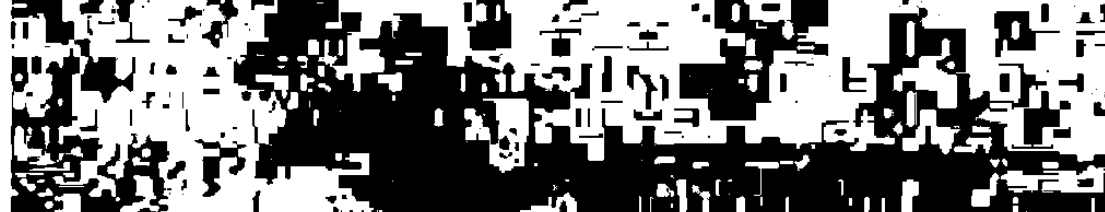

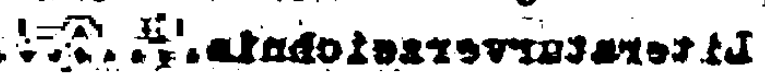


"Die Artikelform ist einer der hervortretendsten Züge des Bulgarischen. Zusarmen mit dem analytischen Charakter des Nominalsystems bildet sie das Wesentlichste und Typischste, das den besonderen Platz des Bulgarischen unter den übrigen slavischen Sprachen bestimmt." (Mirčev) ${ }^{l}$ ) Der sogenannte 'bestimmte' Artikel wird auBer im Neubulgarischen auch im Makedonischen und im 0sttorlakischen verwendet (timočko-lužnički govori, zaplanjski govor). ${ }^{2}$ ) Während also dem deutschen 'FluB', 'ein FluB', 'der FluB' im Ostslavischen, Westslavischen und Serbokroatischen ein reka (russisch) entspricht, lauten die neubulgarisch-makedonischen Oppositionsglieder reka 'PluB', 'ein PluB' - rekata 'der PluB'.

Der Bedeutung des Problems entsprechend, gibt es zu der Genesis des Artikels im Bulgarischen eine umfangreiche Sekundärliteratur, in der verschiedene Theorien über die Ursache dieser Artikelentstehung und über seine Entwicklungszeit vertreten werden. Bei der Entstehung werden entweder interne bulgarisch-makedonische Sprachverhältnisse oder ein fremdsprachlicher Einfluß als mögliche Gründe, bei der Entwicklungszeit die Ausbildung des Artikels schon in der altkirchenslavischen Epoche oder erst im Mittelbulgarischen (12. 14. Jahrhundert) als mögliche Datierungen angenommen.

Die vorliegende Arbeit will zu verschiedenen, die Entstehung und Entwicklung des bulgarischen Artikels betreffenden Prären neue Deutungsmöglichkeiten vortragen. Sie stützt sich dabei auf die in der slavistischen Forschung zusammengestellten Belege aus der Geschichte des Bulgarisch-Makedonischen, welche neu interpretiert werden. Die hier vorgelegte Interpretation geht von folgendem aus:

1. Die Belege sollen "einer systematischen Methode und Betrachtung des zu untersuchenden Materials nicht als Sammlung verstreuter Pakten, sondern als zu éiner Struktur gehörig, mit den ihr innewohnenden GesetzmäBigkeiten" (Civ'jan) ${ }^{3}$ ) un- 
terzogen werden, wie sie sich schon 1939 in den Beiträgen zum nicht abgehaltenen III. Slavistenkongre $B$ in Belgrad unter dem EinfluB N. S. Trubetzkoys und R. Jakobsons abzeichnete. Dadurch erhält das gesammel te und genügend geordnete Material eine seiner internen Systemhaftigkeit entsprechende theoretische Begründung.

2. In den Pällen, in denen eine systeminterne Begründung für die Sprachentwicklung des Bulgarischen nicht gegeben werden kann, werden die Sprachen, die im Laufe der Historie mit dem Bulgarischen in Kontakt standen, auf parallele systeme hin untersucht, um wechselseitige systemberührungen feststellen und abgrenzen zu können. In diesem Zusammenhang ist die Zugehörigkeit des Bulgarischen zum balkanischen Sprachbund zu beachten. Einer genetischen Untersuchung in den Grenzen der Slavistik kann eine typologische, mit den Methoden der Balkanlinguistik, neue Aspekte eröffnen:

"Die Slavistik allein kann uns wohl kaum in der Erforschung der Entstehung des bulgarisch-makedonischen Artikelsystems weiterführen. Auch die Balkanistik kann dieses Problem nicht allein lösen. Aber diese beiden Disziplinen zusammen werden zweifellos dazu beitragen, in dieser Prage voranzukommen." (Svane $)^{4)}$

Den sich in der slavistik wie in der Balkanphilologie (siehe T.V. Civ'jan) ${ }^{5}$ ) bemerkbar menden Tendenzen zur systemhaften Betrachtung des linguistischen Materials auch für die sprachliche Diachronie verdankt der vorliegende Versuch einer Interpretation seine Anregung. 
I. LINGUISTISCHER KONTAKT AUP DEM BALKAN

1. Theorie des Kontakts

Die Zusammenfassung der Sprachen des Balkans zu einem Sprachbund gründet sich auf N.S. Trubetzkoys bekannte Definition ${ }^{6)}$ : "Unter den Sprachgruppen sind zwei Typen zu unterscheiden: Gruppen, bestehend aus Sprachen, die eine groBe hhnlichkeit in syntaktischer Hinsicht, eine Xhnlichkeit in den Grundsätzen des morphologischen Baus aufweisen und eine groBe Anzahl gemeinsamer Kulturwörter bieten, manchmal auch äuBere hhnlichkeit in Bestande des Lautsystems, - dabei aber keine systematischen Lautentsprechungen, keine Ubereinstimmung in der lautlichen Gestalt der morphologischen Elemente und keine gemeinsamen Elementarwörter besitzen, - solche Sprachgruppen nennen wir Sprachbunde (!)." Der entgegengesetzte, genetische Begriff ist die 'Sprachfamilie'.

Die Ahnlichkeit zwischen den Sprachen eines Sprachbundes geht auf ihre wechselseitige Beeinflussung im Laufe der diachronischen Sprachentwicklung zurück, wobei der Einflub einiger Sprachen stärker sein kann als derjenige der übrigen. Zwei Sprachen stehen miteinander in Kontakt, wenn sie abwechselnd von ein und derselben Person gesprochen werden. Diese bilingualen Personen stellen den ort des Sprachenkontakts dar. ${ }^{7)}$ Damit Abweichungen in der Rede bilingualer Personen einen Einflub auf die kontaktierenden Systeme haben können, ist eine genügend groBe Anzahi von Bilingualen mit gleichen Abweichungen erforderlich. Die Voraussetzung für die Einwirkung einer Sprache auf eine andere ist daher der Zustand des Bilinguismus in einer gegebenen sozialen Gruppe. ${ }^{8}$ ) Erscheinungen von Sprachenkontakt setzen einen sozialen Kontakt voraus.

Die Pälle, in denen die Rede einer Person rom System einer Sprache als Ergebnis der Kenntnis einer anderen Sprache, d.h. als Resultat des Sprachenkontaktes abweicht, heiBen Interferenzerscheinungen. 9) Die Häufigkeit ihres Auftretens hängt rom Grad der Beherrschung der Fremdsprache ab. Geringe 
Kenntnis hat auf das grammutische System der eigenen sprache kaum einen Einfluß. Bei ex:rem guter Beherrschung ist es dem Sprecher möglich, beide Sprachsysteme auseinanderzuhalten, so daB sie in ihm koexistieren. Er kann das Gemeinte mit den spezifischen Mitteln einer jecen der beiden Sprachen wiedergeber, ohne ein Element $E^{\prime}$ aus der Sprache $S^{\prime}$ in die gerade gesprochene Sprache $S$ übernehmen zu müssen. Die Elemente beider Sprachen könner sich daher niemals in identischer Umgebung befinden, sie sind komplementär verteilt. 10) Bei einem solchen idealen Bilingualen erscheint $z . B$. kein russischer Ausdruck im englischen Kontext, und umgekehrt.

Jedoch ist eine solche extrem gute Beherrschung der Fremdsprache selten im Verhältnis zu den Fällen, in denen der Sprecher neben seiner Muttersprache die zweite Sprache nur mit Einschränkungen gut kennt. In diesem sprecher existieren nicht zwei Sprachsysteme unabhängig voneinander, sondern eines ist defekt, weil manche seiner Elemente dem Sprecher unbekannt sind und durch Elemente aus seiner Muttersprache ersetzt werden. Daraus folgt eine ständige Reïnterpretation der Elemente des defekten systems durch die Elemente des vollständigen Systems. Fälle von Interferenz treten in demjenigen langen Abschnitt von Fremdsprachenkenntnis auf, der über einer bestimmten Null-Schwelle und unter einer in der Praxis selten erreichten Höchstschwelle liegt und in dem die bilinguale Person me $\mathrm{h}$ a $1 \mathrm{~s}$ e $\mathrm{n}, \mathrm{a}$ b $r$ w $n i g e r$ a $l s$ z e $i$ s y $s$ e me beherrscht.ll) "Die Entwicklung eines morphologischen Systems unter der Einwirkung eines anderen systems ist ein Sonderfall der Entwicklung linguistischer systeme im allgemeinen." (Vogt) ${ }^{12)}$ Das bedeutet: Ein bilingualer sprecher, der durch seine Rede an der ununterbrochenen Weiterentwicklung einer sprache $S$ teilnimmt, hat die Möglichkeit, für das ältere system $S^{\prime}$ ein jüngeres System S" nach den Tendenzen zu bilden, die aus den internen Widersprüchen von $S^{\prime}$ hervorgehen (interne systemablösung einer Sprache), oder er kann das System $S^{n}$ nach dem 
Vorbild des kontaktierenden Systems $T^{\prime}$ der Sprache $T$ formen, wodurch die internen Tendenzen der Sprache $S$ teilweise intensiviert, teilweise aufgehoben werden.

Beim Kontakt der beiden Sprachen $S$ und $T$ können folgende Interferenzerscheinungen in $S$ oder in $T$ auftreten ${ }^{13)}$ : 1. Liorpheme von $S$ werden in $T$ verwendet, z.B. Lehnwörter. 2. Eine grammatische Beziehung wird von $S$ auf $T$-Horpheme in $T$ angewendet, oder eine solche Beziehung wird in $T$ nicht berücksichtigt, weil sie in S nicht existiert, z.B. bei Deutschamerikanern: He comes tomorrow home statt he comes home tomorrow. 3. Identifikation eines liorphems oder einer gramratischen Kategorie von $S$ mit einer ebensolchen in $T$ : die $T$-Form wird in einer Funktion verwendet, die aus dem Verhältnis Form : Funktion in $S$ abgeleitet ist. Für die T-Form bedeutet dies eine Reduktion oder Extension der Funktionen. Gründe für die Identifizierung von Morphemen und Kategorien zwischen $S$ und $T$ sind entweder formale Annlichkeit oder Annlichkeit in Teilfunktionen. Vgl. als Beispiel das spätlateinische habeo scriptum, das für eine Nachbildung des griechischen (griech.) gehalten wird. Vieil scriptum und preapplerer in anderen Funktionen übereinstimmten, wurde das lateinische (lat.) scriptum auch in die Finktion zum Ausdruck des Perfekts eingesetzt. Der lat. Umgestal tung liegt die Proportionalität der fremdsprachlichen Oppositionen in der Empfängersprache zugrunde, da

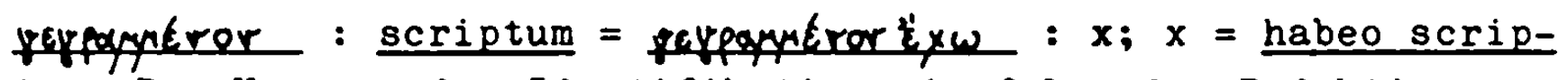
tum. Der Vorgang der Identifikation mit folgender Reduktion oder Extension der Funktionen einer Form heibt Replik. 14) Der Ubergang von der Rede ins Sprachsystem entscheidet über das Schicksal einer solchen sprachlichen Neuerung. In der Rede trat die Interferenzerscheinung infolge der persön 1 i $c h$ e $n$ K $n n t n$ is der fremden Sprache durch den Sprecher auf, Faktoren der Sprachenkenntnis und der Begründung für die Ubernahme waren entscheidend. Im Sprachsystem, nach der Einführung durch häufigen Gebrauch in der Rede, ist die Verwendung der 
Neuerung nicht mehr vom Bilinguismus des Sprechers abhängig. Wenn eine Porm $F$ der Sprache $S$ durch die Form $G$ der Sprache $T$ ersetzt wird (bzw. wenn eine Replik gebildet wird), ohne daB der Sprecher von $S$ die' Sprache $T$ kennt, sondern weil er $G$ von anderen Sprechern in S-AuBerungen gehört hat, dann kann $G$ als Element des Sprachsystems $S$ betrachtet werden. 15) Auf der Ebene des Sprachsystems sind nicht mehr die Gründe und Bedingungen der Entlehnung von Bedeutung, sondern die lautliche, grammatische, semantische und stilistische Integration des betreffenden Elementes. Wie auch im sprachinternen Neuerungsvorgang, werden viel weniger Produkte der sprachlichen Interferenz in das System aller Teilnehmer einer Sprachübereinkunft eingegliedert, als in der Rede von Individuen auftreten. Das komplexe System übt einen Widerstand gegen die Aufnahme von Entlehnungen aus und nimmt sie erst nach einer $A$ u $s$ w a h 1 auf, die nach linguistisch-strukturellen, psychologischen und sozio-kulturellen Gesichtspunkten getroffen wird.

Ein in ein Sprachsystem integriertes, vom genetischen Standpunkt fremdsprachliches Element bzw. eine Replik wird wie alle anderen Elemente bzw. Konstruktionen des Systems bei seiner Ablösung durch ein Nachfolgesystem behandelt. Eine durch die Obernahme fremdsprachlicher Elemente und Repliken ins eigene System ausgelöste Entwicklung kann sich in der Diachronie fortsetzen (die Bildung der nachfolgenden systeme bestimmen), gleichgültig, ob der Impulsgeber noch wirkt oder nicht. 16) "Von der Rede bilingualer Personen ihren Ausgang nehmend, kann eine Sprachgemeinschaft, indem sie systematisch die Funktionen von Morphemen in ihrer Sprache ausdehnt, nicht nur den Gebrauch einzelner Formen verändern, sondern auch ein ganz neues Paradigma obligatorischer Kategorien nach dem Modell einer anderen Sprache entwickeln" (Weinreich). 17) Als Beispiele nennt er den postpositiven Artikel und die Ersatzkonstruktionen für den Infinitiv in den Balkansprachen. Nach Aufhebung der ursächlichen Verknüpfung zwischen dem Einwirken der Gebersprache und der Neiterentwicklung der Nehmersprache 
kann eine frühere Replik in den Nachfolgesystemen durchaus eine größere Verbreitung erlangen als ihr früheres Modell in den Nachfolgesystemen der Gebersprache. ${ }^{18)}$ Der Grad der Ausbildung eines Elementes oder einer Gruppe von Elementen in zwei vergleichbaren Sprachsystemen hat keinen Aussagewert darüber, welche der beiden Sprachen das Modell für eine $R e-$ plik in der anderen geliefert hat.

Zwei miteinander in Kontakt stehende Sprachen, bei denen außerlinguistische Gründe $z u$ starken Interferenzerscheinungen geführt haben, besitzen eine größere Anzahl von gemeinsamen Sprechmustern, die das Ergebnis von Repliken sind. Die Formen der Sprechmuster sind dem eigenen (genetisch gesehen) System entnommen, ihre Anordnung und Funktion gehorchen dem fremdsprachlichen Modell. Man kann von einer Differenzierung zwischen der ursprünglich e ig e n s p a c h 1 i$c h$ e $n$ F $\circ \mathrm{r}$ und der ursprünglich fremdsprachlichen $\mathrm{S} u$ b s t a n $z$ sprechen. ${ }^{19)}$ Goląb nennt die strukturellen Parallelismen kontaktierender Sprachen Isogrammatismen: "Ein Isogrammatismus kann als das Auftreten eines identischen strukturellen Musters in zwei oder mehr Sprachen definiert werden, mit dem das morphologische Material einer jeden Sprache verbunden wird, um morpho-syntaktische Einheiten höheren Ranges zu bilden" ${ }^{20}$ ). Kann ein Isogrammatismus als Replik einer der Sprachen nachgewiesen werden, so handelt es sich um eine Lehnübersetzung (calque linguistique). "Eine linguistische Calque ... ist ein historisch determinierter Isogrammatismus" (GoXg̨b). 2l) 2wischen einer Lehnübersetzung und der Funktionsausweitung einer sprachform unter fremdem EinfluB besteht nur ein gradueller Unterschied.

Erfassen in zwei oder mehreren Sprachen die Isogrammatismen ein ganzes Teilsystem der betreffenden Sprachsysteme, so können diese Teilsysteme in den einzelnen Sprachen durch den bilingualen Sprecher identifiziert werden. Im Rahmen dieses Teilsystems gibt es für den Sprecher ein Signifikat (z.B. eine auszudrückende sprachliche Kategorie) und zwei signifi- 
katoren (d.h. Formen), getrennt nach dem Sprachmaterial der beiden Systeme. Das systematische Element $E$ hat zwei Realisationen, $R$ und $R^{\prime}$, die komplementär verteilt sind. Vgl. im Lehnwortbereich: /Versammlung = Rede/ als $E, R=$ cuvint (rum.), $\mathrm{R}^{\prime}=\underline{\text { zbor }}\left(\right.$ mak.), $\mathrm{R}^{n}={ }^{\prime} \alpha \gamma \circ \rho_{\alpha}^{\prime}$ (ngriech.). Entsprechend den Isogrammatismen wird hier von 'Isosemantismen' gesprochen. 22) Sie entstehen nicht durch Ubernahme des lexikalischen Materials einer fremden Sprache ("outright transfer"), sondern durch Wandlung der semantischen Struktur, des semantischen Wertes und der semantischen Basis (Etymon) in den betroffenen Wörtern ("loanshift"). Sčerba berichtet, daß die bilingualen Sorben nur éin Sprachsystem mit zwei Arten der Realisation (deutsch und slavisch) haben, d.h. e i $n$ System von Funktionen und $z$ e $i$ Reihen von Formen. 23) A. Loewe 24 ) nennt dies ein 'zweigliedriges System ein und derselben Sprache'.

Die Beziehungen zwischen zwei genetisch verschiedenen Sprachen, die in ihren jüngsten Schichten ähnliche Teilsysteme aufweisen, lassen sich noch präzisieren. Zwei Sprachen mit vielen Isogrammatismen werden isomorph genannt, wenn man eine Eins-zu-Eins-Entsprechung zwischen den Elementen ihrer Systeme aufstellen und dabei die Beziehung der Elemente in den eigenen Systemen aufrechterhalten kann. 25) Zwei solche Systeme lassen sich synchronisch als Repräsentanten e i $n$ e abstrakten Systems betrachten. Dieses Metasystem stellt eine höhere Stufe der Abstraktion dar als ein 'Sprachsys tem' :

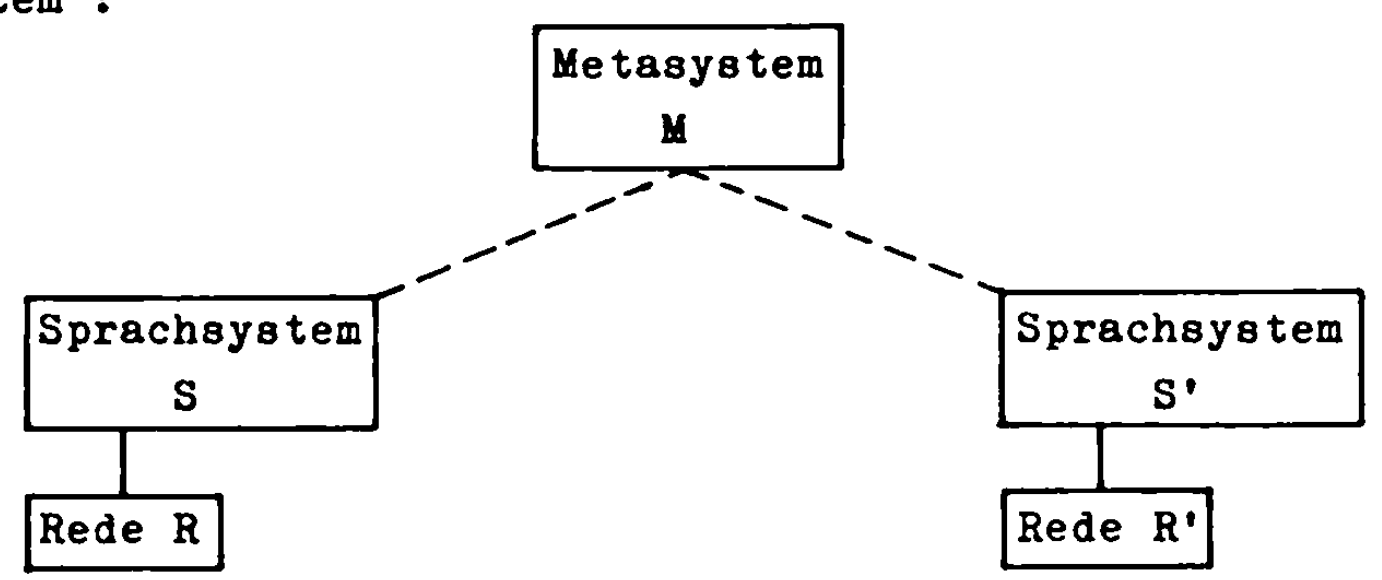


Die diachronische Zueinanderentwicklung mehrerer Sprachen, die als Ergebnis einen Sprachbund bilden, durch "konvergente Entwicklungstendenzen" (H. Birnbaum) ${ }^{26}$ ), läßt sich rückblickend als Weg zum späteren Metasystem durch die Vermehrung von Isogrammatismen verstehen.

Die Nähe einer Sprache $S$, die Teilnehmer am Metasystem $M$ ist, zu anderen Sprachen kann entweder typologisch oder genetisch bestimmt werden. Im Idealfall wird sich die typologische Affinität auf die struktur, die genetische Affinität auf das Material der Sprache $S$ beziehen. Diese Unterscheidung entspricht der Forderung, daB ein Urteil stets von der Angabe seiner Relation ('in Bezug auf': Genetik, Typologie) begleitet ist. Diese Forderung ist nicht erfüllt in Xußerungen wie: "Wenn man ausschlieBlich strukturelle Kriterien in Betracht ziehen wollte, käme man zu den a b s u r d e s t e n Konsequenzen, z.B. daB die makedonischen und bulgarischen Dialekte dem Arumunischen und dem Rumänischen $n \ddot{a} h$ e $r$ sind als den slavischen sprachen." (P. Ivić) 27 )

Die Mitgliedsprachen des balkanischen Sprachbundes gehören unterschiedlichen (genetischen) Sprachfamilien an: Slavisch (Bulg., Mak., z.T. Serbokroatisch), Romanisch (Dakorumänisch, Arumunisch, Meglenorumänisch, Istrorumänisch), Neugriechisch und Albanisch. Sie zeigen neben vielen lexikalischen und phraseologischen Ubereinstimmungen in ihrem grammatischen Aufbau eine groBe Anzahl von Isogrammatismen, die als wechselseitige Entlehnungen zu erkennen sind. Die Voraussetzungen für den zwischen ihnen aufgetretenen Kontakt sind historische Ereignisse und das daraus resultierende enge räumliche Nebeneinander der Teilnehmer dieser verschiedenen Sprachen. Je enger der geographische Raum des Sprachbundes gefaßt wird, um so dichter ist das Netz der Isogrammatismen und umso intensiver der Sprachbund. ${ }^{28)}$ Die balkanischen Sprachen besitzen kein nur ihnen eigenes Charakteristikum. Ihre sogenannte 'Balkanität. wird durch das Nebeneinander (cooccurence) mehrerer Isogrammatismen bestimmt, die einzeln auch in anderen Sprachen 
vorkommen können. Mit dem Erheben dieses Nebeneinanders zum Kriterium der Balkanität müssen das Slovenische, das Ungarische und das Türkische aus dem Sprachbund ausgenommen werden, obwohl ihm ein jedes von ihnen durch einzelne Ubereinstimmungen verbunden ist, vgl. den 'Zusammenfall' von Genitiv und Dativ im Ungarischen. ${ }^{29)}$ Die Balkanität läBt sich am ehesten durch die Untersuchung der gemeinsamen Entwicklungstendenzen der betreffenden Sprachen festatellen, als deren Ergebnis ein balkanisches Metasystem zu erkennen ist. Dieses ist für den Nominalbereich von T.V. Civ'jan herausgearbeitet worden: die Metagrammatik operiert mit einem Minimum an grammatischen Mitteln, so daß das Metamodell eine synthetisch einfache Sprache darstellt (leicht zu formulieren durch den sprecher, schwer zu analysieren durch den Hörer) 30 )

Der Versuch, den Aftikel des Bulg.-Mak., der einen Teil des nominalen Metasystems bildet, in seiner Entstehung zum Sprachenkontakt in Beziehung zu setzen, hat zur Voraussetzung, daB die Porm des heute feststellbaren balkanischen Metasystems als Ergebnis des Zusammentreffens verschiedener gegebener Sprachen auf dem Balkan betrachtet wird. Für die Entstehung des Metasystems sind deshalb die älteren Sprachphasen des Südslavischen, Ostromanischen und Albanischen von wichtigkeit. Gerade in vorliterarischen Epochen sind die Bedingungen für die Verbreitung von Repliken günstig. 31 ) Der zwischen den genannten Sprachen stattfindende Kontakt mit Interferenzerscheinungen läBt sich nach der Rolle der jeweiligen Sprecher einteilen in Substrat-, Superstrat- und Adstratwirkung. Ich gebrauche diese Termini in dem Sinne, dab eine Sprache S, deren Sprecher zum Gebrauch einer neu hinzugekommenen Sprache $T$ übergehen, ein Substrat in $T$ bildet; daB eine Sprache $S$, deren Sprecher in das Verbreitungagebiet der Sprache $T$ einwandern und zum Gebrauch von $T$ übergehen, ein Superstrat in $T$ bildet; daB eine Sprache $S$ zu einer koexistierenden Sprache $T$ ein Adstrat bildet, falls 1. die Sprecher von $S$ auch $T$ beherrschen und damit die Entwicklung von $T$ beeinflussen, 
oder 2. die Sprecher von $T$ auch $S$ beherrschen und aufgrund dieser Kenntnis die Entwicklung von $T$ beeinflussen. Gewöhnlich werden nur Adstratverhältnisse unter dem Gesichtspunkt der linguistischen Interferenz betrachtet. Das ist ungerechtfertigt. Was Substrat und Superstrat anbelangt, so liegt dem ProzeB der Assimilation einer Sprache durch eine andere ebenfalls eine mehr oder weniger lange Periode des Bilinguismus zugrunde, im Verlauf derer einige Elemente der später aussterbenden Sprache in die überlebende sprache durch Interferenz eindringen. ${ }^{32}$ ) Von linguistischer Relevanz ist bei der vorgenommenen Einteilung, $d a b$ im Falle einer Substrat- und Superstratbildung die Sprache $S$ auf die siegreiche Sprache $T$ vermittels Lieferung neuer $T-S p r e c h e r$ einwirkt, im Falle einer Adstratbildung dagegen direkt auf die alten T-Sprecher. Die neuen T-Sprecher neigen nun'aber sehr viel stärker zu durch $S$ bedingten Abweichungen vom korrekten T-System als die al ten $T-S p r e c h e r$ mit vollständiger Kenntnis des korrekten TSystems. Ob man für die konvergierenden Tendenzen der Balkansprachen Substratwirkung oder Bilinguismus annehmen 8011 (80 die Fragestellung bei H. Birnbaum ${ }^{33)}$ ), m.a.W. Substrat- oder Adstratwirkung in den Erscheinungsformen 1 und 2 (8.0.), ist also eine Alternative, die nicht den Mechanismus der Entstehung von Interferenzerscheinungen, sondern nur deren Intensität und zeitliche Einordnung (frühes uittelalter oder beginnende Neuzeit) betrifft.

\section{Phasen des balkanischen Sprachkontaktes}

Der balkanische Sprachkontakt teilt sich in drei Hauptphaeen:

den altbalkanischen Sprachbund. Er umfaßt das Thrakische, $\mathrm{My}-$ sisch-Dakische, Altmakedonische, Phrygische und hat Beziehun- 
gen zum Iranischen, Gemeinslaviscnen, Altgriechischen. Siehe dazu Kap.IV.

den frühalb.-frührumänischen Kontakt. den rumänisch-bulgarischen Kontakt.

\section{a. Prühalbanisch - Prührumänisch}

Das Alb. muB, wenigstens zum Teil, als Nachfolger des DakoMysischen, einer dem Thrakischen nahe verwandten Sprache, betrachtet werden (Hirt, Weigand, Baric, Dečev, VI. Georgiev u.a.), seine Urheimat ist in Makedonien, Nordbulgarien, 0stserbien und vielleicht Rumänien zu suchen. In dem ursprünglich illyrischen Albanien werden die Albaner erst im 11. Jhd. urkundlich erwähnt, hier bilden sie ein Superstrat zu den slavischen Ansiedlern, wie die ursprünglich slavische Toponymie in Albanien zeigt. ${ }^{34)} \mathrm{Vgl}$. die Pachdiskussion und Literaturhinweise bei I. Popovic. 35)

Die Romanisierung des unteren Donaubereichs beginnt im 1. Jhd. u.z. und führt zur Eroberung Daciens durch Trajan in den Jahren 101-107 u.Z.: "... das Territorium, in welchem sich das Volkslatein siegreich gegenüber den thrakischen Mundarten durchsetzte ...., muB entlang des Unterlaufs der Donau angesetzt werden, von der Mündung der TheiB bis zum Meer. Hier hat die romanische Herrschaft mindestens 600 Jahre gedauert" (Rosetti).36) Zur Intensität der Romanisierung zu beiden Seiten der Donau $\nabla g$. Rosetti 37 ).

Der EinfluB des korrekten Lateins und die Beziehungen des romanischen Balkans zum italischen Zentrum wurden im 3. Jhd. (275 u.z. Aufgabe der römischen Provinz Dacien) entscheidend geschwächt ${ }^{38)}$, die vita romana erhielt sich jedoch in den Städten beiderseits der Donau bis in das 6. Jhd. ${ }^{39)}$, inr Untergang ist eine Folge des Slaveneinfalls.

Der 'frühalb.-frührum.' Sprachenkontakt ist also ein Synonym für den Zusammenstoß des Thrakisch-Dakischen mit dem Ostromanischen, der größtenteils zur linguistischen Romanisierung der Daker und Thraker führte, nur das Frühalb. ent- 
ging diesem Schicksal. Der frühalb.-frührum. Kontakt ist deshalb nur in geringerem MaBe als Adstrat-, vorwiegend eher als Substrat-Verhältnis zu verstehen: Sprecher des Frühalb. oder diesem nahestehender dakisch-thrakischer Dialekte bildeten ein massenhaftes Substrat für das 0stromanische, das Resultat dieser Substratbildung ist das Früh- oder Gemeinrumänische. Dieses zeichnet sich durch eine Reihe von frühalb. (= dakischthrakischen) Reliktwörtern ${ }^{40}$ ) und von Repliken zum Frühalb. aus; soweit diese letzteren dem Nominalsystem angehören, werden sie in dieser Untersuchung zur Sprache kommen. Chronologisch läßt sich die Phase des älteren alb.-rum. Kontaktes mit der Angabe 1. - 6. Jhd. u.z. grob umreiBen, $n$ a $c h$ dem 6. Jhd. dient das Rum. nicht mehr als Sprache, die ihren Bereich ausdehnt; zusammen mit Resten des Dakisch-Thrakischen (= Prühalb.) wird es zum Substrat im Südslav. und verringert seinen Geltungsbereich.

Ein jüngerer rum.-alb. Kontakt ergibt sich seit dem 10. Jhd. zwischen dem vom übrigen Rum. getrennten Arumunischen in Makedonien, Nordgriechenland und Albanien mit dem Alb. in seinem neuen, westlichen Gebiet.

\section{b. Rumänisch - Bulgarisch}

Die Prage, ob Sprecher des Dakisch-Thrakischen von den Slaven auf dem Balkan noch angetroffen wurden ${ }^{41)}$, ist positiv $z u$ beantworten. Zum einen gibt es dafür Zeugnisse in den historischen Quellen (Jordanes; Niketas, Bischof von Seres), zum anderen müssen einige ONN ohne romanische oder griechische Vermittlung aus dem Thrakischen ins Altbulg. übernommen worden sein, wie z.B. der Name von Plovdiv, altbulg. Plbpbdivs

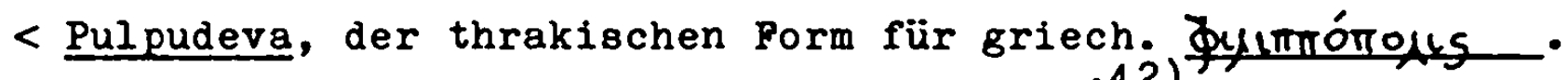
Zu beidem vgl. die Einzelheiten bei Popovic ${ }^{42}$. "Die Slawen haben in den Rhodopegegenden noch namhafte Reste von der thrakischen Bevölkerung vorgefunden... Die Bessen (Thraker) haben noch lange nach der slawischen Invasion ihre ethnographische 
Individualität behauptet, sodab man ت̈on ihnen sogar noch im 13. Jhd. Erwähnung macht, wie z.B. Niketas, Bischof von Seres. Dennoch kann man die totale Slawisierung des thrakischen Elementes, mit wenigen Ausnahmen, schon für das 10. Jahrhundert im allgemeinen als durchgeführt ansehen" (Miletič). 43)

Zur Erklärung von bulg.-alb. Ubereinstimmungen im Nominalsystem ist dieser älteste frühalb.-8lav. Kontakt jedoch keine unabdingbare Voraussetzung: Das Rum. mit seinem frühalb.-thrakischen Adstrat und Substrat konnte die auf diesen Sprachenkontakt zurückgehenden Interferenzerscheinungen als eigene Elemente weiterentwickeln und sie später als Adstrat und Substrat des Slavischen diesem mitteilen.

Der direkte slav.-frühalb. Kontakt, der auf das 6.-10. Jhd. zu datieren ist, war weniger massiv als der slav.-rum. zu derselben zeit und beschränkte sich, soweit er zu sich behauptenden Interferenzerscheinungen führte, auf die gebirgigen Rückzugsgebiete des Frühalb.-Thrakischen, in denen dieses der Romanisierung entgangen war. Das hauptsächliche Substrat des Bulg.-Mak. Ist im Balkanromanischen zu sehen, welches seinerselts durch den frühalb. Einfluß mitgeformt ist.

Als letzte Woge der völkerwanderung ${ }^{44}$ ) besledelten die Südslaven die Balkanhalbinsel und zwar in zwei Gruppen, nach dem Isoglossenbündel auf der Iinie Vidin-Kjustendil zu urteilen ( $P$. Ivit) ${ }^{45)}$ : einer westlichen, mit den späteren Serben und Kroaten, und elner östlichen, den späteren Bulgaren und Makedonen. Slavo-Bulgaren werden zum erstenmal im Jahre 525 u.z. bel Prokop von Cäsarea ${ }^{46)}$ erwähnt. Die Anwesenheit von Slaven auf dem Balkan im 5. Jhd. ist nicht nachweisbar.

Eine Folge des Slaveneinfalls ist die Abtrennung des späteren Arumunischen, Meglenorumänischen und zuletzt des Istrorumänfschen vom späteren Dakorumänischen. Für das Jahr 976 erwähnt die byzantinische Geschichtsschreibung einige arumunische Karawanen z̈rischen dem Prespasee und Kastoria ${ }^{4}$ ). Die erste Erwähnung romanischer Bevölkerung im Norden der Donau (Siebenbürgen und Moldau) stammt aus dem 11. Jhd. 
(hypothetisch) und dann aus dem 12. Jhd. (1164).48) Ein Teil der Arumunen scheint südlich des Balkangebirges autochthon gewesen zu sein. ${ }^{49)}$

Damit stellt sich die Prage nach der 'Urheimat' der Rumänen, $d . h$. nach den Gebieten der Balkanhalbinsel, in denen die späteren Bulgaren und Makedonen auf eine masaive romanisierte Bevölkerung trafen. Vgl. die Diskussion mit den vorgebrachten Argumenten in der Zusammenfassung von I. Popovit50). Am ehesten hat sich die Auffassung rom Entstehen des Rumänentums nördlich u $n$ d südlich der unteren Donau bis zu der alten griech.-lat. Sprachscheide Iissus - Scupi - Serdica Nordrand des Haemus - Odessos - Donaumündung 51 ) durchgesetzt. Dabei sind zwei Geblete für den rum.-bulg. Kontakt von besonderer Wichtigkeit:

\section{a. der Donauraum}

Wie unter römischer Herrschaft bildete die Donau in altbulg. Zeit einen wirtschaftichen Mittelpunkt, so dab hier eine maximale Konzentration von römischer Tradition mit einer besonders intensiven slavischen Besiedlung zusammentraf. Das Gebiet zwischen der Donau und dem Balkangebirge, im Jahre 86 u.2. als Moesia inferior dem Imperium Romanum einverleibt, bildet in der Geschichte der bulg. Staatsbildungen immer das Kernland, mit den sukzessiven Hauptstädten Pliska, Preslav, Trrnovo. Sobald die Slaven auf beiden Ufern der Donau aiedelten, trennte der FluB nicht mehr, er $v$ e $r$ b a $n$ d. Vom 8. Jhd. an schloB das Bulg. Relch auch das Nordufer in bre1tem Streifen mit ein. In der Moldau verlief die Grenze zwischen Süd- und Ostslaven ${ }^{52)}$, und das heuttge Rumänien hieb gegen Ende des 7. Jhd. bei dem byzantischen Chronisten Theophylaktos Simokattes Sclavinia - 'slavenland'.53) Ab 802 , unter den bulg. Chanen Krum, Omurtag und Boris dehnte sich der bulg. Staat bis in das Banat und nach Siebenbürgen (TheiBgrenze) aus, ebenso im 2. Bulg. Reich. Die orthodoxe Kirche, seit 1359 in Rumänien bezeugt, hat slavo-bulg. Charakter, die beiden Metropolien unterstanden der Verwaltung in ohrid und 
unterlagen dem EinfluB des Patriarchen von Tbrnovo. 54) Da das Bulg. Daciens zur NO-bulg. (mysischen) Dialektgruppe in engster Verbindung steht, zeigen die slav. Elemente des Dakorumänischen NO-bulg. Charakter. Zu den lautlichen Charakteristika der ältesten slav. Elemente im Rum. gehören ě > ea, $\underline{b}>$ o (10. und 11. Jhd.) 55 ). Manche ungarischen Lehnwörter im Rum. sind durch No-bulg. Vermittlung gegangen. Ort und zeit dieser Vermittlung (Südpannonien und Siebenbürgen, ab Ende des 9. Jhd.) zeigen die Ausbreitung der NO-Gruppe des Bulg. Die noch im 10. Jhd. bestehende kulturelle Einheit zwischen den norddanubischen und den süddanubischen Gebieten wurde in der Polgezeit allmählich aufgehoben durch die wachsende Bedeutung des rum. Elementes nördlich der Donau (Zuzug aus den Rückzugsgebieten in den südkarpaten und aus der Moesia superior). Das fortschreitende Erlöschen des Bulg., das spätestens im 16. Jhd. abgeschlossen war und das zu einem starken bulg. Substrat im Rum. führte ${ }^{56)}$, ist am Schicksal der bulg. schriftlichen Tradition nördlich der Donau zu verfolgen. Bernštejn nimmt an, dab vom 10. Jhd. an aufgrund der bulg. Vorherrschaft im heutigen Rumänien ebenso wie im süden der Donau schon $v$ o $r$ der Plucht der bulg. Iiteraten (1393) nach Rumänien hier eine ähnliche kirchlich-literarische Tradition bestand wie auf dem Gebiet des heutigen Bulgariens und Makedoniens. 57) Ebenso wurden schon lange $v \circ r$ dem Türkeneinfall in der Walachei die Schriftatücke in bulg. Kanzleisprache verfaßt. Bernštejn weist in der sprache der vlachobulg. Urkunden (14.-15. Jhd.) den EinfluB der örtlichen norddanubischen bulg. Dialekte nach, der aus der häufigen Unkenntnis der Urkundensprache (Kirchenslavisch) entsprang. 58) Manche Vertreter der rum. Iinguistik vertreten dagegen die Auffassung, daB das Slav, auf dem Gebiet des heutigen Rumäniens schon lange vor dem 16. Jhd. nur noch auf die Kanzleien und die kirchliche Sphäre beschränkt war. 59)

Dieser Uberblick sollte es wahrscheinlich machen, daB der heutige bulg. und rum. Donauraum in der zeit bis mindestens zum 10. Jhd. einen einzigen slavisch dominierten Kul- 
tur- und Sprachraum darstellte, in welchem die sozial niedrigen romanischen Schichten (Hirten, Bauern), soweit sie nach dem Slaveneinfall nicht abgewandert waren, ein atarkes rum. Substrat im Bulg. bildeten. Daneben ist auch die Wirkung der romanischen Stadtkultur auf das Bulg-Mak. im Donauraum und in der Moesia superior zu berücksichtigen.

Vaillant, Rosetti u.a. weisen darauf hin, dab sich in einer Reihe von vorslav. Städten, die in aksl. Zeit bezeichnenderweise ihre vorslav. Namen bewahrten, wie Bbdynb (Bononia, Vidin), Drbstrb (Durostorum, Silistra), Srbdbcb (Serdica, Sofija), Plbpbdivb (Pulpudeva, Plovdiv), das romanische Element unter bulg. Herrschaft und von Sprechern des Bulg. umgeben, noch längere Zeit gehalten haben muß. ${ }^{60)}$ Eine Konzentration von städten befand sich nun gerade im Donaugebiet. Der Anlab für eine solche Adstratwirkung des Prührum. war ein gewisses Prestige der romanischen Stadtbevölkerung gegenüber den sie umgebenden slav. Landgemeinden, das sich auf die Reste der lat.-griech. Kultur stützte. Vaillant bringt Beispiele für rum. Wörter, die durch Vermittlung der Stadtkultur ins Altbulg. gelangten, z.B. mrěkorija 'Marktplatz,61). Die Adstratwirkung hat man sich so vorzustellen, daB die romanische Bevölkerung beim Gebrauch der slav. Verkehrssprache ihre eigenen Grammatismen und Semantismen (dagegen nur wenige Lexeme) hineinmischte und daß diese Neubildungen durch die slav. Bevölkerung nachgeahmt wurden, weil die Stadtbevölkerung eine Autorität darstellte. Im Laufe der Jahrhunderte verschwand der Gebrauch des Romanischen auch in diesen Städten, so daB im heutigen Rum. eine ursprüngliche stadterminologie völlig fehlt, weshalb Puşcariu von einer "Rustikalisierung des Lateinischen" auf dem Wege zum Rum. spricht. 62)

Ich betrachte daher das Romanisch-Prührum. nördlich und südlich der Donau bis zum Nordrand des Balkangebirges (alte lat.-griech. Sprachgrenze) und das Bulg. derselben Gebiete als von einer bilingualen Sprachgemeinschaft getragen, die sich auf eine völlige Slavisierung hinbewegte. Dieser Proze $B$ 
wird im Norden der Donau durch eine später aufkommende entgegengesetzte Entwicklung (Rumänisierung) rückgängig gemacht.

\section{b. Moesia superior}

Der zweite bilinguale Raum von Slav, und Rum. liegt auf dem Gebiet des heutigen (Jugoslavisch-) Makedoniens und südserbiens. Zwischen Serben und Bulgaren hielt sich bis nach dem 10. Jhd. ein breiter balkanromanischer streifen. ${ }^{23}$ ) Die Ausdehnung des serbischen Staates Raška nach 0sten liegt gegen Ende des 12. Jhd., die Bulgaren dringen im 9. und 10. Jhd. in das Gebiet zwischen Niš, Sofija und Skopje vor (Einnahme Serdicas durch die Bulgaren im Jahre 809). Trotzdem war das Gebiet auch vorher von Slaven neben den Romanen besiedelt. Aufgrund der historischen Bedingungen rechnen mehrere Linguisten mit einem (arumunisch-) rum. Substrat im Zentralmak. und im Südserbischen, d.h. bei der Morava-Timok-Dialektgruppe des Serbischen (so Belik, van Wijk, vgl. Golab ${ }^{64}$ )). Die slav. Siedler bildeten, vor allem in Zentral- und südmakedonien, mit den Resten der Balkanromanen und den Albanern eine gemeinsame balkanische Zivilisation, deren Ende, nach Seliščev65), im 14. Jhd. liegt. Vgl. bei I. Popovif ${ }^{66)}$.

Manche bulg. Iinguisten meinen, daß sich in einer bilingualen Sprachgemeinschaft, die sich auf eine slavisierung der rumänischen Sprecher hinbewegte, das Bulg. unverändert in slav. Bahnen weiterentwickel te und gegenüber rum. EinPlüssen in seinen wichtigeren Teilsystemen immun war: "Objektive Pakten, die im Bulgarischen und Rumänischen zu beobachten sind, legen uns Zeugnis davon $a b$, daB bei der Formung des Rumänischen ein starker Einfluß vom Bulgarischen ausging, und nicht umgekehrt." (Mirčev) 67) Unter 'objektiven Pakten' werden hier die lange bulg. politische und kulturelle Herrschaft über die Rumänen, die groBe Zahl slav. Lehnwörter im Rum. und die geringe Zahl rum. Lehnwörter im Bulg. verstanden. Gblbbov argumentiert ${ }^{68)}$, daB, wenn eine grammatische Erscheinung parallel im Bulg. und im Rum. vor- 
handen ist, ein EinfluB des Rum, auf das Bulg. weniger wahrscheinlich sei als vice versa, weil das Rum. trotz groBer toponymischer Reste auf bulg. Gebiet eine verhältnismäBig geringe Anzahl von Lehnwörtern im Bulg. hinterlieB.

Eine Argumentation, die zu zeigen bestrebt ist, dab auch die umgekehrte Erklärung für bulg.-rum. Isogrammatismen, die rum. Einflußnahme auf das Bulg. in der bilingualen Sprachgemeinschaft, nicht auszuschließen ist, muB sich entsprechend Mirčevs und Gslsbovs Beweisführung auseinandersetzen mit

a. der Bedeutung des Herrschaftsstatus des Bulg. für seinen Kontakt mit dem Rum.,

b. den bulg. Lehn- und Reliktwörtern im Rum.,

c. den rum. Lehn- und Reliktwörtern im Bulg.-Mak. a. Das Bulg.-Slavische überschichtete in den Kontaktgebieten die Substrate Frührumänisch, Prühalbanisch, Griechisch und verschiedene Turksprachen. Jede überlebende Sprache bildet Repliken zu Formen der verdrängten Sprache, wenn die Sprecher dieselben bleiben ${ }^{69)}$ und wenn kein auBerhalb der Kontaktzone gelegenes Sprachzentrum die Polgen des Bilinguismus zurückdrängt (durch Intoleranz gegenüber den Neuerungen und Beharren auf der korrekten Rede), d.h. die sprachgemeinschaft setzt der Ubernahme der Neuerungen von der Rede in die Sprache kein Hindernis entgegen. Im Palle des Bulg. hatte das Aksl. eine solche sprachreinigende wirkung auf die übrigen Dialekte n $i$ c $h t$, wie die weitere Entwicklung des Bulg.-Mak. zeigt: Bulg. als politisch herrschende Verkehrssprache konnte Elemente des Rum. als der stärksten Substratsprache aufnehmen. Die politische Uberlegenheit einer Sprache über eine andere verhindert also prinzipiell nicht die Beeinflussung der überlegenen Sprache; die Beeinflussung ist besonders wahrscheinlich, wenn der überlegenen sprache eine kulturell bedingte Normierung fehlt. Als gut dokumentiertes Beispiel mögen die süditalienischen Mundarten dienen", die als kulturell herrschende von den kulturell degradierten italo-griechischen Mundarten den sogenannten 'Infinitivverlust' übernommen haben, 
die aber von den nicht mit dem Griech. kontaktierenden italienischen Mundarten zu sehr isoliert waren, als dab diese Neuerung hätte nivelliert werden können. 70)

b. + + . . Die Gegenüberstellung der zahlreichen bulg. Elemente im heutigen Dakorumänischen und der relativ geringen rum. Elemente im heutigen Bulg. erlaubt es nicht (wie Mirčev und Gslsbov es tun), Schlüsse auf die stärke des wechselseitigen Einflusses von Bulg. und Rum. in der Periode bis zum 10. Jhd. zu ziehen: Die bulg. Elemente im Rum. gehören zwei verschiedenen Perioden an, einer frühen von ca. 6.-10. Jhd. und einer späten vom ca. 10. Jhd. an abwärts.

Die bulg. Lexeme im Rum. aus der ersten Periode, die durch die Altertümlichkeit des zugrundeliegenden slav. Lautstandes (rum. sütä < sbto) und durch das Vorhandensein in allen rum. Dialekten (Dakorumänisch, Arumunisch, Meglenorumänisch, Istrorumänisch), d.h. im Frührum. vor seiner Aufteilung, oft mit parallelen veränderungen (vr̆tèti > DR a Invirti, AR anvirtésc, MR anvärtés), zu erkennen sind, betragen $10-80$ an der Zahl. 71) Da in der Zeit bis zum 10. Jhd. in den Kontaktgebieten das Rum. zur Substratbildung im Slav. tendierte, nicht umgekehrt, und da die heutigen groben rum. Dialekte auf dfe Mundarten der möglichst isoliert lebenden und deshalb nicht ąs8imilierten Hirtennomaden zurückgehen, sind die frühen Slavismen im Gesamtrumänischen vorwiegend als Lehnwörter, als Produkte eines Adstratverhältnisses zu betrachten.

Dagegen entspringen die slav. Elemente, die im DR ungefänr zwel Pünftel des Wortschatzes slavisch werden lieben ${ }^{72)}$, dem sich seit dem 10. Jhd. nördlich der Donau bildenden bulg. Substrat. Pür die Beurtellung der stärke des slav. Einflusses auf das Rum. In der zeit bis zum 10. Jhd. können sie $n i c h t$ herangezogen werden. Es ist deshalb methodisch falsch, die zahlreichen Slavismen des heutigen Rum. den geringen Rumänismen des heutigen Bulg. gegenüberzustellen: Die von Th. Capidan 73) zusammengestellten Rumänismen im Aksl. und Bulg., von denen die Hirtenwörter die ältesten sind ${ }^{74}$, kön- 
nen nur mit den 70 - 80 Slavismen im Prührum. als zeitlich parallel verglichen werden. Der Vergleich ergibt, daß zwischen den bulg. Lehnwörtern im Frührum. und den rum. Lehnwörtern im Altbulg. kein bedeutender quantitativer Unterschied besteht. Das Argument, das Verhältnis von wechselseitigen Lehn- und Reliktwörtern im Bulg. und Rum. schlösse die Einflußnahme des Rum. auf das Bulg. bei der Bildung von Isogrammatismen bis zum 10. Jhd. aus, ist damit aus dem Wege geräumt.

Tatsächlich wird ein solcher frührum. Einflub auf das Altbulg. bei der Bildung von Isogrammatismen (besonders im Bereich des Nomens) von mehreren maBgeblichen Linguisten postuliert; die rum. Substratwirkung zwischen dem 6. und 10. Jhd. (zur Datierung der älteren bulg.-rum. Kontakte vgl. Bernštejn ${ }^{75)}$ ) lasse bereits für das Altbulg. Abweichungen von den innerslavischen Entwicklungstendenzen erwarten, vor allem in den bulg.-mak. Mundarten der bilingualen Zonen: "... es ist unzweifelhaft, daB dieser fremdsprachliche EinfluB besonders intensiv in den ersten drei Jahrhunderten nach der Ansiedlung der bulgarischen Slaven auf der Balkanhalbinsel war." (Duridanov) ${ }^{76)}$ Duridanov datiert die aus der substratwirkung resuitierenden Neuerungen im bulg. Nominalsystem auf die zweite Hälfte des 9. Jhd. ${ }^{77)}$, Svane auf das 10. - 11. Jhd. ${ }^{78)}$. Auch vl. Georgiev rechnet mit einer sprachlichen Progressivität des NO-Bulg. (Donauraum) gegenüber dem SW-Bulg./Mak. schon in früher Zeit. ${ }^{79)}$ Als Entstehungszeit der nbulg.-mak. Neuerungen (Artikel und Deklinationsumgestaltung) im No setzt er das 8. - 9. Jhd. an. ${ }^{80)}$ Die kirchenslavischen Literaturdenkmäler der Preslaver Schule in NO-Bulgarien (Suprasliensis, Schriften des Exarchen Johann) zeichnen sich durch zahlreiche Neuerungen gegenüber der genormten Sprache der übrigen kanonischen Schriften aus ${ }^{81)}$ : "Die Pakten der Sprache Johannes des Exarchen veranlassen uns zuzugeben, daß gewisse ostbulgarische Dialekte des 10. und 11. Jhd., d.h. der Zeit, aus der die erhaltenen Kopien der altbulgarischen kyrill-methodianischen Denkmäler stammen, eine in ihrer Entwicklung recht 
fortgeschrittene Artikelform gehabt haben." (Mirčev) ${ }^{82)}$

Auf diese fortschrittlichen Mundarten geht die moderne nbulg. Schriftsprache zurück. Vom 12. Jhd. an murde die Mundart von Tbrnovo als maßgebliche Verwal tungssprache verwendet, von der jedoch keine Belege erhalten sind ${ }^{83)}$, und in demselben Gebiet bildete sich gegen Ende der Türkenherrschaft ein neues wirtschaftliches und kulturelles Zentrum ${ }^{84)}$, das seinem lokalen Dialekt Geltung verschaffte. Diese dialektale Untergruppe der bulg. Balkanmundarten, die sich auf Loveč, Trajan, Gabrovo, Levskigrad-Karlovo, Kalofer und Kazanlsk stützt ${ }^{85}$ ), unterscheidet sich vom Donaudialekt (mysischer Dialekt) in phonetischen und lexikalischen Details. Der Balkandialekt dehnte sich im Donaubereich und nach süden in die thrakische Ebene aus. Es ist diese Sprache, deren Formen als vorläufige Endpunkte und fortschrittlichste Vertreter der bulg. Sprachentwicklung festzustellen sind.

Rechnet man mit der Möglichkeit, daß das Prührum. auf das Altbulg. (besonders in einigen Kontaktgebieten) grammatische Einflüsse ausgeübt hat, so bleibt zu erklären, warum diesen grammatischen Einflüssen, die einen engen rum.-bulg. Kontakt voraussetzen, eine nur kleine Anzahl von rum. Reliktwörtern im Bulg. gegenübersteht.

Das widersprüchliche Verhältnis zwischen offensichtlichen arumunischen Einflüssen auf den grammatischen Bau des Mak. und der geringen Zahl arumunisch-rum. Lehnwörter im Mak. untersucht 2. GoX (qb. ${ }^{86)}$ Er erklärt die Divergenz beim EinfluB der verschiedenen sprachlichen Teilsysteme des Rum. auf das Slav. durch die sozio-kulturellen Bedingungen, unter denen die mak. Stämme im Mittelalter mit der romanischen Bevölkerung dieser Gebiete (Moesia superior) in Kontakt kamen. Die höhere kulturelle und soziale Stufe der Sprecher des Mak. 80wie deren Autorität als herrschende Schicht, verbunden mit einer genügend groBen Bevölkerungszahl, bewog die Sprecher des Prührum. teilmeise zur Aufgabe inrer Sprache, wobei sie sich des Slav. zunächst in dessen von den gröbsten lingui- 
stischen Beziehungen konstituierten Teilsystem, der Lexik, bemächtigten, um dieses sodann durch die höher strukturierten Beziehungen der romanischen Morphosyntaktik und Semantik zu Sätzen zu ordnen. Daß die Abweichungen eine über einen Jargon hinausgehende Verbreitung erfuhren, liegt zum einen an den entgegenkommenden Tendenzen des slav. Sprachbaus, zum anderen muß auf eine größere Anzahl assimilierter Romanen geschlossen werden. Das arumunische Adstrat (die nicht assimilierten Rumänen) trug zur Wiederholung und Festigung der Interferenzerscheinungen im Slav. bei. Die Form der slav. Wörter nicht berührend, konnte das rum. Substrat deren semantischen Bereich verändern. Aus der Aktion des Substrats erklären sich die oben besprochenen Isogrammatismen und Isosemantismen, vgl. mak. zbor 'Wort' aus sbborb 'Versammlung'; rum. cuvint 'Wort, Versammlung' aus conventus 'Versammlung'.

Mit der Aufzählung fremdsprachlicher Wortformen in einer Sprache kann demnach ein fremdsprachlicher Einflub in seiner Stärke nicht genügend klar beurteilt werden, im Substratfall ein solches Verfahren sogar zu falschen Schlüssen führen. Die starken Reste von slav. Wortformen im Dakorumënischen sind einer anderen sozio-kulturellen Lage der von den Rumänen sssimilierten slav. Bevölkerung zuzuschreiben, jedoch liegt dies außerhalb meines Themas.

Bei einer solchen Interpretation, wie sie oben gegeben wurde, geht die Existenz der quantitativ vergleichbaren älteren Lehn- und Reliktwörter des Frührum. im Altbulg. und der älteren Lehnwörter des Altbulg. im Frührum. von der Anwendung eines bestimten linguistischen Gesetzes auf zwei verschiedene Kontaktsituationen aus. Das Gesetz lautet: Das Vokabular einer Sprache, welches beträchtlich lockerer strukturiert ist als deren Phonematik und Grammatik, ist am leichtesten in eine andere Sprache zu entlehnen und stellt gegenüber der Phonematik und der Grammatik die Entlehnungsdomäne par excellence dar (Weinreich). ${ }^{87}$ ) Im Falle des rum. Substrats im Slav. hat diese Regel eine fast vollständige Aneignung des 
slav. Vokabulars durch die Rumänen ermöglicht, die rum. Relikt- und Lehnwörter im Bulg.-Mak. haben sich, meist aus Gründen der sachkultur, $t r \circ t z$ des intensiven slav.rum. Bilinguismus und der folgenden rum. Substratbildung im überlebenden Bulg.-Mak. gehalten. - Dagegen gilt für die alten slav. Lehnwörter im Frührum. die Folgerung aus dem obengenannten Gesetz: "Lexikalisches Entlehnen ist weniger auf den bilingualen Teil einer sprachgemeinschaft beschränkt als lautliche oder grammatische Interferenz." (Weinrich) ${ }^{88}$ ) Die slav. Wortformen konnten in das Rum. durch einen wenig intensiven Sprachenkontakt entlehnt werden, der nicht voraussetzte, daß die entlehnenden Rumänen das slav. Sprachsystem in seinem überwiegenden Teil beherrschten. Gerade weil Teile des Prührum. dem Bilinguismus entgingen, sind die bis zum 10. Jhd. entlehnten slav. Wörter in einem überlebenden Rumänisch heute isolierbar.

Die eingangs genannte Interpretation (Mirčev, Gblsbov): Die große Zahl der slavischen Wortformen im heutigen Rum. und die geringe Zahl der rum. Wortformen im heutigen Bulg.-Mak. lasse auf einen überwiegend slavischen EinfluB bei der Bildung von rum.-bulg. Isogrammatismen schließen, läßt sich mit der folgenden möglichen Interpretation konfrontieren: Die beschränkte Anzahl von rum. Wortformen im Bulg.-Mak. erklärt sich bei richtiger Wertung der sozio-kulturellen Beziehungen zwischen Altbulgaren und Frührumänen und des Charakters von Wortentlehnungen durch die intensive Substratwirkung eines Teils des Rum. im Bulg. bis zum 10. Jhd., - die gleichfalls beschränkte Anzahl von slav. Wortformen im Prührum. durch die losen Adstratbeziehungen des anderen Teils des Rum. zum Altbulg.

In diesem Zusammenhang ist die Methode $E$. Seidels abzulehnen, Rum. und Russisch (als einen Vertreter des nichtbalkanischen slavisch) miteinander zu verileichen und aufgrund der sich ergebenden grammatischen Ahnlichkeiten festzustellen: "Die Tatsache, dab viele slawo-rum. Gemeinsam- 
keiten nicht nur am Bulgarischen, sondern am Russischen demonstriert werden konnten, beweist die These, dab im Wesentlichen das Slawische, nicht das Rumänische, der gebende Teil ist."89) Die zwischen dem Rum. und dem Russ. bestehenden grammatischen Parallelen sind in der Hauptsache durch das jüngere slavisch-bulg. Substrat im Rum. in der Zeit nach dem 10. Jhd. nördlich der Donau in das Rum. gelangt. DaB Seidels Urteil für den älteren slav.-rum. Kontakt, bis zum 10. Jhd., nicht gilt, zeigt sich daran, dab gerade im Artikel- und Deklinationssystem zwischen Rum. und (z.B.) Russisch $k$ e i $n e$ Parallelen existieren, dagegen aber zwischen Rum. und Bulg. Für den wichtigen Komplex des rum. 'Neutrums' ist vor dem Slav. das Frühalb. als möglicher Verstärker und Bewahrer des lateinischen Neutrums zu berücksichtigen. Der wichtigste Pall von wirklich altem slav. Einfluß auf das Gesamtrum. - da in allen Dialekten verbreitet - ebenso wie auf das Albanische ist die Bildung der Zahlwörter von 11 - 19.

Die folgende linguistische Untersuchung geht von der bisher dargestellten Möglichkeit eines auch den grammatischen Bereich erfassenden starken rum. Substrateinflusses auf das Bulg. aus. Ich $8 \mathrm{chlieBe}$ mich damit den obengenannten Iinguisten an (Vl. Georgiev, Bernštejn, Svane, Duridanov) und gebrauche als Arbeitshypothese für die zeit vom 6./7. - 10. Jhd. (zur unteren Zeitgrenze vgl. Gblobov ${ }^{90)}$ ) die Aussage Capidans: "Der rumänische Einfluß hat sehr viel tiefere spuren im Bulgarischen hinterlassen als der slavische Einfluß im Rumänischen, denn er (der rum. EinfluB) hat auch seine (des Bulg.) innere struktur erfaßt und sich nicht nur auf die Einführung von Wörtern beschränkt."9l) Mit anderen Worten: Das (untergegangene) Prührum. als Substrat veränderte die struktur des (überlebenden).Slavisch, während sich das (überlebende) Slavisch vorerst als Adstrat auf lexikalische Einflüsse im (überlebenden) Rum. beschränkte. - Einflüsse des Rum. auf das Bulg.Mak. $n$ a $c h$ dem 10./11. Jhd. sind regional enger begrenzt und weniger tiefgreifend. 92) 
Wenn angenommen wird, daB der rum.-altbulg. Sprachkontakt bereits bis zum 10. Jhd. zu nennenswerten Veränderungen im Nominalsystem der kontaktierenden altbulg. Mundarten führte, so bleibt $z$ e erklären, warum die im 9. Jhd. geschaffene altkirchenslavische (aksl.) Schriftsprache solche Veränderungen kaum erkennen läßt.

Mirčev ${ }^{93)}$ argumentiert, ein aprachlicher Unterschied zwischen dem NO (Bulg.) und dem SW (Mak., Bulg.) habe in der Zeit bis zum 10. Jhd. nicht bestehen können, weil dem rum. EinfluB im Norden ein griech. Einflub auf das Altbulg. im Süden entsprach. Deshalb seien die frühen aksl. Texte für den Sprachzustand des gesamten bulg.-mak. Gebietes in jener zeit repräsentativ.

Dagegen ist zu sagen, daB die politische und sozio-kulturelle Lage der romanisierten und der hellenisierten Balkanbevölkerung nach dem slaveneinfall nicht identisch war, und diese unterschiedliche Lage beeinflubte den Verkehrswert des Balkanromanischen und des Griech. und folglich die stärke inres Einflusses auf das Altbulg.. Die Sprecher des Balkanromanischen waren seit Jahrhunderten ohne politischen und kulturellen Kontakt zum lateinischen Zentrum, welches hätte verhindern können, daB die Balkanromanen vom romanischen Verkehrajargon (Frührum.) zum Slavischen übergingen und in diesem ein massenhaftes linguistisches Substrat bildeten. Im Palle des Griech. war es schon vor der Ankunft der Slaven zu keiner Ausbildung eines besonderen Balkangriech. gekommen als Entsprechung zum Balkanromanischen -, weil das Griech. dieser Gebiete an der Entwicklung des nichtbalkanischen Griech. ununterbrochen teilnahm und bis zum Slaveneinfall im byzantinischen Herrschaftsbereich gelegen war. Auch später ging die Verbindung des balkanischen Griech. zu den helleniotischen Zentren (Konstantinopel, Saloniki) nicht verloren, und in den dem slaveneinfall folgenden Jahrhunderten wurde sein Prestige durch den oströmischen Machtanspruch und die häufige Machtübernahme auf dem Balkan gefestigt. Wegen dieser 
äußeren Stellung des Griech. war das griech. Substrat im Slav. bedeutend geringer als das romanische. Welches auf dem südlichen Balkan die bevorzugte Verkehrssprache war, zeigt die Tatsache, daß die im 6. Jhd. auf der Peloponnes erschienenen Slaven einer in der zweiten Hälfte des 8. Jhd. einsetzenden und von Byzanz, Thessalonike, Korinth, Patras, Serres ausgehenden Hellenisierung unterworfen waren 94 ). In den nördlicheren Gebieten, die dem Ausstrahlungs- und Machtbereich des bulgarischen Staates näherlagen, wie z.B. im Norden von Thessalonike, verebbte die Hellenisierungswelle, und Slav. und Griech. standen sich mit annähernd gleichem Prestige gegenüber und konnten zueinander in ein Adstratverhältnis treten. Da ein Adstratverhältnis schon bei einem weniger intensiven Zustand von Bilinguismus eintreten und weniger tiefgehend wirken kann (stärker auf das Vokabular, schwächer auf grammatische Konstruktionen) als ein Substratverhältnis, umfabt der zu Recht angenommene und nachgewiesene griech. Einfluß auf das Aksl. die wichtigsten im NO-Bulg. auftretenden Neuerungen in geringerem Grade. Der geringere Grad des griech. Einflusses gegenüber dem stärkeren rumänischen kann als zeitliche Verzögerung interpretiert werden. Der Kontakt des Griech. mit dem Slav. auf der Peloponnes läßt sich mit dem Verhältnis Slavisch-Substratrumänisch vergleichen, der Kontakt des Griech. mit dem Slav. in zunehmender Nähe zum bulgarischen Staat mit dem Verhältnis Slavisch-Restrumänisch (nichtassimiliertes Rum.). Im Unterschied zum Bulg. hatte das Griech. sprachnormierende auBerbalkanische Zentren, die die Resultate des Substrateinflusses weitgehend beseitigten.- Der Pall, daB das Griech. einer Kontaktsprache politisch und sozio-kulturell unterlegen war, wodurch die Stärke des griech. Einflusses auf das Bulg. mit der Stärke des rum. Einflusses auf das Bulg. gleichzusetzen wäre (wie Mirčev annimmt), ist auf dem Balkan in größerem Maße nicht eingetreten, er findet sich jedoch in süditalien (8.0.), wo das Verhältnis Substratgriechisch-Italienisch dem Verhältnis Substratrumänisch-Bulgarisch entspricht. 
Die archaischsten Dialekte des Bulg.-Mak. liegen heute an der südlichen und südwestlichen Peripherie des bulg.-mak. Sprachraumes. Bulgarischerseits zählt dazu die SW-rhodopischè Mundart, welche mit der archaischen mak. Mundart im westen von Saloniki viele Gemeinsamkeiten hat. Diese Rhodopenmundarten werden vor allem von im 16. Jhd. islamisierten Bulgaren, den sogenannten Pomaken, gesprochen. Archaische mak. Mundarten finden sich außerdem im äußersten $S$ des Mak., in den Dörfern Drenovjane und Boboščica bei Korča (Albanien). Obwohl diese Mundarten in Albanien durch viele Altertümlichkeiten mit dem Dialekt des sogenannten Bogdansko bei Saloniki (in den Dörfern Sucho und Visoka) verbunden sind, weisen sie vor allem in der Phonetik tiefgreifende Unterschiede auf. 95) Ich erkläre diese Unterschiede bei gleichzeitiger Ahnlichkeit der genannten bulg. und mak. Mundarten dadurch, dab diese drei ursprünglich voneinander verschiedenen Mundarten durch ihre Entfernung von den nördlichen bulg.-mak. Innovationszentren viele Archaismen in Phonetik und Morphologie bewahrten, was thnen nach der südausbreitung der Neuerungen in die übrigen Mundarten eine sekundäre Ahnlichkeit verlieh. Auch die im 19. Jhd. ausgestorbene Mundart von Kulakija, die letzte Phase des slav. Dialekts von Saloniki, zeigt eine bedeutsame Abweichung vom übrigen bulg.-mak. Sprachgebiet gerade im Bereich der Artikelverwendung, die in Kulakija jüngeren Datums und vom Griech. beeinflubt zu sein scheint ${ }^{96)}$, vgl. Kap. II.

Gewöhnlich wird angenommen, daB sich die im 9. Jhd. geschaffene aksl. Literatursprache auf den mak. Dialekt der Umgebung von Saloniki in seiner damaligen Entwicklungsphase stützt, der sich mit seinen Ausläufern nach 0sten im Südrhodopengebiet bis nach Byzanz (Jagic) und im Westen bis nach Albanien hinein erstreckte. 97 ) Die Ubereinstimmung im Wortschatz zwischen den beutigen Dialekten und dem Aksl. ist am geringsten im Nordmak., weniger gering im NO-Bulg., stärker in den Rhodopenmundarten und am stärksten im Südmak. 98) Wenn auch das Aksl. mit keinem bestimmten mak. Dialekt der Neuzeit 
identifiziert werden kann ${ }^{99)}$, so ist doch die Zugehörigkeit des dem Aksl. zugrundeliegenden Dialekts zur konservativen bulg.-mak. Südgruppe nicht zu bezweifeln, schon aufgrund der geographischen Lage von Saloniki, woher die Slavenapostel stammten.

Die mit großer Wahrscheinlichkeit zu vertretende Annahme, dab zwischen dem NO-Bulg. und gewissen zentralmak. Mundarten einerseits und dem SW-Mak./Bulg. andererseits schon zur Zeit der Entstehung des Aksl. gewisse Dialektunterschiede bestanden, ist in der Slavistik seit langer Zeit ausgesprochen worden: zuerst von B.J. Lamanskiji 100), dann Sčepkin ${ }^{101)}$, B. Oblak $^{102)}$, neuerdings mit besonderem Nachdruck von S. Bernštejn in seinen Razyskanija ${ }^{103)}$. Svane fabt diese Annahme zusammen: "Wir stellen es uns so vor, daB in der Zeit der Ausbildung eines Artikelsystems mit zwei Dialektgebieten zu rechnen ist: einerseits, der peripheren, archaischen Sprachform ohne Artikelbildung, welche durch die aksl. Texte im Soluner Dialekt vertreten wird, andererseits, der zentralen, in mancher Beziehung neuen Sprachform, mit einem mehr oder weniger entwickel ten Artikelsystem in den weiter nach Norden gelegenen Gebieten." 104)

Pür die Ablehnung dieser Auffassung durch manche bulg. Linguisten ist die Argumentation Mirčevs bezeichnend ${ }^{105)}$ : Es sei unzulässig, bedeutendere Unterschiede zwischen dem Soluner Dialekt und den nördlichen Dialekten anzunehmen, da "der Beginn des Prozesses zum analytischen Bau (des Bulg.) in die Zeit nach dem 10. Jahrhundert gestellt werden muB, als das Bulgarische aufgrund seiner inneren Gesetze begann, sein Lautsystem zu verändern." Der Beginn dieser Veränderungen aber liege deshalb nach dem 10. Jhd., weil "der soluner Dialekt mit seinem klar unterstrichenen synthetischen Charakter" sie noch nicht aufweist. In dieser Argumentation erklärt der synthetische Bau des Aksl. dessen gesamtbulg.-mak. Charakter im 9. Jhd. und der so gefolgerte gesamtbulg.-mak. Charakter des Aksl. das späte Eintreten des Analytismus im Gesamtbulg.- 
Mak.: ein Circulus vitiosus!

Auch der dem Aksl. zugrundeliegende Dialekt zeigt Veränderungen auf das balkanische Metamodell hin (aufgrund des Adstrateinflusses), jedoch "nur keimhaft und in Ansätzen, vielfach auch nur als e i $n$ e unter mehreren zur Verfügung stehenden Ausdrucksmitteln." (Birnbaum) ${ }^{106}$ ) Zum EinfluB des Balkanlateins auf das Aksl. vgl. Sedlaček 107), Birnbaum 108), Vaillant ${ }^{109)}$ und Gerov ${ }^{110)}$.

Bestand schon ein Unterschied zwischen den nördlichen Dialekten und dem der peripheren konservativen Randzone angehörigen Soluner Dialekt zur Zeit der Entstehung des Aksl., so wurde dieser Dialekt von der progressiven bilingualen Sprachzone noch weiter entfernt durch seine Erhebung zur Schriftsprache.111)

Aufgrund besonderer historischer Bedingungen wurde zur bulg.-mak. Schriftsprache im 9. Jhd. nicht der Dialekt des Zentrums des damaligen bulg. Staates, der von Pliska-Preslav (im NO) erhoben, sondern eine konservative Mundart, die bis zur 2. Hälfte des 9. Jhd. auBerhalb des bulg. Staatsbereiches blieb und deshalb am slav.-protobulg.-rum. EinschmelzungsprozeB keinen Anteil nahm. 112) Zwischen dem Aksl. und dem ihm zugrundeliegenden Dialekt von Saloniki im 9. Jhd. kann kein Gleichheitszeichen gesetzt werden. 113) Das hat seinen Grund a. im Charakter von Schriftsprachen überhaupt, b. im Charakter einer Schriftsprache zu religiösen 2 wecken.

Die Schriftsprache als Kulturgegenstand ist als künstliche Sprachschicht am stärksten auBerlinguistischen Einflüssen ausgesetzt, ihre Form gestaltet sich nach dem schreibenden Individuum und den Willkürlichkeiten seiner Rede: seiner Begabung, seiner Erziehung, Bildung, seiner persönlichen Disziplin und seinem Geschmack, einem ästhetischen Faktor. 114) Eine tiefeingewurzelte syntaktische Gewohnheit der betreffenden Sprache und der Augenblickseinfall des Schreibers stehen im einzelnen Text auf der gleichen stufe. "Wenn die Zuhilfenahme Iiterarischer Texte oft ein notrendiges Ubel ist (...), 
so darf man sich keine Illusionen über den Tert der aus ihnen gewonnenen Auskünfte machen." (Bally) 115 )

Diese Künstlichkeit des Aksl., die es mit jeder anderen Schriftsprache teilt, wird verstärkt durch die Rolle einer Kultussprache. Im bulg. Staat übernahm das Aksl. die Aufgaben des Griech. auch als Staatssprache (Griech. war die offizielle Sprache Bulgariens bis 893). Um seinen Platz neben den 'heiligen' Sprachen Lat. und Griech. einzunehmen, mußte es deren Kennzeichen erwerben: die archaische Form gegenüber der Umgangssprache (Attisch-Romäisch, Lat.-Romanisch) und den bewuBten Abstand von örtlichen Dialekten zum Zwecke der überregionalen Wirkung. Die vom Griech. und Lat. bekannte Diglossie auch im bulg. Staat zwischen dem Aksl. und der Umgangssprache durchzuführen, konnte nur im Interesse der Kirche sein. Mit der Ersetzung des über den slav., türkischen, romanischen, thrakischen Dialekten stehenden Griech. durch das Aksl. fiel das Oppositionsglied 'Slavisch' nicht etwa mit der neuen Hochsprache zusammen, sondern es fand sofort eine starke Differenzierung zwischen der slav. Schriftsprache und der slav. Umgangssprache statt, aufgrund der Proportion:

Kirchenlatein : Prührumänisch = Attisch-griechisch : Romäisch =

Altkirchenslavisch : Altbulgarisch/Al tmakedonisch

Der Terminus 'Aksl.', der die kulturelle Funktion unterstreicht, ist deshalb vom 'Altbulgarischen' zu trennen.

Die Praxis sah so aus, dab der Ubersetzer, der mit beiden Varianten des Griech. vertraut war, die entsprechende hohe Stilebene nun auch im Slav. suchte und damit die Spaltung gleichsam ins Slav. hineininterpretierte. Die Differenzierung zwischen den NO- und SW-Dialekten kam ihm zu Hilfe. Deshalb wurden alle Neuerungen, die sich im Stadium der Entwicklung befanden und noch nicht generell verbreitet waren (z.B. Akkusativ statt Genitiv nach verneinten Verben), aus den Texten herausgehalten, ebenso die protobulg. Superstratwörter, die in NO-Bulgarien jedenfalls häufiger vorkamen. ${ }^{116)}$ 
Es ist vorstellbar, daß man sich der Existenz des No-bulg. Mischjargons durchaus bewußt war und daß dessen Eigentülichkeiten in den Texten bewuBt vermieden wurden. Die Bearbeltung des Aksl. in der großmährischen Umgebung, welche die archaisch-synthetischen Tendenzen stärkte, hat zweifellos für die Bildung der Kirchensprache eine gewisse Bedeutung ${ }^{117}$ ) und entsprach ihren überregionalen Bestrebungen. Das Ergebnis all dieser Bemühungen und der Bearbeitung des zugrundeliegenden Dialekts von Solun war eine Stabilisierung und Verfeinerung vor allem seines syntaktischen systems und die Annahme eines konstanten Instrumentariums von Konstruktionen. 118) Bei jeder syntaktischen Bildung der aksl. Texte ist deshalb zu fragen, ob sie einem wirklichen Gebrauch im Soluner Dialekt oder der Ausweitung von sonst selten auftretenden Konstruktionen entspringt.

In den folgenden Jahrhunderten entwickeln sich die aksl. Schriftsprache und die bulg.-mak. Dialekte immer weiter auseinander. Der bei jeder Diglossie eintretende Moment, da die Hochsprache durch zu große Entfernung von der Umgangssprache sich zu verändern droht und deshalb durch eine schriftliche, traditionelle Kodifizierung abgestützt wird (vgl. Hebräisch, Griechisch), liegt für das Aksl. in der 2. Hälfte des 14. Jhd., als der Patriarch Evtimij die Normen der kyrill-methodiandschen Sprache wiederherstellt, mit dem Ergebnis, daB die Quellen aus Tbrnovo ein archaischeres Bild bieten als die des 13. Jhd. Die von der Umgangssprache weniger entfernten schriftlichen Denkmäler sind die Inschrift von Bojana (13. Jhd.), die Trojanska pritča (14. Jhd.), die Cergeder Texte und die vlachobulg. Urkunden (14.-15. Jhd.). Dabei schwankt das Ksl. vom 12.-14. Jhd. nicht richtungslos 2wischen den normierten und den umgangssprachlichen Formen hin und her, sondern es zeigt Ansätze zu einer eigenen, von der Hauptmasse der Umgangssprache gelösten, Weiterentwicklung, die ungefähr der Entwicklung der übrigen slav. Sprachen entspricht (Ausgleich von Stämmen, Genera, Endungen). 
Viele in den Texten auftretende unkonventionelle Formen stellen keine reine Ubernahme aus der Umgangssprache dar, sondern Reaktionen der Schriftsprache auf Veränderungen in der Umgangssprache, mit schriftsprachlichen Mitteln. Umgangssprachliche Neuerungen gelangten zuweilen nicht direkt, sondern nur in schriftsprachlicher Verfremdung in den Text (so der Artikel).

Wir haben eine Situation, in der zwei Prozesse mit unterschiedlichen Richtungen ablaufen. Die von einem Dialekt des südbulg.-mak. Gebietes abgeleitete Schriftsprache bleibt weitgehend unbeeinfluBt von der Umgangssprache der folgenden Jahrhunderte und entwickelt sich nach ihren eigenen Gesetzen, während die meisten übrigen Dialekte, schließlich auch die des südlichen Raumes, mit den Neubildungen aus den bilingualen Zonen bekannt wurden. Besonders in NO-Bulgarien um das 10. Jhd. entstanden, verbreiteten sie sich im 11.-12. Jhd. im übrigen bulg.-mak. Sprachgebiet. ${ }^{119)}$ Die besondere Entwicklung der Schriftsprache nach gemeinslav. Tendenzen kann sich auf die Entwicklung der archaischen Randdialekte bis zum (späteren) Zeitpunkt ihrer Balkanisierung stützen. Wenn auch dem Bulg.-Mak. im Laufe seiner Geschichte ein einzelner Dialekt als ständige Norm für die Umgangssprache fehlte, so ist doch nicht $z u$ übersehen, dab das Gebiet zwischen der Donau und dem Balkangebirge, mit in der Geschichte einander ablösenden Hauptstädten, ein kontinuierliches Sprachzentrum gebildet und seine Ausstrahlungen in die übrigen Dialekte geschickt hat, hierbei unterstützt von lokalem Sprachenkontakt in Makedonien und in den früher griech. Gebieten.

Die heutige geographische Lage der bulg.-mak. Dialekte hat für die Frage ihrer wechselseitigen Beeinflussung in der Geschichte nur eine geringe Aussagekraft, und $z$ war wegen der ständigen Bevölkerungsverschiebungen, die im 10. Jhd. begannen, durch den Türkeneinfall im 14.-15. Jhd. verstärkt wurden und bis ins 19. Jhd. anhielten. Westliche und südliche Dialekte wurden nach Norden und Osten verpflanzt ${ }^{120)}$, Donau- 
dialekte in den Süden des Balkangebirges, nach Thrakien, nach Burgas, in die Strandžal2l); die Bevölkerung der thrakischen und der danubischen Ebene wurde im 14.-15. Jhd. vernichtet 122) oder siedelte in die Walachei und ins Banat über. Die Dialekte in den Ebenen sind heute schwer zu klassifizieren und nicht bodenständig. Als einigermaßen konstant können nur die Gebirgsmundarten betrachtet werden ${ }^{123)}$, so im Balkangebirge, in den Rhodopen, auch die archaischen mak. Mundarten in Albanien und bei Saloniki. Diese Zweiteilung bei der Einschätzung der geographischen Lage erlaubt es einerseits, den heutigen archaischen Dialektgürtel im Süden für die Begründung der Annahme einer südlichen konservativen Dialektgruppe im 10. Jhd. auszuwerten, und andererseits bei der linguistischen Untersuchung die Formen heutzutage weit voneinander entfernter Dialekte zusammenzustellen.

Manche bulg. Linguisten setzen voraus, dab die im Bulg. auftretende 'analytische' Tendenz, die zu den Neuerungen im Nominalsystem (Artikel, Kasusflexion) führte, indem sie einige im Aksl. nur isoliert auftretende Typen forciert entwikkelte und generalisierte, in $\mathrm{n}$ e $\mathrm{b} u l g$ a $\mathrm{r} g \mathrm{c}$ e $\mathrm{n}$ U r sprungs ist (so Mladenov ${ }^{124}$ ), Miletičl25), Duridanov ${ }^{126)}$ ). 'Innerbulgarisch' kann in diesem Zusammenhang jedoch nur genetisch verstanden werden, und hier hat Meillet darauf hingewiesen, daß die Einheit der slav. Sprachen eigentlich nicht in der äuBeren Xhnlichkeit der Formen, sondern im Wirken paralleler Entwicklungstendenzen besteht. 127) Wenn also das Bulg. von einem dem Gemeinslav. so nahestehenden System wie dem Aksl. in einem so gravierenden Teilsystem wie der Nominalflexion zu einem nbulg.-mak. Resul tat gelangt, das von allen übrigen Slavinen abweicht, so ist es offensichtlich $n i c h t$ den aus den internen Widersprüchen des gemeinslav. Systems sich ergebenden innerslav. Tendenzen gefolgt, sondern hat die interne Systemablösung durch eine externe (aus einer anderen Sprache) ersetzt. ${ }^{128}$ ) Dieses neue System zwang das Bulg. zur Teilnahme an den den balka- 
nischen Sprachbund charakterisierenden Tendenzen, die 'analytische' Tendenz ist demnach unslav. Ursprungs, obwohl sie in dem Augenblick ein integraler Bestandteil des Bulg. wurde, als die Interferenzerscheinungen zu Elementen des Bulg. (im Sprachsystem) geworden waren.

Gegen die Methode, zwischen dem Bulg.-Mak, und den übrigen Balkansprachen unverbindliche 'gemeinsame (analytische) Entwicklungstendenzen' anzunehmen und gleichzeitig den 'äußeren, mechanischen' Einfluß dieser Sprachen auf das Bulg.-Mak. zu verwerfen (so Mirčev ${ }^{129}$ ), war die obige Darlegung gerichtet, die zeigt, daß 'gemeinsame Tendenzen' nur durch linguistische Vorgänge entstehen, die in den Termini des Sprachenkontaktes zu beschreiben sind (Systemübernahme durch Replikbildung). Was wäre unter 'inneren, nicht-mechanischen' Einflüssen zu verstehen?

Die theoretischen Möglichkeiten, die ein Sprachenkontakt für die Weiterentwicklung der kontaktierenden Sprachen bietet, und die Häufung eines solchen Kontakts auf der Balkan empfehlen die Aufgabe gewisser scholastischer Argumentationen, in denen die gewünschten Resultate als Ausgangspunkt des Beweises fungieren, wie bei Mirčev:

"Die Ergebnisse aus der Untersuchung der Entwicklung der Artikelform im Bulgarischen stehen in scharfem Widerspruch zur Annahme irgendeiner äußeren, mechanischen Einwirkung seitens einer anderen Balkansprache." 130 ) 


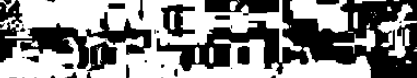

$15=2$ 
II. DIE ENTSTEHUNG DES ARTIKELS IM BULGARISCH-MAKEDONISCHEN 1. Theorie der Artikelflexion

Die Zeichen einer Sprache (ihre Formen) lassen sich unterteilen in Morpheme mit lexikalischer und Morpheme mit grammatischer Bedeutung. Die lexikalischen Bedeutungen der ersten Gruppe von Morphemen, der Semanteme ('Pferd-', 'lauf-'), stimmen mit dem Inhalt des gemeinten Begriffs überein. 131) Die grammatische Bedeutung, durch die die zweite Gruppe von Morphemen (die Morpheme im engeren Sinne) gekennzeichnet ist ('Pferd-e'', 'lauf-en'), "ist immer mit der lexikalischen Bedeutung verknüpft, sagt über die Eigenschaften und Beziehungen der gegebenen Wortzeichen aus und, durch ihre Vermittlung, über die Eigenschaften und Beziehungen der realen Gegenstände, die in der Einheit von Denken und Sprache widergespiegelt werden (z.B. Geschlecht, Zahl, vielfältige Beziehungen zwischen den Gegenständen usw.)." (A. Schaff) ${ }^{132)}$ Daraus folgt, daB die grammatischen Morpheme als synsemantische Sprachzeichen (gegenüber den Semantemen als autosemantische Sprachzeichen) ${ }^{133)}$ diese inre grammatische Funktion in Begleitung von Semantemen ausüben und deshalb häufig gebundene Formen darstellen, wie in 'Pferd-e'.

Die Semanteme und grammatischen Morpheme einer Sprache existieren in absentia in potentiell erinnerbaren, assoziativ verbundenen Gruppen auf der paradigmatischen Ebene (PE) 134 ) und werden für den Sprechvorgang auf der syntagmatischen Ebene (SE) aktualisiert, d.h. in praesentia miteinander $z u$ einer linearen Folge verbunden. 135) Zwischen den Zeichen auf der PE bestehen paradigmatische Beziehungen (Oppositionen), zwischen denen auf der SE bestehen syntagmatische (syntaktische) Beziehungen. Im skr. Satz:

Hajduci su ubili konjanika

bestehen zwischen 'hajduci' und 'konjanika' syntaktische Beziehungen (Subjekt-Objekt), zwischen 'hajduci' und (den nicht anwesenden) 'hajduk', 'hajduka', 'hajducima' etc. paradigma- 
tische Beziehungen (Nominativ Plural - Nominativ Singular, etc.).

Das MiBverhältnis von unendlich vielen auBersprachlichen Objekten (von denen die Begriffe abgeleitet werden) und Beziehungen zu einer begrenzten Anzahl von Sprachzeichen bringt es mit sich, daß ein gemeinter Begriff oder eine gemeinte Beziehung oft erst durch eine Kombination von Zeichen auf der SE, im Kontext, wobei sich die verschiedenen Zeichen wechselseitig beeinflussen, dem Hörer vermittelt wird. 136) Ebenso ist es möglich, einen Begriff oder eine Beziehung, die ein eigenes Zeichen auf der PE besitzt, durch eine Kombination anderer Zeichen auf der SE auszudrücken (Umschreibung): vulgärlat. rapida mente - 'auf hastige Weise' für rapide 'hastig' - Adverb. Sprachzeichen, die neben der durch paradigmatische Oppositionen gegebenen primëren Funktion regelmäßig eine solche sekundäre Funktion im Kontext ausüben, sind funktionell inhomogen. "Die primäre Punktion basiert auf relevanten Oppositionen, die sekundäre auf der primären plus Kontext." (Kurylowicz) 137) Diese Unterscheidung ist rein synchronisch. Zur Methode der Trennung von primärer und sekundärer Funktion eines Sprachzeichens im synchronischen System siehe Chodova. 138)

Der Umstand, daB ein Zeichen im synchronischen System eine primäre und eine sekundäre Bedeutung haben kann, trägt dazu bei, daB in diachronischer Hinsicht die $P E$ in einer ständigen Erneuerung begriffen ist, dergestalt, dab sich die Zeichen der PE über den Weg der Realisierung auf der SE und den daraus resultierenden sekundären Funktionen zu neuen 2 eichen der PE entwickeln, $d . h$. in ihrer paradigmatisch gegebenen Funktion verändert werden: vulgärlat. rapida mente $>$ französisch rapidement - 'schnell'/Adverb, -ment ist zum Adverbmorphem geworden.

Das diachronische Wirken der SE auf Inhalt und Umfang der PE zeigt sich auch in der Flexion der idg. Sprachen, in der die generelleren grammatischen Beziehungen zwischen den Semantemen in einem System zusamengefaßt sind. Dieses System 
unterliegt einem ständigen diachronischen Umbau dadurch, daß grammatische Beziehungen, die zuvor nur durch die Verwendung von Sprachzeichen mit primär anderer Funktion bei der linearen Realisation auf der SE, in sekundärer Funktion ausgedrückt werden konnten, nun durch einen obligatorischen Gebrauch dieser Zeichen in der früher sekundären Funktion ein eigenes, kontextunabhängiges Zeichen erhalten: die früher sekundäre, auf der SE sich einstellende Bedeutung eines Zeichens wird als primäre Funktion ebendieses Zeichens in die PE eingeführt. Vergleiche die Entstehung von Infinitivmorphemen in den idg. Sprachen, die auf verschiedene Verbalabstrakta plus Kasusmorphem zurückgehen.

Der Eintritt eines Semantems (romanisch mente) oder eines granmatischen Morphems (z.B. altbulg. na, woraus später das Dativmorphem wird) in die Flexion, in der diejenigen grammatischen Beziehungen zusammengefaßt sind, welche den meisten Semantemen einer Sprache gemeinsam sind, mit dem Extremfall der Gültigkeit einer Beziehung für alle Semanteme (dies trifft für die flektivisch ausgedrückten syntaktischen Beziehungen $\mathrm{zu}$ ), hat eine zunehmende Abstraktion des Zeichens von seinen früheren begrifflichen und konkreten Inhalten zur Folge: Die Möglichkeit einer Kombination mit möglichst vielen Semantemen steigt mit der Ubernahme des Ausdrucks von nicht-konkreten Beziehungen, die weniger als konkrete Beziehungen mit der Bedeutung der Semanteme kollidieren können. Ein aksl. *na molitvě ist nicht möglich, dagegen ein nbulg. na molitva 'einem Gebet'/Obliquus. Kurylowicz: "(...) die Sprache bewahrt ihren Status eines grammatischen Systems, indem sie sich ständig ihrer räumlichen und zeitlichen Begrenzungen entledigt."139)

Der Ausdruck einer vielen Semantemen gemeinsamen Beziehung durch ein grammatisches Morphem konstituiert eine Kategorie der Flexion, die mit wachsender Abstraktheit aufgrund des Systemcharakters der Flexion dazu tendiert, ihre Verwendung auch auf solche Semanteme auszudehnen, für welche 
die betreffende Beziehung nicht sinnvoll ist (begrifflich kollidiert), so bei der Anwendung der Pluralkategorie auf Gattungsbegriffe. Solche expansive Kategorien der Nominalflexion in den idg. Sprachen sind der Plural, die Kasus und in jüngeren Epochen der Artikel.

Der Artikel (gemeint ist hier immer nur der sogenannte 'bestimmte' Artikel, zum 'unbestimmten' siehe weiter unten!) stellt ein grammatisches Morphem dar, das aufgrund seiner hohen Frequenz und Abstraktheit zur Plexion gehört. Zur Geschichte des grammatischen Terminus 'Artikel' siehe Kurz. 140) Als grammatisches Morphem tritt der Artikel stets in Verbindung mit einem Nomen (Semantem) auf, er ist der lexikalischen Bedeutung des Nomens beigegeben. ${ }^{141}$ Der Artikel kann in unterschiedlichen Sprachsystemen als gebundene (rum. casa) oder freie Porm (französisch la maison) auftreten, wobei der Grad der Gebundenheit in der Diachronie einer Sprache der Veränderung unterworfen ist: frührum. *omu $11 u<$ homo ille, daraus dakorumänisch omul.

Als grammatisches Morphem drückt der Artikel in Verbindung mit einem Semantem eine gegebene grammatische Beziehung ('Determination') des begleitenden Semantems in primärer Punktion aus, d.h. ohne dab dazu ein weiterer linguistischer Kontext notwendig wäre. Dadurch konstituiert er die Kategorie 'Determiniertes Nomen'. - Da sich, diachronisch gesehen, das Artikelmorphem von einem anderen Morphem, dem Demonstrativpronomen, abzuleiten pflegt, wie auch im Bulg.-Mak., ist es zweckmäßig, die (synchronischen) Funktionen des Artikels im Kontrast $z u$ den Funktionen des Demonstrativpronomens zu definieren.

Die Funktionen von Demonstrativpronomen, Artikel (und Relativpronomen) entstehen auf der Grundlage des MiBverhältnisses 2 wischen der unbegrenzten Anzahl zu bezeichnender Gegenstände (Designate) und der begrenzten Anzahl verfügbarer Sprachzeichen. Die sprachliche Konvention verfährt hier so, daß ein sprachliches Zeichen mehrere ungefähr gleichartige 
Gegenstände (hierunter fallen auch Aktionen etc.) bezeichnet. Ein solches Zeichen (Wort) bezeichnet nicht mehr einen bestimmten konkreten Gegenstand, sondern ist dem Begriff dieses Gegenstandes zugeordnet. Dagegen verhält sich ein Eigenname ein-eindeutig zu dem bezeichneten Gegenstand oder Lebewesen. "Sage ich (...) 'Baum', so hängt dieser Ausdruck gleichsam in der Luft und bekommt erst dadurch Boden unter die Füße, daß ich inn auf einen bestimmten Gegenstand beziehe. Frege sagte: Ein solches Wort ist 'ergänzungsbedürftig' oder 'ungesättigt', es führt eine 'leere Stelle' mit sich, die man, einer Gewohnheit der Mathematiker folgend, eine Variable nennen kann. 'Baum' heibt dann so viel wie ' $x$ ist ein Baum', ein Ausdruck, der in eine Aussage übergeht, sobald die durch den Buchstaben $x$ angedeutete Leerstelle 'von einem Eigennamen ausgefüllt wird oder von einem Ausdrucke, der einen Eigennamen vertritt' ." (Kamlah-Lorenzen) 142)

Ein in allen Sprachen für diese notwendige Konkretisierung verwendetes Mittel ist der Gebrauch von Demonstrativpronomina. Sie sind dadurch gekennzeichnet, dab sie stets in mehreren Exemplaren im Sprachsystem vorkommen, die zueinander in Opposition stehen. Diese Opposition gründet sich auf die unterschiedlichen räumlichen Bezüge der Demonstrativpronomina ('dieser' - 'jener').

Gewöhnlich unterscheidet man zwischen der deiktischen (primären) und der relativen oder anaphorischen (sekundären) Funktion des Demonstrativpronomens. ${ }^{143)}$

In der primären Funktion geht der Sprecher davon aus, dab in der gegebenen Sprechsituation mehrere Gegenstände durch das von ihm verwendete Wort bezeichnet werden; um für den Hörer den einzig intendierten (gemeinten) Gegenstand kenntlich zu machen, gliedert er ihn durch Angabe seiner räumlichen Stellung in der realen Welt aus. "Aus der Fülle der Gegenstände, denen der Prädikator 'Fenster' zukommt, wird durch Hinzeigen genau einer ausgewählt - freilich so, dab wir nun wieder an die Redesituation gebunden sind. Haben wir es 
in einer solchen Situation mit mehreren Penstern zu tun, so müssen wir eindeutig hinzeigend sagen: 'dieses Penster klappert.'" (Kamlah-Lorenzen) ${ }^{144}$ ) Die Verwendung eines bestimmten Demonstrativpronomens, das als solches einem System von oppositionellen Demonstrativpronomina angehört, impliziert immer das Vorhandensein mehrerer Gegenstände, von denen nur einer als intendiert herausgehoben wird: der Ausdruck 'dieses Fenster' gibt implizite an, dab noch ein oder mehrere Penster in der Sprechsituation existieren, die der Sprecher nicht meint. Das Demonstrativpronomen gibt eine reale Lokalisierung des zu einem Wort ('Begriff') gehörigen Gegenstandes in paradigmatischer 0pposition $z u$ anderen, in der Sprechsituation vorhandenen Gegenständen an und verbindet (identifiziert) dadurch das Wort und den intendierten Gegenstand.

Die sekundäre Funktion ergibt sich aus der primären und der Einwirkung des Kontextes. Wieder können in einer Sprechsituation mehrere Gegenstände unter ein verwendetes Wort fallen, diesmal aber ist der vom Sprecher intendierte Gegenstand bereits im vorausgehenden linguistischen Kontext erwähnt worden oder seine Spezifizierung wird in nicht zu groBem Abstand der Nennung des Wortes folgen. In diesem Pall kann der Sprecher die Identifiziemang von Wort und intendiertem Gegenstand dadurch vornehmen, daß er mit dem Demonstrativpronomen auf die Vor- oder Nacherwähnung des Gegenstandes im Kontext hinweist. Jetzt ist für die Auswahl des Demonstrativpronomens nicht mehr die reale Stellung des Gegenstandes in Opposition zur realen Stellung anderer Gegenstände, sondern die Lage der Vor- oder Nacherwähnung im Kontext ausschlaggebend: Tam, kažetsja, byl eščë odin ne snjatyj dom? $\mathrm{Da}$, no dom étot pokazalsja mne takim plochim, čto ja ego ne osmatrival. (Jakubinskij) (45) - Oni uvideli togo čeloveka, kotorogo davno uže iskali. Die reale Lokalisation des intendierten Gegenstandes wird durch eine kontextuelle oder grammatische Lokalisation der Vor- oder Nacherwähnung dieses Gegenstandes ersetzt. Die grammatische Lokalisierung führt zu einer Identi- 
fizierung der von zwei Semantemen bezeichneten Begriffe und über diese Vermittlung zu einer Identifizierung von TortBegriff und intendiertem Gegenstand. Dies wird sichtbar an Beispielen, in denen unterschiedliche Semanteme im text aufeinander bezogen werden, da ihre Begriffe für ein und denselben Gegenstand stehen: (Kroatisch, 13. Jhd.) I v te dni Aleksandar pir velik vlastelem svoim učini, $i$ ta dan dare častne mnoge od vsega svita $k$ nemu pridoše, i na tom obedi vesele veliko učini (Zivot Aleksandra Velikoga). $1 \frac{146)}{\text { statt }}$ von der deiktischen werde ich im folgenden von der real 10kalisierenden Funktion des Demonstrativpronomens in seiner primären Verwendung und statt von der relativen (oder anaphorischen) von der grammatisch lokalisierenden Funktion des Demonstrativpronomens in seiner sekundären Verwendung sprechen, durch die in beiden Fällen eine Identifizierung von Wort und intendiertem Gegenstand erreicht wird.

Ihre besondere Wichtigkeit gewinnt die sekundäre Punktion des Demonstrativpronomens dadurch, daB sie es dem Sprecher erlaubt, das Demonstrativpronomen in solchen Situationen für die Identifizierung zu verwenden, in denen es entweder keine konkurrierenden Gegenstände zum intendierten Gegenstand gibt oder in denen er sie nicht berücksichtigen will. $O b$ der gemeinte Gegenstand 'hier' oder 'dort' ist, braucht der Sprecher dem Hörer nicht mitzuteilen, wenn nur der Gegenstand im Kontext des verwendeten Wortes erwähnt wird: dann genügt eine Beziehung auf diese Erwähnung, und der intendierte Gegenstand ist spezifiziert. Die Identifizierung ohne Angabe der realen Lokalisation ergibt sich sonst nur bei der Verwendung des Artikels (s.u.). In Sprachen, denen der Artikel fehlt, ist deshalb die sekundäre Verwendung des Demonstrativpronomens häufiger als in solchen, in denen der Artikel besteht. $\nabla g l$. folgende Sequenz aus dem artikellosen Schriftbulg. des 14. Jhd. (Trojanska pritča): i doide na edins ot otok lěps $i$ krasens velmi, koi sę zověse kalkadinovb otok, $i$ vb toms otocě běše pirgos krasenb, 1 vb toms pirdzě 
běše kralb 1menemb koeta kralb, 1 u togo bě kralě .5 . dbšter11. 147)

Bei der Identifizierung eines Wortes mit dem intendierten Gegenstand durch das Demonstrativpronomen ist der Sprecher an exakte Bestimmungen gebunden: bei der primären Verwendung des Demonstrativpronomens muB er dem Hörer eine konkrete Lokalisierung des intendierten Gegenstandes liefern, die sekundäre Verwendung hat zur Voraussetzung, daß dem Hörer die Ident1tät des Gegenstandes schon durch Vorerwähnung klar 1st oder dab diese Information sofort im Kontext nachgeliefert wird. Im Palle des Demonstrativpronomens unterscheidet sich deshalb die vom Sprecher gegebene Information nicht von derjenigen, die der Hörer zum Verständnis benötigt: die Kodierung (Synthese durch den Sprecher) ist schwierig, die Dekodierung (Analyse durch den Hörer) ist leicht, da ihm alle notwendigen Informationen geliefert werden.

Oben wurde gesagt, der Artikel drücke eine grammatische Beziehung bestimmter Semanteme, ihre 'Determination', in primärer Punktion aus. Fine genauere Beschreibung dieses unscharfen, In der Iinguistik jedoch akzeptierten Terminus läBt sich im AnschluB an das zur Funktion des Demonstrativpronomens Gesagte geben.

Der Artikel identifiziert ein Wort mit dem vom Sprecher intendierten Gegenstand. Dabei informiert er weder über dessen räumliche Stellung in der realen Welt noch lot sein Auftreten von einer kontextuellen Erwähnung dieses Gegenstands abhänglg. Diese Funktion geht aus Situationen hervor, In denen für Sprecher und Hörer der Bezug des verwendeten Tortes eindeutig lot und diese Eindeutigkeit formal ausgedrückt werden soll. "Befinden wir uns in einem Raum mit nur einem Penster, so sagen wir: 'das Penster klappert.' Oder beim Frühstück sagt jemand: 'Darf ich um die Butter bitten?' Hier relcht der bestimmte Artikel, als abgeschwächtes Zeigewort, zur Kennzelchnung des besprochenen Gegenstandes aus." (Kamlah-Iorenzep) $^{\text {148) }}$ Diese Punktion des Artikels ist von den 
Logikern FREGE und RUSSELl festgestellt worden.

Da für die Verwendung des Artikels durch den Sprecher keine linguistischen Bedingungen (wie beim Demonstrativpronomen) zu erfüllen sind, ist diese Verwendung durch den Sprecher auch außerhalb eindeutiger Situationen möglich: Für den Sprecher gibt es nur ein infragekommendes Designat, und er kann dessen Identifizierung mit dem verwendeten Wort-Begriff formal kennzeichnen, ohne sich darum zu kümmern, auf welche Weise der Hörer die Identität des intendierten Gegenstandes feststellt. Deshalb ist die Kodierung des Artikels leicht, die Dekodierung schwierig. Nach der Informationslage des Hörers lassen sich folgende Situationen bei der Dekodierung unterscheiden:

I. Dem Hörer ist der gemeinte Gegenstand aufgrund der Sprechsituation bekannt. Vgl. die obigen Beispiele. II. Der Hörer ist sich über den gemeinten Gegenstand aufgrund der Sprechsituation nicht von vornherein klar.

1. Auch der Kontext bietet keine diesbezügliche Information. In diesem Fall erscheint dem Hörer der von dem artikulierten Semantem gemeinte Gegenstand als bekannt postuliert, d.h. er hat das Gefühl, ihn kennen zu müssen, da der Sprecher offensichtlich diese Kenntnis voraussetzt.

2. Der intendierte Gegenstand wird durch den Kontext spezifiziert.

a. durch Erwähnung im vorausgehenden Kontext:

(Christa Wolf, Der geteilte Himmel) 'Er nahm eine glänzend aufgemachte Zeitschrift vom Tisch und blätterte sie vor Wendland auf (...) Palsch. Manfred klappte das Heft zu und legte es auf den Tisch zurück.' Aus der Sicht des Hörers identifiziert hier der Artikel den durch das artikulierte Substantiv ausgedrückten Begriff mit dem von der Vorerwähnung ausgedrückten Begriff und über diese Vermittlung das artikulierte Wort mit dem intendierten Gegenstand. b. durch Erwähnung im folgenden Kontext:

(Christa Wolf, Der geteilte Himmel) 'Manfred, der gerade mit 
einem seiner Studenten eine lange Reihe von Reagenzgläsern prüfte, war überrascht, daß ausgerechnet Wendland zu ihm kam. Aber der abweisende Zug, auf den Wendland wartete und der ihn sofort dazu gebracht hätte, wieder kehrtzumachen, kam nicht in Manfreds Gesicht.'

Für die Funktion des Artikels gilt hier das Entsprechende zu a.; der Sprecher unternimmt eine solche 'verfrühte' Artikulierung gewöhnlich dann, wenn das betreffende Wort durch das Nachfolgende wesentlich in seiner Objektzugehörigkeit spezifiziert wird.

Die hier gegebenen Funktionsbeschreibungen von Demonstrativpronomen und Artikel zeigen, daB sich zwischen der Verwendung des Demonstrativpronomens in sekundärer (kontextueller) Funktion und der des Artikels, sofern sein Auftreten für den Hörer durch den Kontext motiviert erscheint, Berührungspunkte ergeben. In einem Sprachsystem, in welchem Demonstrativpronomen und Artikel koexistieren, wie im Deutschen, sind in diesem Falle beide Morpheme - mit gewissen stilistischen Nuancen - austauschbar. In der Ubersetzung von einer artikellosen in eine artikelhaltige Sprache läBt sich das in sekundärer Funktion gebrauchte Demonstrativpronomen der artikellosen durch den Artikel der artikelhaltigen Sprache wiedergeben. $V_{g l}$. den oben angeführten mittelbulg. Text mit seiner Ubersetzung ins Deutsche: 'Und er kam auf eine der Inseln, die war schön und wunderbar und hieB K.-Insel, und auf der Insel war ein munderbarer Turm, und in dem Turm war ein König mit Namen König K., und der König hatte fünf Tö́chter.' Omgekehrt haben artikellose Sprachen die Möglichkeit!, einen kontextuell motivierten Artikel durch das Demonstrativpronomen in sekundärer Funktion wiederzugeben.

Der Funktionskontakt von Demonstrativpronomen und Artikel erklärt sich daraus, dab sie in diesem Falle beide an ein Semantem treten können, dessen Identifizierung mit dem intendierten Gegenstand durch den Kontext vorbereitet wird. Dieser Kontext ist für die Setzung des Demonstrativpronomens durch 
den Sprecher die Vorbedingung, falls er nicht durch eine reale Lokalisierung identifizieren will, - für die Setzung des Artikels durch den Sprecher ist der Kontext nicht notwendig, bestenfalls liefert er eine Informationshilfe für den Hörer. - Die kontextunabhängige Funktion des Artikels, die Bezeichnung von implizite bekannten Gegenständen oder die Postulierung der Bekanntschaft mit ihnen: 'Die Regierung läBt erklären ...' (zu Beginn eines Textes) kann vom Demonstrativpronomen nicht nachvollzogen werden, ein: 'Diese Regierung läßt erklären ...' (zu Textbeginn) drückt immer zusätzlich die reale Lokalisierung des intendierten Gegenstandes aus, was die Existenz von konkurrierenden Gegenständen in der Sprechsituation voraussetzt.

Um in Situationen, in denen die Identität des intendierten Gegenstandes eindeutig ist und keine anderen Gegenstände da sind, die unter dasselbe Hort fallen und von denen der gemeinte Gegenstand durch reale Lokalisierung abgehoben werden müBte, die Identifizierung von Wort und Gegenstand dem Hörer formal kenntlich $z$ machen, haben manche Sprachen in der Diachronie aus den Morphemen des Demonstrativpronomens Artikelmorpheme entwickelt. Ausgangspunkt war dabei die partielle Funktionsähnlichkeit von Demonstrativpronomen und Artikel in kontextuellen Situationen. Die Evolution des Artikels verläuft über eine verstärkte Ausnutzung der sekundären Funktion des Demonstrativpronomens, über dessen Verwendung in Situationen, die nicht mehr durch Kontextbedingtheit gerechtfertigt sind, und über die formale Aufspaltung des Demonstrativpronomens in primär real lokalisierende Morpheme (Demonstrativa) und in identifizierende Morpheme (Artikel). Zur Artikel theorie vgl, auch Reichenkron ${ }^{149)}$, mit der dort angeführten, theoretisch unergiebigen Literatur. Vor der Aufstellung einer Artikel theorie durch die Logik sprach man in der Linguistik von den 'bestimmenden', 'individualisierenden', 'generalisierenden', 'aktualisierenden', 'präsentierenden', 'realisierenden', 'signalisierenden', 'kon- 
kretisierenden' Funktionen des Artikels, vgl. die bei Kurz ${ }^{150)}$ angeführten Definitionen. Hansen ${ }^{151)}$ und Svane 152) sprechen in Bezug auf die Kategorie 'Determiniertes Nomen' von einem 'nominalen Aspekt'. Die Meinung Guillaumes ${ }^{153)}$ vom Artikel als Aktualisator beim Ubergang von der Ebene der Sprache zur Ebene der Rede: HOMME (Sprache) - l'homme (Rede), ist unannehmbar.

Diese in den Sprachen mit Artikelmorphem festgestellte Artikelfunktion ist für den Beschreiber der linguistischen Diachronie vorgegeben. Seine Aufgabe kann es nicht sein, die Evolution einer Funktion als solcher in der Sprachgeschichte zu verfolgen, sie besteht vielmehr darin, die unterschiediche Zuordnung von Zeichen zu dieser Funktion in der Geschichte einer Sprache zu beschreiben. Alle bis heute festgestellten linguistischen Kategorien sind daher in allen Systemen als potentielle oder Protokategorien für den Linguisten vorhanden. Die Berechtigung dieses Vorgehens zeigt sich beim Vergleich zweier zeitlich getrennter Systeme einer Sprache bezüglich der Nominalen Determination. Im älteren System I. bedeutet nomen - 'Name', 'der Name', 'ein Name', wobei die unterschiedlichen Kategorien, die in der wissenschaftlichen Metasprache (hier: Deutsch) reflektiert werden, nur im Kontext zu unterscheiden sind, sie sind im Nomen implizit vorhanden. Auf einer jüngeren Sprachstufe wird eine der Kategorien expliziert. Durch das Auftreten des zusätzlichen formalen Ausdrucks entsteht zwischen dem Semantem ohne Morphem und dem Semantem mit Morphem die Opposition merkmallos: merkmalhaft (privative Opposition ${ }^{154}$ )). Als formal negatives Glied der Opposition erhält mit dem Auftreten der neu formalisierten Kategorie auch die merkmallose Grundform eine neue explizite Bedeutung, d.h. aus ihrem Bedeutungsumfang wird eine Bedeutung herausgelöst, zu der sie selbst nun die Kontrastbedeutung (kontextfre1) ausdrückt. Das gleiche Nomen in zwei zeitlich voneinander getrennten Systemen einer Sprache, die eine Porm zum primären Ausdruck dieser Kategorie heran- 
bildet, hat in jedem System unterschiedliche Bedeutungen, da sich seine Oppositionsglieder geändert haben:

II. nomen - 'Name', 'ein Name' gegenüber illud nomen 'der Name'. 155) Daraus ist zu schließen, daß in System I die Nominale Determination als Protokategorie vorhanden ist.

Eine Kategorie wird dem Sprecher in dem Maße bewußt, wie sie die Grenzen der kontextbedingten Verwendung eines Morphems überschreitet, also durch das betreffende Morphem in kontextunabhängiger, primärer Funktion ausgedrückt wird. Daneben kann das Morphem mit seiner früheren primären Funktion formal unverändert weiterexistieren, so dab es scheinbar zwei primäre Funktionen hat. In diesem Fall handelt es sich jedoch nicht mehr um e in Morphem, sondern um zwei homophone Morpheme, vgl. im Deutschen 'Mann' und 'man'. In den meisten Fällen geht die Entwicklung jedoch mit einer morphematischen Differenzierung Hand in Hand, vgl. im Englischen 'one' (Zahlwort) und ' $a$ ' ('unbestimmter' Artikel).

Methodisch unzulässig sind m.E. daher die Versuche, die Entstehung des Artikels durch die Entwicklung seines Morphems und zugleich durch die Entwicklung der Artikelfunktion zu beschreiben. Bei richtiger Auffassung der wissenschaftlichen Metasprache ist diese Funktion (die eine Protokategorie bzw. Kategorie konstituiert) konstant. Die genannten Versuche (vor allem bei Miletič) begehen den Fehler, den Inhalt der Kategorie im BewuBtsein des Sprechers und im Bewußtsein des Linguisten gleichzusetzen, sie machen aus der Konstanten der Kategorie eine auf den Sprecher bezogene Variable und operieren mit zwei Variablen (Form und Inhalt der Kategorie), mit dem Ergebnis, daB in der linguistischen Beschreibung die Form aus dem Inhalt und der Inhalt aus der Form erklärt wird. Dagegen gehe ich im folgenden von der diachronischen Konstanten 'Identifizierung' aus. Das Kriterium dafür, ob durch diese Funktion eine offene Kategorie konstituiert wird, ist die Existenz einer morphematischen Form mit entsprechender kontextunabhängiger Funktion. Dies impliziert eine gewisse 
Obligatheit der Verwendung des Morphems in den Situationen, in denen eine Identifizierung durch den Sprecher naheliegt. 156) Allerdings unterliegt gerade die Verwendung des Artikels, wie wir gesehen haben, stark der Willkür des Sprechers.

In vielen Sprachen, in denen die Kategorie Determiniertes Nomen nicht besteht, übernehmen Morpheme mit einer semantisch nahestehenden primären Funktion den Ausdruck der Protokategorie in sekundärer Funktion (auf der SE): Demonstrativ-, Indefinit-, Relativpronomina, 'determinierte Adjektiva'. Pormal liegt 'zwischen den Extremen 'bestimmter Artikel' und 'Pehlen eines solchen' (...) ein Ubergangsgebiet, das, ohne einen bestimmten Artikel zu kennen, dem Bedürfnis einer deutlichen Bezeichnung der Determination in anderer Weise entgegenkommt." (Schwyzer) 157)

Zum determinierten bildet das indeterminierte (nichtidentifizierte) Nomen das Oppositionsglied. Seine Form variiert in den verschiedenen Sprachsystemen. Es ist

$$
\begin{aligned}
& \text { eingliedrig in: bulg. (sinst) - sin } \\
& \text { zweigliedrig in: rum. (casa) - o casā - casã }
\end{aligned}
$$

Die Entwicklung von der Eingliedrigkeit zur Zweigliedrigkeit ist in der Diachronie mancher Sprachen zu beobachten, 2.B. im Bulg.: schriftbulg. (sinbt) - sin, dagegen in bulg.-mak. Dialekten (sinbt) - eden sin - sin. Welches ist das funktionelle Verhältnis des determinierten zum indeterminierten und das der beiden Glieder des indeterminierten Nomens untereinander?

Durch den Artikel wird das von ihm begleitete Semantem mit einem bestimmen der unter den Begriff fallenden Gegenstände, welcher vom Sprecher als gegeben oder bekannt hingestellt wird, identifiziert. Sinnvoll ist die Identifizierung deshalb nur bei Semantemen, unter deren Begriff mehrere Gegenstände fallen: nur bei ihnen können als bekannt vorausgesetzte von nicht bekannten Gegenständen, die durch ein und dasselbe Semantem bezeichnet werden, unterschieden werden. Nicht sinnvoll ist die Identifizierung von Nomina, wenn sie im generellen Sinne verwendet werden, und von Eigennamen. 
Erstere sind mit einer Identifizierung begrifflich nicht zu vereinbaren, letztere bezeichnen ihren Gegenstand ein-eindeutig ('gedankliche' oder 'inhärierende' Determination bei Schwyzer ${ }^{258)}$ ). Den Eigennamen schließen sich die Verwandtschaftsnamen an, die psychologisch gesehen häufig den Wert von Eigennamen haben, "weil die bezeichnete Person für den Sprechenden ein Individuum ist." (Seidel) ${ }^{159)}$ - Die Kategorie 'Determiniertes Nomen' ist aber aufgrund der zahlenmäBigen Uberlegenheit der pluralistischen Verwendung von Nomina expansiv und wird auch auf Eigennamen angewendet, was zu einer Hyperdetermination führt. ${ }^{160)}$ Aus demselben Grunde können für die Verwendung von Nomina im generellen Sinn die Kategorien des Plurals und der Determination übernommen werden, und nur in der Bedeutungsneutralisierung der übernommenen Kategorien gibt sich die generelle Verwendung $z u$ erkennen (siehe hierzu Koschmieder) ${ }^{161)}$ : Tier generell läBt sich ohne Bedeutungsunterschied realisieren als ein Tier $=$ das Tier $=$ Tiere = die Tiere. Die formale Artikulierung von Nomina in genereller Verwendung und von Eigennamen stellt eine sekundäre Ausweitung des Artikelgebrauchs dar.

Folglich zeigt ein das Semantem begleitender Artikel an, daß das Semantem in einem solchen Palle keine generelle oder begriffliche, sondern eine individuelle Bedeutung hat. Als Identifikator ist der Artikel zugleich Individualisator.

Durch den sogenannten 'unbestimmten Artikel' kennzeichnet der Sprecher ebenfalls, daB sich das betreffende Semantem auf nur einen der unter den Begriff fallenden Gegenstände bezieht. Anders als beim Artikel stellt der Sprecher diesen Gegenstand jedoch nicht als bekannt hin, eine Identifizierung des Semantems mit dem intendierten Gegenstand unterbleibt, weil dieser - nach Ansicht des Sprechers - durch die Sprechsituation nicht gegeben ist. Für den 'unbestimmten Artikel' verwende ich im folgenden den Arbeitsterminus Individualisator. Damit stehen sich gegenüber:

Artikel - identifizierend, individualisierend 


$$
\begin{gathered}
\text { Individualisator - individualisierend, } \\
\text { nicht-identifizierend } \\
\text { Zeromorphem - nicht-individualisierend, } \\
\text { nicht-identifizierend }
\end{gathered}
$$

(Das Zeromorphem steht vor dem ungekennzeichneten Semantem: $\varnothing$-Nomen.)

Aus der Funktionsverteilung ergibt sich, dab der Individualisator nicht aus der Opposition zum Artikel entsteht, sondern aus der Opposition zum unmarkierten Nomen, wodurch eine Gegenüberstellung: individuelle - generelle Verwendung geschaffen wird. ${ }^{162)}$ Das Entwicklungsschema des Individualisators ist $n i c h t$ :

$\begin{array}{llll}\text { System I } & \begin{array}{l}\text { rex } \\ \text { System II }\end{array} & - & \text { ille rex } \\ & \text { unus rex } & - & \text { ille rex }\end{array}$

System I rex - individuell, generell

System II I unus rex - individuell $\rightleftarrows$ rex - generell

Vgl. als Bestätigung das Serbokroatische, wo sich ein Individualisator entwickelt, ein Artikel aber fehlt: Mlinarica jedna uzela me u službu (8. Reichenkron) ${ }^{163)}$. In einem solchen System wird die Funktionsverteilung sein:

čovek - generell, individuell/identifiziert jedan čovek - individuell/nicht-identifiziert

In den Sprachen, in welchen das generell gebrauchte Nomen schlieblich auch den nur für das individuell gebrauchte Nomen sinnvollen Kategorien unterworfen wird (formale Individualisierung, Pluralisierung, Identifizierung), wie z.B. im Deutschen, geraten Artikel und Individualisator durch Wegfall des formalen Kriteriums: individuell - generell, in eine binëre Opposition mit den ausschließlichen Funktionen: identifizierend - nicht-identifizierend. 
Der bulg. Artikel ist (nach Gblbbov) ${ }^{164}$ ) gekennzeichnet a. durch das Nebeneinander von dreigliedrigen und einEliedrigen Artikelsystemen, $\underline{b}$. durch die ausnahmslose Postposition des Artikels nach dem ersten Glied des nominalen

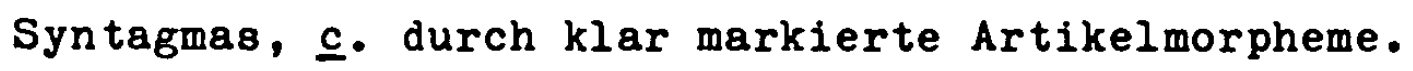
Ich untersuche diese drei Merkmale auf ihre Entstehung hin. Auf bulg.-mak. Sprachgebiet bestehen eingliedrige Artikelsysteme: car-ôt, žena-ta, selo-to, ženi-te, sela-ta neben dreigliedrigen Artikelsystemen: car-ot - car-ov (car-os) 'der Zar hier bei mir' - car-on 'der Zar dort bei ihm', žena-ta - žena-va (žena-sa ) - žena-na etc.

Die Verbreitung der dreigliedrigen Artikelsysteme ist:

a. Torlakiseh 165 )

b. Wes tmak. 166 )

c. Bulg. in Trsnsko ${ }^{167)}$ und in den Rhodopenmundarten ${ }^{168)}$. Für die Artikulierung eines Objekts im Bereich der 1. Person verwenden das Mak. und die Mundart von Trsnsko den Stamm ovb, die Rhodopenmundarten $\underline{s b}$ mit Angleichung an die nichtpalatalen Stämme ts und ons: detęsq ${ }^{169}$ ).

Die Mundarten mit dreigliedrigem Artikelsystem befinden sich - grosso modo - an der südwestlichen Peripherie des ehemaligen rum.-slav. bilingualen Raumes: "C'est aux deux extrémités opposées du domaine linguistique qui nous occupe que nous trouvons les trois séries le plus complètement et le plus régulièrement développées (...)n (Lamouche) ${ }^{170)}$ Das eingliedrige Artikelsystem ist in der überwiegenden Anzahl der bulg. Mundarten vertreten, sowie im 0stmak. 171) Dabei ist es auffällig, daß sich in den Gebieten mit herrschendem dreiglieqrigen Artikelsystem immer wieder, z.T. archaische, Mundarten mit eingliedrigem Artikelsystem finden, so im peripheren SW-mak. Dialekt von Boboščlca (Albanien) ${ }^{172)}$ und im Rhodopengebiet die Cepiner Mundart und die Mundart der Pavlikaner ${ }^{173)}$. 
Dieses Nebeneinander von dreigliedrigen und eingliedrigen Artikelsystemen führt zu der Annahme, das dreigliedrige Artikelsystem sei in einer früheren Periode allgemeinbulg.mak. gewesen und der einstige Zustand sei an der sprachlichen Peripherie bewahrt worden (so Koneski ${ }^{174}$ ), Svane ${ }^{175}$ ), Gslbbov ${ }^{176)}$ ). Dies würde erklären, warum in einer Reihe von Dialekten, die die Entwicklung des Halbvokals (HV) - $\underline{\underline{b}}>-\underline{0}$ nicht kennen, der Artikel heute in der Porm $-0(t)<-b t b$ vorliegt ${ }^{177)}$, nämlich durch eine Ubertragung des Vokals ㅇas brěgovs, brěgons < brěgs ovs, brěgs ons auf brěgsts $>$ brěgot $^{178 \text { ) }}$ vgl. die umgekehrte Entwicklung zu mưžsv, múžsn < mužov, mužon unter EinfluB von mǔžst in Trsnskol79) und ebenso konjbv, konjbn nach konjbt im Torlakischen ${ }^{180}$ ), sowie den Ausgleich der Demonstrativpronomina otaj neben taj nach ovaj neben vaj, ondj neben naj in Zumberk (Jugoslavien) ${ }^{181)}$; ovoj, ovja im Westmak., voj im 0stmak. ${ }^{182)}$; in allen Rhodopenmundarten: soja - noja - tojal83).

Um zu erklären, welches die Gründe für eine solche innerbulg.-mak. Entwicklung vom dreigliedrigen zum eingliedrigen Artikelsystem sein können und ob sie für die Erklärung dieses Prozesses ausreichen, betrachte ich im folgenden die Systeme von Demonstrativpronomina, denen die betreffenden Artikel entnommen sind.

Das älteste slavische (und entsprechend das baltische) System von Demonstrativpronomina, das Zeigesystem, wird durch $\underline{s b}$ - tb - ons repräsentiert. 184 ) "Ein dreigliedriges System von Demonstrativpronomina ging anscheinend in allen Sprachen dem zweigliedrigen voraus." (Jakubinskij) 185) Das dreigliedrige System stellt eine Anpassung der deiktischen Morpheme an das Dreiersystem der Personalpronomina dar: ich/ wir - du/inr - er, sie, es/sie, vgl. im Skr. ovo meni, to tebi, ono njemu. 186)

Der sprachliche Ausdruck einer realen Lokalisierung baslert auf der binären Relation nah-fern, gemessen von einem näher $z u$ bestimmenden 'Subjekt' aus, wie die zweigliedrigen 
Zeigesysteme bestätigen: russ. étot - tot, nbulg. tozi onzi, englisch this - that, französisch ceci - cela. Wie erscheint diese Relation in das dem Dreiersystem der Personalpronomina nachgebildete dreigliedrige Zeigesystem eingegliedert, welches im Aksl. oder im Skr. vorliegt? Zur Beantwortung dieser Frage ist einleitend der Aufbau des Dreiersystems der Personalpronomina zu untersuchen.

Im personalen Dreiersystem lassen sich zwei Aspekte erkennen, unter denen der Sprecher die gesamte außersprachliche Realität, sich selbst eingeschlossen, betrachtet. Es kann angenommen werden, daß diese Aspekte in diachronischer Hinsicht das personale Dreiersystem mit den fundamentalen Gliedern ich - du - er haben entstehen lassen.

Der erste Aspekt besteht in der Unterscheidung von 'Subjekt' (Sprecher) und den externen 'Objekten' (= alle anderen) ${ }^{187)}$, also:

Aspekt I

$$
\frac{\text { nicht-ich }}{i c h}
$$

Der zweite Aspekt besteht in der Abgrenzung der Sprecher-Hörer-Gruppe (年klusives 'wir', s. Kurylowicz ${ }^{188}$ ), von den $z u$ dieser Gruppe externen 'Objekten':

Aspekt II

nicht-wir

wir

Die Differenz zwischen beiden Aspekten besteht in der Zuordnung der Hörerperson: "Der Hörer ist einerseits ein Gegenüber des Sprechers, eine Art von bevorzugtem Teil der Realität außerhalb vom Sprecher, gehört aber gleichzeitig (...) zu dieser Realität." (Kurylowicz) 189)

Aus dem Vergleich von Aspekt I, der auf dem einfachen Glied 'ich' basiert, mit Aspekt II, der auf dem komplexen Glied 'wir' basiert, ergeben sich die übrigen Personalpronomina des Dreiersystems: Aspekt II läßt sich unter Benutzung des Gliedes 'ich' aus Aspekt I umformulieren $z u$ Aspekt II

$$
\frac{\text { nicht }-(i c h+x)}{i \operatorname{ch}+x}
$$


Das gewonnene Glied $\underline{x}=$ Hörer ('du') wird in Aspekt I eingesetzt:

Aspekt I

$$
\frac{d u+y}{i c h}
$$

mit dem gewonnenen Glied $y=$ 'er' wird Aspekt II weiter umgeformt zu:

Aspekt II

$$
\frac{e r}{d u+i c h} \text { oder } \frac{\text { er }}{\text { nicht-er }}
$$

In der Umformulierung auf nicht-komplexe Glieder lauten die Aspektformeln folglich:
Aspekt I
$\frac{\text { nicht-ich }}{i c h}$
Aspekt II
$\frac{\text { er }}{\text { nicht-er }}$

Das positive Glied in Aspekt I ist 'ich', von Aspekt II 'er', wenn man das komplexe Glied 'wir' in einfache Glieder aufgelöst hat, d.h. wenn die Aspekte im existierenden dreigliedrigen Personalsystem ich - du - er aufgezeigt werden. Zum fundamentalen Charakter von 'ich' und 'er' im Personalsystem vgl. Kurylowicz.190)

Jede Person des personalen Dreiersystems (lat.)

(B)

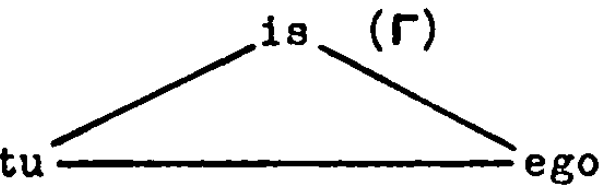

erhält ihre Stellung im System durch die Berücksichtigung ihrer Positionen in beiden Aspekten:

\begin{tabular}{l|c|l|l} 
is & nicht-ich & \multicolumn{1}{|c|}{ er } & $=(-)(+)$ \\
\hline ego & icl & nicht-er & $=(+)(-)$ \\
\hline tu & nicht-ich & nicht-er & $=(-)(-)$ \\
\hline & Aspekt I & Aspekt II &
\end{tabular}

Das Pronomen des Hörers $(t u)$, welches dadurch gekennzeichnet ist, daß es im Aspekt I zum Nicht-ich, im Aspekt II zum Nicht-er gehört, zeigt durch seine doppelte Negativität $n i c h t$ an, daß es aus der Personeneinteilung herausfällt und etwa an ihr nicht teilnimmt. Seine Charakteristik 
'nicht-ich' im Aspekt I schließt die Charakteristik 'nicht-er' im Aspekt II nicht aus, zwischen beiden Charakteristiken besteht eine dritte Möglichkeit, die der Bezeichnung des Hörers, der im komplexen Glied 'wir' des Grundaspekts eingeschlossen ist. Mit anderen Worten: Die Beziehung zwischen dem Sprecher, dem Hörer und den externen Objekten ist eine ternäre (dreipolige) Relation, so daß sich durch die Negation von 'ich' und 'er' ein ebenso systemhaftes, aspektunabhängiges Glied ergibt ('du'), wie es 'ich' und 'er' sind: 'tu' bezeichnet eine konkrete Person in der Realität.

Entsprechend dem Personalsystem bezeichnet das dreigliedrige Zeigesystem den Raum in der auBerlinguistischen Realität, die jeder der drei Personen zugeteilt wird:

(B)

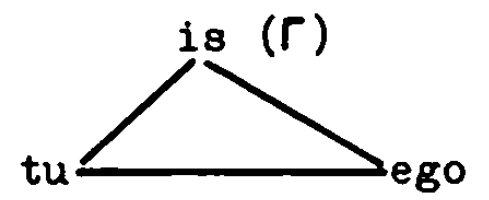

$(\beta)$

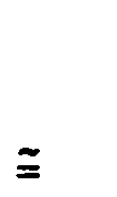

(B) iste

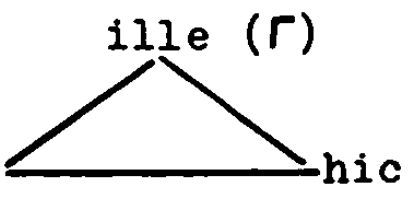

$(\beta)$

mit der Bedeutung $\underline{\text { hic }}=\operatorname{der}$ bei mir Befindliche

$$
\begin{aligned}
& \text { iste }=\text { der bei dir Befindliche } \\
& \underline{\text { ille }}=\text { der bei ihm Befindliche. }
\end{aligned}
$$

Auch das dreigliedrige Zeigesystem wird durch zwei den personalen Aspekten parallele Aspekte konstituiert:

Aspekt I

Aspekt II

$$
\text { (= skr. } \frac{\text { ne-ovamo }}{\text { ovamo }}
$$

$$
\text { (= skr. } \left.\frac{\text { onamo }}{\text { ne-onamo }}\right)
$$

Die drei Demonstrativpronomina beziehen ihre systematische, aspektunabhängige Stellung aus der Berücksichtigung ihrer Positionen in beiden Aspekten:

\begin{tabular}{l|c|l|l} 
ille & nicht bei mir & bei inm & $=(-)(+)$ \\
\hline hic & bei mir & nicht bei ihm & $=(+)(-)$ \\
\hline iste & nicht bei mir & nicht bei ihm & $=(-)(-)$
\end{tabular}

Die systematische Charakteristik von iste (doppelt negativ) konstituiert, da das Zeigesystem auf das ternäre Personalsy- 
stem bezogen 1st, den konkreten Raum der 2. Person: skr. ne-onamo und ne-ovamo umschreiben tamo. In der Bezogenheit auf das Personalsystem wird das Pronomen 1ste (slavisch tb) aspektunabhängig als auf den Raum der 2. Person bezogen verstanden: skr. ta kuka - 'das Haus bel dir'.

Jedoch bezeichnen die Pronomina ille - iste - hic, skr. onaj - taj - ovaj mehr als nur den jeder der drel Personen zugeteilten Raum. Ein skr. kupujemo ovu ku\&u, tražimo onoga čoveka, enthält auch ein Urteil des Sprechers darüber, ob die bezeichneten Objekte nah oder fern von inm gelegen sind: das dreigliedrige Zeigesystem enthält auch die binäre Relation nah-fern, auf der eine reale Lokalisierung auBerhalb der personellen Raumzuordnung basiert, wie englisch this that, russ. ètot - tot, nbulg. tozi - onzi zeigen. Diese Relation ist im dreigliedrigen Zeigesystem auf den Sprecher bezogen: ova kuca bedeutet 'das Haus' im Bereich des Sprechers und zuglelch 'das Haus' nahe vom Sprecher; onaj čovek bedeutet 'der Mensch' im Bereich der 3. Person und zugleich 'der Mensch' fern vom Sprecher.

Die Eingliederung der Nah-Pern-Relation ins dreigliedrige personaldominierte Zeigesystem erfolgt durch Imitation der Position von 'ich' und 'er' im Personalsystem und 'bel mir' - 'bei inm' im Zeigesystem:

Aspekt I $\frac{\text { nicht-ich }}{i c h} \cong \frac{\text { nicht bei mir }}{\text { beimir }} \cong \frac{\text { nicht-nah }}{\text { nah }}$
Aspekt II $\frac{\text { er }}{\text { nicht-er }} \cong \frac{\text { bei ihm }}{\text { nicht bei ihm }} \cong \frac{\text { fern }}{\text { nicht-fern }}$

Der prinzipielle Unterschied zwischen den personalgebundenen und den Nah-Pern-Aspekten besteht darin, daB erstere ein ternäres System generieren, während die Nah-Fern-Relation binär 1st. Die Onterordnung der Nah-Pern-Information unter die Information über den personellen Raum im dreigliedrigen Zeigesystem führt dazu, daß ein Glied des Dreiersystems eine Lücke im Ausdruck der Nah-Pern-Relation bildet: 


\begin{tabular}{l|c|l} 
ille & nicht-nah & fern \\
\hline hic & nah & nicht-fern \\
\hline iste & nicht-nah & nicht-fern
\end{tabular}

Für das Pronomen der 2. Person ergibt sich die systeminterne Charakteristik: nicht-nah/nicht-fern, was einander ausschliebt; eine dritte, dazwischenliegende röglichkeit existiert nicht. Das Demonstrativpronomen der 2. Person im dreigliedrigen Zeigesystem kann der binären Nah-Fern-Relation nicht systematisch zugeordnet werden.

Daraus ergeben sich zwei Polgerungen für den Gebrauch dieses Demonstrativpronomens (slavisch ts) in der Nah-FernLokalisierung:

1. Das Demonstrativpronomen der 2. Person kann eine Aussage über 'nah' oder 'fern' nur liefern, wenn es im Kontext zum Demonstrativpronomen der 1. oder 3. Person in Kontrast steht, d.h. in Aspektgebrauch. Wird iste, welches die Grundbedeutung 'der bei dir Befindliche' hat, zu hic in Kontrast gesetzt (Aspekt I), so bezeichnet es nicht-nah = fern vom Sprecher; gegenüber ille (Aspekt II) bezeichnet es nicht-fern = nah beim Sprecher. ${ }^{191)}$ Entsprechend verhält es sich mit aksl. ts. 192) Während also die Grundbedeutung konstant bleibt, kann ts je nach seinem Kontext ein 'Nah' oder 'Pern' vom Sprecher bezeichnen. Diese Bedeutungsexpansion des Demonstrativpronomens der 2. Person bewirkt in diachronischer Hinsicht, dab ts, sobald seine Bindung an die 2. Person des Personalsystems aufgehoben wird, durch Generalisierung eines der Aspekte als systematischer Ersatz entweder für ons (fern) oder $\underline{B b}$ (nah) eintreten kann.

2. Steht ein Pronomen ts nicht in kontextbedingtem Kontrast zu ons oder sb, liegt also kein Aspektgebrauch vor, so kommt die systeminterne Bedeutung von ts im Verhëltnis zur NahPern-Relation (doppelt negativ) zur Geltung: systemintern ist ts rom Kessen mit 'nah' oder 'fern' frei. Da diese Maßangaben zur Lokalisierung von Gegenständen in der realen Welt (reale Lokalisierung) dienen, ist das Demonstrativprono- 
men der 2. Person vom Standpunkt der Nah-Pern-Relation für die reale Lokalisierung wenig geeignet. Dagegen kann es verwendet werden in den Fällen, in denen eine zusätzliche kontextuelle Erwähnung des intendierten Gegenstandes den Sprecher der realen Lokalisierung des Gegenstandes enthebt; die Nullwertigkeit von ts für die Nah-Fern-Relation qualifiziert es gerade für das Verweisen im Kontext, für die grammatische Lokalisierung. Vgl. skr.: (Barac, Jugoslovenska knjižernost) U svojim pripovijestima i romanima Cippico je opisivao život kako ga je upoznao u svome zvanju. Iz njegovin djela izbija spoznaja kako je taj život velik i lijep u svojoj prirodnosti i nagonskoj čistoci (...) Es handelt sich um eine besondere 'Lebensform', die dem Sprecher fern liegt, eine reale Lokalisierung würde onaj život erfordern. Da die Spezifizierung des gemeinten Gegenstandes jedoch schon durch die Vorerwähnung (... kako ga je upoznao u svome zvanju) erfolgt ist, reicht zur Identifizierung des 'život velik $i$ lijep' der Rückverweis durch das nah-fern-neutrale Demonstrativpronomen taj aus. Ein Aspektgebrauch von taj entsteht nicht, da ovaj und onaj im Satz nicht vorkommen. - Eine noch höhere Frequenz erreicht tb in den Fällen, in denen der Sprecher gar keine konkurrierenden Gegenstände berücksichtigt und die sekundäre Punktion der Demonstrativpronomina zum 2 weck der reinen Identifizierung benutzt (in artikellosen Sprachen). Soweit die Stämme ons und $\underline{\text { sb }}$ für die grammatische Lokalisierung Verwendung finden, schwindet ihre räumliche Opposition zu tb, was zur Folge hat, daB sich in der Diachronie ts für die grammatische Lokalisierung immer mehr durchsetzt. Vgl. Joh.19, 7-8: 'Die Juden antworteten ihm: Wir haben ein Gesetz, und nach dem Gesetz muß er sterben; denn er hat sich zu Gottes Sohn gemacht. Als nun Pilatus dieses Wort hörte, fürchtete er sich noch mehr.' Für das griech. roṽor tor $\lambda^{\circ}$ yor zeigen Zogr., Mar., Sav. kn., Assem. se slovo, das mittelbulg. Dobrejšovo-Evangelium aber to slovo. -

Parallel zur Vorerwähnung wird ts früh für den Vorverweis 
auf eine Nacherwähnung verallgemeinert, wofür es im Aksl. und im Mittelbulg. Belege gibt. 193)

Die Verwendung des Demonstrativpronomens der 2. Person für die grammatische Lokalisierung, die auf seine stellung in der Nah-Pern-Relation zurückgeht, führt dazu, daB die Bindung dieses Pronomens an die Hörerperson fallengelassen wird. Dies ist notwendig, damit der kontextuelle Gebrauch von ts frei von jeder realen Lokalisierung ist, also auch vom Hinweisen auf den der Hörerperson zugeordneten Raum. In dem obigen skr. Beispiel ist taíživot von jeder Beziehung zum Hörer gelöst. Die verstärkte Realisierung der Nullwertigkeit von ts in der Nah-Fern-Relation für die grammatische Lokalisierung leitet also den ProzeB der Entpersonalisierung von ts ein.

Auf diese Weise erklärt sich die häufig festgestellte 'abstrakte' Punktion des Demonstrativpronomens der 2. Person. Vgl.: "Die Gruppe $\underline{t}-$ ist die extensivste und tritt neben der zweiten Person auch in der Rolle des neutralen Anzeigers auf." (Netteberg) 194) - Das Demonstrativpronomen der 2. Person ist der 'schwache Punkt' des dreigliedrigen Zeigesystems, an welchem die Veränderung einsetzt, die das gemischt personalgebunden-lokalistische Zeigesystem durch einen AbstrahierungsprozeB ${ }^{195)}$ in ein rein lokalistisches überführt, dessen Glieder nur nach dem binären Verhältnis nah-fern funktionieren (vgl. Kurylowicz ${ }^{196)}$ ), wie nbulg. tozi (nah) - onzi (fern), wobei die Urteile 'nah' - 'fern' nicht mehr sprechergebunden verwendet werden müssen (etwa: nah = bei mir, fern $=$ bei $i h m)$, sondern vom Standpunkt eines jeden messenden Nomens im Text abhängen können: 'er sprach lange von dieser seiner Erfindung'.

Auf das altbulg. dreigliedrige Zeigesystem

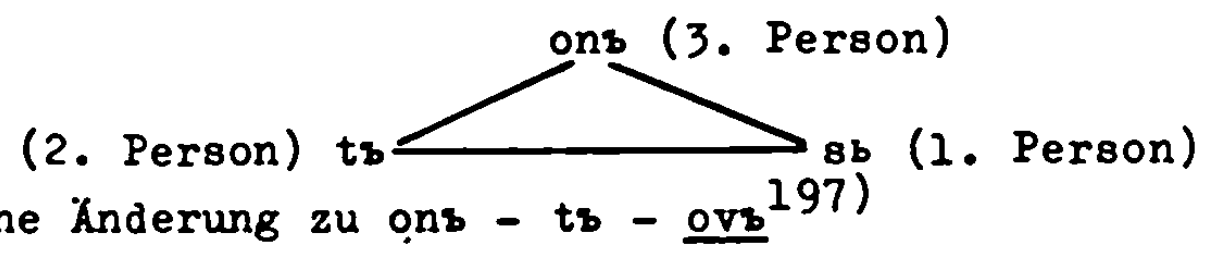

bzw. seine Anderung zu ons - ts - ovs 197)

gehen die dreigliedrigen Artikelsysteme des Bulg.-Mak. zu- 
rück. In den Dialekten mit dreigliedrigem Artikelsystem 1st auch das dreigliedrige Demonstrativsystem erhalten geblieben. ${ }^{198)}$ Deshalb ist jedes dreigliedrige Artikelsystem

a. personalgebunden: ja go glédaf so bčive, šótî-je úbaf slasot, snije fude ja imaet Ubavana kúca. ${ }^{199)}$

b. belastet durch räumliche Nebenbedeutungen ${ }^{200)}$ nach der Nah-Pern-Relation. Detéto (Torlakisch) bedeutet 'das Kind', eine reine Identifizierung; dagegen detévo und deténo 'das $\mathrm{Kind} / \mathrm{nah}$ ' - 'das Kind/fern' mit zusätzlicher Information über die Position des identifizierten objekts in der realen Welt: "detévo und deténo bedeuten immer ovój deté und onoji deté" (Belit über das Torlakische). 201)

c. gekennzeichnet durch die Tendenz, den Gebrauch von -ov/-os und -on zurückzudrängen. Entsprechend den Verhältnissen im dreigliedrigen Zeigesystem ist -ot auch der vom Personalsystem gelöste, generelle Artikel und auf Kosten der übrigen Artikel, der sog. Halbartikel, expansiv. 202)

Durch den Abstrahierungsproze $B$, der das dreigliedrige, gemischt personalgebundene und binär-lokalistische in ein zweigliedriges, nur binär-lokalistisches, überführt, wird auch das dreigliedrige Artikelsystem affiziert: "In dem System mit zwei Demonstrativa wird der postponierte Artikel elngliedrig" (Mazon-Vaillant).203) Der formale Umbau des dreigliedrigen Zeigesystems zum zweigliedrigen erfolgt durch Erhebung. einer der beiden, je nach Kontextopposition wechselnden Bedeutungen des Demonstrativpronomens der 2. Person in der Nah-Pern-Relation, entweder 'nicht-fern' oder 'nichtnah', zur kontextunabhängigen, primären Funktion dieses Pronomens, d.h. durch eine formale Generalisierung eines der beiden Zeigeaspekte:

Aspekt I

Aspekt II nicht-nah

nah

$\frac{\text { fern }}{\text { nicht-fern }} \quad($ on $-/ t-)$


Das heutige zweigliedrige Zeigesystem des Russischen ist durch Aspekt I entstanden: tot (nicht-nah) - sej (nah), mit jüngerer Ersetzung von sej durch ${\underline{\dot{e}-t o t^{204}}}^{20}$, das zweigliedrige des Polnischen durch Aspekt II: 6w (fern) - ten (nicht-fern), mit jüngerer Ersetzung von of durch tam-ten. Das ältere $\delta \mathrm{w}(<\mathrm{ovb})$, das im Polnischen für ons eingetreten war, bezeichnete ursprünglich 'den einen - den' anderen' und trat in Teilen des Südslavischen für sb ein.

Auch in den neuen 2 weiersystemen ist das Funktionieren des Stammes $\underline{t}-$ als 'nicht-nah' bzw. 'nicht-fern' ( $n$ i c h t als 'fern' bzw. 'nah'!) zu erkennen: "Obgleich die Pronominalpare, welche die zweigliedrigen Demonstrativsysteme in den slavischen Sprachen bilden, verschieden sind und ihre Hechselbeziehungen charakteristische Besonderheiten zeigen, ist ihnen gemein, daß in allen zweigliedrigen System $t$ - das unmarkierte Glied ist. Uberall ist es weniger an das Merkmal der Deixis gebunden und hat ein größeres Anwendungsfeld." (Velčeva-Bojadžleva) 205) $\mathrm{Vgl}$. im Russischen dlja togo (tot nicht-nah) und im Bulg. za tova (tozi - nicht-fern).

Im Bulg.-Mak. entstanden die folgenden zweigliedrigen Zeigesys teme:

Aspekt I: altbulg.
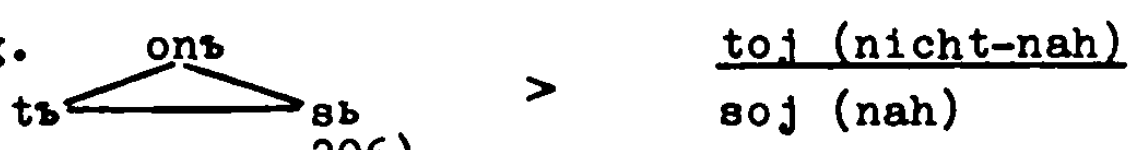

im mak. Dialekt von Boboščlca 206), ebenso tonzi/senzi in den Csergeder Texten (NO-bulg. Mundart). 207) Entsprechend mit Ersetzung des älteren $\underline{s b}$ durch ovs:

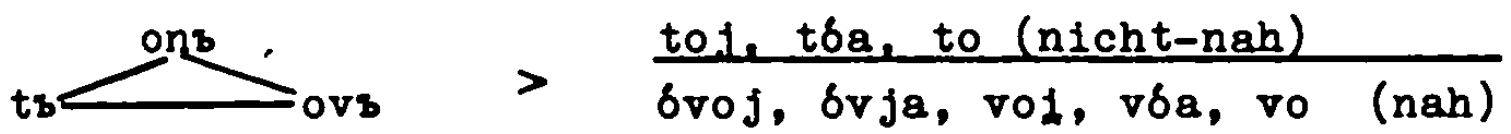

in den mak. Zentralmundarten südlich von Debar und in den Südmundarten bis Saloniki. 208)

Aspekt II: altbulg.

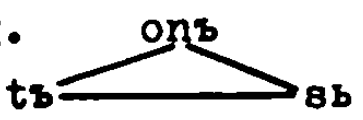

$>\quad$ nos, nus (fern)

in Sucho (bei Saloniki). Vgl. die Isoglosse für tos, nos im Mak. 209) 


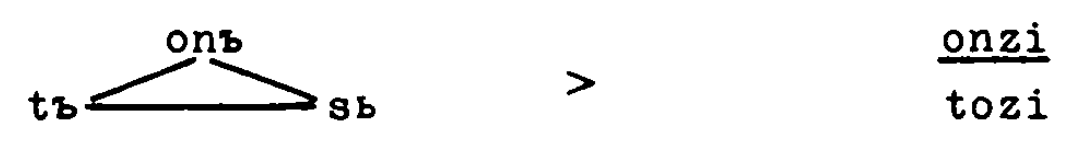

entspräche theoretisch ein ArtikelprozeB

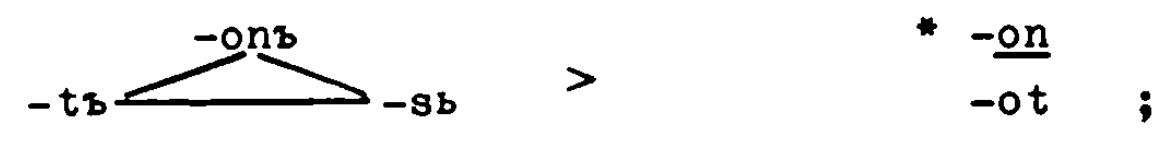

da -ot für die Nah-Pern-Relation nullwertig ist, läßt sich eine lokalistische Opposition zwischen -on und -ot nicht aufrechterhalten, -on verliert seine lokalistische Funktion und fällt mit -ot zusammen (= kommt auBer Gebrauch). Ebenso im Palle von artikelhaftem $-o n b /-t b /-s b>*-o t /-0 s$. Der ProzeB der Entpersonalisierung durch formale Generalisierung eines der Zeigeaspekte, der das Zeigesystem zu einem rein binär-10kalistischen System veränderte, bewirkte im Artikelsystem zusätzlich zur Entpersonalisierung eine Entlokalisierung und die Bildung eines eingliedrigen Artikelsystems mit der ausschlieblichen Funktion der Identifizierung. Daß dieser einzige Artikel in den bulg.-mak. Mundarten mit eingliedrigem Artikelsy$s$ tem ausnahmslos durch das Morphem $-b(0) t<-t \underline{b}$ repräsentiert wird, erklärt sich durch die generelle und räumlich unbelastete Funktion, die ts im dreigliedrigen Zeigesystem einnahm. Zusammenfassend ist zu sagen, daß das heutige Nebeneinander von dreigliedrigen und eingliedrigen Artikelsystemen im Bulg.-Mak, als zwei Entwicklungsstufen eines das Zeigesystem erfassenden Abstrahierungsprozesses interpretiert werden kann, dieser ProzeB nimmt von den internen Widersprüchen des älteren Zeigesystems seinen Ausgang und läßt sich innerhalb einer Sprache durchführen.

Gegen die Annahme eines internen bulg.-mak. Prozesses als a 1 l e $i \mathrm{n} i g$ e Erklärung für das Nebeneinander von dreigliedrigen und eingliedrigen Artikelsystemen, wodurch für alle Dialekte ein ursprünglich dreigliedriges Artikelsystem vorausgesetzt wird, spricht jedoch die Tatsache, daß einige Mundarten, die in den übrigen Teilsystemen sehr konservative Züge aufweisen, längst ein zweigliedriges Zeigesystem und ein 
eingliedriges Artikelsystem besitzen. Es sind dies vor allem der periphere mak. Dialekt von Boboščica in Albanien und der NO-bulg. Dialekt von Cserged, den die im 16. Jhd. verfaßten Csergeder Texte (eine bulg. Kolonie in Siebenbürgen) zeigen. Der Csergeder Dialekt repräsentiert nach allgemeiner Ansicht den Zustand des progressiven NO-Bulg. im 13. Jhd. 212) Hier kann auch die Sprache der vlachobulg. Urkunden (14. - 15. Jhd.) genannt werden, die mit wenigen Ausnahmen ${ }^{213)}$ nur den Artikel -ot kennt.

Die Verhältnisse in den aksl. Texten können in dieser Frage keinen AufschluB geben, da in inrer Sprache kein Artikelsystem existiert ( $v g l$. Kap. II, 3.). DaB in den Texten $-8 t b /-0 t b,-38 b /-08 b,-0 n b$ als Demonstrativa postpositiv und teilweise mit Vollvokalisation verwendet werden, beweist also $n$ i $c h t$, "daB der Gebrauch des dreifachen Artikels einst ein gemeinbulgarischer Zug war" (Gblbbov). ${ }^{214}$ ) Die von Miletič und Gslsbov aufgestellten Statistiken, aus denen hervorgeht, dab die Fälle mit postponiertem -bsb im Aksl. häufiger sind als -stb, was die 'artikelhafte' Verwendung auch von sb beweisen sol1215), verlieren inre Aussagekraft, wenn für die genannten Linguisten die Vollvokalisation $z u-0 s b /-e s b$ und -ots/-ets und die Postposition der Demonstrativpronomina ausreichende Kriterien für das Vorhandensein eines Artikels sind, ohne Rücksicht auf die Bedeutung, weshalb auch Fälle wie dbnesb 'heute', nočesb etc. für die genannte statistik verwertet werden. 2lo)

Ich sehe in dem Nebeneinander von dreigliedrigen und eingliedrigen Artikelsystemen im Bulg.-Mak., welches durch die ganz ungleichmäßige Durchführung des theoretisch rein al tbulgarisch möglichen Abstrahierungsprozesses beim Demonstrativpronomen und Artikel überrascht, einen Zusammenhang mit dem Nebeneinander von dreigliedrigen und eingliedrigen Artikelsystemen, wie es vor der Ankunft der Slaven auf dem Balkan im Prührum. und Prühalb. bestanden haben muB.

Das rum. Artikelsystem war, ein romanisches Erbe, in 
jedem Punkt seiner Entwicklung eingliedrig, es verwendete stets nur den Stamm lat. ille als Artikelspender, und das Fehlen von von anderen Stämmen gebildeten Halbartikeln machte inn frei von lokalisierenden und personalen Nebenbedeutungen. Im eingliedrigen Artikelsystem des Bulg.-Mak. und des Rum. glaubte Skok ${ }^{217)}$ einen Unterschied in der Herkunft des jeweiligen Uorphems $z$ sehen: das Rum. verwende das alte Pronomen für die 3. Person (ille), das Bulg. dagegen das alte Pronomen der 2. Person (tb), deshalb könne der bulg. Artikel nicht vom rum. Artikel angeregt worden sein. Trifft diese Beobachtung zu?

Das Lat. besaß ein personalgebundenes dreigliedriges Zeigesystem:

(2. Person) iste

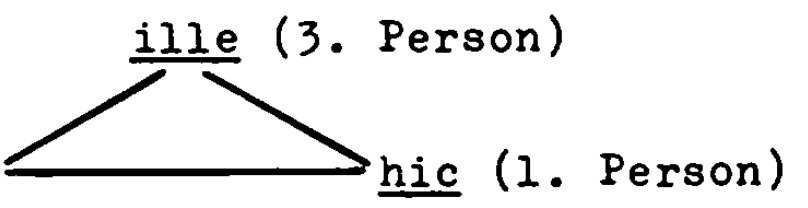

Das in diesem System durch seine Position für den Artikel prädestinierte Pronomen der 2. Person (iste) entwickelte sich in keiner romanischen Sprache zum Artikelmorphem, wofür Piotrovskij ${ }^{218)}$ semantische Gründe anführen zu können glaubt (edinično-vydelitel'noe značenie iste). Den tieferen Grund für das Ausbleiben dieser Entwicklung sehe ich im lat. Demonstrativpronomen $\underline{i s}$, welches in einer früheren Periode den Platz von ille ( 3 . Person) eingenommen haben muß und aus diesem Grunde auch das Anaphorische Pronomen (deutsch 'er') lieferte. Im klassischen Latein stand is bereits außerhalb des personalgebundenen dreigliedrigen Zeigesystems, es war nur noch schwach real lokalisierend. ${ }^{219)}$ Seine hauptfunktion war nun die grammatische Lokalisierung: Omnia habet suum circulum, suum fatum, suum interitum. Ex praeteritis causis circulum eum prospicere nonnunquam. Damit ist iste in eben dieser Funktion zurückgedrängt, es nimmt nur die Funktion der Raumbezeichnung der 2. Person wahr und tritt das grammatische Zeigen an is $a b, d . h$. es realisiert allein seine aus der Personalbindung hervorgehende systematische Bedeutung, mit möglicher Angabe von 'nah' oder 'fern' im kontextuellen Aspekt- 
gebrauch, jedoch nicht seine aus der Nah-Fern-Relation hervorgehende systematische Bedeutung (Verweisen im Text). Während des Bestehens des personalgebundenen dreigliedrigen Zeigesystems im Latein hat die Ausbildung eines (notwendigerweise dreigliedrigen!) Artikelsystems $n i c h t$ eingesetzt.

Der romanische Artikel entspringt dem Zeigesystem, welches sich im Vulgärlat. herausbildete und aus den heutigen romanischen Sprachen rekonstruiert werden kann (rum. ac-el / ac-est):

$$
\frac{\text { ille (fern) }}{\text { iste (nah) }} \quad=\text { Aspekt II }
$$

Es ist entstanden aus den Verschiebungen im Zeigesystem:

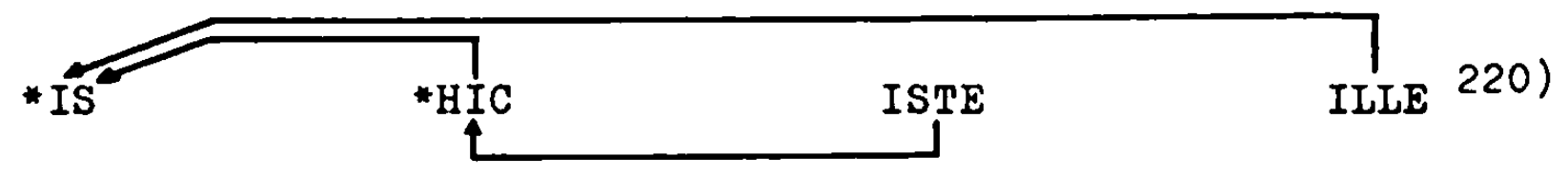

Personalgebundene Dreiersysteme von Demonstrativa konnten sich in Teilen der Westromania neu bilden. 221)

Während ille anfangs nur die real lokalisierende Funktion von is im personalgebundenen Zeigesystem übernommen hatte, erfaBte es bei dem Ubergang zum $Z$ weiersystem auch die anaphorische und grammatisch lokalisierende Funktion des zu dieser zeit ganz außer Gebrauch kommenden is. Aus diesem Grund hat der Stamm ille in allen romanischen Sprachen auBer der realen Lokalisierung für den Fernbereich auch die Funktion des Anaphorischen Pronomens und des Artikels (in morphematischer Aufspaltung): französisch ce(-ci) / celle(-ci) = Demonstrativpronomen, il / elle = Anaphorisches Pronomen, le / la = Artikel; rum. acel = Demonstrativpronomen, el = Anaphorisches Pronomen, $-2 u=$ Artikel.

Es handelt sich also bei ille nicht um das Demonstrativpronomen der 3. Person, sondern um das für den Fernbereich geltende Glied eines zweigliedrigen Zeigesystems; dieses Glied war aus historischen Gründen expansiv wie sonst in regelmäßigen dreigliedrigen Zeigesystemen das Demonstrativpronomen für den Bereich der 2. Person. Zieht man die Möglich- 
keit eines rum. Anstoßes bei der Auswahl des slav. Artikels in Betracht, so spricht das Verhältnis von romanischem 1lle slavischem ts zumindest nicht dagegen. Das expansive Glied des romanischen 2 weiersystems, ille, konnte das ihm in der grammatischen Lokalisierung entsprechende expansive Glied des slav. Dreiersystems, ts, zu einer Ausweitung seiner Funktion veranlassen, wodurch der ProzeB der Artikelbildung ausgelöst wurde. Dem vulgarlat. Casa in oppido stat. Habitamus in illa casa entsprach ein altbulg. Domb vo gradě stoits. Zivemb vs domě toms. Indessen bedarf es noch eines nachprüfbaren Hinweises, dab eine solche romanische Partizipation bei der Auswahl des bulg. Artikels tatsächlich bestanden hat.

Diesen Hinweis liefert die Form des Anaphorischen Pronomens im Bulg.-Mak. ('er, sie, es'), das überwiegend vom Stamm ts gebildet wird. Das 0stmak. sowie Teile des Westbulg. verwenden in dieser Funktion den Stamm onb, wie alle übrigen Slavinen und z.T. das Baltische.222) Ebenso im Torlakischen: on - 'er', -at, -as, -an 'Artikel'. 223)

Die Form des Anaphorischen Pronomens geht in den idg. Sprachen auf das Demonstrativpronomen der 3 . Person im älteren, dreigliedrigen Zeigesystem zurück ${ }^{224}$ ), dieser Regel folgt das Slavische mit der Verwendung von ons für 'er'. Im zweigliedrigen Zeigesystem ist das Pronomen des Fernbereichs der potentielle Spender.

Das bulg.-mak. toj - 'er' läßt sich systemgerecht weder aus dem dreigliedrigen (onb-tb-sb, onoj-toj-ovoj) noch aus dem zweigliedrigen Zeigesystem onzi-tozi, nos-tos erklären, in denen ts das Demonstrativpronomen der 2. Person bzw. des Nahbereichs darstellt. Daß das Anaphorische Pronomen to auf die zweigliedrigen Zeigesysteme toj-soj oder toj-ovoj (s.o.) zurückgeht, die in einigen Mundarten existieren, ist zu be-. zweifeln:

1. In den süd- und ostmak. Mundarten, die ein Zeigesystem to- / ov- aufweisen, wird als Anaphorisches Pronomen vorwiegend on gebraucht, so am unteren Vardar (Kulakia, Gevǵgli): 


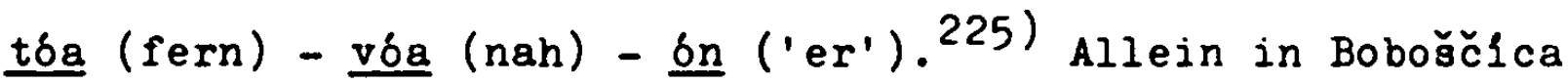
(Albanien) und in Cserged (Siebenbürgen) entspricht einem Zeigesystem toj-soj (Cserged: tonzi-senzi) der feste Gebrauch eines Anaphorischen Pronomens toj.

2. Die Möglichkeit einer Propagierung des isolierten toj 'er' seitens dieser peripheren Dialekte auf die Hauptmasse des Bulg.-Mak. ist gering, zumal die Zeigesysteme der letzteren nicht $2 u$ toj-soj u. ä. umgeformt wurden.

3. Die Gegenüberstellung von z.B. südmak. tóa-vóa/bn, ostbulg. onzi-tozi/toj, Sucho nos-tos/toj mit dem zentralmak. ovoj-toj-onoj/toj, torlakisch ovój-toj-onój/on, Rhodopen soja-toja-noja/toj weist darauf hin, daB die Auswahl des Anaphorischien Pronomens, bevorzuge sie ons oder tb, in der Hauptmasse des Bulg.-Mak. vor dem Ubergang des dreigliedrigen in das zweigliedrige Zeigesystem erfolgt ist, mit der

1. Phase: $s b-t s-o n s \longrightarrow t b$ oder ons - 'er', 2. Phase:

$a b(o v b)-t b-o n s>t s-s b(o v b)$ oder onb-ts, daneben weiterbestehend aus der 1. Phase: ts oder ons - 'er'.

Diese Ansicht findet eine Bestätigung im Aksl.. Bereits in diesen Texten ist die Verwendung von jb für den Nominativ des Anaphorischen Pronomens, welcher stets als besonders deiktisch empfunden wird, während die obliquen Kasus zeigeschwächere Morpheme aufweisen können 226), wegen der schwachen Deixis von jb unmöglich. Die Spuren eines demonstrativen jb im Altčechischen ${ }^{227)}$ zeigen, daß auf einer früheren Stufe des Gemeinsläischen ein demonstratives jb angenommen werden kann ${ }^{228)}$ und damit vor allem seine Verwendung im Nominativ des Anaphorischen Pronomens. Im Aksl. ist jb jedoch auf die obliquen Kasus beschränkt, und um den Nominativ konkurrieren die Demonstrativpronomina ons und tb (in sekundärer Funktion). Dabei ist ons der systemgerechte Nachfolger von jb, jedoch zeigt gerade das Aksl. ein Anwachsen von ts in dieser Funktion 229): Vaillant nimmt ts als generelles Anaphorisches Pronomen im Aksl. an 230), während Netteberg ${ }^{231)}$ und Kurz 232 ) eher eine Konkurrenz von ons und ts beobachten. Kurz stellt 
eine zunehmende anaphorische Verwendung von tb gerade im Suprasliensis fest ${ }^{233)}$, parallel zu den zunehmend häufigen Artikelreflexen. Der Suprasliensis aber entstammt dem NObulg. Sprachbereich, in welchem die bulg.-rum. bilinguale Sprachgemeinschaft bestand. $V_{g l}$. auch die abwechselnde Verwendung von toj und on für den Nominativ des Anaphorischen Pronomens in den vlachobulg. Urkunden des 14. - 15. Jhd. 234) Damit ist bestätigt, daß die Evolution von tb zum Anaphorischen Pronomen bereits während der Herrschaft des dreigliedrigen Zeigesystems im Gesamtbulg.-Mak. einsetzte, obwohl es diesem Zeigesystem nicht systemintern entsprungen sein kann.

Gegenüber dem Slav., in welchem aufgrund des geltenden dreigliedrigen Zeigesystems ts als 'abstraktes' Glied zum Artikel und onb als Pronomen für den Zeigebereich der 3 . Person zum Anaphorischen Pronomen prädestiniert waren, besteht im Romanischen eine Koppelung der Stämme des Artikels, des Anaphorischen Pronomens und des Demonstrativpronomens für den Fernbereich, die sich daraus ergibt, dab alle drei auf das demonstrative 2 weiersystem des Frühromanischen zurückgehen, in welchem ille nach Aspekt II vom Pronomen für den Bereich der 3. Person zum Pronomen für den Pernbereich, unter vollständiger Ubernahme der Funktionen von is, avanciert war. Siehe oben. Ille funktioniert als Demonstrativpronomen des Fernbereichs und als Anaphorisches Pronomen, da es frühzeitig is in der Stellung des Pronomens für den Zeigebereich der 3. Person ablöste, und ille funktioniert als Artikel, da es is auf einer jüngeren Stufe in seiner 'abstrakten' Funktion (grammatische Lokalisierung) ersetzte. Die systemfremde Auswahl von tz zum Anaphorischen Pronomen im Bulg.-Mak. beruht deshalb auf einer Ubertragung der rum. Koppelung von Artikel und Anaphorischem Pronomen ins Slavische (Replikbildung). Die gegenüber den nicht-balkanischen Slavinen erweiterte Funktion des Stammes ts im Bulg.-Mak. 235) als Demonstrativpronomen, Anaphorisches Pronomen und Artikel erklärt sich durch die entsprechenden Funktionen des Pronomens ille im Rum. - (tozi) : toj : - ot $\cong$ (acel) : el : 느. 
Eine Replikbildung erfolgt durch die Identifizierung zweier Morpheme verschiedener Sprachen aufgrund ihrer Ahnlichkeit in Teilfunktionen und die anschlieBende Funktionserwe 1terung des identifizierten Morphems der Sprache A nach dem Vorbild des Funktionsradius des zweiten identifizierten Morphems in der Sprache B (Kap. I.l.) Eine Ahnlichkeit der Teilfunktionen bestand 2 wischen ille und ts nur für die grammatische Lokalisierung ( $>$ Art1kel), als Anaphorisches Pronomen und als Pronomen des Pernbereichs entsprach dem romanischen ille das slavische ons des dreigliedrigen Zeigesystems. Die Neubildung von ts - 'er' setzt die Identifizierung des rum. Artikels und des slav. Demonstrativpronomens tb in grammatisch lokalisierender = identifizierender Funktion durch den bilingualen Sprecher voraus; die Identifizierung von ille und tb zeigt an, dab in der Kontaktzeit die Funktion von tb der Funktion des rum. Artikels sehr nahe kam, andernfalls wäre die Identifizierung beider Morpheme unterblieben. Infolge der Gleichsetzung von $\underline{1 l l e}=$ romanischer Artikel und ts durch den bilingualen Sprecher wurde der Gebrauch von tb auf die anaphorische Punktion erweitert: ille (Artikel): ille (Anaph. Pron.) $=t_{s}$ (Artikel) : $x ; \underline{x}=t_{b}=$ Anaphorisches Pronomen.

DaB es sich bei der Gleichsetzung von ille und ts in grammatisch lokalisierender Funktion, mit Behandlung von tb als Artikel, um einen AnstoB des Rumänischen handelt, daB also die Substratbevölkerung die Gleichsetzung erst dadurch möglich machte, daB sie das slav. ts wie romanisch ille als Artikel verwendete, dab folglich $n$ i $c h t$ ein bulg.-mak. Artikel schon vor dem slav.-rum. Kontakt gebildet und systemgerecht ausgewählt war, von den Rumänen angetroffen und alsbald mit lle gleichgesetzt wurde, ist wahrscheinlich, da die Verbreitung von $\underline{t s}=$ Protoartikel und $\underline{t s}=$ Anaphorisches Pronomen in den aksl. Texten eine annähernd gleich hohe Prequenz hat, mit dem Kulminationspunkt im NO-bulg. Suprasliensis: tb als Artikel ist im Aksl. nicht weiter entwickelt als ts = Anaphorisches Pronomen und vice versa, trotzdem finden sich genügend 
Spuren von beiden in den Texten, um inr paralleles Entwicklungsstadium auch am Rande der rum.-bulg./mak. Kontaktzonen zu dokumentieren. Dieses parallele Entwicklungsstadium von ţ-Artikel und ţ-Anaphorisches Pronomen läßt auf eine parallele Entstehungszeit schließen. - Anders als dem bulg. Artikel, der keine systemgerechtere Konkurrenz kannte, ist dem Anaphorischen Pronomen to nicht in a $11 \mathrm{e} \mathrm{n}$ Punkten des Sprachgebietes die Verdrängung des systemgerechten Anaphorischen Pronomens ons gelungen, ts als Anaphorisches Pronomen ist weniger generell im Bulg.-Mak, als ts in Artikelfunktion.

Wenn, wie hier dargelegt, der Anstoß zur Auswahl des Demonstrativpronomens ts als Artikel vom eingliedrigen romanischen Artikel ille ausging, so muB ein eingliedriges bulg.mak. Artikelsystem seit der bulg.-rum. Kontaktperiode (bis zum 10. Jhd.) bestanden haben, ohne aus dem oben beschriebenen Abstrahierungsproze $B$ des bulg. Zeigesystems hervorzugehen. Der bilinguale (Substrat-)Sprecher schrieb dem slav. ts die Eigenschaften des rum. Artikels $z$, der ohne personelle oder lokalistische Nebenbedeutungen funktionierte, und diese lösung des Demonstrativpronomens ts von der Personalbindung und der Nah-Fern-Relation bei der Imitation des rum. Artikels konnte nicht ohne Folgen für das dreigliedrige Zeigesystem sein. Tb tendierte auch in deiktischer Funktion zur Aufgabe der Personalbindung und löste so den ProzeB der Umwandlung des dreigliedrigen Zeigesystems aus, der oben für das Bulg.Mak. verfolgt wurde. Diese Veränderung kann, da sich das geschlossene dreigliedrige Zeigesystem einer Innovation widersetzte, mit längerer zeitlicher Verzögerung gegenüber der Bildung des eingliedrigen Artikelsystems eingesetzt haben, sie ist jedoch heute überall vollzogen, wo ein eingliedriges Artikelsystem herrscht. Im Palle der Zeigesysteme von Cserged und Boboščlca (sb:ţ:ons > s-: t-) bestimmte das Substrat sogar den für das zweigliedrige Zeigesystem generalisierten Zeigeaspekt (I), so daß hier die rum.-slav. Ubereinstimmung in der Verwendung des Stammes ţ vollständig ist und das Demon- 
strativpronomen einschliebt: tonzi ( $\underline{\text { fern }}$ ) : toj ('er') : -ot $\left(\right.$ 'der' $^{\prime}=\operatorname{acel}(\underline{\text { fern }}):$ el $($ 'er') : -ul ('der'). Hierher rührt die oben behandelte, sonst im Bulg.-Mak. sel tene Ubereinstimmung von Anaphorischem Pronomen und Demonstrativpronomen des Fernbereichs im zweigliedrigen Zeigesystem der genannten Mundarten.

Ein rum. Substrateinfluß kann zwar einen Teil der eingliedrigen Artikelsysteme des Bulg.-Mak. erklären, er sagt jedoch nichts über den Ursprung der dreigliedrigen slav. Artikelsy-

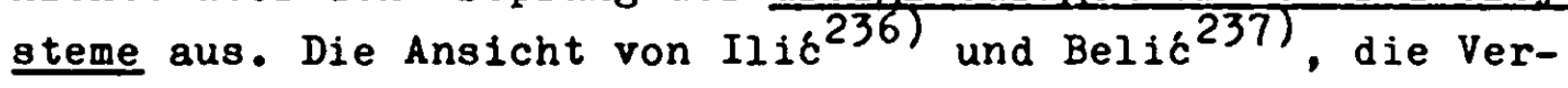
wendung der Halbartikel -ov/-os und -on im Bulg.-Mak. sei eine durch spätere Angleichung an das dreigliedrige Zeigesystem geschaffene Neuerung des Slavischen gegenüber dem Rum., ist funktionell schwer zu begründen, denn die Rückkehr eines 'abstrakt' funktionierenden Artikels (ts) zu einer personellen Nebenbedeutung (2. Person), wie sie sich aus der Einbeziehung von ons und ovs (sb) in das Artikelsystem ergeben muB, läuft den Tendenzen der slavischen Sprachentwicklung zuwider, die allgemein zur Bildung von zweigliedrigen Zeigesystemen und eingliedrigen Artikelsystemen neigt, im Zuge einer fortschreitenden Abstrahierung; die Rückkehr eines Demonstrativpronomens in die Personalbindung ist im Slavischen nicht zu belegen. Im Gegenteil ist der ProzeB, der vom dreigliedrigen zum eingliedrigen Artikelsystem führt (und nicht umgekehrt), noch heute im Bulg.-Mak. wirksam.

Wenn das eingliedrige romanische Artikelsystem mit der Genesis des eingliedrigen bulg.-mak. Artikelsystems in Verbindung gebracht werden kann, dann ist das Verhältnis des dreigliedrigen Artikelsystems im Bulg.-Mak. zum dreigliedrigen Artikelsystem des Frühalb. einer näheren Beleuchtung wert.

Das heute im Alb. eingliedrige Artikelsystem verwendet drei (bzw. vier) Pronominalstämme in kontextbedingter Verteilung, d.h. sie bilden das Paradigma des e $i \mathrm{n}$ e $\mathrm{n}$ alb. Artikels: gur-i 'der Stein', pat-a 'die Gans' < idg. *is oder el-, vgl. lat. mask. is, fem. ea, slav. jb, ja; zog-u 
'der Vogel', njer1-u彑 'der Mensch' nach Gutturalkonsonant und betontem Vokal <*-(0)uos, vgl. slav. ovb, ${ }^{238)}$ guri-t 'dem

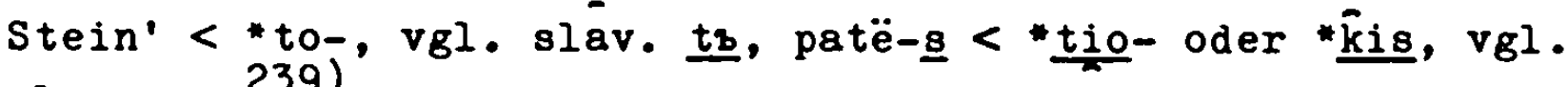
slav. $\underline{8 b}$.

Natürlich sind to- und ovo- im Alb. keine nach dem 7. Jhd. U.Z, aus dem Slav. getätigten Entlehnungen, wie Piotrovskij meint ${ }^{240)}$, sondern alb. Erbwörter. Piotrovskij hält daher das alb. Artikelsystem für einen 'vergleichsweise neuen ProzeB'.

"Aus all diesem geht hervor, daB man im Albanischen mehrere Demonstrativpronomina für die Funktion des definiten Artikels verwendet hat" (Skok) 24l). Barić "Ein solcher Gebrauch von mehreren Artikeln muB auch im Albanischen bestanden haben." 242) Diese Annahme wird durch das Armenische bekräftigt, welches mit dem Alb. durch zahlreiche Isoglossen verbunden ist. 243) Im Altarmenischen existiert ein dreigliedriges Arti-

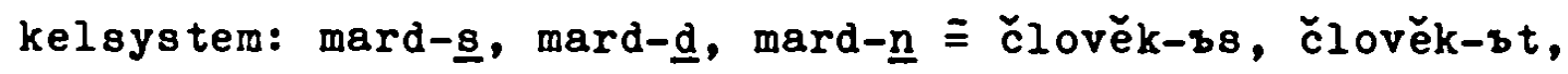
člověk-sn. Auf den bulg.-armenischen Parallelismus in der Artikulierung machte schon Brugmann aufmerksam. 244) - Dieses System ist im Neuarmenischen durch Symkretismus der Stämme in ein eingliedriges Artikelsystem umgeformt worden: Vokal + Artikel - $\underline{n}$, Konsonant + Artikel - $\underline{e} \cdot 245)$ Die Parallelität zum Alb. und Balkanslav. ist offensichtlich.

Im Frühalb. muB damit parallel zum dreigliedrigen Artikel- ein dreigliedriges Zeigesystem bestanden haben, welches später in ein zweigliedriges überging und damit das heutige alb. eingliedrige Artikelsystem hervorrief. Die Zuordnung der erschlossenen Stämme *is, *oyos, tos und *isis zu den einzelnen Zeigebereichen kann nicht mit letzter Sicherheit vorgenommen werden. Jedoch spricht das moderne a-i 'jener' für * is als das Demonstrativpronomen der 3 . Person und $\underline{k-y}<$ * $k-\bar{u}$ 'dieser'246) für *uos als Pronomen der 1. Person. Die Nebenform ay ist unter EinfluB von ky entstanden, als alle Stämme in éinem Paradigma vereinigt waren. Für tos bliebe dann der Bereich der 2. Person übrig, was mit dem Slav. und Armenischen übereinstimmt. Schwierigkeiten macht die Einglie- 
derung von kis, dessen Existenz wegen alb. si-vjet 'heuer', so-nte 'heute nacht', sot 'heute' 247) angenommen werden muB, während sich patë-s auch aus tio- ableiten ließe. ${ }^{248)}$ Ich nehme an, daß man es bei * mit dem jüngeren Demonstrativpronomen der 1. Person zu tun hat und daB die Ablösung ähnlich verlief wie im Südslav., wo $\underline{a b}$ durch ovs ersetzt werden konnte. Das dreigliedrige alb. Zeigesystem und entsprechend das frühalb. Artikelsystem erhält damit die Form:

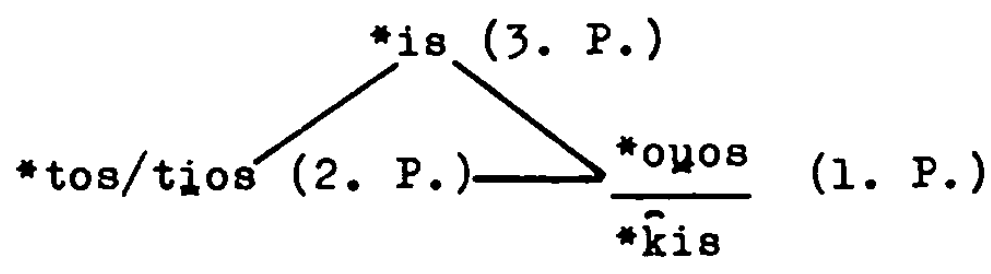

Der Ubergang zum zweigliedrigen Zeigesystem und zum eingliedrigen Artikelsystem im Alb., den Skok ausdrücklich mit den bulg.-mak. Verhältnissen vergleicht, vollzieht sich nicht derart, daB es dem Alb. "nach den Bedürfnissen der Klarheit der Pormen gelungen war, im Laufe der Zeiten daraus (dem mehrgliedrigen Artikelsystem) ein festes System zu errichten" (Skok) ${ }^{249)}$, sondern es wirkte hier im Alb. wie im Slavischen und Armenischen der oben beschriebene AbstrahierungsprozeB.

Im Zeigesystem wie im Artikelsystem verlief dieser ProzeB im Alb. nicht über die Generalisierung eines Zeigeaspektes, sondern es fand ein Synkretismus aller Stäme zu e i n e m Demonstrativ- bzw. Artikelparadigma statt. Das Zeigesystem hat heute im Nominativ die Form:

$$
\frac{a-i \text { (fern), obl. a-tij, acc a-té etc. }}{k-y \text { (nah), obl. kë-tij, acc. kë-té etc. }}
$$

Beim Artikel wurde die Verteilung auch von phonetischen Ge-

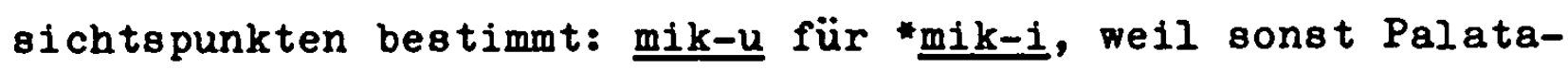
lisierung $z u$ mig eingetreten wäre, miq aber ist schon Nominativ Plural; shiu für *ghi-1, das $2 u$ * gh̄̄ kontrahiert worden und mit der unartikulierten Porm shi zusammengefallen wäre.252)

Das dreigliedrige Zeigesystem im alb. Dialekt von Borgo 
Erizzo (Dalmatien): áj (3.P.) - năi (2.P.) - kü (1.P.) ist eine Neuerung und gibt keinen Hinweis auf den frühalv. Zustand, denn inm entspricht ein eingliedriges Artikelsystem in demselben Dialekt. Italienischer Einflub (so Weigand 25l), ist weniger wahrscheinlich als eine spontane Innovation.

Das Vorhandensein von Artikeln im Alb. zur römischen Zeit, als lat. Wörter ins Alb. Eingang fanden, hat $N$. Jokl nachgewiesen, wenngleich der alb.-armenische Artikelparallelismus eine noch frühere Existenz von Artikeln und Protoartikeln (s. Kap. IV) im Alb. vermuten läBt ${ }^{253)}$ :

Im unartikulierten Nominativ Singular ftón, *ftō 'Quitte' waren die Bedingungen für die Diphthongierung von -on im Silbenschlub zu -ua, - ue gegeben, also > ftue. Das Wort ftue ist ein lat. Lehnwort der älteren Schicht < cotōneum. Die Form des artikulierten Nominativs ftoi setzt nun den Bestand des Artikels schon zur Zeit dieses Prozesses voraus (*fto-i), denn die Diphthongierung unterblieb. 254)

Die geographischen Mōglichkeiten eines direkten slav.alb. Kontaktes decken sich mit den heutigen peripheren Gebieten des Bulg.-Mak., die das dreigliedrige Artikelsystem kennen: Zur Zeit der Ankunft der Slaven auf dem Balkan murde in den Rückzugsgebieten Dac1ens, Mösiens und Thrakiens noch Thrakisch, ein dem Frühalb. eng verwand tes Idiom, gesprochen. 255) Uber thrakische Bevölkerung in den Rhodopen bis ins 10. Jhd. berichtet Miletič ${ }^{256)}$, das Gebiet des heutigen Mak. befindet sich im sogenannten 'Van-Wijkschen Graben', d.h. dem lange Zeit weder zu Serbien noch zu Bulgarien gehörigen, wenn auch slavisch besiedelten Dardanien und oberen rösien, wo sich Rumänen und Protoalbaner länger hielten. 257) Die der rum.-slav. bilingualen Sprachzone angehörigen bulg.-mak. Dialekte mit dem Zentrum um die Donau wurden dagegen von keinem dreigliedrigen Artikelsystem in der Kontaktsprache affiziert.

Das Nebeneinander von eingliedrigen und dreigliedrigen Artikelsystemen im heutigen Bulg.-Mak. hat folglich vier Ur- 


\section{sachen:}

1. Das frühalb. Substrat im Slav. regte die Bildung von dreigliedrigen Artikelsystemen an, die dem bestehenden dreigliedrigen Zeigesystem des Slavischen entgegenkamen. Der frühalb. Substratsprecher übertrug die Funktionen des frühalb. Zeigesystems, darunter die artikelhafte Funktion aller Zeigemorpheme, auf das sehr ähnliche altbulg. Zeigesystem.

2. Das frührum. Substrat im Slavischen regte die Bildung von eingliedrigen Artikelsystemen an, die einen Abstraktionsprozeß des slav. Zeigesystems auslösten. Mit der im Laufe der Zeit erfolgten Ausbreitung der Merkmale der progressiven mysischen und balkanischen slav. Dialekte, die der bulg.-rum. Kontaktzone entstammen, griffen diese beschleunigend in den Proze $B$ des Ubergangs vom dreigliedrigen zum eingliedrigen Artikelsystem in den übrigen Dialekten ein, ein EinfluB, der heute noch andauert. 258) Deshalb haben die Dialekte mit bewahrtem dreigliedrigen System eine zum Donauzentrum periphere Lage (auch das Mak.); die eingesprengten Dialekte mit eingliedrigem System dagegen reflektieren alte Sprachgruppen mit primär eingliedrigem System (romanische, evtl. frühalb.).

3. Die Widersprüche innerhalb des dreigliedrigen Zeige- und Artikelsystems können in den durch Kontakt dreigliedrigen Systemen systemintern zum zweigliedrigen Zeige- und zum eingliedrigen Artikelsystem geführt haben, wie eingangs beschrieben.

4. Nicht in allen Dialekten muB das drei-oder eingliedrige Artikelsystem auf Substrateinwirkung zurückgehen, mit sprachinternem Kontakt ist ebenfalls zu rechnen. So darf z.B. das dreigliedrige Artikelsystem des Torlakischen als auf den EinfluB des dreigliedrigen mak. Artikelsystems zurückgehend betrachtet werden.

Vom Beginn der Entstehung der Kategorie 'Determiniertes Nomen' an gab es auf bulg.-mak. Sprachgebiet nebeneinander Dreiartikel- und Einartikelsysteme, die letzteren waren aus strukturellen Gründen expansiv. Die mak.-bulg. Verhältnisse 
sind deshalb eine Funktion (im mathematischen Sinne) der vorslav. Nominalsysteme auf dem Balkan: hier existierten nebeneinander das ältere frühalb. dreigliedrige und das jüngere romanische eingliedrige Artikelsystem, bedingt durch die entsprechenden Zeigesysteme. Während das Alb., aus strukturellen Gründen oder unter romanischem Einfluß, zum eingliedrigen System fortschritt, leben die Repliken zum frühalb. System selbständig in manchen slavischen Dialekten weiter und vollziehen erst allmählich den strukturell konsequenten Ubergang zum eingliedrigen Artikelsystem, dazu gedrängt durch den EinfluB jener Repliken (dem eingliedrigen System), die andere slavische Dialekte von Anfang an zum romanisch-rum. Artikelsystem bildeten: "Der EinfluB seitens der benachbarten Mundarten von der Ebene untergräbt allmählich die dreifache Artikelform in der Mundart der Ropka" (Miletič). 259) Im Diagramm:

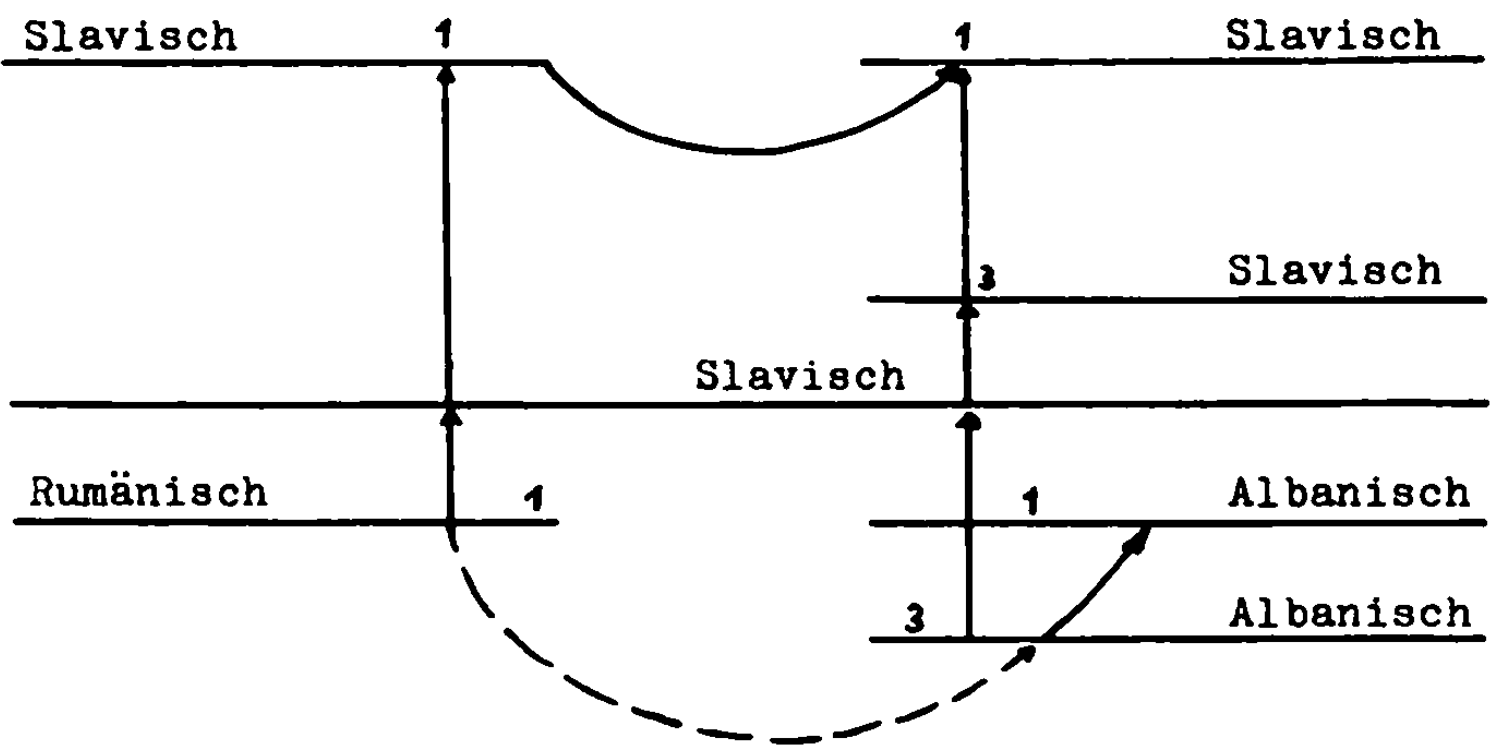




\section{Morphemposition}

a. Innerslavieche Tendenzen

Im Nbulg.-Mak. steht das Artikelmorphem ausnahmslos an der zweiten Stelle des nominalen Syntagmas: novo-to selo, selo-to. Von einem noch heute spürbaren 'leichten Schwanken' zwischen den Typen selo-to und to-selo (so Miletič) 260 ) kann keine Rede sein. In Miletičs Dialektbeispielen: i si imal toga dobra konja, tija mužki deca, izvadi tuju ostru sablju, pie toe ladno vino ${ }^{261)}$ und solchen aus dem serbisch beeinflußten Dialekt von Novo Selo, wie ta,j žsnà "die Praun262), handelt es sich um die sekundäre Funktion des Demonstrativpronomens: grammatische Lokalisierung und dadurch Identifizierung, in welcher das Demonstrativpronomen funktionell, jedoch kontextbedingt, dem Artikel nahesteht. Schon formal sind diese Beispiele als Demonstrativpronomina vom Artikel unterschieden (tuju-tu, toe-to etc.).

Ausnahmen von der Position des Artikels an der zweiten Stelle des nominalen Syntagmas zeigt auf mak.-bulg. Sprachgebiet der im 19. Jhd. ausgestorbene Dialekt von Kulakija (heute Chalkstra) bei Saloniki ${ }^{263)}$; neben der gewöhnlichen Artikulierung Adjektiv + Artikel + Substantiv kann der Artikel auch verdoppelt werden: na zagubéniti 6 fcjtit, oder nur beim Substantiv stehen: na témno nadvorés̆n'oto. Das letztere ist nur bei Possessivadjektiven auf -ov weiter verbreitet, die eine Postartikulierung vermeiden, wie schon: na Gospodínova carštı́na_ neben: uf carštinata Gospodinska zeigt. 264) $\mathrm{Vgl}$. weitere Beispiele: Gospodinof valtárut, 'lwárr -uva glávata, mójo jadénito, na négovi Učẹnicịte, danákut ranéti to (griech.

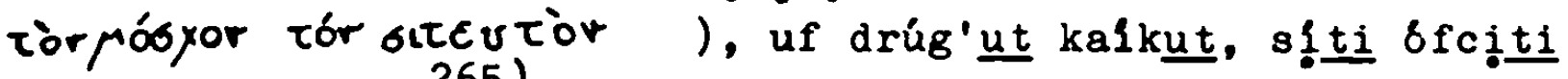
neben sfti $6 f(j .265)$ Ich erkläre diesen Ansatz zur Zerstörung des Musters Adjektiv-Artikel-Substantiv in Richtung auf eine Postartikulierung nur des Substantivg hin, gleich in welcher Position es sich befindet, durch den EinfluB des Griech. Im Jahre 1912 bestand die Bevölkerung Kulakijas aus drei Teilen 
Griechen und einem Teil 'Bulgaren'. "Kulakija befand sich gleichsam an der Grenze zwischen der bulgarischen Masse und der hellenischen Masse, aber es erfuhr stärker die Anziehungskraft der letzteren" (Mazon-Vaillant). 266) Die Texte sind in griechischer Schrift verfaBt. Der Mechanismus der griech. Einwirkung hat folgende Porm:

I. rà mpóßara rà ámopwjóra $\longrightarrow$

A

$B$

$A$

B

o $\lambda o ́ \gamma \circ$

A $B$

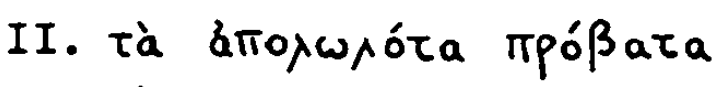
A

$B$ zagubéni-ti bfci-ti

B

nach dem Muster:

$\cong$ slovo-to

B A

zagubéni bfci-ti

B $B \quad A$

nach dem Muster:

slovo-to
B $A$

Das Resultat II wurde von der Tendenz des Dialekts von Kulakija aufgegriffen, die Postartikulierung der Possessivadjektiva auf -ov zu vermelden, und erfuhr dadurch eine gewisse verbreitung. Jedoch weichen diese für das Bulg.-Mak. einmaligen Fälle-nicht vom Grundmuster Substantiv + Artikel ab, d.h. sie zelgen keinen Artikel, der seinem Bezugswort vorangeht. Von diesem Grundmuster zeigen auch die älteren bulg. Texte, wie die Csergeder Texte, die vlachobulg. Urkunden und die Damaskinen keine Ausnahme. 267) Wie erklärt sich seine Entstehung?

Beginnen wir mit der Erklärung der Artikelposition aus der glavischen Struktur des Bulg.-Mak. "Der Umstand, daB die bulgarische Artikelform inrer Herkunft nach eigentlich ein altes Enklitikon darstellt, erklärt leicht auch ihre Postposition, d.h. einen ausschlieblichen Gebrauch nach den Nomina" (Mirčev). 268) Die Bezelchnung 'Enklitikon' meint in diesem Falle das Demonstrativpronomen in sekundärer Punktion, welches im Aksl. (und Altruss.) häufig postponiert ist: Sbl prinoss prinesensi têbě $\bar{B} \dot{1}$, dagegen: Prīmi $\bar{g} \dot{1}$ prosims tje prinoss $8 \dot{b}$ (Kiever Blätter). 269) 
Die innerbulg. Erklärung arbeitet also mit einer Koppelung von sekundärer, rein identifizierender Funktion des Demonstrativpronomens und seiner Postposition im Altkirchenslavischen, Altrussischen, Altbulgarischen. Der Nachweis für eine grundsätzliche Gültigkeit dieser Koppelung läBt sich indessen nicht führen:

Die rein identifizierende Punktion des Demonstrativpronomens ist nur im Kontext $z u$ erkennen. Ob ein Demonstrativpronomen in sekundärer (identifizierender) Funktion gebraucht wird, geht aus dem Kontext hervor und nicht aus der Position des Demonstrativpronomens in Verhäl tnis zu dem ihm übergeordneten Nomen.

Nun ist das Demonstrativpronomen in sekundärer Funktion natürlich schwächer akzentuiert als in einführendem, semantisch lokalisierenden Gebrauch. Deshalb kann es im ersteren Palle an die tonschwächste stelle des nominalen Syntagmas treten, hinter das Substantiv. Dies ist die Stellung der Enklitika, und dab ein Demonstrativpronomen in der Voranstellung stärker betont ist als in der Postposition, ist an den aksl. Texten festzustellen: Den Pronomina ts, $\underline{s b}$, ons können in der Voranstellung beliebige Einschübe folgen, während bei der Postposition zwischen ihnen und dem Substantiv höchstens (und ganz selten) die Partikel že oder bo auftreten. 270) Auch die Zeigebereiche der Pronomen varileren je nach der Position: ts in der Voranstellung tritt ein für griech. Exẽves, aúcós und sogar oưtog, in der Nachstellung meist für altóg; $8 b$ in der Voranstellung bezeichnet einen Gegensatz, eine besondere Kennzeichnung, ons in der Voranstellung bedeutet 'jenseits befindlich', in der Postposition nähert es sich der Bedeutung von ts. 271 ) Ist das Demonstrativpronomen des griech. Originals betont, folgt aber dem Nomen, so läBt sich in den Evangelientexten fast ausschlieblich Ubergang in die Voranstellung feststellen, z.B. Mt. III,l Ér $\delta \dot{\varepsilon}$

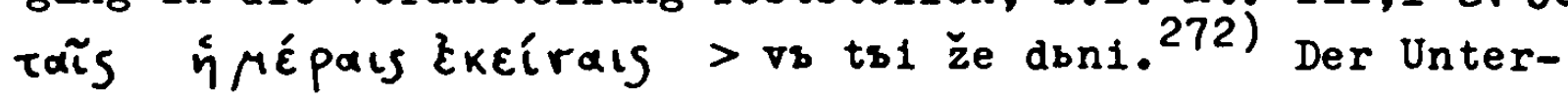
schied in der Betonung des vorangestellten und des nachge- 
stellten Demonstrativpronomens läBt sich am Verhältnis von vorangestelltem Demonstrativpronomen und nachgestell tem Artikel im mak. Dialekt von Boboščica (Albanien) noch feststellen: $t^{j}{ }_{\underline{a} m} d^{j} j_{\ddot{a} c e}-d_{e c} j_{\ddot{a}}$-tẹm < děcětěm - těm děcě, nach dem Lautgesetz: 兰 unter Akzent $>\underline{j_{\ddot{Q}}}$, unbetont zu e. ${ }^{273)}$

Da die Position des Demonstrativpronomens jedoch für seine deiktische oder identifizierende Funktion nicht relevant ist, handelt es sich bei der Postposition des Demonstrativpronomens in rein identifizierender Funktion um ein stilmittel des Sprechers (Schreibers) in seiner Rede, nicht um ein Element des Sprachsystems. Abweichungen von der Koppelung 'Identifizierung' - 'Postposition' finden sich deshalb, auBer im Aksl., auch in allen anderen Slavinen, die sich die Möglichkeit des älteren idg. Sprachstadiums, Demonstrativpronomina dem Substantiv voran- wie nachzustellen ${ }^{274)}$, erhalten haben: Russisch (čtenie èto), Ukrainisch (did toj), älteres Skr. (žene one $\left.{ }^{275}\right)$ ), Cechisch (dcera ta), Polnisch (w chalupie tej).

Vgl. älteres Kroatisch: I tu obraz cara najdoh na stupu visoku (...): na tom stupu razboji etc., neben: I tako stup visok u tom otoci postavi (...) slova grčka na stupu tom napisa; (...) i stup visok posrid Persidije sazidati reče, 1 na ta stup uzlize, neben: (..$)$ do otoka dojde. Ljudl otoka toga pokloniše se njemu. ${ }^{276)}$ Hier ist die Identifizierung durch das Demonstrativpronomen von dessen Position unabhängig. Denn andererseits können postponierte Demonstrativpronomina uneingeschränkt eine reale Lokalisierung ausdrücken: I voe živo zemlje te meču predaše - 'und alles Lebende dieses Landes überantwortete er dem Schwerte', rad bih otok ta viditi; 1 voćem otoka-ovoga hranimo se. ${ }^{277)}$ Diese Beispiele lassen sich aus allen Sprachen mit doppelter Position des Demonstrativpronomens vermehren, so spätlat.: ${ }^{278)}$ Requivisi de eo, quam longe esset ipse locus. Tunc ait ille sanctus presbyter etc., also präpositiv trotz Identifizierung. Weiter gehören hierhin diejenigen slav. Dialekte, die im Begriff sind, einen 
präpositiven Artikel auszubilden. Unter deutschem EinfluB stehen dabei Slovenisch: V1 ste ta 801 te zemlje: 'ihr seid das Salz der Erde'; čechische Umgangssprache: Ten krumlovský zámek - 'das Krumauer Schlob'; Obersorbisch: we tym času král'a Herodaša, Niedersorblsch: we tom času togo krala Herodesa - 'zu der Zeit des König Herodes'.279) Ohne deutschen oder italienischen EinfluB in skr. Dialekten ${ }^{280)}$, siehe vor allem G. Reichenkron ${ }^{281)}$, der Anfänge einer Artikelausbildung in der čakavisch-ikavischen Prosa des 13., 15. und 16. Jhd. findet. In den genannten Dialekten hat das Demonstrativpronomen in rein identifizierender Funktion das morphologische Material für den Artikel geliefert, der dennoch proklitisch ausgebildet wird.

Diese Beispiele bestätigen, daß der überwiegende Gebrauch des identifizierenden Demonstrativa in der Postposition ein Stilmittel der Rede ist: "Gewöhnlich wird das Demonstrativpronomen in relativer Funktion postpositiv gestellt", konstatiert Jakubinskij ${ }^{282)}$ für das Aksl. und Altruss..

Das Demonstrativpronomen mit identifizierender Funktion in der Postposition kann nicht als Enklitikon behandelt werden. Enklitika sind Wörter mit einer gegebenen morphologischen Porm, die wegen ihrer Bedeutung als bloBe Determinanten nach dem Wackernagelschen Gesetz ${ }^{283)}$ an die zweite Stelle im Satz oder Syntagma treten. Im Slavischen können die Partikel bo, že, li und die flektierten Stämme, d.h. die einsilbigen obliquen Kasus der Personalpronomina, die Pormen des Verbums byt1 und das Prësens des Hilfsverbs chstětl Enklitike sein.

Als ihr Charakteristikum giit: Sie können nicht "die verschiedenen signifikativen Oppositionen ausnützen, welche die freie Mortstellung bietet" (Jakobson) ${ }^{285}$ ), d.h. bel gegebener morphologischer Porm durch Ubertreten in die Orthotoniertheit eine neue, kontextbedingte signifikation annehmen, etra:
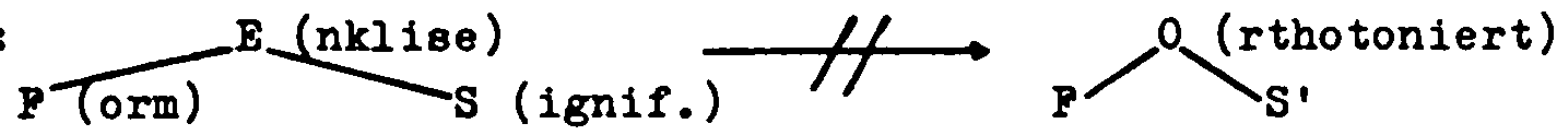
sondern sie müssen, wollen sie in die Orthotoniertheit übertreten, eine $n e u e$, nicht kontextbedingte, sondern systemhaf te morphologische Form annehmen, z.B. skr. doci cu (Enkl.) - hocu doci (Orthoton.)

nbulg. vikat me (Enkl.) - mene vikat (Orthoton.) also:
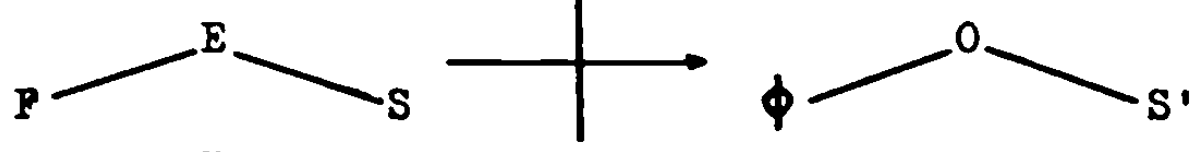

( $S$ ' bedeutet: stärker betont, also eine kontextbedingte $\mathrm{Be}-$ deutungsvariation)

Techselt dagegen das Demonstrativpronomen die Position (dómbţ - ţ่ dómb), so hat dieser synchronische ProzeB die Form:
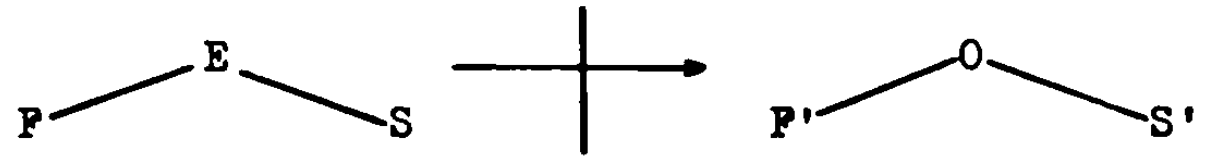

F' bezeichnet einen kontextbedingten Pormwandel (stärkere Akzentuierung), S' die verstärkte Deixis. Der Unterschied zwisehen Enklitikon und postpositivem Demonstrativpronomen besteht also darin, dab die Porm eines Enklitikons nicht die gleiche Positionsvariabilität wie seine Signifikation aufweist ( $\left.\longrightarrow S^{\prime}\right)$, während die Form des Demonstrativpronomens ebenso wie seine Signifikation positionsvariabel sind ( $S^{\longrightarrow} S^{\prime}$, $\left.\mathrm{P} \longrightarrow \mathrm{F}^{\prime}\right)$. Im diachronischen ProzeB ist auch die Form des Enklitikons von der Position abhängig: jesmb + Partizip > jesam, Partizip + jesmb > sam (skr.).

Das postpositive Demonstrativpronomen nimmt auch an der diachronischen Entwicklung der Enklitika nicht teil, wie die bulg.-mak. Sprachgeschichte zeigt. Slawski fordert, das Artikelmorphem als Enklitikon behandelnd, die Untersuchung der Artikelentwicklung im Rahmen der übrigen Enklitika. 286) Er teilt die Enklitika des Aksl. ein in a. Satzenklitika, b. Wortgruppenenklitika, die letztere Gruppe wird im Bulg. durch die Dativkurzformen mi, ti, si etc. und die postpositiven Artikel in ihren verschiedenen Realisationen gebildet. Im Aksl. gehört -jb hierher: dobrb-jb. Das im Laufe der bulg.-mak. Sprachgeschichte zu bemerkende Streben der Enklitika in die 
unmittelbare Nähe des Verbums und damit auch in die Prokli$\mathrm{se}^{287)}$, vgl. mak. Si bil éden car ...288), mi kapna liceto ${ }^{289)}$, konstatierend und sie mit außerslavischen, balkanischen Einflüssen verknüpfend (dagegen Gslsbov) ${ }^{290)}$, vermibt Slawski eine gleiche Tendenz beim postponierten Artikel und hält dessen Position deshalb für sinen durch die slav. Struktur bedingten Archaismus inmitten der balkanischen Tendenzen des Bulg.-Mak. 291). Da sich die Tendenz zur Proklise beim adnominalen Dativ mi, ti, si (seloto mi - mein Dorf) nicht findet, der daneben in adverbaler Funktion auch proklitisch auftritt (mi kapna liceto), so empiliehlt es sich, die sogenannten 'Wortgruppenenklitika' von der Untersuchung über die Proklisetendenzen auszunehmen: da zum Nomen gehörig, unterliegen sie nicht der Attraktion des Verbums. Von einem 'Archaismus' der Artikelposition im Bulg.-Mak. kann nicht die Rede sein, die Vergleichspunkte (Satzenklitika) sind hier falsch gewählt. Auch die sprachliche Diachronie rechtfertigt also nicht die Behandlung des Demonstrativpronomens vom Typ domssb im Rahmen der Enklitika.

Die Theorie vom Enklitikcharakter des aksl. Demonstrativpronomens in sekundärer, grammatisch lokalisierender Funktion hat bei den Iinguisten, die sie vertreten, das Urteil über den Stand der Ausbildung der Kategorie 'Determiniertes Nomen' im Altkirchenslavischen bestimmt. Als Literatur- und Kunstsprache ${ }^{292)}$, die noch dazu die Wortfolge der griechischen Vorlagen zu imitieren suchte, ist das Aksl. gerade in Pragen der Wortfolge für die Beurteilung der damaligen Umgangs8prache unzuverlässig. Wie die klassischen Sprachen strebte das Aksl. nach einer künstlich freien Wortstellung. Deshalb ist es unzulässig, alle postpositiv gebrauchten Demonstrativpronomina unabhängig vom griech. Original und häufig auch vom Inhalt als Artikel aufzufassen, wie es Miletič und neuerdings Gblsbov tun.

"Wie gezeigt murde, besteht die grundlegende Charakteristik des bulgarischen Artikels in der Tatsache, daB er konse- 
quent und ausnahmslos der Enklitikregel unterworfen ist. In den frühesten Perioden der Geschichte des bulgarischen Artikels - das gilt auch für die altbulgarische Epoche - ist diese formale Eigentümlichkeit die einzige formale Charakteristik, durch die er sich von den sonst ihrer Porm nach vollkommen identischen Demonstrativpronomina unterscheidet" (Golsbov). 293) Das führt zur Feststellung eines Artikels in Belegen wie: Mar. J. XVIII, 15 učeniks že ts - ó dè paj̃ हkยน̃ros . 294) Dazu Miletič: "Uberhaupt ist der Unterschied zwischen diesen beiden Funktionen (Demonstrativpronomen und Artikel) anfangs sehr gering. Deshalb beweist es nichts gegen unsere Meinung bezüglich der Entwicklung des bulgarischen Artikels, wenn man irgendwo in seiner Bedeutung noch die rein demonstrative Kraft entdeckt, sobald die postpositive Form des Artikels vorliegt." 295$)$ Dieses Vorgehen kritisiert auch S(awski. 296) Miletič wirft das Bestehen der Funktion im Bewubtsein des Linguisten und in dem des Sprechers durcheinander, er und Gblbbov verwenden als deus ex machina für die Beurteilung des aksl. Sprachsystems ein diesem fremdes Element, die unbedingte Postposition des Demonstrativpronomens in sekundärer, grammatisch lokalisierender Funktion, onne Beachtung der prinzipiellen Möglichkeit der älteren idg. Sprachen und heute noch vieler Slavinen, Demonstrativpronomina ohne Folgen für ihre Signifikation im Sprachsystem dem Nomen voran- oder nachzustellen.

Was läßt sich über den Grad der Ausbildung des Determinierten Nomens in den aksl. Texten verläßlich aussagen?

1. Hätte das Aksl. im Augenblick der Erstübersetzungen ein Artikelsystem gekannt, so wäre es zweifellos zur Wiedergabe des griech. Artikelsystems benutzt worden (so auch Svane).297) Ein Artikelsystem hätte sich nicht a priori der Anerkennung durch die Schriftsprache widersetzt (als 'vulgär'), da das Griech. als lingua sacra ein ebensolches System aufwies. Das Aksl. kannte demnach kein Artikelsystem. N a c h AbschluB der Kodifizierung des Aksl. mit der Entsprechung ó fófog $\cong$ 
slovo muBte sich diese Kunstsprache jedoch gegen den Einbruch eines neuen Subsystems aus den fortschrittlichen Dialekten sperren, mit denen es durch Ausbreitung der Innovationen in Kontakt kam. 298) Die aksl. Autoren und Ubersetzer dachten nicht diachronisch: Sie verkannten die diachronische Parallelität von ójófos und dem sich entwickelnden slovo-to, sondern sie dachten synchronisch, das aksl. System als unantast-

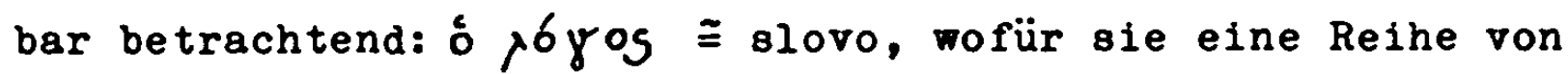
Umschreibungen und inadäquaten Ubersetzungen in Kauf nahmen. Nicht das Griech. also verhinderte den Einbruch des Artikelsystems in das Aksl., sondern die Kodifizierung der anfänglichen aksl.-griech. Zeichenentsprechung.

Als junge sprachliche Kategorie ist das Artikelsystem in vielen Sprachen der Einwirkung von künstlicher Archaisierung ausgesetzt. 299) "Im Griechischen und anderswo gehören sie (die Artikel) namentlich der Prosa an; die Sprache der hohen Dichtung braucht sie wenig, da sie, in der epischen Produktion der nachklassischen Zeit sogar in steigendem Maße, den Artikel unter dem übertriebenen Vorbild des alten Epos überhaupt ablehnt (wozu das Deutsch gewisser Literaten eine wenig erfreuliche Parallele liefert)." (Schwyzer) 300 ) - Aus seiner Not, ohne Artikelsystem auskommen zu müssen, machte das Aksl. im Laufe der Zeit eine kunstsprachliche Tugend, die auch auf die Diskussionen in der Periode der Schaffung einer nbulg. Schriftsprache einwirkte, aus der einige den Artikel als vulgär heraushalten wollten.

2. Wenn das Aksl. auch kein Artikelsystem besaß, so kannte es, nach der Meinung einiger Linguisten (Gslsbov, Marguliés, Mirčev, Trifonov) den Artikel. Ohne ein Artikelsystem ist jedoch ein Artikel nicht existent, weil ein Sprachzeichen an sich, auBerhalb seiner Oppositionsgruppe, nichts bezeichnet. 301) Das Kennzeichen für das Bestehen eines Systems ist u.a. das regelmäßige Auftreten seiner formen in einer GesetzmäBigkeit, von der sich Abweichungen in Regeln fassen lassen müssen. Im Aksl. ist diese Bedingung, was den Gebrauch des 
Demonstrativpronomens in sekundärer Funktion betrifft, offensichtlich nicht erfüllt. Zu erklären bleiben die Pälle, in denen einem bloßen Artikel im Griech. ein meist postpositives (vgl. jedoch: Zograph. J XII, 18. ěko slyšašę (se) sstvorbša

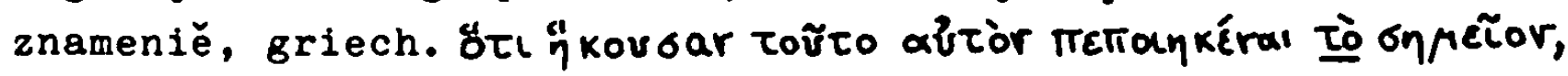
dagegen im Marian. und Sav. kniga: se znamenie) Demonstrativpronomen entspricht.

Es sind dies in den kanonischen Texten (Kurz gibt nur die Zahl für die Fälle mit postponiertem aksl. Demonstrativpronomen, die Pälle mit präponiertem Demonstrativpronomen sind gering 302), 88 Pälle, von 1159 vergleichbaren griech. Artikelkonstruktionen, d.h. 7,5\%. Die gröBte Anzahl (65 Pälle) davon stellt allerdings der Codex Suprasliensis, z.B.

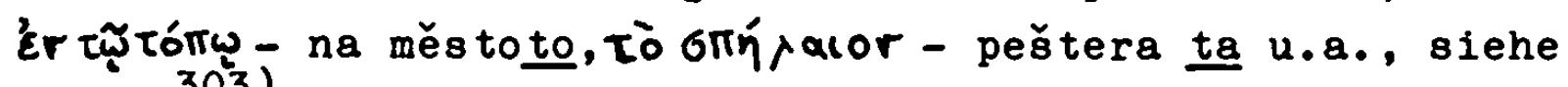
Mirčev 303), und noch häufiger ist dieser Gebrauch in den hier nicht mitgerechneten Schriften des Exarchen Johannes. 304 ) $\mathrm{Zu}$ Recht erklärt Kurz den Sondercharakter der genannten Texte bezüglich ihrer Neuerungen durch das Territorium, auf dem sie entstanden, dem Gebiet der NO-bulg. fortschrittlichen Dialekte. ${ }^{305)}$

Die Fälle von Entsprechungen: aksl. Demonstrativpronomen - griech. Artikel erklären sich aus der internen Situation des Aksl.306) In den Sprachen, welche für den Ausdruck der Identifizierung kein Morphem in primärer Funktion (Artikel) haben, z.B. im Al tindischen, Li tauischen, Lateinischen, läBt sich ein verstärkter Gebrauch des Demonstrativpronomens beobachten. 307) Ebenso im Skr., vgl. Maretic(308). Diese erhöhte Frequenz des Demonstrativpronomens erklärt sich durch seine angewachsene Verwendung in sekundärer Punktion: die Möglichkeit, durch grammatische Lokalisierung mit dem Demonstrativpronomen eine Identifizierung vorzunehmen, wird in denjenigen Sprachsystemen häufiger benutzt, die zu diesem 2 weck keinen Artikel aufweisen. Die Bedingung für den Eintritt der sekundären Funktion ist dabei der passende Kontext, d.h. die vorherige Erwähnung des betreffenden Nomens oder eines semantisch nahestehenden Begriffes. 
Mit der erhöhten Prequenz des Demonstrativpronomens in sekundärer Punktion haben wir es auch im Aksl. zu tun. Sie resultiert hauptsächlich aus den innersprachlichen Erfordernisgen und konnte durch die Notwendigkeit zur Verdeutlichung mancher griech. Konstruktionen verstärkt werden - dieser Verstärkung miBt N. Radoševic 309) groBe Bedeutung bei -, óhne daB die Bedingung der Kontextbedingtheit bei der Identifikation verletzt murde. Die identifizierten Nomina waren im voraufgehenden Kontext in einer oder der anderen Gestalt anwesend, und solche Pälle wie Niedersorbisch: we tom času togo krala Herodesa - 'zu der Zeit des König Herodes', wo zu Beginn eines Textes das Demonstrativpronomen ohne reale Lokalisierung identifiziert, wodurch die Kontextbedingtheit dieser Bunktion beseitigt wird, sind im Aksl. nicht belegt. Vergleichbar dem Aksl. sind die Verhältnisse im Gotischen. 310)

In seinem Aufsatz 311 ) hat Kurz in jedem einzelnen Fall von griech. Artikel - aksl. Demonstrativpronomen dargelegt, dab es sich um ein Demonstrativpronomen in sekundärer Funktion (Kurz nennt sie anaphorisch) handelt, vgl. z.B. "Nr. 215 (Supr. 174.21). Posbla že vb afrikijg nečbstivoje te zapovědb.

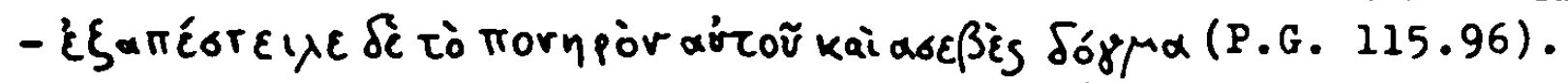
Das Pronomen hat anaphorische Bedeutung (das mit dem Pronomen verbundene Substantiv bezeichnet sumarisch das, wovon vorher erzählt wurde). Im griech. Text, der etwas unterschiedlich lautet, steht der einfache Artikel; aber in der slavischen Obersetzung ist das Pronomen völlig am Platze." (Kurz) 312) Dasselbe Ergebnis erzielt Kurz in den übrigen Fällen.

Die verhältnismäßig breite Funktion der Demonstrativpronomina im Aksl. muBte manchen Schreiber, in dessen Dialekt ein Artikelsystem bereits bestand, mit den Forderungen der Kunstsprache in Konflikt bringen, so dab er, bestrebt, den Text von Einflüssen der eigenen Mundart frei zu halten, auch echte Demonstrativformen aus der Vorlage beim Kopieren ausließ. Vgl. die Beispiele bei Radoševic. 313) Dieselbe Wirkung scheint das häufige Kopieren einer aksl. Vorlage durch russi- 
sche Schreiber gehabt zu haben, deren Sprache in Bezug auf die Frequenz des Demonstrativpronomens in sekundërer Funktion wahrscheinlich der Sprache des Exarchen Johannes nachstand. So erklärt sich der Unterschied zwischen dem Sestodnev mit hoher Frequenz des Demonstrativpronomens und dem Bogoslovie des Damaskin (übersetzt von Johannes dem Exarchen), welches früh nach Russland gelangte und dort häufig kopiert wurde. 314) Kurz' Resüme lautet315): "Wenn wir den Artikel als ein Sprachelement definieren, welches regelmäßig an Substantiva tritt, wenn es sich darum handelt, dab die Vorstellung, die durch das entsprechende Substantiv ausgedrückt wird (...), als schon bekannt bezeichnet wird, und wenn wir gebührend die Unterschiede beachten, die zwischen der Artikelverwendung einerseits und der des Demonstrativpronomens andererseits in seiner anaphorischen Funktion festzustellen sind, dann können wir in unserem Material nicht die Bedeutung des einfachen Artikels finden." In der hier verwendeten Terminologie: Die identifizierende Verwendung des Demonstrativpronomens ohne reale Lokalisierung stellt im Aksl. in jedem Pall die synchronisch als sekundër und kontextbedingt zu definierende Funktion dar.

Dagegen sind in die nach-aksl. Texte, vom 12. - 13. Jhd. an, aus der mittelbulg. Umgangssprache vereinzelte Artikel eingedrungen, d. h. aksl. Demonstrativpronomina in artikelhafter Verwendung, in ihrer rein identifizierenden Funktion nicht durch den Kontext bedingt. Diese Fälle bilden untereinander kein System, sie sind Reflexe des in der damaligen Umgangssprache bestehenden Artikelsystems, wobei der Schreiber den Vermittler darstellt. Vgl. Mirčev über den Bitolski triod, den Ochridski apostol, das Bojansko evangelie u.a.316). Dies gilt teilweise auch für die von Svane vor allem aus dem Dobrejšovo-Evangelium 317) zitierten Beispiele. Allerdings stellen die am häufigsten vorkommenden 'Artikel 1. Grades' sämtlich Demonstrativpronomina in sekundärer Verwendung dar, vgl. 318) Dobrejšovo - izvede $i$ duchb vs pustyng $i$ běše vs 


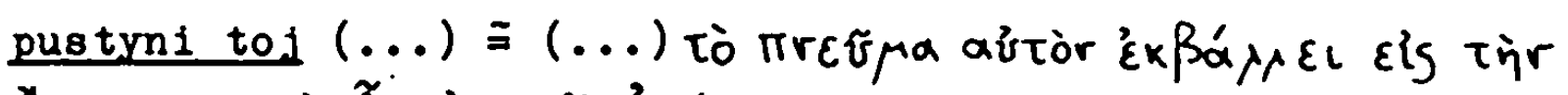

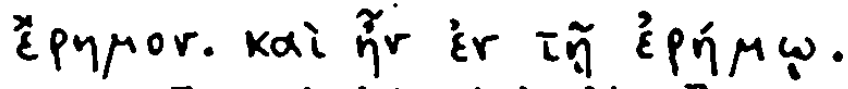

Es erhebt sich die Prage, ob die aksl. Denkmäler, die wegen der unsystematischen Verwendung von Demonstrativpronomina in sekundärer Funktion, dabei in nicht systematisch geregelter Position, keine eindeutige Erklärung für die rigoristische postpositive Artikelverwendung des Nbulg.-Mak. bieten, nicht zumindest durch eine statistisch erfabbare Tendenz einen Wert für die Prage nach der Position des (Proto-)Artikels im Altbulg., der Umgangssprache des 9.-10. Jhd., haben.

Im Syntagma Substantiv-Adjektiv-Demonstrativpronomen sind im Aksl. grundsätzlich die Sequenzen DSA, DAS, SDA, ADS, $S A D, A S D$ möglich, und keine von ihnen kann vom diachronischen Standpunkt aus für ursprünglicher oder normaler gehalten werden. 319) Für die Reihungen ASD und SAD, d.h. mit dem Demonstrativpronomen an letzter Stelle, stellt Kurz fest, dab es sich bei ibnen in der Mehrzahl der Pälle um feste, typisierte Verbindungen von Substantiv und Adjektiv handelt, wie rabs trojb $8 b$, rabs božijb sb, brats naš $8 b$, in denen Substantiv und Adjektiv eine Sinneinheit bilden ${ }^{320}$, so daB sich auch in diesen Sequenzen das Demonstrativpronomen eigentlich an zweiter Stelle befindet. Dagegen ist in ADS und SDA der semantische Gehalt von Substantiv und Adjektiv voneinander unabhängiger, beide müssen keine Sinneinheit bilden, darum handelt es sich um eine echte Postposition des Pronomens. 321) Die Prage, ob von den Pällen mit Nachstellung des Demonstrativpronomens die Polgen SAD/ASD (so Svane) oder ADS/SDA (Grlbbov) normaler seien, beantwortet sich demnach dahingehend, daB den Sequenzen mit Voranstellung (DSA, DAS) im Grunde nur e i $n$ Typ der Nachstellung gegenübersteht: SDA/ S-A D und ADS/ A-S D. 322). Treten im Attribut zwei Adjektiva oder Partizipia auf (mit oder ohne Kopula), so tritt das Demonstrativpronomen in sekundärer Funktion immer an die zweite Stelle, z.B. chudyję oeje našje žizns 323 ). Diese Beispiele sind häufig und zeigen, daB an solchen kritischen Punkten der Ubersetzung 
die künstliche Freiheit der Wortstellung eingeengt wurde.

Von den von Kurz gegebenen Statistiken greife ich eine extreme Ubersetzungssituation heraus, nämich wenn ein griech. Syntagma Substantiv-Adjektiv-Artikel (in jeder möglichen Sequenz) eine aksl. Entsprechung Substantiv-Adjektiv-Demonstrativpronomen erhält. Extrem nenne ich die Situation, weil mit der Hineinnahme des Adjektivs ins Syntagma die Positionsmöglichkeiten des Demonstrativpronomens $\underline{6}$ sind (s.o.) gegenüber zweien ohne Adjektiv (DS - SD) und weil dem griech. Artikel die slav. Pronomina $\mathrm{sb}$, ts, ons entsprechen können, wodurch sich die aksl. Ubersetzungsmöglichkeiten des genannten griech. Syntagmas auf 18 erhöhen: A-sb-S, A-tb-S, A-onb-S, AS-8b, $A S-t s, A S-O n b, S A-8 b, S A-t b, S A-O n s, S-8 b-A, S-t b-A, S-O n b-A$, 8b-AS, ts-AS, ons-AS, $8 b-S A$, $t b-S A$, ons-SA. Welche Ubersetzung ist am häufigsten?

Hier die Zahlen für die Evangelien, den Psalter, Trebnik, Sin. Blätter, Clozianus, Rilaer glagol. Blätter, Kiever Blätter, Suprasliensis:

Zahl der mit dem Griech. vergleichbaren adjektivhaltigen Syntagmata:

268

324)

davon mit Demonstrativ für griech. Artikel:

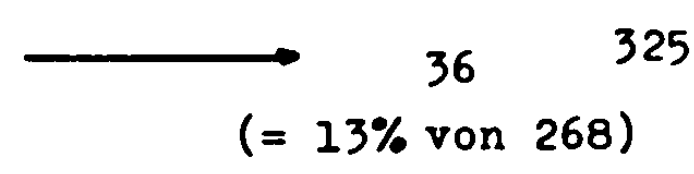

davon mit Postposition des slav. Demonstrativs:

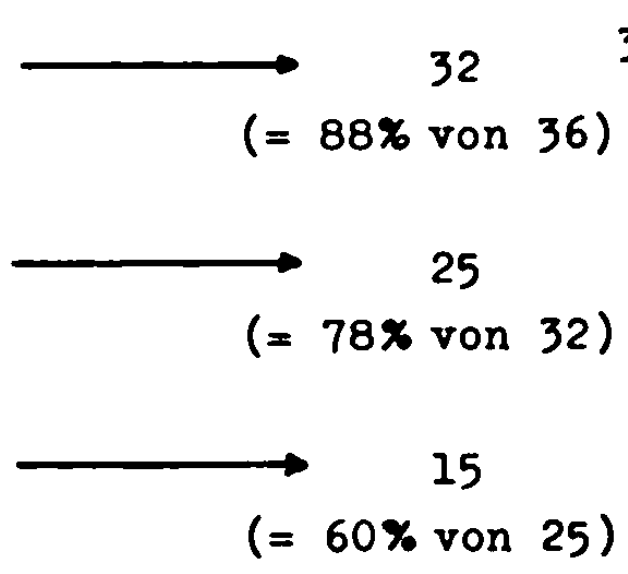

davon in der Sequenz ADS:

davon mit $D=\underline{t s}$ : 
Von den 18 Ubersetzungsmöglichkeiten tritt im Falle der Ubersetzung des griech. Artikels durch ein slav. Demonstrativpronomen die Sequenz A-ts-S in 15 von 36 , d.h. in $41 \%$ aller Pälle ein.

Von den 36 zugrundegelegten Fällen entstammen 27 dem Suprasliensis. Pür inn sieht die Rechnung wie folgt aus: Demonstrativ für griech. Artikel: 27

davon mit Postposition des

slav. Demonstrativs:

-

davon in der Sequenz ADS:

davon mit $D=t s$ :

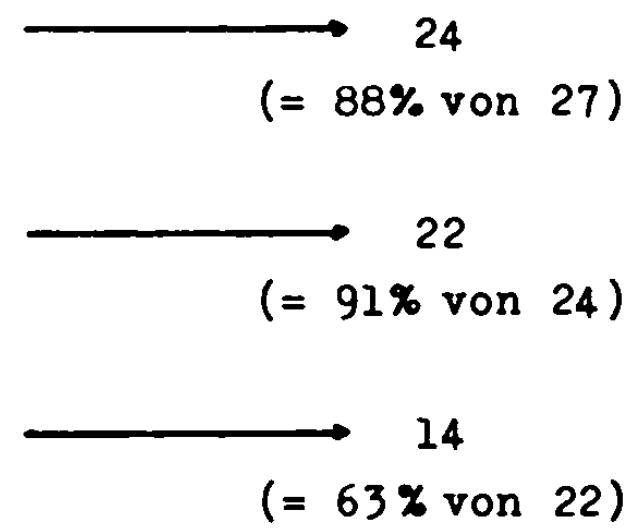

Im Suprasliensis tritt im Pall der Ubersetzung des griech. Artikels durch ein slav. Demonstrativpronomen die Sequenz A-ts-S in 14 von 27 Pällen, d.h. in $21 \%$ aller Pälle auf.

Bei der (seltenen) Ubersetzung des griech. Artikels durch ein slav. Demonstrativpronomen in den aksl. Texten überwiegt also die Postposition des Demonstrativpronomens, bei der Postposition die Sequenz ADS, für $D$ in ADS das Demonstrativpronomen ts. Diese ohne Nachprüfung der Zahlen auch von Kurz ${ }^{328)}$ und Marguliés ${ }^{329)}$ getroffene Peststellung besagt: Durch das Zusammenwirken der stilistisch bedingten Postposition des Demonstrativpronomens in sekundärer Funktion und innerhalb von ihr der Sequenz ADS und der systembedingten grammatischen Zeigefunktion des neutralen Demonstrativpronomens ts favorisiert die ältere slavische Syntax (... sootve tsvuet duchu slavjanskogo sintaksisa - Kurz) ${ }^{330}$ ein Syntagma vom Typ A-ts-S und also auch $S-t_{b}$ als Prototyp eines Syntagmas mit nominaler Determination.

Da sich alle sprachlichen Erscheinungen, die sich spä- 
ter zu einer Gesetzmäßigkeit zusammenfinden, zu Beginn ihrer Entstehung in Tendenzen äußern, könnte man sich mit der festgestellten aksl. Tendenz zur Erklärung der Artikelposition im Nbulg.-Mak. zufriedenstellen: ein Artikel muB sich für die Voran- oder die Nachstellung entscheiden, und aus diesem Grunde werden Tendenzen der Rede, stilistische Besonderheiten etc. an einem Punkt der Diachronie zu prinzipiellen Regeln des Sprachsystems erhoben, wie es die romanischen und germanischen Sprachen in ihren Artikelpositionen zeigen. Der Unterschied vom optionalen Element 'Artikelpostposition' zum obligatorischen Element 'Artikelpostposition' ist nur ein gradueller, abhängig von der Anzahl der realisierten Postpositionen. 33i)

Da sich jedoch aus der im Aksl. festzustellenden Tendenz auBerhalb des Bulg.-Mak.-Torlakischen kein Artikelsystem entwickelt hat (zum Russischen s.u.), erblicke ich beim Ubergang von der Optionalität des postpositiven Demonstrativpronomens in rein identifizierender Funktion zur Obligatheit der Postposition des Artikels im Bulg.-Mak. ein die slavische Tendenz zumindest verstärkendes Mitwirken des Rumänischen, das sich auch bei der Auswahl des Artikelmorphems mit dem Bulg.-Mak. in Interaktion befand.

b. Artikelpositionen des rumänischen Substrats

Der von den meisten Linguisten angenommene Zusammenhang zwischen der Artikelevolution im Bulg. und im Rum. wird oft dahingehend formuliert, daB das Romanische im Bulg. die Entstehung des Artikels anregte, das Bulg. jedoch dem rum. Artikel seine meist postpositive Stellung gab (Vaillant ${ }^{332}$ ), Seidel ${ }^{33}$ ) Georgiev 334 ), Piotrovskij335) ).

Gegen eine bulg. Einwirkung auf die Position des rum. Artikels sprechen:

1. das fehlende Junktim von sekundär-identifizierender Funktion des Demonstrativpronomens und seiner Postposition im Al tbulg. So auch Svane. 336 ) 
2. Die Intensität des rum. Einflusses auf das Bulg. in der ersten Phase ihres Kontaktes vom 6.-10. Jhd., nicht umgekehrt. Der rum. Artikel muß spätestens im 10. Jhd. postpositiv gewesen sein. 337)

3. die Möglichkeit, die verschiedenen Positionen der rum. Artikel parallel zu den Positionen des albanischen Artikels zu erklären. Vgl. das Folgende.

Das am meisten ernstzunehmende Argument gegen eine Mitwirkung des rum. Substrats an der ausnahmslosen Postposition des bulg.-mak. Artikels ist der Hinweis darauf, daß das Rum. neben einem postponierten auch präponierte Artikel aufweiat: "(...) wenn der bulgarische Artikel, wie sehr oft behauptet wird, unter dem Einfluß des Rumänischen entwickelt worden ist, so bleibt unverständlich, warum das bulgarische Phänomen nur einen Teil des reichen Repertoires der rumënischen Artikulierung reproduziert" (Gblsbov).338)

Das moderne dakorumänische (DR) Sprachsystem kennt sogenannte Artikel in postpositiver und präpositiver Verwendung. I. Postponiert

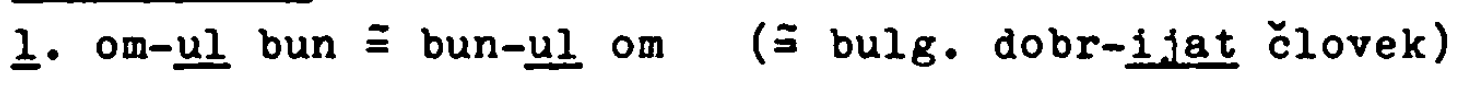

Die Funktion des postponierten Artikels besteht in der reinen Identifizierung.

II. Präponiert

2. cel vor Adjektiven, die auf ein postartikuliertes Substantiv bezogen sind,

a. obligatorisch, wenn das Adjektiv von diesem Substantiv durch Einschübe getrennt ist: codul civil si cel penal 'der Zivil- und Strafkodex'.

b. fakul tativ in der unmittelbaren Aufeinanderfolge von Substantiv und Adjektiv: omul cel bun neben omul bun ( 1 ).

2. al (a)

a. obligatorisch vor substantivischen Attributen, die auf ein postartikuliertes Substantiv bezogen sind und diesem nicht unmittelbar folgen: calul frumos al prietenului, aber: calul prietenului. Ebenso vor einem auf ein nicht-postartikuliertes 
Substantiv bezogenen substantivischen Attribut: un cal al prietenului.

b. vor Possessivpronomina wie unter 3.a.: calul frumos al meu, calul meu, un cal al meu.

c. obligatorisch vor identifizierten und nicht-identifizierten Ordinalzahlen: al doilea 'der zweite', un al doilea 'ein zweiter'.

4. Iui

Obligatorisch zum Ausdruck des Obliquus bei nicht-postartikulierten Eigennamen, fakultativ bei Verwand tschaftsbezeichnungen und artikulierten Eigennamen: lui Ion, lui Lupu(1).

Für die folgenden Erörterungen schließe ich eine Aufzählung der albanischen Artikel an:

I. Postponiert

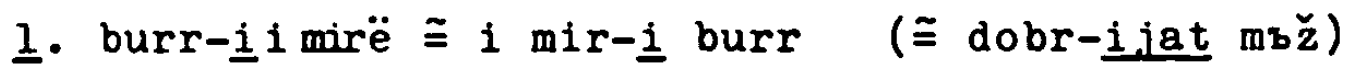
Funktion: reine Identifizierung.

II. Präponiert

2. 1 vor jedem Adjektiv in jeder Position, z.B. burri 1 mirë 'der gute Mann', nji burr $\underline{i}$ mirë 'ein guter Mann', 1 miri burr 'der gute Mann'. Adjektiva ohne den präpositiven Artikel sind ursprünglich Substantiva. 339 )

2. vor jedem substantivischen Attribut in jeder Position, 2.B. kali $\underline{i}$ mikut 'das Pferd des Freundes', kali 1 ri 1 mikut 'das junge Pferd des Freundes', $n j i$ kal $\underline{i}$ mikut 'ein Pferd des Preundes'.

4. als Possessivpronomen der 3. Person vor Verwand tschaftsbezeichnungen: 1 ati 'sein Vater'.

Als Ergebnis ist festzustellen, daB im Rum. und Alb. nur der postponierte Artikel eine Identifizierung ausdrückt. Bei den präponierten Morphemen hat der Terminus 'Artikel' keinen synchronischen Aussagewert.

Von den präpositiven Artikeln lassen sich die Typen rum. 2 und 3 , alb. 2 und 3 miteinander vergleichen. Die Punktion von rum. cel, al $(2,3)$, alb. $\underline{i}(2,3)$ besteht in einer Kennzeichnung bzw. Betonung des Attributcharakters des dem präpositiven Artikel folgenden Nomens. Das rum. codul civil gi cel 
penal, nivelul social al interlocutorului zeigt, dab diese innzeichnung durch Wiederaufnahme und Ersetzung des übergeordneten Substantivs in der Wiederaufnahme durch ein Pronomen, den präpositiven 'Artikel', erreicht wird < codul civil si codul penal; nivelul social, nivelul interlocutorului, so dab auBer Zweifel gestellt wird, auf welches Substantiv sich das betreffende Attribut bezieht. Die genannten präpositiven Artikel signalisieren Attribute, indem sie, grammatisch lokalisierend, auf das übergeordnete Substantiv verweisen.

Die Kennzeichnung des Attributcharakters durch die präpositiven Artikel ruft eine Reihe von sekundären Funktionen hervor:

1. Rum. al (3.8.), alb. 1 (3) unterscheiden des Attribut vom indirekten objekt, da für beide nur éin paradigmatischer Kasus, der Obliquus, vorhanden ist:

un cal al prietenului = Attribut; el zice - prietenului $=$ indir. Objekt

nji kal 1 mikut = Attribut; 1 thotë - mikut = indir. Objekt Eine zusätzliche Unterscheidung kann durch die objektreprise (alb. i thotë mikut - 'sagt er zu dem Freund') erfolgen. 2. Rum. al (3.c.) kennzeichnet Ordinalzahlen. 3. Alb. 1 (2) kennzeichnet die Klasse der Adjektiva, ohne präpositiven Artikel fungieren sie als Adverb.

Rum. lui (4) und alb. i (4) haben keine Beziehung zur Kennzeichnung des Attributs durch Wiederaufnahme des überge-

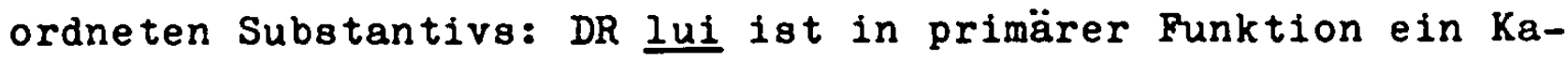
susmorphem - o sonatā a lui Beethoven $\equiv$ o sonată de Beethoven. Während sich die präpositiven Artikel rum. cel, al, alb. 壬 auf das übergeordnete Substantiv beziehen und mit diesem in Konkordanz stehen, bezieht sich lui auf das folgende Attribut und steht mit diesem im gleichen Kasus.

Das Eintreten der Attributssignalisierung durch den präpositiven Artikel ist im $D R$ nach Maßgabe des Kontextes obI1gatorisch (2.a., 3.a.b.), im Alb. ohne Kontextbedingtheit obligatorisch (wie DR 3.c.), d.h. ein unmittelbar dem Attri- 
but vorhergehender postpositiver Artikel verhindert nicht wie im $D R$ das Eintreten des präpositiven Artikels zur Signalisierung des Attributs. Einzig und allein in dem DR Typ 2.b. ist die Verwendung des präpositiven Artikels fakultativ, der Sprecher kann wählen zwischen omul bun und omul cel bun. Der Bedeutungsunterschied im modernen $\mathrm{DR}$ ist gering: cel hebt ein Adjektiv hervor, ohne dessen Stellung hinter dem Substantiv $z u$ verändern, während der literarische Gebrauch auch die Inversion zum Zwecke des Nachdrucks häufiger verwendet: publicul mare - publicul cel mare - marele public. 340)

Im modernen $D R$ und $A l b$. besteht demnach eine Koppelung der Identifizierung mit der Postposition des Artikels und der attributssignalisierenden Funktion mit seiner Präponierung. Präponiertheit und Postponiertheit des Artikels entscheiden über seine Funktion, was deutlich wird, wenn die präponierten und postponierten Artikel morphematisch identisch sind (alb.). Damit ist die Annahme der Civ'jan bei der Untersuchung des synchronischen Wertes des Merkmals 'Artikelposition' widerlegt: es könnte sein, daß sie "keine Bedeutung für die Prozesse der Analyse und der Synthese hat". 341)

Es fragt sich, welche Positionen der rum. Artikel in der Periode bis zum 10. Jhd. neben der postpositiven einnehmen konnte und welche Punktionen sich mit den verschiedenen Positionen verbanden.

Für die Entstehung von om-ul 'der Mensch' im Rum. kann die Romanistik, vergleichbar den rein slavistischen Analysen der bulg. Artikelposition, nicht mehr als vulgärlat. Tendenzen feststellen, die zudem eher die Präponierung des identifizierenden Artikels begünstigen als seine Postponierung, vgl. die allgemeine Präponierung im West- und Zentralromanischen. Piotrovskij hat in einer längeren Analyse gezeigt, dab eine Ableitung des postponierten rum. Artikels aus den 'natürlichen Entwicklungstendenzen' der lat. Syntax, wie sie Gamillscheg und Puşcariu annehmen, nicht in Frage kommt. Diese Entwicklungstendenzen führten zur Präponierung (s. Piotrovskij ${ }^{342)}$, 
wo Statistiken und weitere Literatur angegeben werden): "(...) die Postposition des balkan-romanischen Artikels widerstrebt diesen analytischen Tendenzen (die zur Präponierung führten), welche (...) sich die Syntax der adjektivischen Demonstrativpronomina schon lange vor der Epoche der Romanisierung der Balkanhalbinsel zu unterwerfen begannen" (Piotrovskij).343) Das späte vulgärlat. Idiom (8. Jhd.) zeigt artikelhaftes ille/ ipse nur in präpositiver Verwendung. 344 )

Eine innerromanische Erklärung der rum. Abweichung streben folgende Theorien an:

1. Die von Gamillscheg/Puscariu angenommene 'fallende Redetaktkurve' des Rum. im Gegensatz zur übrigen Romania, wodurch unbetonte Wörter an die zweite Stelle des Syntagmas treten. 345) Sie ist zurückgewiesen worden für die übrige Romania von Giese 346$)$ und Coteanu ${ }^{347)}$, für das Rum. besonders durch Piotrovskijs Intonationsexperiment ${ }^{348)}$. Vgl. Portugiesisch, wo die Enklitikregel uneingeschränkt für alle unbetonten Personalpronomina gilt (rogo-lhe - que lhe rogo) und trotzdem o cose 'das Haus' gilt.

2. Tanase ${ }^{349)}$ rechnet den Artikel mit reiner Identifikation $z u$ den 'definiten Determinantien' eines Substantivs, die im Gegensatz zu den 'indefiniten Determinantien' im Rum. generell postponiert werden: om- ul $\cong$ domnu nou / un om $\cong$ fiecare zi. Tanase unterläßt es, uns zu informieren, warum eben diese Postposition des qualifikativen Adjektivs, das $z u$ den 'definiten Determinantien' gehört, im Unterschied zur übrigen Romania im Rum. eingetreten ist. 3. Coteanu ${ }^{350)}$ postuliert: Da der romanische Artikel von Anfang an auch eine Kasusfunktion gehabt habe, sei er von dem jewelligen Kasusmorphem attrahiert worden: so im Frz. fille de roi > la fille de le ( $>d u$ ) roi, deshalb präpositiver Artikel; im Rum. "casa feate > casă-a fete-éi, also postponiert, von da aus Ubertragung der Artikelpostposition in die Gruppe Substantiv-Adjektiv: omu-1u (celu) bunu. Dagegen ist zu sagen: a. Coteanu vernachlässigt die Artikelfunktion 'Identifi- 
zierung', der Artikel wurde zum sekundären Kasusmorphem erst $\mathrm{n}$ a $\mathrm{c} \mathrm{h}$ dem Umbau der rum. Deklination (dominus, dominum, dominō > rum. domnul). b. Coteanu setzt als selbstverständlich voraus, daß im Frührum. der synthetische Kasusausdruck aufgrund seiner syntaktischen Uberlegenheit allein herrschend war und dadurch die Artikelposition entschied, jedoch bestand bis ins Altrum. des 16. Jhd. eine Konkurrenz zwischen cale de cetate (wie altfranzösisch) und calea cetățider Stadt'. Analog zu der übrigen Romania wäre dann auch ein rum. cale de-ella cetate, d.h. ein präpositiver Artikel zu erwarten. Vgl. zu den Punkten a. und b. das Kap. III.

Am wahrschsinlichsten für eine Erklärung der rum. Artikelpositionen ist die Theorie von Al. Graur ${ }^{351)}$. Er nimmt eine frühere Einheit von präpositivem und postpositivem Artikel im Rum. an: *homo-ille-bonus, welches aus homo ille-bonus entstanden ist, d.h. der Artikel gehörte ursprünglich zum nachgestellten Adjektiv und trat später an das vorausgehende Substantiv: homo ille-bonus > homo-ille bonus > homo-ille (omu-lu). Nicht überzeugend sind die Einwände Puącarius 352 ). Golbbov miBversteht Graur, wenn er aufgrund dieser Theorie 353) ein ursprüngliches rum. Syntagma Artikel + Substantiv/Artikel + Adjektiv354) annimmt. Ich habe an anderem Ort355) die Graursche Theorie so weiterzuentwickeln versucht, dab sie auch die Entstehung der rum. präpositiven Artikel erklärt und die immer wieder angenommene Abhängigkeit des rum. Artikelsystems vom Alb. 356) herausgearbeitet. Im Folgenden gebe ich eine wesentlich weiterentwickelte Passung dieses Erklärungsversuches, unter besonderer Berücksichtigung der Funktionen der präpositiven und postpositiven Artikel in der frührum.-frühalb. Feriode bis ungefähr zum 10. Jhd..

In einigen Inkonsequenzen und Relikten des heutigen DR Artikelsystems finden sich Hinweise darauf, dab der heutige postpositive Artikel des Substantivs auf einer älteren Zeitstufe präpositiv zum Attribut stand, also mit den Vorläufern der heutigen präpositiven Artikel des Attributs identisch ist. 
1. Ein substantivisches Attribut (ebenso ein Possessivpronomen) muB stets einem Artikel in direkter Sequenz folgen, entweder dem präpositiven Artikel al (mask.) oder dem postpositiven Artikel -ul (mask.):

calul frumos al vecinului

un cal al vecinului

calul vecinului

Damit übernimmt der postpositive Artikel (auf synchronischer Ebene) neben der identifizierenden die kontertbedingte Funktion der Signalisierung eines Attributs. Die synchronische Erklärung kann $n i c h t$ lauten, daB der präpositive Artikel al mit $\emptyset$ alteriert, d.h. daß der präpositive Artikel zum Attribut nur dann hinzutritt, wenn es vom übergeordneten Substantiv getrennt wird, um den Bezug klarzustellen, und dab dagegen in der direkten Sequenz (calul vecinului) der Attributsbezug klar sei. Vgl. das Gegenbeispiel: frumosul cal al vecinului. Ausschlaggebend ist nicht die Sequenz von Substantiv und Attribut, sondern von Artikel und Attribut.

"Es ist sicher, daß in diesen Pällen der Artikel zum (Attribut) gehört, denn dieses kann isoliert mit dem Artikel verbunden werden: al meu 'der Meinige' ('mein Mann' bei den Bäuerinnen); aga-1 omul nostru, al dracului - 'der Mann ist ein Anhänger des Teufels' (wörtlich: 'so ist unser Mann, er ist des Teufels $8^{\circ}$ )." (Graur) 357 )

2. Entsprechendes gilt für den obligatorischen Gebrauch des präpositiven Artikels cel vor einem adjektivischen Attribut, wenn dieses in unterbrochener Sequenz einem postartikulierten Substantiv folgt: codul civil si cel penal. "Das erste Adjektiv hatte auch den Artikel, aber dieser ist vom Substantiv an sich genommen worden." (Graur) ${ }^{358)}$ Die unter 1. und 2. genannten, "auf der aktuellen Zeitebene nicht erklärbaren" (Graur) 359) Alternationen von postpositivem und präpositiven Artikeln in bestimmten Kontexten ließen sich historisch so erklären, daB der postpositive Artikel -ul in calul vecinului aus den präpositiven Artikeln des Attributs, 旦 und 
cel (oder deren Vorform), entstanden ist und deren Funktion (Attributssignalisierung) im Kontext noch ausübt. Auf diesen historischen Prozeb weisen auch die folgenden zwei Fälle hin:

3. "Wenn das Substantiv im Vokativ von einem Genitiv begleitet wird, nimmt es den postpositiven Artikel, und der Genitiv verliert seinen präpositiven Artikel: (..) boule! 'boeuf'!, aber: boul lui Dumnezeu! 'imbécile' (wörtlich: 'le boeuf de Dieu')." (Graur) 360 ) < bou al lui Dumnezeu.

4. Für rum. 'Vater' bestehen zwei verschiedene postartikulierte Formen nebeneinander: tata (alter mask. a-Stamm mit femininem Artikel) und tată (jünger: Ubernahme des maskulinen Artikels entsprechend dem natürlichen Geschlecht). Historisch aufschluBrelch ist die Verteilung von tata und tatăl: tata wird nur alleinstehend verwendet, $d . h$. wenn kein Attribut folgt, dagegen erscheint tatăl vor Attribut: am vorbit cu tata, vino la tata, fratele tatei, am cerut voie tatei - tatăl meu, tatăl ceresc, fratele tatălui meu, am cerut voie tatălui meu. "Neben dem alten Artikel mit femininer Form (verursacht durch die feminine Endung des Wortes) ist ein neuer Artikel mit maskuliner Form dort aufgetaucht, wo tata von einem Adjektiv begleitet wird. Das Genus des Artikels wird hier durch das Genus des folgenden Adjektivs bestimmt, welches, der Porm wie dem Sinn nach, maskulin ist." (Graur) 361 ) - Die Hypothese, daß der postpositive Artikel des Substantivs ursprünglich präpositiv zum Attribut gehörte, impliziert, daß auf jener Entwicklungsstufe ein Substantiv formal nur dann identifiziert erscheinen konnte, wenn es ein Attribut besaB, in dessen Begleitung der Artikel auftrat. Reflexe eines solchen Zustandes finden sich im Rum. und Alb.: 5. "Die Substantiva, denen Präpositionen vorausgehen, können nicht artikuliert werden (mit Ausnahme der Präpositionen cu, die den Artikel duldet, und de-a, die ihn fordert): pe cal - 'auf (dem) Pferd', in sat - 'in (dem) Dorf', sub scut - 'in Sicherheit' (wörtlich: 'unter dem Schild'), etc. Aber wenn dem Substantiv ein Adjektiv folgt, kann es den Ar- 
tikel tragen: pe calul bălan - 'auf dem weiBen Pferd', in satul vecin - 'im benachbarten Dorf', sub scutul legii - 'unter dem Schutz des Gesetzes', und so fort." (Graur) 362 ) Vgl. auch: sā chemi pe caporali şi pe sergenţi - 'appelle les caporaux et les sergents', aber: sā chemi pe caporali si pe sergentili de $z i$ - 'appelle les caporaux et les sergents de jour'; o parte din procurori, magistrałł gi oameni 'une partie des procureurs, des magistrats et des hommes de 101'.363) - Im Alb. muß der Artikel sogar nur bei substantivischem Attribut folgen (immer unter der Voraussetzung, daß das übergeordnete Substantiv identifiziert werden soll): në shtëpi time 'in meinem Haus', aber në shtëpinë e mikut 'im Haus des Preundes'.

Das Nominalsystem, welches sich im Rum. und Alb. nur nach Präpositionen erhalten hat, läßt sich unter Berücksichtigung der Punkte 1-5 rekonstruieren als:

$\begin{array}{lll}\text { *calu } & * k a l & \text { 'Pferd', 'ein Pferd' } \\ \text { *calu ellu-bunu } & * k a l \text { i-mirë } & \text { 'das Pferd' } \\ \text { *calu ellu-vecinu } & \text { *kal 1-faini gute Pferd' } & \text { 'das Pferd des } \\ & & \text { Nachbarn' }\end{array}$

Daraus ergibt sich für das indeterminierte Substantiv mit Attribut:

* calu bunu / bunu calu *kal mirë / mirë kal

* calu vecinu

*kal fqini

'ein gutes Pferd'

'ein Pferd des

Nachbarn'

Die Muster gelten nur für die Position der Elemente, nicht für den historischen Lautstand. Die frührum. Porm *ellu (< 11le) ist im Vorgriff auf das Polgende eingeführt worden. Das Kennzeichen dieses Nominalsystems ist, dab eine Identifizierung ohne Zuhilfenahme der realen Lokalisierung oder der sekundären Funktion des Demonstrativpronomens nur 
dann formal ausgedrückt werden kann, wenn das mit dem intendierten Gegenstand $z u$ identifizierende Nomen ein Attribut bei sich hat. Daß solche Systeme existieren, beweist u.a. das Aksl.: člověks / dobrs-jb člověks / dobrs člověks.

Dabei erfolgt die Identifizierung des übergeordneten Nomens durch den Protoartikel. Kein Protoartikel erscheint ohne ein folgendes Attribut, dagegen kann das übergeordnete Nomen fehlen: "ellu-bunu 'der Gute' (s. dazu unten). Folglich betrifft die primäre Funktion des Protoartikels das Attribut. Jedem Protoartikel folgt ein Attribut, aber nicht jedem Attribut geht ein Protoartikel voraus (*calu bunu). Die Funktion des Protoartikels besteht demnach darin, zu kennzeichnen, daB das inm folgende Attribut einem zu identifizierenden Nomen untergeordnet ist. Um welches Nomen es sich handelt, ergibt sich erst in der kontextuellen Zusammenstellung:

$$
\begin{aligned}
& \text { calu 'Pferd' + ellu-bunu 'das Gute' > } \\
& \text { calu ellu-bunu 'das gute Pferd' }
\end{aligned}
$$

Die Identifizierung des übergeordneten Nomens durch den Protoartikel ist eine indirekte.

Die weiteren Darlegungen werden nun zeigen, wie sich aus dem rekonstruierten Nominalsystem die zu Beginn dieses Abschnittes beschriebenen heutigen rum. (und alb.) Artikelformen/-positionen und Artikelfunktionen ableiten lassen.

Evolution der verschiedenen Artikel aus dem Protoartikel

A. *calu ellu-bunu, *calu ellu-vecinu > calul (Typ 1.)

Form und Position: Die Reflexe von vulgärlat. ille / illu unterscheiden sich im Rum. je nach ihrer Punktion und Position.

1. Vollstufe: $i l l u>e^{\prime} l u>e ́ l>l e l$ - betontes Anaphorisches Pronomen 'er', entstanden alleinstehend und unter Akzent.

2. Reduktionsstufe: illu $>$ èllu $>$

a. al(u) - un cal al vecinului (Typ 3.a.b.c.) 
b. $\underline{a l}(u)$ - omul $\underline{a l}$ bun > omul cel bun (Typ 2.a.b.) 3. Schwundstufe: 1llu / 1lle > ellù / ellè > lu $/ \underline{\text { le }}$ omul $(u)$, cinele. (Typ 1.) $)^{364)}$

Als gemeinsame Vorstufe aller rum. präpositiven und postpositiven Artikel erscheint *ellu. 363 Auf sein Paradigma lassen sich auch die postponierten DR Artikelformen cinele, omul(u), oamenil, casele, omului, casei, caselor zurückführen, mit Bewahrung von $-11>\underline{1}$ oder durch Palatalisierung $>$ $\left.I^{\prime}>1.366\right)$ Im Obliquus des Singulars hatte *ellu die schwach-

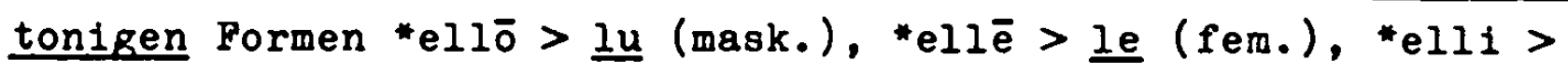
$\underline{1}$ (mask. und fem.) und die starktonigen Pormen *ellui > lui (mask.), *ellei > ei (fem.), vgl. unten Abschnitt D. Der Obliquus des postpositiven Artikels lautet - lui, -ei, verwendet also die starktonigen Pormen. 367) In der Position *6mu èllu-búnu war *ellu stärker betont als in einer möglichen enklitischen *6mu-ellu. Daher bezeugen die heutigen Obliquusformen omului, casei, daß der postpositive Artikel sein Morphem aus dem präpositiven Artikel des Attributs bezog (*omu ellui-bunu $>$ *omu-ellui bunu). Auf die einstige Tonstärke der Artikelform weist auch hin, $d a b$ in einigen alten Texten die obliquusformen -lui und -lor mit einem sekundären Akzent (") bezeichnet sind, und ein solcher Akzent ist nach Dräganu auch heute noch in den Volksliedern zu hören. ${ }^{368)}$

Für die Entstehung des postpositiven Artikels aus dem Syntagma *omu ellu-bunu spricht also einerseits, dab seine Pormen, da starktonig, ursprünglich nicht enklitisch standen, andererseits, daB sie sich auch nicht im absoluten Anlaut des Syntagmas befunden haben können: Die Porm des femininen postartikulierten Substantivo casa geht auf *casā-a zurück, jedoch zeigen DR stea - steaua, zi - ziua, daB der feminine Artikel früher -11a lautete, mit $-11+a>\underline{\text { ua }}$. Dementsprechend lst für die übrigen Pormen des postpositiven Artikels ebenfalls ein ursprüngliches -llu, -llui, -lle, -lli, -llei, -llor und nicht -lu, -lui, -le, -1i, -lei, -lor anzunehmen. 369) Die Pormveränderung des postpositiv an das Substantiv getretenen 
Artikels *ellu besteht demnach nicht, wie beim westromanischen Artikel, in der Aphärese der anlautenden Silbe: ille > le, illa $>1 a^{370)}$, sondern resultiert aus der Betonungsverlagerung von 1lle, 1llu> *ellè, *ellù unter dem Einflub der schon früher endbetonten obliquen Kasus 1/llùi, 1/llàei, $i / l l o ̀ r u(m)$, die einen Schwund des anlautenden $\underline{e}$ (i) bewirkte. ${ }^{371)} \mathrm{Da}$ die westromanische Synkopierung illa $>1 a$ etc. ein Zeichen für die Position des Artikels im absoluten Anlaut ist $\mathrm{t}^{372}$, kommt eine solche Position für den identifizierenden Artikel des Rum. im Augenblick seiner Entstehung nicht in Prage. Der Ausfall des e- im Rum. läbt sich aus der neuen Verbindung des Artikels mit dem vorangehenden Nomen erklären: * $\delta m u$ èllu-búnu > $\delta_{m u}$ ellú-búnu $>$ *mu-ellù (bunu) > $\delta m u-l l u$.

Neben den Pormen -lui, -ei kennt das Rum., vor allem im Altrum. und in DR Dialekten, die Pormen - $\underline{\underline{l u}}$ und $-\underline{i}$ für den postpositiven Artikel im Obliquus ( $z u \underline{\text { lu }}$ und $\underline{i}$ als präpositive 'Artikel' vgl. Abschnitt $D$ ): Impăratu-lu neben impăratu-lui, färă-1 neben făre-eí, wobei allerdings die -lui/-ei-Bildungen weit in der Mehrzahl sind. ${ }^{373)}$ offensichtlich handelt es sich hier um Relikte von schwachtonigen Obliquusformen, die darauf hindeuten, daB der postpositive Artikel seine Formen außer aus "omu èllu-bunu auch aus einem " $\delta$ mu-ellu bezog. Wie sich dieses Syntagma zu dem oben angegebenen Protosystem verhält und welche Funktion es gehsbt haben kann, soll zum SchluB dieses Abschnitts (II. 3.b.) diskutiert werden.

Funktion: Das Nominalsystem

calu - calu bunu / kal - kal mirë nicht-identifiziert calu - calu ellu-bunu / kal - kal i-mirë identifiziert

war unsymmetrisch gebaut und deshalb für Veränderungen anfällig, die eine Symmetrie herzustellen suchten.

In der direkten Sequenz von übergeordnetem Substantiv und Attribut ergab sich die Sprecheinheit calu-ellu-bunu (alb. kal-i-mirë). Aus ihr murde aufgrund der Proportionalität von Oppositionen ein neues Glied für die Umbildung des obigen Sy- 
s tems gewonnen:

$$
\text { calu bunu : calu-ellu-bunu = calu : } x ; \underline{x}=\text { calu-ellu }
$$

In calu-*ellu 'das Pferd' liegt der kontextunabhängige Artikel vor, das Morphem, welches in primärer Funktion die Icientifizierung eines intendierten Gegenstandes mit dem inm zugeordneten Nomen bezeichnet.

Die Konsequenz aus der Entstehung des Artikels hät:e zu lauten, daß damit die zwischen dem Protoartikel und dem :hm folgenden Attribut bestehende funktionelle Verbindung zu existieren aufhört. Das Attribut bunu im Syntagma calu-ellu bunu unterscheidet sich nicht vom Attribut bunu im Syntagma calu bunu.

Ein nach der Evolution des Artikels konsequent durchgefüntes Nominalsystem hätte demnach die Form:

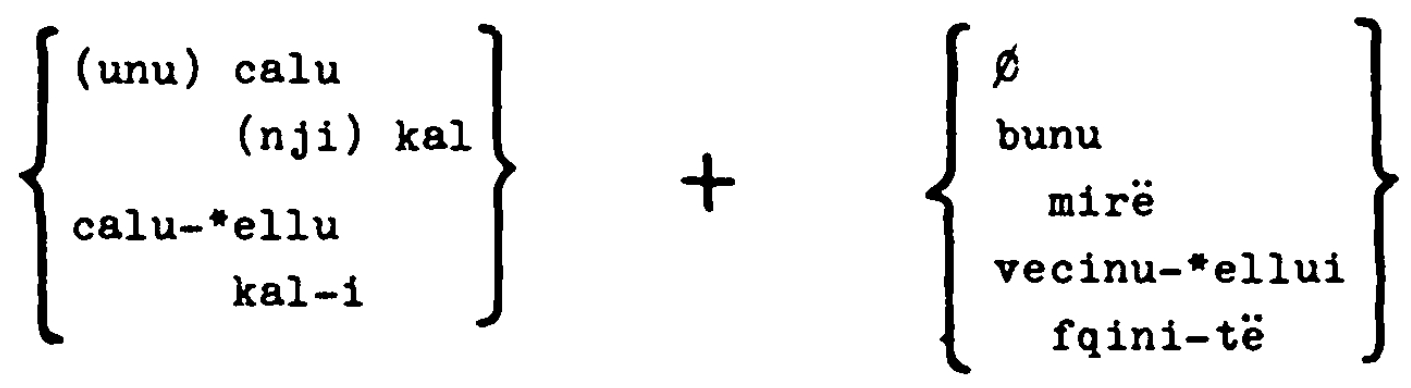

Daneben ist noch mit der Inversion (unu) bunu calu, (nji) mirë kal zu rechnen.

Dieses System ist indessen weder im Rum. noch im $k$ b. vollständig durchgeführt worden. Zwar heibt es rum. un cal, un cal bun, calul, calul bun, calul vecinului, alb. njl kal, kali

nach dem hier entwickelten System, jedoch finden sich davon abweichend

rum. un cal al vecinului, calul cel bun alb. nji kal $\underline{1}$ mirë, nji kal $\underline{1}$ fqinit, kali $\underline{1}$ mirë, kali $\underline{1}$ fqinit.

Diese Abweichungen sind durch die Verwendung präpositiver Artikel gekennzeichnet, die, wie unten zu zeigen ist, darauf 
zurückgehen, daß die rum. und $a l b$. Nominalsysteme nicht vollständig nach den aus der Bildung des kontextunabhängigen Artikels sich ergebenden Konsequenzen umgestal tet wurden.

Das Alter des attributsunabhängigen Artikels im Rum. (omu-lu < omu-*ellu) kann nur durch indirekte Uberlegungen erschlossen werden. Terminus ad quem ist das 10. Jhd., denn das bis zu dieser Zeit vom übrigen Rum. abgetrennte Arumunische (AR) zeigt Typ 1. wie auch das DR, Meglenorumänische (MR) und Istrorumänische (IR) als ein allen rum. Gruppen gemeinsames Merkmal. Coteanu nimmt für die Entstehung von Typ 1. das 8. Jhd. an, das in der Westromania als Beginn der Artikelverwendung gilt. 374) Da das rum. Artikelsystem jedoch einerseits mit dem Alb. und andererseits mit dem Bulg.-Mak. in der Zeit vor dem 10. Jhd. in Verbindung gesetzt werden kann, ist dieses Datum möglicherweise noch vorzuverlegen, vgl. Kap. II. 4.d.

Für das Alb. hat $N$. Jokl die Einwirkung eines postpositiven Artikels auf die phonetische Umgestaltung lat.-römischer Lehnwörter im Frühalb., also zu römischer Zeit, nachgewie$\operatorname{sen}^{375)}$ : *fõ-i > ftoi 'die Quitte', dagegen *ftõ > ftue 'Quitte' < lat. cotōneum, vgl. Kap. II.2. Dafür spricht auch die Parallelität zwischen dem altarmenischen und dem erschlossenen frühalb. dreigliedrigen Artikelsystem.

Die in der rum. Volkssprache seltene Voranstellung des adjektivischen Attributs (Inversion): bunul om ist nach omul bun modelliert. DaB die Artikelposition in der Inversion jünger ist, zeigen altrum. Fälle wie: cinstitą faţa Dumneavoastra ${ }^{376)}$ mit Postartikulierung des nachgestellten Substantivs vor folgendem Attribut. Die Inversion findet auch (selten) im Alb. statt. Dem rum. Muster entsprechen die alb. Relikte Shënt-i shpirt 'der Heilige Geist', Lúme-ja V1rgjinë 'Beata Virgo'; modern dagegen $\underline{i}$ miri kal, e mira vajzë 'das gute Mädchen'.

B. *alu ellu-bunu > $\begin{aligned} \text { calul cel bun (Typ 2.a.b.) } \\ \text { calul al doilea (Typ 3.c.) } \\ \text { bunul cal al meu (Typ 3.b.) }\end{aligned}$ 
Form: Die präpositiven Artikel des Adjektivs, der Ordnungszahl und des Possessivpronomens haben im Rum. und Alb. inr Morphem aus dem Protoartikel entwickelt, ebenso wie der postpositive Artikel des Substantivs. Im heutigen Rum. ähneln sich deshalb die Formen des postpositiven und der präpositiven Artikel, im Alb. sind sie sogar häufig noch identisch.

Für das Alb. traf diese Peststellung H. Pedersen. 377) Kasus, die vom Schema der Artikeldoppelung (vajzëв së mirë 'dem guten Mädchen', djali 1 mirë 'der gute Junge') abweichen, stellen entweder jüngere Veränderungen je nach der Position des Artikels (*tom, tam > të in der Präponierung, $>-\underline{n}$ in der Postponierung, * $j a>\underline{e}$ in der Präponierung, $>-\underline{a}$ in der Postponferung) oder auf Analogie beruhende Ersetzungen im Bereich des präpositiven Artikels dar: acc. sing. mask. fem. vajzën e mirë 'das gute Mädchen', vajzat e mira 'die guten Mădchen' (nom. acc. plur.), mit Eintreten von e für të. Die Ersetzung erfolgte nicht in der unterbrochenen Sequenz von Substantiv und Attribut, daher: acc. sing. fem. vajzën e mirë edhe të re 'das gute und junge Mädchen' < X-tam tam-Y edhe tam-2.

Im Rum. bildet *ellu den gemeinsamen historischen Nenner von postpositivem und präpositiven Artikeln. Die ältere Form für DR omul cel bun, calul cel bun lautet calul $\frac{a l}{78}$ bun, so noch in DR Mundarten, vgl. die Karte bei Puscariu $3 \frac{18}{17}$, im Altrum. gelegentlich auch al: \$1 i-am făcut această carte să-i fie peste cärfile ale bätrine ${ }^{379}$ ), wohl unter dem EinfluB des präpositiven Artikels bel substantivischen Attributen (al calului). Die dialektal erhaltenen Plural- und Obli-

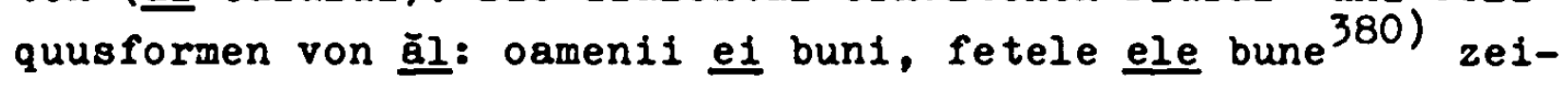
gen klar die Ableitung des ăl aus *ellu. Die modernen Plural-

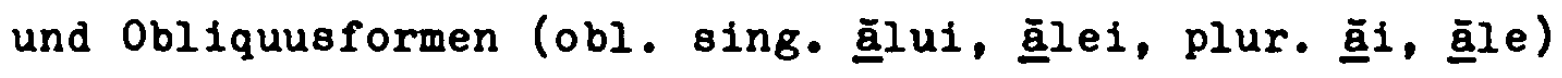
sind Analogiebildungen zu ăl und zum gleichlautenden Demonstrativpronomen. 381 ) Die Form cel ist eine Neubildung < *cce-illu382) mit Abfall des a- der volleren Demonstrativform acel. Das a- < ecce im absoluten Anlaut konnte vom rum. Spre- 
cher als deiktisches Element < lat. hāc oder als balkanisches deiktisches Element a- interpretiert (zu alb. a 8. Camaj383), und im präpositiven Artikel fortgelassen werden.

Da neben den Demonstrativpronomina acest, acel die volkssprachlichen DR Formen ăst, a् al (und nur im DR) vorkommen und die Verbindung calul ăl bun ebenfalls nur im DR registriert ist, erklärt Procopovici $3 \overline{84}$ ) das Demonstrativpronomen äl als Analogiebildung zum stets vorhandenen Par acest - äst: acest verhält sich zu acel wie àst zu $x ; \underline{x}=\ddot{a} l .385)$ Wegen der alb.

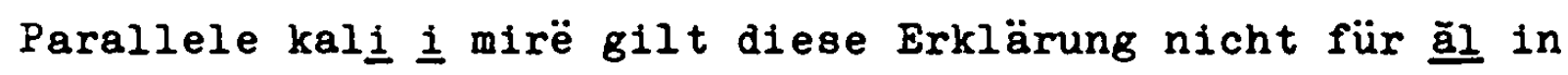
calul ăl bun; dieses wird direkt *ellu fortsetzen, zur Bil-

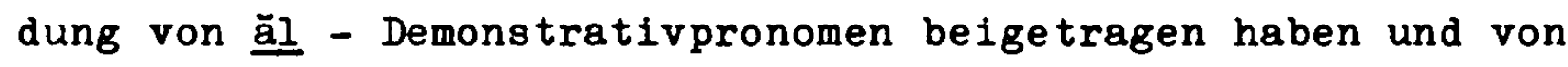
diesem Demonstrativpronomen im $D R$ in seiner Existenz neben calul cel bun erhalten worden sein, während aㅣ (präpositiver

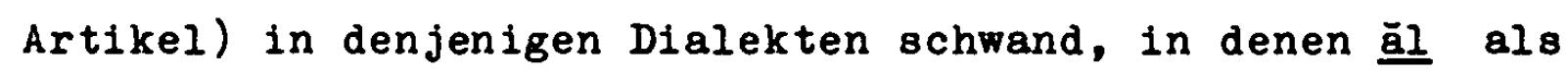
Demonstrativpronomen nicht neu gebildet wurde.

Funktion: In der Zeit vor der Entstehung des postpositiven Artikels wurde ein Substantiv calu formal identifiziert, wenn es mit einem Attribut *llu-bunu zusammentrat. Das Syntagma calu *llu-bunu murde realisiert als

$$
\text { calu-ellu-bunu }
$$

mit Zusammentreten der einzelnen Elemente zu einer Sprecheinheit. Dabei wurde calu durch den Protoartikel *ellu indirekt identifiziert (8.0.).

Aus der Opposition von calu-ellu-bunu 'das gute Pferd' zu calu-bunu 'ein gutes Pferd/gutes Pferd' entwickelte sich allmählich calu-*ellu 'das Pferd'. In dem Maße, wie es sich entwickelte, hätte es auch zu der Konsequenz calu-*ellu bunu führen müssen, wo calu durch den Artikel *ellu direkt identifiziert wird. Diese Konsequenz wurde jedoch dadurch behindert, dab das Syntagma calu-*ellu bunu unter Zusammentreten der einzelnen Elemente $z u$ einer Sprecheinheit $z u$ realisieren war als

$$
\text { calu-ellu-bunu. }
$$


Das bedeutet: Während calu-*ellu 'das Pferd' immer mehr zu einem Element des Sprachsystems wurde, konnte es in der Zusammenstellung mit einem Attribut nicht von calu *ellu-, konnte der direkt identifizierende Artikel nicht vom indirekt identifizierenden Protoartikel unterschieden werden, denn die Realisationen beider Konstruktionen waren gleich: calu-ellu-bunu stellte die Kontinuität zwischen dem älteren Nominalsystem mit Protoartikel und dem jüngeren mit Artikel her. Die Konkurrenz läBt sich graphisch darstellen als:

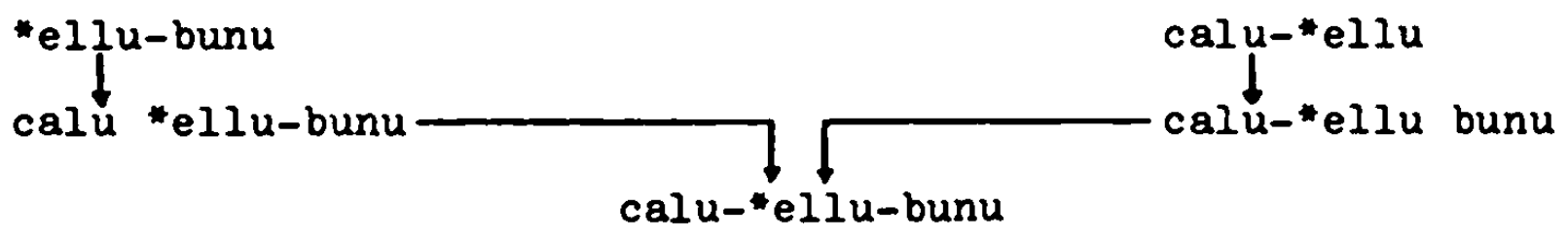

Auch für die Konstruktion des Attributs in unterb́rochener Sequenz Substantiv-Attribut ergab sich keine Differenzierung. Hier lautete die ältere Konstruktion mit Protoartikel:

* calu ellu-(bunu gi frumosu) 'das gute und schöne Pferd' * calu ellu-(bunu vecinu) 'das gute Pferd des/eines Nachbarr.

Entsprechend ergab sich für die Artikelkonstruktion:

$$
\begin{aligned}
& \text { calu-"ellu (bunu gi frumosu) } \\
& \text { calu-"ellu (bunu vecinu) }
\end{aligned}
$$

Hieder verbarg die sprachliche Realisierung calu-*ellu-bunu 81 frumosu, calu-*ellu-bunu vecinu den Onterschied in der Funktion der beiden Artikel.

Die Nichtunterscheidung von Artikel und Protoartikel hat zur Voraussetzung, daB beide phonetisch noch nicht differenziert waren (rum. "ellu, alb. i), sie bewirkte, dab die Evolution des Artikels in Verbindung mit Attributen und damit die Durchsetzung des Artikels überhaupt verzögert wurde. Das Syntagma von Substantiv und abhängigem Attribut calu-*ellu-bunu konnte weiterhin zu calu + *ellu-bunu analysiert werden und damit die Existenz des Protoartikels stützen. Eine Bestätigung für die konkurrierende Existenz des 
Artikels und des Protoartikels im Prührum. und Frühalb. erblicke ich darin, daß der postpositive Artikel den präpositiven (< Protoartikel) z.T. bis heute in einer Teilfunktion des Protoartikels nicht abgelöst hat, die gewöhnlich in den Bereich des postpositiven Artikels gehört. Die primäre Funktion des Protoartikels bestand darin, das inm folgende Attribut als irgendeinem $z u$ identifizierenden Substantiv untergeordnet zu kennzeichnen (s.0.). Bei Ellipse des übergeordneten Substantivs erhält man:

$\begin{array}{lll}\text { *ellu-bunu } & \text { *i-mirë } & \text { 'der Gute' } \\ \text { *ellu-vecinu } & \text { *i-fqini } & \begin{array}{l}\text { 'der dem Nachbarn } \\ \text { Zugehörige' }\end{array} \\ \text { *ellu-meu } & \text { *i-më } & \text { 'der Meinige' } \\ \text { *ellu-doile } & \text { *i-dytë } & \text { 'der 2weite' }\end{array}$

Das übergeordnete, identifizierte Substantiv erscheint hier durch den Protoartikel vertreten, was im Deutschen nur im Palle eines substantivischen Attributs sichtbar wird: 'der des Nachbarn'. Ein adjektivisches oder pronominales Attribut läßt sich dagegen an die stelle des fehlenden übergeordneten Substantivs setzen, so daß sich eine 'Substantivierung' des Adjektivs oder des Pronomens ergibt, dieses 'Substantiv' ist formal durch den Protoartikel identifiziert. Die Identifizierung ist für den Hörer entweder eine postulierte, wenn ihm der intendierte Gegenstand nicht bekannt ist, und bezeichnet potentiell alle möglichen Gegenstände: *ellu-bunu 'der Gute' (generell), oder sie ist eine kontextspezifizierte, wenn die Bekanntschaft mit dem intendierten Gegenstand durch den $2 u-$ sammenhang vermittelt wird: *ellu-bunu 'der Gute' (individuell).

Der postpositive Artikel hätte die elliptischen Konstruktionen verändern müssen $z u$

\begin{tabular}{|c|c|}
\hline *bunu-ellu & $*_{\operatorname{mir}-1}$ \\
\hline *case-ellu 'der des Hauses' & *fqini-i 'der des Nachbarn' \\
\hline *meu-ellu & ${ }^{*} \mathrm{~m}-\mathbf{i}$ \\
\hline *doile-ellu & $\star d y t-i$ \\
\hline
\end{tabular}


Jedoch zeigen das moderne Rum. und $A l b$., daB bei Ellipse des übergeordneten Substantivs die Ersetzung des präpositiven Protoartikels durch den postpositiven Artikel nicht überall und sofort durchgeführt wurde.

Das Rum. kennt zwei Möglichkeiten, ein Adjektiv zu substantivieren: bolnavul und cel bolnav 'der Kranke'. Dabei bezeichnet cel bolnav den Kranken generell 386$)$, formal iat es eine Portsetzung von "ellu-bunu. Dagegen meint bolnavul einen bestimmten Kranken, es stellt die jüngere elliptische Konstruktion bunu-ellu dar. Im Altrum. erscheinen Kontaminationen beider Konstruktionen: cel marele 'der Große.387). - Im Alb. ist die substantivierende Wirkung des präpositiven Artikels dadurch aufgehoben worden, dab er vor jedem Adjektiv verallgemeinert wurde. Altes "i-mirë 'der Gute' wurde überführt in 1 miri, mit zusätzlicher Verwendung des postpositiven Artikels des Substantivs. Jedoch finden sich Fälle wie 1 bregas 'der Küstenbewohner' (alb. breg), italo-alb. i Arbërésh 'der Albaner 388$)$, wo der Artikel vor alten Partizipia bzw. Adjektiva steht. Ferner gehören hierher die Relikte tëmbël 'das SüBe' (> 'Milch') < të ëmbël, modern 1 ëmbël 'süß'; terrtë 'die Finsternis'< të errtë, modern 1 errët 'finster'389). Vgl. auch modern $n j i$ tjetër 'ein anderer', tjetri 'der andere', wo der präpositive Artikel zum Stamn gezogen worden ist. Ursprüglich lautete die Opposition të jetër 'der andere' -

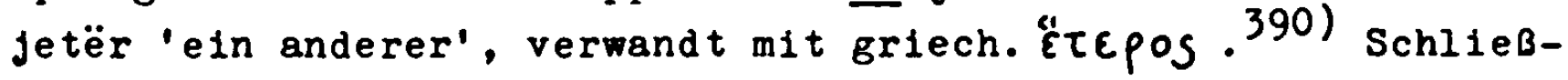
lich stelle ich hierzu alb. Adjektiva mit präpositivem Artikel, die vor dem 8. Jhd. ins Rum. übernommen wurden 391): rum. clut 'odnorogif' < alb. të shut, farc 'zimnij zagon dlja skota' < të thark, fupatä 'großes Beil' < të sëpatë (ohne den Artikel wäre das rum. Ergebnis "giut, "sarc, "supatā gewesen). 392)

Zur Porm des substantivischen Attributs bei Ellipse des übergeordneten Substantiva im Rum. vgl. das obenerwähnte al dracului 'der des Teufels'.

Das rum. 只 meu 'der Meinige' setzt "ellu-meu fort. Ein *meu-ellu iat nicht entwickelt worden. Während al meu, al dra- 
cului im Kontext (un cal al meu, un prieten al dracului) von der Bezeichnung der Identifizierung losgelöst sind, tritt in der elliptischen Verwendung ihre Identifizierung wieder hervor. - Die Form des alb. Possessivpronomens zeigt, daß es früher ebenfalls substantivisch gebraucht wurde: im 'mein' < i-më, yt 'dein' < y-të, ynë 'unser' < y-në, juaj (juej) 'euer' < jo-u. In dem deiktischen Element ist der Artikel zu erkennen, in der jüngeren Lautung $\underline{1}$, e oder in der $\ddot{l} l-$ teren $y$, jo. 393) Damit standen sich anfangs gegenüber:

*më at 'mein Vater' (wie "mirë kal 'ein gutes Pferd')

*i-më 'der Meinige' (wie *i-mirë 'der Gute')

*kal i-më 'mein Pferd' (wie *kal 1-mirë 'das gute Pferd'), das letztere, wohl eine Neuerung, mit Verknüpfung der Verwendung des Possessivpronomens mit der formalen Identifizierung. Wie kal i-mirë zu kali i mirë, entwickelte sich *kal i-më zu kali im und sogar, da der Protoartikel in dem Morphem des Pronomens nicht mehr erkannt wurde, zu (gegisch) kali i em. Der Veränderung *i-mirë 'der Gute' zu 1 miri entspricht die Veränderung *i-më 'der Meinige' zu 1 imi. Im Falle der älteren Verwandtschaftsbezeichnungen wurde im aus der Postposition in die Voranstellung gehoben: im at. Der Grund dafür wird sein, daB sich in Verbindung mit Verwand tschaf tsbezeichnungen die Voranstellung des Possessivpronomens am stärksten hielt. Seit der türkischen Periode ist diese Stellung des Pronomens nicht mehr produktiv: gegenüber im at heiBt es baba-i im 'mein Vater', hierbei ist baba türkisches Lehnwort. ${ }^{394)}$

Auch für die Ordinalia rum. al dollea, alb. I dytë ' 2 weiter' ist eine ursprüngliche Opposition dytë 'ein Zweiter' - $i$ dytë 'der Zweite' anzunehmen. (Das rum. Element -lein doilea stellt eine Replik zu alb. -të in dytë dar, wobei das Wortbildungselement des Alb. als Artikel miBverstanden wurde.) Heute ist der präpositive Artikel zum Kennzeichen einer jeden Ordnungszahl geworden, daher auch rum. un al doilea 'ein 2 weiter', alb. nji $i$ dytë. 
Die lautliche Entwicklung von *ellu-meu, *ellu-doiim Rum. zu al meu, al doilea erklärt sich aus der Häufigkeit inrer Realisierung mit Ellipse des übergeordneten Substantivs, wodurch sie in den absoluten Anlaut (e $>$ a) gerieten, vgl. DR aci, AR a tsia ( lat. eccum hic. ${ }^{395)}$ Dagegen hat das substantivierte Adjektiv cel aus der Position calul cel bun für älteres calul àl bun übernommen.

DR cel bolnav, al dracului, al meu, alb. i bregas, 1 Arbërésh sprechen wegen ihrer Porm und Funktion, DR al doilea, alb. tëmbël, tjetër, im, 1 dytë zumindest wegen ihrer Form dafür, daB der Protoartikel in der elliptischen Konstruktion *ellu-bunu, *i-mirë mit der Entstehung des postpositiven Artikels nicht durch konsequente Umformung $z u$ *bunu-ellu, *mir-i verschwand.

In einem System calu-*ellu / calu-*ellu-bunu / *ellu-bunu, alb. kal-i / kal-i-mirë / i-mirë konnten calu-*ellu-bunu, kal-i-mirë als *calu ellu-bunu, *kal i-mirë (Protoartikel) oder als calu-*ellu bunu, kal-i mirë (Artikel) interpretiert werden, wobei die jüngere Interpretation in dem MaBe häufiger wurde, wie sich das kontextunabhängige calu-*ellu als systematisches Element verfestigte. Ein solches Nebeneinander von älterer und jüngerer Interpretation des attributhaltigen Syntagmas bei gleichlautendem Artikel und Protoartikel bewahrte das Alb. lange in den Kasus, in denen der postpositive und der präpositive Artikel nicht phonetisch differenziert wurden. Lediglich die 'Substantivierung' des elliptischen Attributs ist in eine obligatorische Attributsignalisierung überführt worden. Die jeweilige Interpretation tritt hervor, wenn der Schreiber das Syntagma in einzelne Worte gliedern muBte:

mal $\underline{i}$ 'der Berg'

nuse $\underline{8}$ mal $\underline{i}$ lartë 'der hohe Berg' $\underline{i}$ lartë
(ältere Interpretation)

nuse旦 bukur

'der schönen jungen Prau' $\underline{\text { së bukur }}$

(jüngere In- 396$)$
terpretation) 


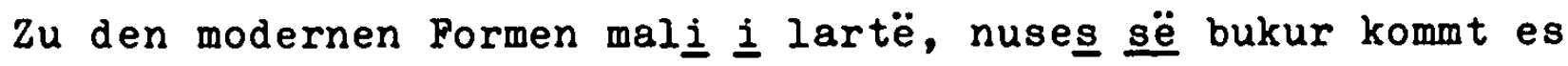
in diesen Kasus erst unter dem EinfluB der Grammatiker im 19. Jhd.

Die phonetische Differenzierung von postpositivem und präpositivem Artikel, die im Rum. in allen Kasus, im Alb. in einigen Kasus eintrat (rum. postpositives *llu> $>l l u>I u>$ I, präpositives *ellu > ălu oder alu > ăl oder all), veränderte das durch die Koexistenz von Protoartikel und Artikel gekennzeichnete Nominalsystem, wobei das attributhaltige Syntagma nach beiden Interpretationen aufgelöst und der Artikel seiner jeweiligen Position entsprechend phonetisch weiterentwickelt werden konnte:

ăl bun

cal āl bun (şi frumos)

calulul bun (ร̧i frumos)

cal āl bun (vecinului)

calul bun (vecinului)

Ein cal ăl bun bedeutete weiterhin 'das gute Pferd', die indirekte Identifizierung des Protoartikels blieb erhalten. Darauf weisen das schon erwähnte rum. tatăl ceresc 'der himmlische Vater' < tatä ăl ceresc neben tata < tatā-(II)a sowie alb. Relikte wie njerl $\underline{i}$ mirë 'der gute Mensch', vajz e mbretit 'die Tochter des Königs'397) hin. Hier sind i mirë. e mbretit aus der Position vor dem Attribut entwickelt worden, die jüngere Interpretation (kal-i mirë) hätte zu vajza mbretit (ebenfalls belegt) und *njeriu mirë geführt. Ein *njerí-u mirë wäre die obligatorische fortsetzung von *njerl- gewesen, denn in einer relativ späten Zeit wurde nach betonten Vokalen und Gutturalkonsonanten der Artikel i durch den Artikel u ersetzt, um eine Palatalisierung der Gutturale

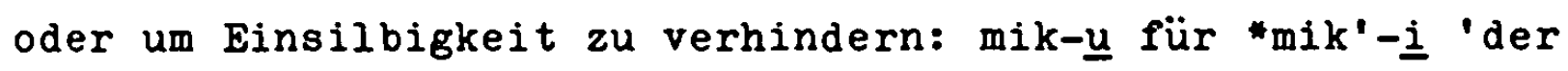
Freund', da schon der indeterminierte Plural miq < *mik' $i$ Lautete, und shi-u彑 für shi-i 'der Regen', da Kontraktion zu ih $\bar{I}$ eintrat und Gleichlautung mit dem indeterminierten Sinular die Folge war. Aus der Tatsache, daB im Alb. ein *njerlu 
mirë nicht existiert, muß geschlossen werden, daB der Artikel 1 nur dann von $\underline{u}$ ersetzt wurde, wenn schon der 'gedoppelte' Artikel (s.u.) "njerl-1 1 mirë vorlag, aus diesem Grunde blieb auch njerl i mirë erhalten. - Die modernen Entsprechungen für vajz e mbretit, njerl $i$ mirë lauten vajza e mbretit, njerlu i mirë.

Das Nebeneinander von cal àl bun si frumos und calul bun si frumes hat Konsequenzen für die Konstruktion des Attributs in der unterbrochenen Sequenz von Substantiv und abhängigem Attribut:

cal àl bun şi frumos / cal āl bun vecinului

cal all bun gi all frumos / cal ăl bun al vecinului

Die Neuerung entsteht durch eine Gleichsetzung der Attribute bun und àl bun in Opposition zum nicht-identifizierten (un) cal bun in der direkten Sequenz von Substantiv und Attribut und anschlieBende Ausdehnung der Gleichsetzung auf die Attribute in unterbrochener Sequenz:

bun : frumos $=\bar{a} l$ bun $: x ; \underline{x}=\bar{l}$ frumos

Dam1t standen für die Bezeichnung der Identifiziertheit die folgenden Konstruktionen zur Verfügung:

1. calul

2. calul bun gi frumos calul bun vecinului

3. cal ăl bun g̨i āl frumos cal äl bun al vecinului kali

kali mirë e bukur

kali mirë fqinit

kal 1 mirë e $i$ bukur

kal i mirë i fqinit

In der Konstruktion (3) besteht ein Unterschied zwischen der Punktion des präpositiven Artikels des Attributs in direkter Sequenz und der des präpositiven Artikels in unterbrochener Sequenz. Nach unserer Definition kennzelchnete der Protoartikel, dab das inm folgende Attribut einem zu identifizierenden Nomen untergeordnet ist, d.h. er vermittelte die Informationen

1. es folgt ein Attribut,

2. dieses ist einem identifizierten Nomen untergeordnet. 
Pür die 2 weiterwähnung des präpositiven Artikels in cal āl bun şi ăl frumos ist die zweite Information redundant, da schon durch die Ersterwähnung des Artikels gegeben; entsprechend wird die Information 'Attribut folgt' wichtiger. Der in unterbrochener Sequenz gesetzte präpositive Artikel leitet die Ubernahme der Attributsignalisierung ein, wie sie heute im Rum. und Alb. besteht.

Nach der phonetischen Differenzierung des postpositiven vom präpositiven Artikel hatte der präpositive Artikel die Pähigkeit verloren, scheinbar auch in das Oppositionssystem des postpositiven Artikels zu passen (calu-*ellu / calu-*ellu-bunu / *ellu-bunu). Deshalb stand cal ăl bun isoliert im Nominalsystem, anders als calul bun:
cal
calul
cal bun
calul bun / cal āl bun

Das Ergebnis war die Ersetzung von cal ăl bun durch das funktionsgleiche calul bun. Der Wechsel von àl bun mit -ul bun ist in der rum. Volkssprache noch möglich, obwohl die Funktionen beider Artikel hier nicht mehr identisch sind: acestul om $\bar{a} l$ bun > acestul omul bun, o sorā a lui > o sor'a lui. 398) Dargegen konnte das immer stärker attributsignalisierend wirkende cal āl bun $\beta^{i} \underline{a l}$ frumos, cal ăl bun al vecinului durch den postpositiven Artikel nicht ersetzt werden. Aus der Ablösung von cal ăl bun in direkter Sequenz durch calul bun ergaben sich deshalb die alternativen Konstruktionen:

1. calul bun si frumos
2. calul bun si âl frumos

AuBer der Ersetzung von cal àl bun durch calul bun bestand noch die Möglichkeit, in die sich als unsystematisch erweisende Konstruktion den postpositiven Artikel einzuführen und dadurch eine Ableitbarkeit von calul herzustellen:

3. calul ăl bun $g^{i}$ al frumos

Diese Konstruktion konnte verwendet werden, wenn es dem Spre- 
cher auf eine Gleichbehandlung aller Attribute, gleich in welcher Sequenz, ankam: der Unterschied in der Behandlung der Attribute in calul bun $s i$ al frumos wurde damit umgangen. Die Beibehaltung (wenn aus cal ăl bun) oder Neusetzung eines präpositiven Artikels des Attributs in direkter Sequenz (wenn aus calul bun) ist daher auf das Einwirken des in unterbrochener Sequenz möglichen präpositiven Artikels des Attributs zurückzuführen.

Veranschaulichen läbt sich diese Entwicklung durch eine z.T. künstliche Parallele im Alb. Während in den Kasus mit unterschiedlichem Morphem des postpositiven und des präpositiven Artikels (acc. mal-në e lartë) die Doppelsetzung ein hohes Alter hat, wie auch im Rum., hat sich in den Kasus mit gleichem Morphem beider Artikel ein mal-i-lartë mit den Realisationen mali lartë oder mal i lartë lange halten können. Vor allem, um die Form des Attributs konstant zu halten, hat die normative Grammatik die Form des Attributs in unterbrochener Sequenz (... i bukur) in die direkte Sequenz eingeführt: mali 1 lartë.

In der Konstruktion calul äl bun $i$ kali 1 mirë e 1 bukur 1st die in der Bildung von cal ăl bun (1) 互 frumos einsetzende Umwandlung des indirekt das übergeordnete Substantiv identifizierenden Protoartikels in den attributsignalisierenden präpositiven Artikel abgeschlossen, die Identifizierung wird direkt durch den postpositiven Artikel des übergeordneten Substantivs bezeichnet. Da der präpositive Artikel nun nicht mehr mit der Identifizierung des vorangehenden Substantivs verbunden ist, spricht prinzipiell nichts dagegen, ihn auch nach nicht-identifizierten Substantiva zur Signalisierung von Attributen zu verwenden. Die Grenze zwischen dem Protoartikel und dem inn fortsetzenden präpositiven Artikel des Attributs wird markiert durch den Portfall der (indirekten) Identifizierung und die zunehmende Ubernahme der Attributsignalisierung zuerst in unterbrochener, später auch in direkter Sequenz zum übergeordneten Sub- 
stantiv, womit dieser Artikel aufhört, ein 'Artikel' im Sinne der in dieser Untersuchung verwendeten Terminologie zu sein. - Dagegen ist die phonetische Differenzierung zwischen dem postpositiven Artikel und dem präpositiven Protoartikel nicht Voraussetzung und Kennzeichen für die Entstehung des modernen präpositiven Artikels, vgl. alb. kali $\underline{1}$ mirë. - Lediglich in den elliptischen Konstruktionen cel bolnav, al meu sowie in alb. Relikten ist die indirekt identifizierende Wirkung des präpositiven Artikels (> Substantivierung) noch erkennbar, in rum. al doilea, alb. 1 mirë, $i$ dytë, im ist dafür die obligatorische Attributsignalisierung eingetreten.

Der Unterschied $z$ wischen den Konstruktionen calul bun si frumos, calul bun gi ăl frumos, calul ăl bun gi ăl frumos (entsprechend alb. kali mirë e bukur, kali mirë e $i$ bukur, kali $i$ mirë e $i$ bukur) besteht in der Nicht-Signalisierung bzw. Signalisierung des Attributs durch ein zusätzliches Morphem. $D a B$ ein solches verwendet wurde, findet seine Erklärung in der Theorie vom balkanischen Sprachenkontakt. Häufig diente eine der Balkansprachen auch Sprechern einer anderen Sprache als Verkehrsmittel oder wurde zur Verständigung mit solchen verwendet. Dabei war die Verkehrssprache den Anderssprachigen häufig nur partiell bekannt. In diesem Pall lieb sich die Verständlichkeit der Verkehrssprache durch morphosyntaktischen Pleonasmus, durch Wiederholung einer bestimmten Information mit morphologischen oder syntaktischen Mitteln erhöhen. Gerade die Vielzahl der balkanischen Artikel zeichnet sich durch pleonastische Verwendung aus. 399) In diesem Sinne ist die Signalisierung des Attributs als ein Mittel zu betrachten, durch das, zusätzlich zur morphologischen Porm des Attributs, die Unterordnung des betreffenden Nomens unter ein anderes Nomen klargestellt und damit die grammatische Hierarchie zwischen den beiden Nomina vor Pehlinterpretationen Beschützt wird. Das Bestreben, die Anwendung von Nicht-Signalisierung und Signalisierung systematisch gegeneinander abzugrenzen und an bestimmte kontextuelle Bedingungen zu knüp- 
fen, hat im Rum. und Alb. zu unterschiedlichen Ergebnissen geführt.

Im modernen Rum. zeigt die Verteilung von attributivem bun / cel bun (<ăl bun) noch die historische Verknüpfung des präpositiven Artikels des Attributs mit der formalen Identifizierung des übergeordneten Substantivs: ein adjektivisches Attribut kann nur nach einem identifizierten Substantiv signalisiert werden. Deshalb heibt es: o expunere utila gi bine informatā 'eine nützliche und gut informierte Darlegung', ohne Verwendung des präpositiven Artikels in direkter oder unterbrochener Sequenz. Von dieser Regelung weicht auch das Altrum. (16. Jhd.) nicht ab.

Nach einem postartikulierten Substantiv ist im modernen Rum. für das abhängige Attribut die Konstruktion (1) calul bun $i$ frumos aufgegeben worden, sofern es sich um ein adjektivisches oder pronominales Attribut handelt. Im Gebrauch sind (2) calul bun si al frumos und ( 3 ) calul ăl bun si ăl

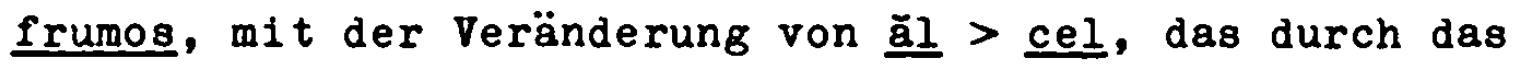
deiktische Element $-\bar{a}$ erweitert werden konnte: cela bun (besonders im Altrum. ${ }^{400}$ ), MR fela bun ${ }^{401}$ ). Jedoch wird (3) nur fakul tativ verwendet und ist auf dem Rückzug vor (2). Für die Konstruktion des adjektivischen und des pronominalen Attributs nach einem postartikulierten Substantiv hat sich deshalb calul bun i cel frumos als maBgeblich durchgesetzt:

expunerea utilă §i cea bine informată

'die nützliche und gut informierte Darstellung'

Der bei der Beschreibung des modernen Artikelgebrauchs im Rum. festgestellte synchronische Wechsel von postpositivem und präpositivem Artikel in der Signalisierung des Attributs (codul civil gi cel penal, ebenso calul vecinului neben bunul cal al vecinului) ist als Ergebnis der Ablösung von cal ăl bun 'das gute Pferd' durch calul bun zu betrachten. In cal ăl bun wurde das Attribut in jeder Position (vgl. ... ga ăl frumos) durch einen präpositiven Artikel signalisiert, von denen der erste das übergeordnete Substantiv auch identifi- 
zierte. Im konkurrierenden calul bun ( 81 frumos) fehlte dagegen jede Verbindung zwischen dem postpositiven Artikel und den folgenden Attributen, vgl. das nicht-identifizierte (un) cal bun gi frumos. Das ältere cal bl bun übergab an das ablösende füngere calul bun auBer der Identifizierungsfunktion auch die Attributsignalisierung, was in der unterbrochenen Sequenz deutlich wird: calul bun 1 al frumos. Das Vorhandensein eines präpositiven Artikels in der unterbrochenen Sequenz trug im folgenden zu der Auffassung bei, daB der postpositive Artikel des Substantivs das untergeordnete Attribut in direkter Sequenz ebenfalls signalisiere. Die Attributsignalisierung ist durch den postpositiven Artikel also erst sekundär wiedergewonnen worden. Der historische Stammbaum der Konstruktion calul bun gi cel frumos hat die Form:

\section{calul bun gi cel frumos}

cal ăl bun gi àl frumos

cal àl bun si frumoe

calu ellu-bunu gi frumosu $\longrightarrow$ calu-ellu bunu gi frumosu

Die moderne DR Regelung ist im Altrum. (16. Jhd.) noch nicht konsequent durchgeführt. Die Konstruktion (1) calul bun gi frumos konkurriert noch mit (2) calul bun gi al frumos und (3) calul àl bun şi àl frumos, vgl, sufletul tău čel bun, dzeul tare gi viu, duhul tău dulč $e^{402)}$, domnul čels tarele, loculb čela frumosulb, sluğile čelia bunele, domnulb čelb tare. ${ }^{403)}$ Wie die Beispiele zeigen, erscheint im Altrum. in der Konstruktion (3) meist eine pleonastische Postartikulierung des adjektivischen Attributs. Diese erklärt sich aus dem EinfluB der Attribute mit Ellipse des übergeordneten Substantivs, die im Altrum. aus *ellu-bunu und bunu-*ellu kontaminiert werden konnten zu *ellu-bunu-*ellu > cel bunul 'der Gute' und dann zum Nebeneinander von calul cel bun und calul 
cel bunul führten. Reste der pleonastischen Postartikulierung finden sich in den rum. Dialekten und im Alb.: kij është $i$ biri im 1 dashurí 'das ist mein geliebter Sohn'.404)

Im 시․ zeigen Reliktfälle wie: Shënti shpirt 'der Heilige Geist' (in der Kirchensprache), Llimeja Virgjinë 'Beata Virgo' (bei Bogdani), në një _ vogël katúnd 'in einem kleinen Dorf' (Attika), _ bukur kopil'e 'ein schönes Mädchen.405) sowie das obenerwähnte nuses _ bukur, daß die Präartikulierung des Adjektivs (in direkter Sequenz und alleinstehend) früher nicht wie heute obligatorisch war (Konstruktion 2: kali mirë e $i$ bukur). Jedoch hat schon in der Konstruktion (2) der präpositive oder postpositive Artikel dadurch eine besondere Beziehung zum folgenden Nomen, als er dessen syntaktisch bedingten Kasusausdruck übernimmt. Soweit es sich dabei um den postpositiven Artikel handelt (nuses bukur für nuses bukure), beweist auch das Alb. die Beeinflussung von kali mirë (rum. calul bun) durch das abgelöste kal 1 mirë (rum. cal ăl bun), welches dem postpositiven Artikel die Beziehung zum folgenden Nomen zurückgab.

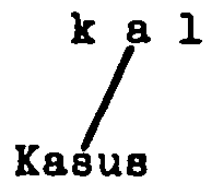

$/_{\text {Kasus }}^{k} a^{1}$

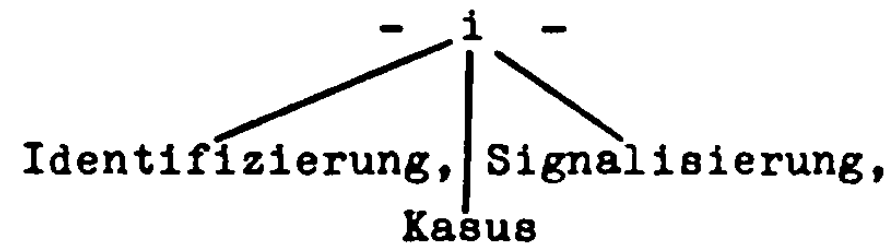

murde verändert zu m

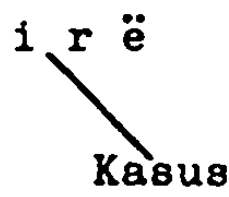

m $i r \ddot{e}$

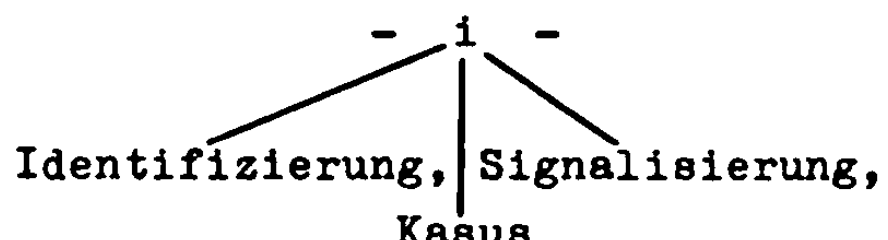

$\underline{\text { Kasus }}$

Der Grund für die generelle Durchsetzung der Konstruktion (3) kali i mirë im Alb. ist darin zu erblicken, daB in unterbrochener Sequenz (kalı 1 mirë e 1 bukur) der präpositive Artikel keine Identifizierung ausdrückte und dadurch eindeutig 
als Kasusmorphem des folgenden Adjektivs funktionierte, dieser Gebrauch wurde auf andere Sequenzen ausgedehnt. In der direkten Sequenz ergibt sich dadurch eine klare Zuordnung der Identifizierung an den postpositiven und der Kasusangabe an den präpositiven Artikel:
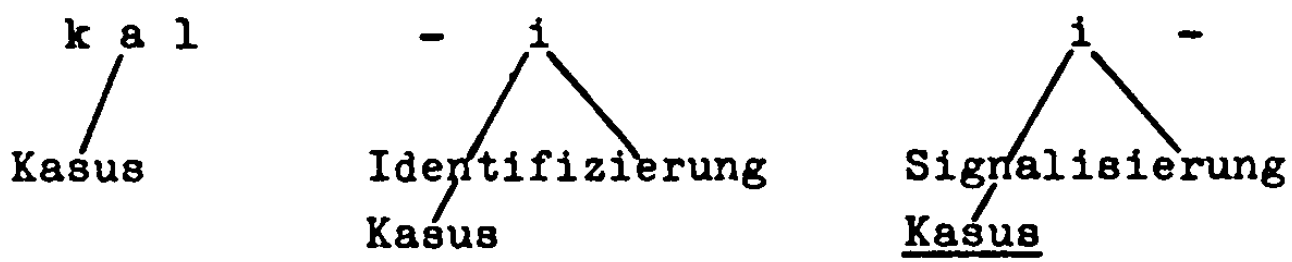

m 1 I $\ddot{e}$

Der präpositive Artikel funktioniert als Kasusmorphem des inm folgenden, nicht mehr synthetisch kasusflektierten Adjektivs, das sich nur nach Genus und Numerus verändert: (nom.) kali 1 mirë - (obl.) kalit të mirë < të miri. Vgl. Kap. III. 2. Die Präartikulierung des Adjektivs in unterbrochener Sequenz zu einem identifizierten Substantiv wurde auch auf Adjektive nach nicht-identifizierten Substantiva und auf die Inversion ausgedehnt: $n j i$ kal 1 mirë, 1 miri kal.

Der Vergleich der Relikte Shënti shpirt, Lúmeja Virgjinë, një vogël kathnd, bukur kopil'e mit dem modernen shpirti $\underline{1}$ shënt, virgjina e lume, një katund e vogël, një kopil'e e bukur zeigt, daB durch die Generalisierung der Präartikulation infolge inrer Kasusfunktion das Adjektiv aus einer möglichen Voranstellung in eine Nachstellung zum Substantiv gezwungen wurde. Die im Vergleich zur mum. Volkssprache noch rigorosere Postposition des Adjektivs beim Substantiv im Alb. 406) erklärt sich dadurch, daB $j e d e$ Adjektiv in die Sequenz der ursprünglichen Konstruktion *kal 1-mirë trat. Von hier aus murde der präpositive Artikel in die seltenen Fälle von Voranstellung des Adjektivs transportiert.

Die Ergebnisse der hier angestellten Untersuchungen widersprechen der neuerdings nicht selten geäußerten Ansicht, "die Enklise habe im Rumänischen die Proklise bewirkt" $\overline{(\text { Coteanu }}{ }^{407)}$; ähnlich Piotrovskij408), E. Cabej $\left.{ }^{409)}\right)$, dieses Urteil gilt höchstens für den Einzelfall der Umformung von 
calul bun, kalimirë zu calul ăl bun, kali i mirë unter dem BinfluB von cal ăl bun $8 \dot{i} \overline{a l}$ frumos, kal $i$ mirë e $i$ bukur und auch da nur im metaphorischen sinne, denn der präpositive Artikel in calul āl bun setzt ja den präpositiven Artikel von cal ăl bun sil ăl frumos fort, dieser seinerseits geht funktionell und formal direkt auf den Protoartikel (calu) *ellu-bunu zurück.

Auch die feststellbare historische Formengleichheit von präpositivem und postpositivem Artikel erklärt sich $n i c h t$ durch eine Verdoppelung des postpositiven Artikels, wodurch erst ein präpositiver Artikel beim Adjektiv entstanden wäre; die Formengleichheit muB m.s. 80 interpretiert werden, daB der postpositive und der präpositive Artikel von $e i n$ e , ursprünglich präpositiven Artikel des Attributs mit indirekt identifizierender Punktion abgeleitet wurden:

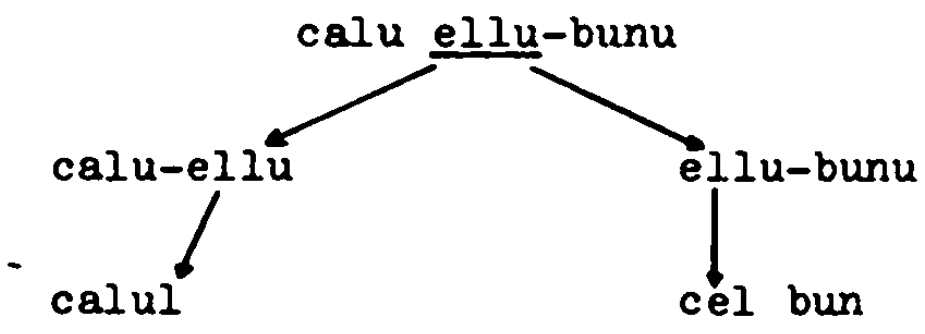

Der Hinweis Cabejs auf das relativ geringe Alter der obligatorischen Präartikulierung des Adjektivs im Alb. darf nicht 80 verstanden werden, daB der präpositive Artikel mit dieser Obligatsetzung erst entstand, es handelt sich nur um seine Entlassung aus der indirekten Identifizierung (in Fällen wie kal $\underline{i}$ mirë) und um die systematisierung seiner pleonastischen Attributsignalisierung. Çabejs Argument, die Ungebundenheit des präpositiven $\underline{i}$ in $\underline{i}$ mirë, $\underline{i}$ malit spreche dafür, das Alter der syntaktischen Verbindung in mal-i 'der

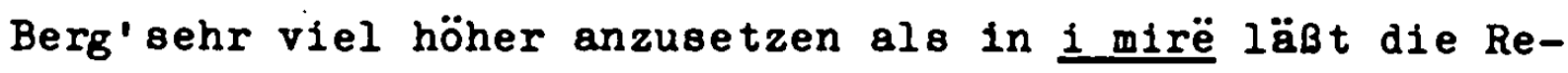
likte Im, tjetër, tëmbël usf. auBer acht; zudem führt die Position eines Pronomens nach einem Nomen häufiger zu einer Bchlieblich auch morphologischen Koppelung beider (durch die Flexion des Nomens), als wenn es dem Nomen vorausgeht. $V_{g l}$. 
aksl. nova-jego > novaago > novago.

In der Abänderung der zitierten Ansicht, die Enklise habe die Proklise bewirkt, möchte ich als Ergebnis meiner Untersuchungen formulieren: Die Proklise hat im Rumänischen und Albanischen die Enklise bewirkt, hat sich, mit dieser konkurrierend, neben ihr erhalten und 1st heute mit ihr zu einem geregelten Nebeneinander durch Funktionsaufteilung gelangt.

Ich kann Coteanu auch darin nicht zustimmen, daB der präpositive Artikel des Adjektivs jünger sei als der des substantivischen Attributs, da ersterer nur im DR und MR, letzterer dagegen im $D R, A R$, IR existiert. ${ }^{410)}$ Beide präpositiven Artikel gehen auf (calu) *ellu-bunu, (calu) *ellu-vecinu, d.h. auf den Protoartikel zurück, beide sind zumindest ebenso alt wie der postpositive Artikel. Ihr Vorhandensein oder Pehlen in den großen rum. Dialekten ist das Ergebnis der Umgestaltung des Artikelsystems, nachdem sich der präpositive Artikel von der indirekten Identifizierung gelöst hatte. Die dadurch entstehende pleonastische Signalisierung des Attributs konnte auf verschiedene Arten systematisiert oder zugunsten einer nicht-pleonastischen Ausdrucksweise aufgegeben werden. Die Verwendung oder Nichtverwendung eines präpositiven Artikels des substantivischen Attributs hing von dem System ab, durch das der jeweilige Dialekt seine Kasus ausdrückte (s. Kap. III); das Fehlen von adjektivischen Artikeln deutet auf eine völlige Durchsetzung der sich aus der Entstehung des postpositiven Artikels ergebenden Konsequenzen hin (Konstruktion l: calul bun 81 frumos), dadurch murden die Reste des Protoartikels beseitigt.

Der Kampf um die Regelung der signalisierenden Verwendung von cel ist noch im Altrum. des 16. Jhd. nicht abgeschlossen. Deshalb ist es wahrscheinlich, dab noch im 10. Jhd. (Terminus ad quem für die Entstehung des postpositiven Artikels) die Konstruktionen calul bun gi frumos, calul bun $g^{i}$ ăl frumos, calul ăl bun şi àl frumos ungeregelt miteinander wechselten, die Attributsignalisierung des präpositiven Arti- 
kels also noch nicht systematisch ausgenützt wurde.

Auf der Konstruktion calul cel bun hat Gamillscheg seine Theorie vom 'Gelenkartikel' aufgebaut, der zwei Redeteile miteinander verbindet: porcus ille silvaticus 411 ) und neben dem vulgärlat. Protoartikel homo ille bzw. "ille homo bestand, welches später den 'echten' Artikel lieferte. Gelenkartikel und echter Artikel seien darauf im Westromanischen zusammengefallen, im Rum. aber getrennt erhal tengeblieben. 412) Diese Theorie ist auf die Ablehnung der maBgeblichen Linguisten gestoBen. Lerch ${ }^{413)}$ zeigt, dab die Verbreitung der Konatruktion vom Typ Babylon illa magna auf Rechnung der Kirchensprache geht, vgl. auch das bibelgriech. GTopìr tìr IIfwrqu. 414) Piotrovakif 415) nennt die Gamillschegsche Theorie 'fruchtlos' und Coteanu416) den 'Gelenkartikel' eine Erfindung. Vgl. zum 'Gelenkartikel' auch Hansen ${ }^{417)}$. Die alb. Parallele zum Rum. läBt Gamillscheg unbeachtet.

C. calu ellu-vecinu > (bunul, un) cal al vecinului (Typ 3.a. Nach der lösung des präpositiven Artikels des Attributs von den Resten der indirekten Identifizierung standen auch für das attributive Substantiv folgende Konstruktionen zur Verfügung, die sich durch die Signalisierung bzw. Nicht-Signalisierung des Attributẹ unterscheiden:

1. calul vecinului, calul bun vecinului

2. calul vecinului, calul bun al vecinului

3. calul al vecinului, calul àl bun al vecinului

sowie nach nicht-identifizierten Substantiva:

4. (un) cal vecinului, (un) cal bun vecinului

Für die Systematisierung dieser Möglichkeiten war entscheidend, daB das Rum. und Alb. für den morphologischen Ausdruck des indirekten objekts und des Attributs nur éinen paradigmatischen Kasus, den Obliquus, besitzen. Das Attribut konnte jedoch rom indirekten objekt durch die Attributgigna- 
lisierung untergchieden werden. Die vom präpositiven Artikel eines attributiven Substantivs gelieferte Information war deshalb weit weniger pleonastisch als die des Artikels vor attributiven Adjektiva. Die Folge ist eine ausgedehnte Verwendung des präpositiven Artikels des attributiven Substantivs im Rum. und Alb. Die Kennzeichnung des indirekten Objekts durch die Objektreprise (auch mak.: mu veli na čovekot 'er sagt zu dem Menschen') ist ein jüngeres Mittel zur Differenzierung und im Rum. falkultativ.

Folglich wurde die Konstruktion (1) weder im Rum. noch im $A l b$. verwendet. Im Rum. hat sich (2) durchgesetzt, wobei calul vecinului das unsystematische cal al vecinului ablöste und dadurch den Bezug zwischen dem postpositiven Artikel und dem folgenden Attribut wiedergewann. Daneben findet sich im Al trum. noch die Konstruktion (3) in zahlreichen Belegen, vgl. pămintul al gr griului, popa a a său, viața a ceriului, sāparea a Ierusalimului ${ }^{48)}$. Die Kasusfunktion des präpositiven Artikels des attributiven Substantivs hat zur Ausdehnung der Präartikulierung auch auf die Konstruktion (4) geführt, wenn ein attributives Substantiv einem nicht-identifizierten Nomen folgt: un cal al vecinului. Das Altrum. zeigt hier noch Beispiele ohne den präpositiven Artikel: sot _ furtisagului, un läcuitoriu _acélui finut ${ }^{49)}$. Der präpositive Artikel konnte in diese Syntagmata eingeführt werden, weil die formale Konstruktion cal al vecinului seit altersher bestand, wenn auch in der Bedeutung 'das Pferd des Nachbarn', worin sie von calul vecinului und calul al vecinului ersetzt wurde. - Die rum. Possessivpronomina haben sich in der Verwendung des präpositiven Artikels der Regelung für das attributive Substantiv angeschlossen.

Für die Form al <*ellu, wodurch ein Unterschied $z u$ àl - präpositiver Artikel des Adjektivs entsteht, würde ich weniger den ProzeB e $>$ a im Anlaut nach Pause verantwortlich machen ${ }^{420)}$, als die Konfusion dieses präpositiven Artikels mit der Präposition a $(<a d)^{421)}$ : lat. casa illa est $\underline{\text { illa }}$ 
vicino meo und casa illa est ad vicinu(m) meu(m) haben nach der Neutralisierung von $\underline{0}$ und $\underline{u}>$ rum. $\underline{u}$ ein gleichlautendes Ergebnis: casa este a vecinu-meu. ${ }^{422)}$ Das Nebeneinander von $\underline{a} l$ und a in parallelen Konstruktionen wurde durch die Bildung eines gemeinsamen attributsignalisierenden Morphems beseitigt: 이, das deshalb auch keinen obliquen Kasus mehr bildet: DR (obl.) domnului mare al tārei. Pür die Einführung des präpositiven Artikels in die Konstruktion (4) kann die Präposition a mitverantwortlich gemacht werden.

Im MR und IR ist die Verwendung des präpositiven Artikels des attributiven Substantivs nicht mehr produktiv. Für das MR sehe Ich die Erklärung dafür nicht in einer phonetisch bedingten Aphärese des a- im Anlaut: alu > 1 $u^{423)}$, sondern in der Schaffung getrennter Morpheme für den Attributs- und Objektsausdruck: MR (gen.) lu ąmpirātu = DR Impāratului, MR (dat.) Ia ampirāt(u) = DR Impāratului. Dadurch wurde die differenzierende Punktion des präpositiven Artikels überflüssig.

Im Alb. zeigen Relikte wie pulomba _ dörës 'die Handfläche', brēzl _ pjakavet 'der Regenbogen' (Calabrien) ${ }^{424)}$, daB dort früher wie im $D R$ die Konstruktion (2) existiert hat. Im modernen Alb. Lst nach Uberwindung der oben besprochenen, verschiedenen Interpretationen unterliegenden Bildungen wie kal-1-falni die Konstruktion (3) generalisiert und auf Attribute nach nicht-identifizierten Substantiva ausgedehnt worden. Vgl. für die direkte Sequenz:

'Lahutą e Malcls' \&sht kryeveprą e letërsis shqiptare - 'die "Laute des Hochlandes" ist das Hauptwerk der albanischen Literatur'. Die Präartikulierung fehlt beim Partitiv, der ein eigenes Morphem hat: fisi asht nji grumbull - der Stamm ist eine Anhäufung von Pamilien,45). Für die unterbrochene Sequenz: majet e nalta të malevet 'die hohen Gipfel der Berge', nach einem nicht-identifizierten Substantiv: nji libër 1 mikut 'ein Buch des Preundes'.

Zur Chronologie: Coteanu, der die Funktion des präpositiven Artikels des attributiven Substantivs in der Bewahrung 
der 'Unabhängigkeit der Wörter' (?) sieht, datiert seine Entstehung ins 9.-10. Jhd., also jünger als der postpositive und etwas älter als der präpositive Artikel des Adjektivs. ${ }^{426}$ ) Vgl. dazu die obigen Uberlegungen zur Chronologie des 'adjektivischen' Artikels. Die Schwankungen im altrum. Gebrauch des präpositiven Artikels des attributiven Substantivs zeigen, daß eine von der indirekten Identifizierung vollkommen gelöste signalisierende Funktion bei ihm für die Zeit vor dem 10. Jhd. wenig wahrscheinlich ist.

\section{D. lui Ion (Typ 4)}

Dieses als Kasusanzeiger funktionierende Morphem hat wegen seiner etymologischen Ableitung von lat. ille zu der Vermutung geführt, daß einst im Rum. ein präpositiver, direkt identifizierender Artikel, vergleichbar dem westromanischen la casa bestand, mit der Lautung *ellu-calu (oder lu-calu) und *aya-casă (oder *a-casă) im Directus, dessen Obliquusform lui durch Verlust der Identifizierungsfunktion zum Kasusmorphem wurde. Die Existenz eines solchen Artikels im Prührum. murde u.a. von Densusianu ${ }^{427)}$, Dräganu 428 ) und Puscariu angenommen: "Die Konstruktion dau lui om ist spurlos verschwunden und durch dau omului ersetzt worden." (Puscariu) 429) Eine Zusammenfassung dieser Theorie findet sich bei Gāzdaru. ${ }^{430)}$ Sie wurde nicht akzeptiert von Graur 431 ) und neuerdings Piotrovskij432). Vgl. auch Coteanu. ${ }^{433)}$ Für unsere Problemstellung wird die Prage eines präpositiven identifizierenden Artikels im Rum. dadurch wichtig, daß Gblbbov im AnschluB an die obengenannten Linguisten seine Existenz im Rum. behauptet ${ }^{434}$ ) und meint, er sei erst unter bulg. Einfluß zu *asă-a verändert worden. Dies gilt bei Gblsbov als Beweispunkt für die unabhängige Entwicklung der bulg.-mak. Artikel position. ${ }^{435)}$

DR. Im modernen Rum. (wie auch im Altrum.) funktioniert das präpositive lui nur als obliquusmorphem, es hat keine Beziehung zur Identifizierung oder zur Attributsignali- 
sierung. Das Beispiel: o sonată a lui Beethoven zeigt, daB $\underline{\text { lui }}$ den Obliquus angibt und $\underline{a}$ diesen als attributiv spezifiziert.

Während heute nur lui Ion, Iui Mary 'Johanns', 'Mary's' möglich sind ${ }^{46)}$, erscheinen in den altrum. Texten lu, lui (maskulin), ei, ii (feminin), lor (Plural) zum Ausdruck des obliquus von Personennamen (lui Christos, ii Marie) und selten in schwer deklinablen Gruppen: a ei noastre credinfe. ${ }^{437}$ ) Da diese Verwendung bei Personennamen vom 16.-18. Jhd. sogar noch ansteigt, verneint Coteanu zu Recht ihre ununterbrochene Existenz seit dem Lat. im Rum. und erklärt ei, lor als durch Innovation aus der Postposition übernommen, nach dem Vorbild des schon früher präpositiven lu/lui: lui Andrei neben Radu-lui führte zu ei Ane < Ane-ei. Der Grund für die Innovation war das Bestreben besonders der Amtssprache, die Eigennamen aus der formverändernden synthetischen Flexion herauszuhalten. Vgl. noch 1926 in einem rum. Sterberegister: a ei Elena, al ei Ancufa.438) In Fällen wie a ei noastre credinte ( 16. Jhd.) haben wir es mit einer künstlichen Konstruktion zu tun, die durch die ungewöhnliche, formelhafte Inversion des Possessivpronomens zu erklären ist. ${ }^{439)}$ Gewöhnlich wäre: a credinfe-ei noastre 'unseres Glaubens'.

Somit reduziert sich das Problem im $D R$ auf das präpositive lu/lui zur Bezeichnung des Obliquus von (ursprünglich nur maskulinen) Eigennamen.

$\underline{M R}+I R$. Auch hier sind präpositives $\underline{\underline{l u}}$, selten $\underline{\underline{l u} i^{440}}{ }^{4}$ als reine Kasusmorpheme für den Genitiv (MR) bzw. für den Obliquus = Genitiv-Dativ (IR) von der Identifizierung getrennt, vgl. IR lu fil'u 'des Sohnes', lu fęta 'der Tochter'44l), die Identifizierung wird durch den nicht-kasusflektierten postpositiven Artikel ausgedrückt; ebenso im MR: lu ampirātu (selten ampirātului) 'des Kaisers', lu un ampirāt 'eines Kaisers', lu feata 'des Mädchens' (selten featăl'ă), lu ună featā 'eines Mädchens', lu featili 'der Mädchen' .442) Die Kennzeichnung des Attributs durch den präpositiven Artikel al ist durch die 
Bezeichnung dee Genitivs überflüssig geworden und murde aufgegeben. MR la zum Ausdruck des Dativs ${ }^{443)}<1$ ilàc ist eigentlich eine in allen Dialekten verhandene Präposition mit der Bedeutung 'auf', 'in' und erst durch bulg. na für den obliquus in Opposition $z u$ lu geraten. Verfehlt ist die Erklärung von $\underline{1 a}$ bei Grlbbov ${ }^{444)}$. Die Verwendung von $\underline{1 u}$ im MR stellt eine Ausweitung des DR Gebrauchs von lui auf alle Appellativa dar, wie sie ähnlich in der DR Umgangssprache vorkommt ${ }^{445}$ ), vgl. Kap. III.2.

AR. Dieser Dialekt zeichnet sich bei der Obliquuskonstruktion seiner Appellativa durch das folgende Nebeneinander aus:

$$
\begin{aligned}
& \text { al }(<a-1 u) \text { trup } \cong a \text { trup-lui } \\
& \text { ali featā } \\
& \cong \text { a feata- } \underline{I}^{\prime} e^{446)}
\end{aligned}
$$

Entkleidet man dieses System der Kontamination mit der Präposition a und möglicherweise mit dem präpositiven attributsignalisierenden Artikel al, so erhält man:

$$
\underline{\text { lu }} \text { trup } \cong \text { trup-lui }
$$

Dieses Nebeneinander läBt sich durch die in den MR und DR Verhältnissen bemerkbaren Tendenzen erklären. Wieder wurde der bei Eigennamen auftretende präpositive Obliquusausdruck lu mit dem postpositiven Artikel im Obliquus der Appellativa, -lui, gleichgesetzt:

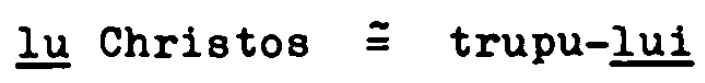

Während sich im MR und DR die Gleichsetzung nur auf den Kasus erstreckte, woraus die Obliquuskonstruktion von Appellativa $l u(i)$ trup-u(l) entstehen konnte, griff sie im AR auch auf die Identifizierung über, woraus sich ein mögliches lu trup ergab. Die Identifizierungsfunktion des präpositiven Artikels im $A R$ Obliquus stellt also eine Neuerung dar.

Die phonetische Erklärung für das DR Dumutru a 11 Ane 'der Demetrius der Anna'. mit $\underline{\underline{l u i}}>\underline{1 i^{447)}}$ kann für AR a-li nicht gelten, da es als Pemininum dem maskulinen al $(u)<\underline{\text { a } l u}$ 
gegenübersteht. Eine Neuerung aus der Postposition wie DR ei (s.o.) stellt es ebenfalls nicht dar, denn es geht nicht wie das postpositive - $\underline{\text { 'ei }}$ auf lat. *illaei zurück, dieses ergab -1 'e 1 , tonschwach -1'i, nicht -11.448$)$ Richtig stellt

Pug̨cariu - $\underline{11}$ zu älterem (a-) le, mit dem phonetischen ProzeB - e > - '1.449)

Neben lu/luí ist also auch (a-) le als präpositives Kasusmorphem im Frührum. feststellbar. Welches ist inre Etymologie? Das klassisch-lat. ille hatte nach dem 4. Jhd. u.Z. sechs Formen für den Dativ sing.:

mask. fem.

akzentuiert

1llui

unakzentuiert

1110, 1111

illaei

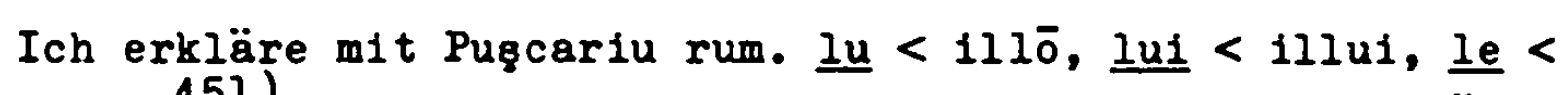
illae. 451$)$ Die Herleitung von ali aus illi ist nicht möglich, da das 1 hätte palatalisiert werden müssen. ${ }^{452)}$ Auf illi zurückgehen kann der präpositive Obliquusausdruck $\underline{i}$ in DR Mundarten: la casa 1 Docă $\cong 1$ a casa Docāi. Die folgenden lat. Formen finden sich demnach in ursprünglicher rum. Präponierung wieder: 1llui > Iui, $1110^{-}>\underline{I u}$ (nicht<1llum $\left.{ }^{453}\right)$ ), illae > le, $1111>1$. Mit der Präposition a konnten die Verbindungen alui, alu ( $>\underline{a l})$, ale ( $>\underline{a l i})$, ai (1i) entstehen. Von diesen vier Pormen läßt sich illui > lui aus der ursprünglichen Präponierung ausschalten. Es ist aus der Postposition aufgrund der scheinbaren Parallelität von lu Petru $\cong$ Petru lui nostru (s. dazu unten) noch vor ef und lor in die Präponierung übertragen worden. Dabei mag die phonetische Annlichkeit von lu und lui eine Rolle gespielt haben. ${ }^{454}$ ) Noch in den al trum. Texten steht lu hauptsächlich vor, lui hinter einem Eigennamen, dabei wird die Nachstellung vorgezogen, wenn dem Eigennamen ein Attribut folgt: Dumnedzeu lui nostru 'unseres Herrgotts' - bunătatea lu(1) Dumnezeu 'die Güte des Herrgotts'. 455) Für den Ausdruck des Obliquus durch ein präpositives Morphem bleiben im Gesamtrum. die Formen 1110 (lu) im Maskulinum, illae (le) im Pemininum, 1111 (i) in 
beiden Geschlechtern als ursprünglich übrig. Der von Coteanu für alle Dialekte angesetzte Grundtyp al präpositives Obliquusmorphem' ist zwar in allen Dialekten (jedoch heute unproduktiv) vor Personennamen belegt: DR Vasile al Bucģoiu456), AR al Mitru 'des Mitru', IR Petru al Chita, stellt aber ein

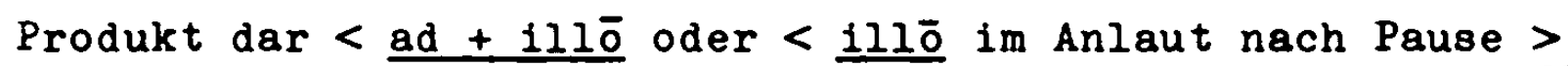
alu > al, entspricht also dem einfachen präpositiven lu. ${ }^{4}$ 457)

Der Uberblick über die verschiedenen präpositiven Kontinuanten von lat. ille in den großen rum. Dialekten hat folgendes ergeben:

1. Ursprünglich befanden sich in der Präponierung nur die unakzentuierten Formen $\underline{\underline{l u}}$, le, $\underline{\underline{1}}$ (obl.); Formen des Nominativs und des Akkusativs finden sich in der Präponierung nicht. 2. Die genannten Formen sind überall präpositive Obliquusmorpheme. Das AR System, das davon eine Ausnahme bildet, ist eine Neuentwicklung.

3. In der konservativen DR Schriftsprache sowie im Altrum. stehen die präpositiven Obliquusmorpheme nur bei Eigennamen, besonders indeklinablen (lui Ion, lu Ester, lui Nuni). Der Wechsel von lu Dumnezeu - Dumnezeului im Altrum. beinhaltet, dab im ersten Fall der Name nicht formal identifiziert, im zweiten Fall seine inhärierende Determination formal gekennzeichnet wird.

4. Die Verwendung von präpositivem ei und lor vornehmlich bei Eigennamen im älteren DR stellt eine Ausweitung des unter 2 angegebenen Gebrauchs dar, sie wurden aus der Postposition einge führt.

5. Ebenfalls jüngeren Datums ist die Verwendung präpositiver Obliquusmorpheme in der DR Umgangssprache, im MR und IR bei Appellativa, wobei der postpositive Artikel für die Identifizierung bestehen bleibt.

6. Die jüngste Entwicklung ist in der Parallelität von postund präpositivem Artikel im AR zu erblicken, erst hier tritt ein präpositiver Artikel mit der direkten Identifizierung in Verbindung. 
Die Ausbreitung der Verwendung des präpositiven 'Artikels' im Rum., vom Kasusausdruck bei Eigennamen über den Kasusausdruck bei Appellativa bis zum Ausdruck der Identifizierung von Appellativa ist also jüngeren Datums und steht mit der Umgestaltung der Kasusflexion der einzelnen Dialekte in Kausalverbindung. Siehe Kap. III.2. Der ProzeB ist so neu, daB sich noch überall die älteren Formen finden: MR featăl'à neben lu feata, AR a featăl'ei neben ali featā, DR omului neben umgangssprachlichem lu omu. Der heutige Zustand erlaubt es deshalb nicht, für die Epoche vor dem Einsetzen der schriftlichen Uberlieferung eine der heutigen vergleichbare Verwendung der präpositiven Kontinuanten von lat. 1lle abzuleiten.

Das sich der Assimilation durch das Bulg.-Mak. entziehende Rum. geriet erst nach dem 10. Jhd. unter einen tiefergehenden EinfluB des Bulg. (vgl. Kap. I.2.). Hätte bis dahin Im Rum. ein direkt identifizierender präpositiver Artikel bestanden, der durch bulg. Einwirkung in die Postposition geriet, so wären für das Altrum. des 16. Jhd. Relikte auch in identifizierender Funktion, zumindest aber Pormen des Directue (Nominativ und Akkusativ) in der Präponierung, gleich in welcher Funktion, zu erwarten. Viel ältere Relikte, wie das mit dem Alb. korrespondierende in sat - in satul nostru, sind im Rum. bewahrt geblieben. Die präpositiven Obliquusmorpheme lu, $\underline{\text { le, }} \underline{i}$ scheinen schon im Altrum. auf ein hohes Alter in dieser Funktion und in diesem beschränkten Anwendungsbereich (Eigennamen) zurückzublicken. - Der angeblich im IR bewahrte urrum. präpositive Artikel, den Gslsbov anführt: lu t\&g̨te lui s-a spoteit (= otec ego rassmejalsja) 458 ) und den er mit $D R$ tatāl 'der Vater' gleichsetzt, stellt die aus dem IR und MR bekannte Obliquusform dar, mit lu als Obliquusmorphem, die Konstruktion 1st unpersönlich: 'dem Vater...'.459)

Die Ablehnung der Ansicht, das Rum. habe bis zum 10. Jhd. einen direkt identifizierenden präpositiven Artikel gekannt, bedeutet nicht, $d \otimes B$ es nicht $f$ i $h$ e $r$ einen 
solchen geben konnte, von dem die präpositiven obliquusmorpheme uㅡ, le, $\underline{1}$ abzuleiten wären. Das Vulgärlat. lieferte dem Frührum. die Tendenz zur Ausbildung eines prëpositiven Artikels (wie in der Westromania), diese Ausbildung erhielt Konkurrenz durch die mit dem Alb. verbundene Entwicklung des postpositiven Artikels. Dies führte bei den Appellativa zu einem Nebeneinander:

*ellu-calu calu-ellu calu-ellu-bunu 'das (gute) Pferd' mit dem Obliquus

*ellu-calu calu-ellui calu-ellui-bunu 'dem (guten)

Pferd'

Die inhärierende Determination der Eigennamen mußte nicht durch einen Artikel formal gekennzeichnet werden. Im Obliquus verlangten sie aber nach einer zusätzlichen Kasusbezeichnung, da viele indeklinabel waren und im Maskulinum die Neutralisierung von Directus und Obliquus Fortschritte machte (lupus, lupō, lupum > lupu). Dies führte zu einer Hyperdetermination der Eigennamen zunächst im Obliquus:

"ellu-Lupu Lupu-ellui Lupu-ellui-bunu 'dem (guten) I.' Solche Namen, die dem rum. Sprecher nicht in das System der rum. Appellativa zu passen schienen (Gheorghe, Ester, Ion, Iona u.a.) wurden nicht postartikuliert, wenn sie kein Attribut bei sich hatten; hatten sie ein Attribut, so trug dieses seinen präpositiven Artikel:

*ellu-Gheorghe --- Gheorghe ellui bunu 'dem (guten) G.' Die Durchsetzung des postpositiven Artikels als einziges Identifizierungsmorphem bei den Appellativa führte bei den o- und a-stämmigen Eigennamen zu:

$$
\begin{array}{ll}
\text { Lupu-lui } & \text { Iupu-lui-bunu } \\
\text { parallel zu } & \\
\text { calu-lui } & \text { calu-lui-bunu }
\end{array}
$$


Ebenfalls parallel zu den Appellativa (obl. calu-lui, dir. calu-1) bildeten diese Namen einen neuen Directus: Lupul und führten damit die Hyperdetermination in allen Kasus durch. Die Gruppe der wie Appellativa flektierten Eigennamen ist noch heute im DR die größte: Lupul - Lupului, Toma - Tomei, Radul - Radului, Ana - Anei usf.

Mit dem Verlust von *ellu- als Identifizierungsmorphem bei den Appellativa wurde *ellu- in *ellu-Gheorghe zum reinen Obliquusmorphem; ganz wegfallen konnte es nicht, da es den Kasus anzugeben hatte. Da der Directus *ellu-calu nicht mehr existierte, kam es auch nicht zur Ausdehnung des präpositiven * ellu- auf andere Kasus des Eigennamens, es ist nur in seiner Obliquusform erhal ten ( $>l u, l e, i)$. In der Konstruktion mit einem Attribut wurde dagegen der ursprünglich dem Attribut präpositive Artikel weiterverwendet:

\section{Iu Gheorghe - Gheorghe lui bunu}

So erklärt sich das altrum. bunātatea lu(i) Dumnezeu - Dumnedzeu lui nostru, in welchem die anscheinend parallele Verwendung von präpositivem Obliquusmorphem und postpositivem Artikel zum Austausch zwischen beiden Morphemen und damit letztlich zur Rückgewinnung der Identifizierungsfunktion durch das präpositive Morphem in einem Teil des Rum. führte.

Die Umwandlung der Obliquusform des proklitischen Artikels in ein reines Kasusmorphem bei Eigennamen vollzog sich in dem Maße, wie sich der postpositive Artikel als einziges Identifizierungsmorphem durchsetzte. Wenn in Kap. II.4.d. die Entwicklung des rum. postpositiven Artikels bis zum 6. Jhd. eingeordnet werden wird, so bedeutet dies auch, daß bis zu dieser Zeitgrenze die Obliquusfunktion der Artikelreste $\underline{\text { lu }}$, le, $\underline{1}$ erreicht war. Das rum. präpositive lu, le, i stellt eine durch die Plexionsentwicklung erhaltene lat.-romanische Schicht gegenüber dem balkanischen System des postpositiven Artikels dar. 
Bei der historischen Erklärung der Funktionen und Positionen der heutigen rum. und alb. Artikel ging ich, wie eingangs bemerkt, von der Theorie Al. Graurs aus. Sie enthält in nuce die beiden wichtigsten Voraussetzungen für eine Erhellung des historischen Vorgangs: die Möglichkeit, daß ein gegebenes Substantiv mit Hilfe eines präartikulierten Attributs formal identifiziert werden konnte, und den Prozeb *calu ellu-bunu $>$ *alu-ellu (bunu); vgl. Graurs Theorie in E. Seidels Paraphrase 460): "Für dieses Sprachbewubtsein ("calu ellu-bunu) war dann das Adjektiv nicht mehr selber determiniert durch den Artikel effiziert -, sondern es war determinierend geworden, eine Determinierung des vorausgehenden Substantivs (...) Da nun der Artikel dem Adjektiv als dem am häufigsten vorkommenden determinierenden Worte - im Gegensatz zu den westromanischen Sprachen - unmittelbar vorausging, wurde dieser Zustand grammatikalisiert ( $>$ calu-ellu bunu) und dehnte sich auch noch weiter aus."

Es bleibt zu fragen, wie im Rum. die Sequenz *calu ellu-bunu mit dem attributabhängigen, indirekt identifizierenden Protoartikel entstehen konnte. Eine Ableitung aus dem Romanischen (so bei Graur)

:Le bonus caballus $\longrightarrow$ rum. *calu ellu-bunu

ist nicht aufrechtzuerhalten, denn die Postponierung des Adjektivs, die im Rum. gegenüber den westromanischen Sprachen die Regel ist, hätte $z$ *ellu calu bunu geführt, wie ja die häufig postponierten attributiven Adjektiva der westromanischen Sprachen die Präponierung des Artikels nicht verhindert haben: frz. le fait important. Nur im Rum. sind der (Proto-) Artikel und das Attribut, nicht das Substantiv wie in der Westromania, miteinander verbunden. Folglich kann der präpositive Artikel des Substantivs in der Testromania den präpositiven Artikel des Attributs im Rum. nicht positionell erklären. Tarum das adjektivische Attribut im Rum. ganz überwiegend postponiert wird, ist ebenfalls ungeklärt. Vgl. die 
Kritik Coteanus ${ }^{461)}$ an der Ableitung der Protoartikelposition aus der Postponierung des Adjektivs in Graurs Theorie.

In der Sequenz *calu ellu-bunu 'das gute Pferd' haben wir es demnach mit drei unbekannten Größen zu tun: 1. dem Grund für die vom Westromanischen abweichende Postponierung des adjektivischen Attributs im Rum., 2. dem Grund für das Auftreten des Protoartikels nur in Verbindung mit dem Attribut, nicht mit dem übergeordneten Substantiv wie in der Westromania, 3. dem Grund für die Präponierung des mit dem nachgestellten Attribut verknüpften Protoartikels (*calu ellu-bunu, nicht *alu bunu-ellu). Für alle drei Punkte läßt sich m.E. eine gemeinsame, allerdings nicht auf das romanische Erbe des Rum. zurückgehende Ursache angeben.

Parallel zur rum. Konstruktion *calu ellu-bunu ist in Funktion und Sequenz der Elemente die alb. Konstruktion kal i-mirë. Hier kann gezeigt werden, daß in dem Element 1 - ursprünglich kein Demonstrativpronomen vorlag, aus dem im allgemeinen die Artikel zu entstehen pflegen. Das Paradigma des alb. Artikels, der auf den Protoartikel zurückgeht, wird aus den Pronominalstämmen is, (0)yos, tos. (und *isis) gebildet, vgl. Kap. II.2. Von ihnen sind tos, *(o)yos, *kis indogermanische Demonstrativstämme: dagegen stellt alb. $\underline{i}$ (fem. $\underline{e}$ ) eine Vermischung dar aus dem Demonstrativpronomen ${ }^{i s,}{ }^{*} i \bar{a}$, * id 462) und dem von inm abgeleiteten Relativpronomen *ios, *ja, *jod 'der dort-ige ${ }^{463)}$, wie Georgiev feststellt. 464 \}

Eine der historischen Komponenten von alb. kal 1-mirë ist demnach als kal ios mirë 'das gute Pferd', wörtlich 'Pferd, welches/das gut (ist)' anzusetzen. In der Verwendung eines Relativpronomens als Protoartikel trifft sich das Alb. mit dem Iranischen und dem Slavischen, mit denen es durch weitere Isoglossen verbunden ist, welche die Zusammenfassung des Balto-Slavischen, Indo-Iranischen, Armenischen und Alb. zu einer Dialektgruppe des Indogermanischen (Meillet) erlauben. Wie das Alb. zeigen das Slav. und das Iranische:

1. die indirekte Identifizierung des übergeordneten Substan- 
tivs durch einen nur mit dem Attribut auftretenden Protoartikel.

alb. kal / kal i (< *jos)-mirë $\equiv$ neupersisch asp / asp I (< avestiech ya-<idg. *jos) hūb $\cong$ slav. konb / dobrb-jb $(<*$ jos ) konb.

2. dis 'Substantivierung' des Attributs bei Ellipse des übergeordneten Substantivs.

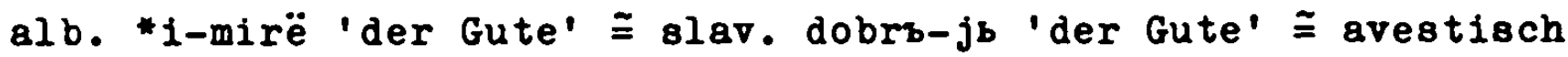
yām angrem (acc.) 'den Peindlichen' = 'den Peind'.

3. die (Proto-)Artikulierung nur des ersten Attributes, wenn einem Substantiv mehrere Attribute untergeordnet sind. alb. kal i-mirë _ fqini 'das gute Pferd des Nachbarn' ミ slav. (Marian. ( 11.31 ) Ijudei sqšte-1 ss njejg i utěšajgšte $j 8^{465)}$, avestisch haṽra ... yazataēibyō yat amašaēibyō spantaēibyō 'mit den unsterblichen, heiligen Yazatao'.466)

Eine Beschreibung der Funktionen des Relativpronomens, die seine Verwendung als identifizierendes Morphem erlauben, sowie die Gründe für die Abweichungen des Slavischen von den parallelen alb.-iranischen Konstruktionen (Umstellung des Relativpronomens, Präartikulierung nur adjektivischer Attribute) werden in Kap. IV gegeben.

Wenn *kal i-mirë, woraus rum. *alu ellu-bunu, auf *kal jos mirë zurückgeht, so erklärt diese ursprünglich relative Konstruktion

a. die generelle Postponierung der Attribute im Verhältnis zum übergeordneten Substantiv, opäter ausgedehnt auf solche Attribute, die einem nicht-identifizierten Substantiv folgen. b. die Bindung des Protoartikels an das Attribut, mit welchem zusammen er allein auftreten konnte.

c. die Position des Protoartikels vor dem Attribut und durch die spätere Agglutinierung *kal 1-mirë > kali die heutige Postposition des Artikels beim Substantiv. Diese Postposition geht also nicht auf die Generalisierung einer der positionellen Möglichkeiten des Demonstrativpronomens zurück, sondern 
auf die Stellung des Relativpronomens zu Beginn der Relativkonstruktion, welche im Alb. (auch modern nur: nji kal që ka katër kambë 'ein Pferd, welches vier Beine hat') generell dem übergeordneten Substantiv folgte. Die obligatorische syntaktische Regelung der Relativkonstruktion im alb. Sprachsystem ist für die linguistische Erklärung der heutigen Artikelpostposition ein wichtigerer Paktor als die stilistische Regelung der Demonstrativposition auf der Ebene der Rede.

Nachdem der relativische Ursprung der Konstruktion *kal 1 -mirë vergessen war, begannen auch die Demonstrativpronomina (in sekundärer, grammatisch lokalisierender Funktion) für das frühere Relativpronomen einzutreten, beginnend mit den Fällen, in denen der intendierte Gegenstand im Kontext des zu identifizierenden Nomens erwähnt wurde: kal i-mirë (< jos) neben kal i-mirë (<*is), kal *tos-mirë, kal *(o)uos mirë, kal * kis-mirë. Die Demonstrativpronomina funktioñierten hier als personalgebundene, mit räumlichen Nebenbedeutungen belastete Protoartikel: 'das gute Pferd dort/da/hier', gegenüber *is kal mirë, *is mirë kal, kal-is mirë, kal mirë *is 'jenes gute Pferd', "tos kal mirë etc. 'das gute Pferd dort', *(o)yos kal mirë etc. 'dieses gute Pferd'. Als Protoartikel nahmen die Demonstrativpronomina die Position des früheren Relativpronomens ein. Die alb. Vermischung von Relativ- und Demonstrativpronomen war bereits abgeschlossen, als das Romanische auf sein frühalb. Substrat traf, wie die rum. Replik zeigt: *calu ellu-bunu (<ille), nicht *calu care-bunu ( < Relativpronomen qualis).

Die Auffassung von kal $\underline{1}$-mirë als Demonstrativpronomen ermöglichte die Entstehung des kontextunabhängigen Artikels kal-i, das formale Vorbild hierfür war das real lokalisierende kal $i(<* i s)$ 'Jenes Pferd'. Neben kal-i entstanden kal-*tos und kal-*uos (kal-*kis). Der Einbruch des frühalb. dreigliedrigen Zeigesystems in die identifizierende Konstruktion des Relativpronomens ist die Voraussetzung für die Entstehung des in Kap. II.2. beschriebenen frühalb. dreigliedrigen Arti- 
kelsystems und damit auch für die spätere Vermischung der Artikel $\underline{i}$ (<*ios und *is), tëe së (<*tos/tios), u (<*uos) und eventuell së (<*is) im Paradigma des heute eingliedrigen alb. Artikels. Der Grund für die Evolution des eingliedrigen Artikels kann das Vorhandensein des vom Relativpronomen jos gebildeten abstrakten, von der Personalbindung und räumlichen Nebenbedeutungen freien Protoartikels *kal $\underline{i}-m i r e ̈$ in Frühalb. sein.

Nach Ausweis von *ftõ-i > ftoi, aber *ftõ > ftue < lat. cotōneum 'Quitte' (s.o.) hatte das Frühalb. schon in lat.römischer Zeit den postpositiven Artikel (mit verschiedenen Morphemen für räumliche Nebenbedeutungen) entwickelt, denn die Einwirkung von $\underline{i}$ auf den vorausgehenden Nasalvokal setzt eine Bindung * fõ-i mirë voraus. Andererseits murde bei der Untersuchung des präpositiven Artikels des Attributs festgestellt, $d a B$ in Verbindungen von Substantiv und Attribut der Protoartikel sehr langsam durch den Artikel abgelöst wurde und daB diese Ablösung in vielen Fällen gar nicht gelang, so daß man sich mit einer Nebeneinandersetzung von Artikel und Protoartikel (> präpositivem Artikel des Attributs) behalf. In Relikten (mal i lartë, njerl i mirë, vajz e mbretit) hat sich die ursprüngliche Konstruktion des Protoartikels bis in die Neuzeit erhalten. Deshalb ist für das Frühalb. mit einem Nebeneinander zu rechnen:

kal-i 'das Pferd' aber kal i-mirë 'das gute Pferd'

$O b$ das Frührum. dieses alb. System übernahm und folglich vom Anfang seiner Entwicklung an einen postpositiven Artikel des Substantivs besaß, der nicht erst aus dem Protoartikel in *alu ellu-bunu entwickelt $z u$ werden brauchte, ist nicht mit sicherheit zu entscheiden. Eventuell können die altrum. und dialektal auftretenden schwachtonigen Obliquusformen Impāratu-lu neben impāratu-lui, fărā-i neben țăre-ei auf ein ursprüngliches *álu-ellu hindeuten. (Die starktonigen Obliquusformen -lui und -ei gehen auf den Protoartikel in *calu èllu-bunu zurück.) Dagegen spricht indessen das nach Präpositio- 
nen im Rum. geltende Reliktsystem: in sat 'in dem Dorf' in satul nou 'in dem neuen Dorf'467), das keinen attributunabhängigen Artikel aufweist. Die Entstehung der präpositiven Artikel des Attributs im Rum. ist besser zu verstehen, wenn man davon ausgeht, daß das Prührum. aus dem Alb. nur die Konstruktion *alu ellu-bunu übernahm, aus der es ein calu-*ellu selber entwickelte. Die Vermeidung des postpositiven, attributunabhängigen Artikels des Alb. durch das Rum. kann so erklärt werden, daß der Stamm *ellu (< lllu-) für die Verwendung als kontextunabhängiger Artikel noch als zu stark real lokalisierend empfunden wurde.

Die oben beschriebene Entwicklung des postpositiven Artikels aus einem Protoartikel hat demnach im Alb. und Rum. nicht gleichzeitig eingesetzt. Der ProzeB *kal i-mirë > kal-i ist im Alb. für die vorrömische Zeit anzusetzen. Neben kal-i bestand jedoch *kal 1-mirë weiter und wurde zum Vorbild für rum. "calu ellu-bunu. Wie *kal i-mirë zu kali, führte *alu ellu-bunu zu calul, bestand jedoch wie kal i-mirë fort. Die Evolution des erhaltenen Protoartikels zum attributsignalisierenden Artikel konnte dagegen in beiden Sprachen ungefähr gleichzeitịg beginnen:

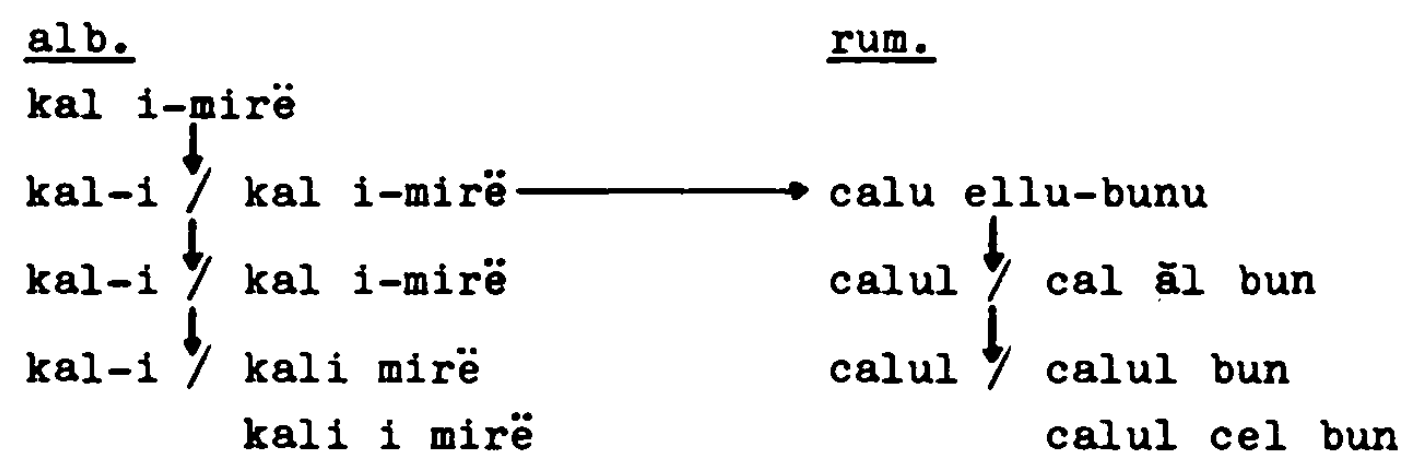

Die typologische Parallelität der heutigen rum. und alb. Artikeltypen 1. - 3. erklärt sich daraus, daB sie auf eine durch einen indirekt das übergeordnete Substantiv identifizierenden, attributabhängigen Protoartikel charakterisierte Konstruktion zurückgehen, die in beiden Sprachen teilweise mit zeitlicher Verschiebung existiert hat.

Das Bulg.-Mak. konnte bis zum 10. Jhd. im rum. Substrat 
die folgenden Muster antreffen:

(un) cal

bun

vecinului

calul '(ein) Pferd'

'(ein) gutes Pferd'

- (ein) Pferd des Nachbarn'

'das Pferd'

Sie zeigen: die durchgehende Opposition 'nicht-postartikuliertes' / 'postartikuliertes Nomen', eine gleichbleibende Form des Attributs in beiden Fällen, zwei potentielle Präartikulierungen des Attributs nach einem postartikulierten Nomen. Das Fehlen von mak.-bulg. Entsprechungen zu den rum. präpositiven Artikeln ist aus den folgenden Gründen kein gültiges Argument gegen die Annahme eines Einflusses des rum. Artikelsystems auf das bulg.-mak.:

1. Das Rum. entwickelte die präpositiven Artikel des Attributs, weil es dazu durch die Ubernahme der durch den Protoartikel charakterisierten Konstruktion *calu ellu-bunu aus dem Alb. veranlaBt wurde. Das Slav. traf diese Konstruktion im Rum. nicht mehr an.

2. Als das Frührum. zum Frühalb. Repliken bildete, existierte der postpositive Artikel nur beim isolierten Substantiv; falls es Ergänzungen bei sich hatte, wurde der Protoartikel weiterverwendet; deshalb kalkierte das Frührum. den Protoartikel als das mehr Kombinationsmöglichkeiten umfassende Morpher. In dem rum. System, das das Slav. antraf, war der postpositive Artikel in allen Kombinationsmöglichkeiten des Substantivs durchgeführt. Das Bulg.-Mak. bildete Repliken zu dem am meisten obligaten und in allen Kombinationen verwendbaren Artikel des Rum., dem direkt identifizierenden, postoositiven Artikel des Substantivs, dem das Bulg.-Mak. kein Morphem mit entsprechender primärer Funktion entgegenzustellen hatte.

3. Der postpositive Artikel des Rum. erforderte keine obliga- 
te Präartikulierung des folgenden Attributs, erlaubte also ein konstantes Attribut nach jedem Substantiv. Diesem symmetrischen System schloB sich das Bulg.-Mak. an. Die im Rum. zusätzlich möglichen Präartikulierungen des Attributs kamen in der Periode bis zum 10. Jhd., der Hauptphase der rum. Substratbildung im Slav., nur nach postartikulierten Substantiva vor, waren demnach noch nicht von der Identifizierung unabhängig geworden. Die geringe funktionelle Differenzierung zwischen calul bun, calul vecinului einerseits und calul cel bun, calul al vecinului andererseits und inr infolgedessen ungeregeltes Nebeneinander, das noch im Altrum. des 16. Jhd. festzustellen ist, waren nicht dazu angetan, der bulg.-mak. Bevorzugung für das systemhafte calul bun, calul vecinului entgegenzuwirken. Die im Rum. in der Entwicklung befindliche, von der Identifizierung des übergeordneten Substantivg unabhängige Signalisierung des Attributs ging bei der Zuordnung slav. Konstruktionen zu den rum. Mustern durch den bilingualen Sprecher im Bulg.-Mak. verloren. - Was die Differenzierung von Attribut und indirektem objekt durch den präpositiven Ar+ikel angeht, die zu dessen größerer Ausbreitung im Rum. ur: Alb. beltrug, so übernahmen einen bedeutenden Teil der im Rirs. substantivischen Attribute die Possessivadjektiva des Slav. Die Differenzierung wurde im Bulg.-Mak. zumindest im frühen Stadium des rum.-slav. Kontaktes auch durch den paradifmatischen Genitiv und Dativ gewährleistet.

Die Einwirkung des rum. Artikelsystems auf die Evolution eines bulg.-mak. Artikelsystems erfolgte zu einer Zeit, als das Rum. den Protoartikel bereits in allen Kombinationen durch den postpositiven Artikel und die präpositiven Artikel des Attributs abgelöst hatte, die attributsignalisierende Pun! tion der präpositiven Artikel jedoch noch nicht von der Idextifizierung unabhängig und damit systematisch verwendbar geworden war. Bei der Replikbildung wählte das Bulg.-Mak. das progressive Artikelsubsystem des Rum. aus, indem es die Regte des Protoartikels verwarf. 
Die ausnahmslose Postposition des identifizierenden Artikels im Rum. und Alb. hat zweifellos die Tendenz des Bulg.-Mak. zur Postposition des sich bildenden Artikels in konb-ts und dobryj-ts konb zu einer obligaten Regelung des Sprachsystems intensiviert, indem sie "immanente slavische Struktureigenheiten" betonte (Svane) ${ }^{468)}$. Dabei empriehlt sich die Unterscheidung zweier Phasen:

1. rum. calul, calul bun (bunul cal)

slav. konb-tb, dobryj konb

Das slav. 'zusammengesetzte' Adjektiv bedeutete bereits, wie das frührum. "calu ellu-bunu, frühalb. "kal i-mirë: 'das gute Pferd'. Eine dem Substantiv entsprechende Postartikulierung war deshalb nicht erforderlich.

2. rum. calul, calul bun (bunul cal)

slav. konb-ts, dobryj-ts konb

Die Erhebung von konb-tb, vormals 'dieses Pferd' (grammatische Lokalisierung) zum Artikel: 'das Pferd' zog die Verwendung des parallelen dobryj-ts konb, vormals 'dieses gute Pferd' (mit der in der grammatischen Lokalisierung häufigsten Sequenz A-Pr-S) als Artikel nach sich:'das gute Pferd'. Die Konstruktion dobryj-ts konb trat mit dobryj konb in Wettbewerb und setzte sich als systemhafter durch (Verwendung eines einheitlichen Artikels tb). Durch die Verwendung von dobryj-ts konb, die durch die vorhandene rum. und alb. Inversion bunul cal, (i) miri kal gestützt wurde, kam es a. zu keiner Postponierung des Adjektivs wie im Rum., etwa konb-ts dobry, womit die Parallelität zum indeterminierten dobrs konb zerstört worden wäre, b. zur Postartikulierung immer des ersten Gliedes eines nominalen Syntagmas, daher nicht: đobryj konb-ts. Damit erreichte das Bulg.-Mak. die Inversibilität des Rum. und Alb.: cal-ul - bun-ul cal entspricht konb-tb dobryj-ts konb.

Die in der Slavistik ausgesprochene Vermutung, das slav. zusammengesetzte Adjekti.v vom Typ dobrb-jb, dobra-ja, dobro-je etc. habe funktionell und positionell den bulg.-mak. Ar- 
tikel initijert ${ }^{469)}$, ist inakzeptabel, da zur Zeit der Artikelbildung im Altbulg. das pronominale Element -jb der Adjektiva bereits kein klar vom Adjektiv zu trennendes Morphem mehr war' (vgl. den Instrumental dobryimb gegenüber dem 'nicht-zusammengesetzten' dobromb), sondern sich auf dem Weg zur Endung einer gesonderten Adjektivflexion befand. Dadurch wurde auch die Bildung von dobrb-jb-tb konb, nbulg. dobrijat kon erleichtert, d.h. die nochmalige Suffigierung des Adjektivs durch den Artikel. Nur diachronisch gesehen handelt es sich in dobryi-ts um zwei Artikel, und der Vergleich, den Svane ${ }^{470)}$ mit dem rum. calul cel bun und dem alb. kali $\underline{1}$ mirë anstellt, ist insofern unzulässig, als der postpositive und der präpositive Artikel im Alb. und Rum. durch funktionelle spaltung aus $e i n$ e $m$ Protoartikel hervorgegangen sind, dagegen ist in dobryj-ts konb ein verblassender Protoartikel durch die Hinzufügung eines Demonstrativpronomens in seiner Identifizierungsfunktion verstärkt worden.

Als Ergebnis ist festzustellen: In der Prage der Artikelposition im Bulg.-Mak. ergibt sich eine ähnliche Dreischichtigkeit der Entwicklung wie bei der Auswahl des Artikelmorphems (Kap. II.2.): I. Das Alb. liefert die Fostposition des Morphems, 2. das romanische ille bonus caballus wird unter alb. Einflub zu calul bun, was den romanischen Tendenzen zuwiderläuft, 3. das Bulg.-Mak. übernimmt mit dem AnstoB zur Artikelbildung und der Auswahl des Morphems vom rum. Substrat auch die Postposition des identifizierenden Artikels, die den slav. Tendenzen entgegenkommt. So erklärt sich der häufig angenommene 'courant linguistique albano-bulgaro-roumain 471 ) im Bereich des Artikels. 
4. Pormale Morphemevolution

Die funktionelle Inhomogenität des Stammes tb (in dreigliedrigen Zeigesystemen der Stämme ţ, onb, gb/ovb), der wegen des rum. und alb. Einflusses sowohl als kontextunabhängiger Artikel wie auch als real lokalisierendes Demonstrativpronomen verwendet wurde, lieB eine formale Differenzierung beider Funktionen durch Veränderung des Pronominalstammes wünschenswert erscheinen. Diese Differenzierung führte im Bulg.-Mak. zum Gebrauch der Morpheme tozi, toja in der real lokalisierenden und der Morpheme -bt, -ot in der rein identifizierenden Funktion, durch sie wurde die Existenz der Kategorie 'Nominale Determination' im Bulg.Mak. auch formal kenntlich gemacht. Der auslösende Punkt für die Differenzierung des Pronominalstames ist die unabhängig von inm entstandene phonetische Veränderung des Halbvokalverlustes im Slavischen, der sich auf dis Pormen des Demonstrativpronomens auswirkt.

Dieser phonetische ProzeB führt zum Verstummen der HV b, b in 'schwacher' Position: gradb > grad, gradbskyjb > gradskyj, und zur Vollvokalisierung der HV in 'starker' Position. Die Qualität der neuentstandenen Vokale ist in den verschiedenen Slavinen unterschiedlich, im Bulg.-Mak. lauten sie $\underline{0}$, e oder $\underline{b}, \underline{b}$, woraus weitere Reflexe möglich sind (nbulg. b ist ein Vollvokal mittlerer Zungenlage und nur graphisch mit dem altbulg. HV s identisch): dobitsks > dobitok, dobitsk - tbmbno > temno, t'bmno.

Der Halbvokalverlust affiziert die Form des Demonstrativpronomens in allen slav. Sprachen in den häufigen Formen $\underline{t_{b}}$ und $\underline{s b}$, deren HV je nach der Position in der Wortgruppe fortfällt oder vollvokalisiert wird, z.B. domb-ts > domo-t, $8 b \mathrm{dbnb}>\underline{8^{\prime}} \mathrm{den}^{\prime}$, ts žbrbcb > to žrec. Da die Vollvokalisation bei einer Umstellung des Substantivs und des Demonstrativpronomens $z u$ anderen Resultaten führte, die in ihrer Bedeutung miteinander identisch waren, entstanden bei den masku- 
linen Substantiva mit neuem konsonantischen Auslaut und beim Demonstrativpronomen im Nominativ positionsbedingte Allomorphe: dom / domo-, $-t /$ to $\left(-8^{\prime} /\right.$ se), vgl. für das Russ. bei Jakubinskij.472) In dem Bestreben, das Morphem des Nomens invariabel zu halten, wurde domot 'jenes Haus' nach dom als dom-ot interpretiert, was zu dieser Periode in den slavischen Sprachen zu den Allomorphen des Demonstrativpronomens (russ.) -ot, to (-08', se) nach nicht-palatalen Konsonanten und -et, to (-es', se) nach palatalen Konsonanten führte, vgl. (Hyp. $106,22-23)$ i bě bo ljubja gorods osb.

$\mathrm{J}$. Rozwadowski ${ }^{473}$ ) sieht in aksl. rodosb 'dieses $\mathrm{Ge}-$ schlecht' ein urslav. thematisches 0 im Auslaut erhalten: < *rodos-8is. VGl. Gblbbov. 474) Diese Annahme wird schon durch das parallele noštêsb < naktịs-8is widerlegt. - Skok 475) sieht im bulg. Artikel -ôt, - bat kein Produkt der Vollvokalisierung, sondern einen sekundären Einschubvokal wie in skr. fakat < lat. factum, also etwa vlbkb-tb > vlbk-t> vlbk-o-t.

Die infolge der Vollvokalisierung entstandenen Allomorphe des Demonstrativpronomens boten in allen slav. Sprachen die Möglichkeit, durch Zuordnung der real lokalisierenden (primären) und der grammatisch lokalisierenden (> rein identifizierenden; sekundären) Funktion an jeweils eines der Allomorphe primäre Morpheme für beide Funktionen zu schaffen, indem die früheren Allomorphe in phonetisch nicht gerechtfertigte Positionen traten, etwa: dom-ot 'Artikel', dom-to, to-dom 'Demonstrativpronomen'. Für diese Funktionsaufteilung mit Hilfe der Allomorphe des Demonstrativpronomens war allerdings Voraussetzung, daß eine genügend starke Kopplung zwischen einer der Funktionen und dem Demonstrativpronomen in einer bestimmten Position, d.h. einem seiner Allomorphe bestand. Wie die Ergebnisse in den modernen Slavinen zeigen, traf dies nur für das Balkanslav. zu, in dem das rum.-alb. Substrat die Zuordnung der grammatischen Lokalisierung des Demonstrativpronomens (> reine Identifizierung) zu seinem postpositiven Allomorph verstärkte. 
In den aksl. Beispielen, die sich häufig in paralleler Form in den übrigen Slavinen wiederfinden, spricht schon die klare deiktische Bedeutung des Demonstrativpronomens gegen die Existenz eines Artikels: in dbnesb, noštesb u.ä. liegt nur eine reale Lokalisierung vor. ${ }^{476)} \mathrm{Vgl}_{\mathrm{gl}}$ dbnesb zimens $\mathrm{Mth}, 16,3$. Marianus (dbnbsb zimns Zograph.) 'dieser kalte Tag', daneben dbnesb zimbno, wo dbnesb Adverb ist. ${ }^{477)}$ - Dobrejšovo Joh. 9,24: my věmb jako čl(o)v(ě) kotb grěšsnb ests - ín $\mu \tilde{i} s$

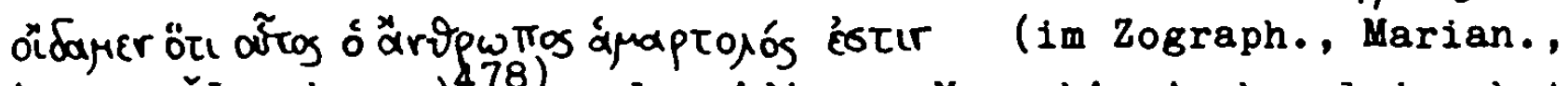
Assem. Človekb sb) ${ }^{48)}$, also 'dieser Mensch'. Auch zblbi rabot

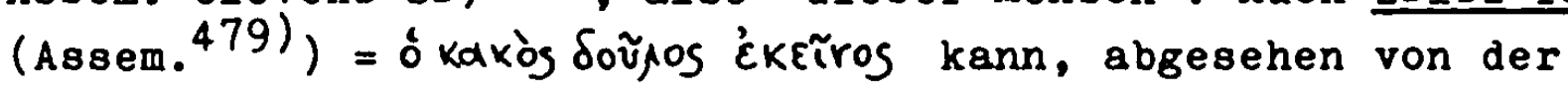
griech. Ubersetzung (Demonstrativpronomen), keinen Artikel enthalten, da dazu die Position rabot zbibi oder zblbi tb rabs erforderlich wäre. Das Allomorph -ot etc. wird in den aksl. Texten für die primäre wie für die sekundäre Punktion des Demonstrativpronomens verwendet, ist also nicht mit der grammatischen Lokalisierung (> reine Identifizierung) gekoppelt und stellt deshalb keinen Artikel dar. Dies gilt auch für die jüngeren (mittelbulg.) kirchenslav. Texte, in denen die Verwendung des Allomorphs -ot etc. stark zunimmt gegenüber der traditionellen Schreibung mit HV: $-s$ ts etc. In funktioneller Hinsicht verbirgt sich hinter einem belegten mittelbulg. člověkots $n$ i $c h t$ eher ein Artikel als hinter člověksts, da sich die syntaktischen Normen des Kirchenslav. hinsichtlich der Demonstrativpronomina und der Freiheit ihrer Position nicht geändert haben. Die zunehmende Frequenz der Schreibungen -ots etc. erklärt sich durch den Dialekt des Schreibers, der bei Einhal tung der syntaktischen Normen des Kirchenslav. die Lautform des nbulg.-mak. Artikels in den Text fließen

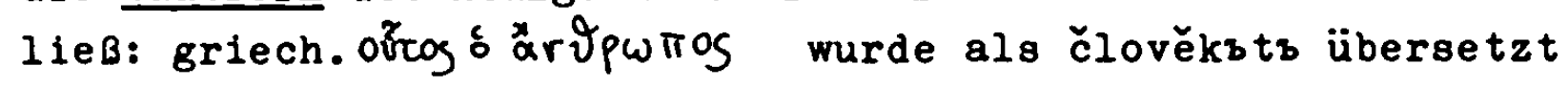
oder kopiert; da im Dialekt des Schreibers nur der Artikel -ot in dieser Position existierte, das Demonstrativpronomen aber die Form ţj, tozi u.ä. und die Voranstellung angenomen hatte, ersetzte der Schreiber člověksts durch člověkotb, wobei seine Kenntnis der kirchenslav. Morphosyntaktik inm sag- 
te: Was heute človekot ' der Mensch' heißt, bedeutete früher ' dieser Mensch'. Zwischen der Verwendung des Allomorphs -ots etc. und seiner Funktion besteht auch in mittelbulg. Texten kein Zusammenhang ${ }^{480)}$, jedoch weist seine erhöhte Frequenz durch Reflexion der Formen auf das Bestehen eines Artikelsystems in der Umgangsgprache hin.

Ebensowenig liegt im Altruss. oder in nordgroßrussischen Dialekten ein Artikelsystem, d.h. eine Kategorie 'Nominale Determination' vor, sondern der grammatisch lokalisierende, sekundäre Gebrauch des Demonstrativpronomens, dessen postpositives Allomorph eine emphatigche Partikel, keinen Artikel, ergeben hat: altruss. chlěbo-sb, nordgroßrussisch mužik-ot, mužik-to. Zu dieser Prage vgl. Wisgemann u.a. ${ }^{481)}$ und vor allem die negative Kritik der Theorie vom 'russischen Artikel' bei Stender-Petersen 482), Jakubinskij 483), Piotrovakij ${ }^{484)}$, Seliščev 485) und den Verweis Bernštejns ${ }^{486)}$ auf die Arbeit von V.K. Cičagov. "Es war nur eine mehr oder weniger verbreitete Verwendung des relativischen (grammatisch lokalisierenden) Pronomens in seiner postpositiven Form, das sich nicht zum Artikel entwickelte. Es ist eigentlich kein zerfallener, sondern ein nichtzustandegekommener Artikel; da er sich nicht entwickeln konnte, veränderte er sich in die Partikel $t$, ta to, die immer mehr zur Porm to verallgemeinert wurde ..." (Jakubinskij).487)

Im Bulg.-Mak. war dagegen die Koppelung von Postposition des Demonstrativpronomens und seiner sekundären Funktion durch den Kontakt mit dem Rum. gegeben. Jede Verwendung des Demonstrativpronomens in grammatisch lokalisierender Funktion führte zum Allomorph -ot etc., und so wurde dieses als Morphem mit der primären Punktion der reinen Identifizierung konstituiert. Da die Allomorphe des Demonstrativpronomens nur im Nominativ sing. masc. existierten, entstand in diesem Xasus die Differenzierung von Demonstrativpronomen und Artikel. 
a. Veränderung des Demonstrativpronomens in identifizierender Funktion

\section{Nominativ sing. masc.}

Die Entwicklung des postpositiven Allomorphs des Demonstrativpronomens zum postpositiven Artikel zeigt sich in dessen Auftreten in phonetisch den Bedingungen des Allomorphs nicht entsprechenden Positionen:

$\propto$. Auftreten der nichtpalatalen Variante des Allomorphs (> Artikel) nach palatalen Konsonanten bzw. nach Zischlauten: lovecos' 'der Jäger' < lovbcbsb gegenüber älterem lovces' 'dieser Jäger'. Die Generalisierung der harten Variante geht auf die Identität des Allomorphs (> Artikel) nach nichtpalatalen und palatalen Feminina sowie nichtpalatalen und palatalen Neutra zurück, nach der Proportion žena-ta : volja-ta = selo-to : polje-to $=$ grad-ot : $x ; x=10 v e c-o t$.

Diese Veränderung wird reflektiert von dem Beleg studenecosb (Dobrejšovo, Joh. 4.12) 'diese Quelle' aus dem 13. Jhd. Vgl. die Erörterung hierzu bei Gblbbov. ${ }^{488}$ ) $\mathrm{DaB}$ es sich in diesem Fall nicht nur um die Verhärtung des auslautenden $-\underline{c}$ handelt, beweist das ebenfalls im Dobrejšovo-Evangelium erscheinende

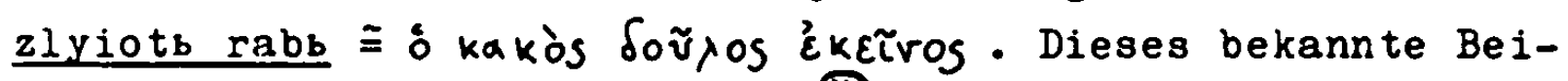
spiel (Mth. 24,48) aš(t)e li rếtb zlyiotb rabb vb srci

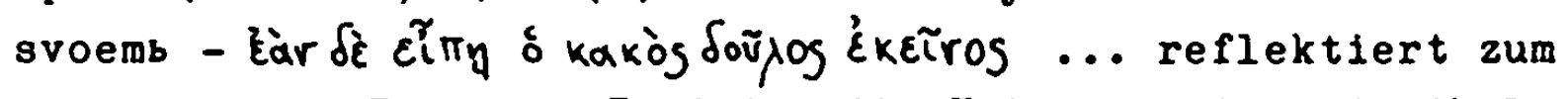
erstenmal in Form und Position die Existenz eines Artikelsystems im Bulg. des 13. Jhd. ${ }^{489}$ ) Die übrigen Kodizes bieten dafür: Zograph. (10. Jhd.) zblbi rabb tb, Asseman. zblbi rabot, Savv. kniga (11. Jhd.) zly tb rabb, Vračansko Ev. (13. Ihd.) zly ts rabs, Ostromirev. zly rabs ts. ${ }^{490)}$ Während also die aksl. Syntax mit künstlich freier Wortstellung die Syntagmata rabb tb, rabb tb zlyib, zlyjb rabs tb, zlyjb ts rabb, rabb zlyib $t_{b}, t_{b}$ rabs nebeneinander verwendet ${ }^{491}$, zeigt das Beispiel aus dem Dobrejšovo-Ev. das zugrundeliegende starre Artikelsystem mit fester Position aller Elemente und einem aus dem primären Syntagma rabb tb abgeleiteten Artikelmorphem.

Das postpositive Allomorph des Demonstrativpronomens im Altrussischen -ot, -et zeigt ähnliche Generalisierungserschei- 
nungen: angel'skojets glagols (bei Avvakum) 492 ) < angelbsksjbts nach dem Muster carets < carbtb, nordgrobrussisch tojno-jet 'der ihrige' zu toj 'ihr' (gen. sing. fem.). 493) Solange jedoch keine primäre Identifikationsfunktion des postpositiven Allomorphs vorausgesetzt werden kann, stehen tot, toj und oot/-et nach wie vor zueinander im Verhältnis von Allomorphen, bzw. das postpositive Allomorph erhält später Partikelcharakter (bildet kein system).

Mit der Generalisierung des postpositiven Allomorphs des Demonstrativpronomens als Artikel ging die Veränderung des präpositiven Allomorphs des Demonstrativpronomens zum neuen Demonstrativpronomen Hand in Hand und trug ihrerseits zur formalen Differenzierung bei. Als besonderer Archaismus ist die Form moi-t trup,. also mit der ursprünglichen Allomorphform ohne das - $0 / \mathrm{s} / \mathrm{e}$ des vorangehenden Nomens in den Csergeder Texten $z u$ werten. ${ }^{494)}$ In diesem Dialekt lautete das entsprechende Demonstrativpronomen aber inzwischen tozi.

Mundarten mit Erhaltung der Dublette -et/-ot (-st) sind wegen der parallelen Weiterentwicklung des Demonstrativpronomens durchaus möglich. In den Dialekten, in denen die HV b, b im Vollvokal $\underline{b}$ ('s) zusammenfielen (BDA I, Nr. 6,152, 153, BDA II, Nr. 5,169,171), kann der Artikel $-b(t)$ auf -bts wie auf -bts zurückgehen, denn auch nach palatal auslautenden Substantiva wird hier die Form $-s(t)$ verwendet (BDA I, Nr. 154, BDA II, Nr. 170). Daher den'b(t)< dbnbts oder dbn'-sts. Die getrennte Evolution von $-s t s$ und $-b t_{b}$ zum Artikel ist in den Dialekten feststellbar, in denen einem stol-o ( $t$ ) (hart) ein ključ-e (t) (weich) entspricht, vgl. stojkov $4 \overline{9}$ ) und BDA I, Nr. 154, BDA II, Nr. 170. Es sind dies in Ostbulgarien die Mundarten zwischen Tolbuchin und Varna, Elchovo und Grudovo, die Mundarten um Krumovgrad und die Mundarten des Smoljansko; in Westbulgarien die Mundart von Blagoevgrad ${ }^{496)}$ und die vom Piánec-Gebiet ${ }^{497)}$, u.a.498) In Makedonien findet sich der Artikel -e neben -o nach palatalen oder früher palatalen Konsonanten in einigen so-Mundarten des Maleševo. ${ }^{499)}$ Pür die 
Kontinuität dieser -e-Formen spricht, daß in den Dialektgruppen, in denen sie auftreten, der HV b neben anderen auch den Reflex e hat. So im Mak., zum Ostbulg. vgl. die Karten BDA I, Nr. 6,154; BDA II, Nr. 6,170. Geographisch liegen diese Dialekte von den progressiven Zentren Makedoniens und der Donau entfernt, verständlicherweise trat die Generalisierung der harten Variante zuerst in den Gebieten auf, die aufgrund des linguistischen Kontakts mit der Schaffung des Artikels begannen; von hier aus breitete sich die Generalisierung wellenförmig aus. Für eine häufige morphologische Entlehnung des Artikelmorphems innerhalb des Bulg. sprechen auch die Reflexe der harten Variante des Allomorphs -bts in den einzelnen

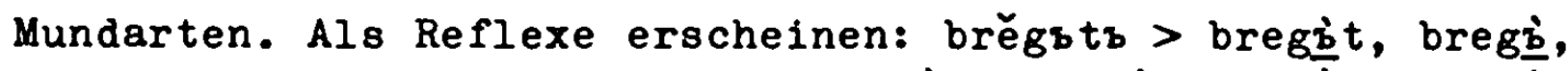

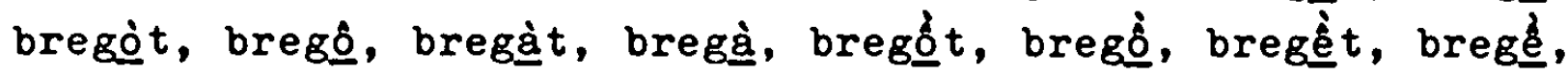
im Bulg.; bregot, brego, bregăt im Mak. (BDA I, Nr. 152 und Kommentar; BDA II, Nr. 169 und Kommentar) 500). Im Torlakischen herrscht ein Nebeneinander von -bt und -at: barútbat bostanat. 501) Dabei handelt es sich um einen synchronischen phonetischen ProzeB $\underline{b}>\underline{a} .502$ )

Alle diese Formen lassen sich auf die beiden Grundreflexe von brěgsts: brěgot und brěģt zurückführen, brěģt hat durch das sogenannte Vtorično izjasnjavane > bregat, bregठt, bregêt geführt. 503) Brěgot und brěģt sind qualitativ verschiedene Ergebnisse der Vollvokalisierung des HV b. Für irrig halte ich die Meinung Mirčevs von der älteren Vollvokalisierung $b, b>0$, e und der jüngeren $b, b>b, ' b$, letztere erst im Mittelbulg.!504) Bulg. b ist von Anfang an ebenso ein Vollvokal wie 으, das Verstummen der HV kann als zusammenhängender ProzeB nicht halbiert werden. - Die Bedingungen für das Eintreten von $\underline{\text { oder }}$ o für den HV $\underline{\text { s }}$ in den einzelnen Dialekten des Bulg. sind nicht ganz klar, während im Mak. HV $b>0, b>\underline{e}$ allgemein ist. ${ }^{505 \text { ) }}$ Der ProzeB HV $b>$ o in Stammsilben (sons > son) hat u.a. in den Mundarten von Stanke Dimitrov (Dupnica), Kjustendil, Blagoevgrad, Krumovgrad (Rhodopen) stattgefunden, in Prä- und Suffixen ist er weiter verbreitet, so in einigen SW-bulg. Dialekten, der 
Mundart von Pirdòp, der Mundart nördlich von Novi Pazar (BDA II, Nr. 2), im thrakischen Dialekt (BDA I, Nr. 2). In NO-Bulgarien ist der ProzeB HV $>$ o unbekannt und in Suffixen erscheint er selten (četvortok, pettok, mómok) ${ }^{506}$ ), ebenso in den vlachobulg. Urkunden. 507) Die Artikelform -ot ist aber gebräuchlich in den mysischen (Donau-) Dialekten, sie zieht sich in breitem Streifen östlich der balkanischen st-Variante bis an die bulg. Südgrenze (BDA I, Nr. 152, BDA II, Nr. 169), auBerdem in der Mehrzahl der westbulg. Mundarten. Dagegen lautet der Artikel $b(t)$, mit weiteren Reflexen, in den balkanischen, thrakischen und nordwestbulg. Mundarten (BDA I, Nr. 152, BDA II, Nr. 169).508)

Was besagt die Diskrepanz zwischen dem allgemein im Bulg. verbreiteten ProzeB HV $s>$ b und der Ausnahme - $b$ ts $>$ -ot beim Artikel? Sie ist am auffälligsten in den Donaumundarten. In ihnen kann von einem Import der Artikelform aus anderen Dialekten aufgrund der historischen Bedingungen (bilinguales Zentrum) nicht die Rede sein. Ich meine, daB in diesem großen Dialekt im rum.-bulg. Kontaktzentrum die seltenen Fälle von $\mathrm{HV}$ s $>$ o in Suffixen benutzt wurden, um eine besonders schnelle Differenzierung von $-s$ ts durchzuführen. So konnte ein vollvokalisiertes -bt noch als Allomorph des Demonstrativpronomens gelten und nach palatalen Konsonanten die Form -bt/et annehmen, während -ot in jeder Position bereits den Artikel darstellte. Mit anderen Worten: Vor die Wahl gestellt, -sts in -st oder -ot zu vollvokalisieren, wurde die generelle Regel HV $>$ s für das Morphem des Demonstrativpronomens verwendet, die seltene Regel HV $s$ 으, wie in dobitsks > dobitok, für die Bildung des Artikels. Die Dialektgruppe, in der diese Regelung bestand, besaß ein primäres Artikelmorphem noch vor der Generalisierung von -bt/ot nach palatalen Konsonanten, wie in lovecst (Balkanmundarten). Von dieser Gruppe innerhalb der Donaudialekte breitet sich der Artikel -ot nun durch morphologische Entlehnung im Donaubereich und weiter nach süden aus. Dafür ist ein typisches Beispiel der im 13. Jhd. aus NO- 
Bulgarien nach Siebenbürgen verpflanzte Dialekt der Csergeder Texte, in dem der ProzeB HV $>$ o $n u r$ in der Artikelform auftritt. Hier handelt es sich offensichtlich um keinen phonetischen ProzeB, sondern um eine Artikelentlehnung. Diejenigen bulg. Dialekte, in denen der ProzeB HV $b>0$ regelmäBig zumindest in Suffixen ist, und das Mak. ausgenommen, läßt sich annehmen, daß die übrigen Dialekte mit o-Artikel diesen entlehnt haben oder daB unter dem Einflub des o-Artikels in der Nachbarmundart der eigene, seltene ProzeB HV $b>$ o eingeschaltet wurde. Uber eine ännliche Verbreitung des b-Artikels läßt sich nichts sagen, da fast alle bulg. Dialekte den ProzeB HV $b$ b in breiter Anwendung kennen, evtl. mit weiteren Reflexen. Vgl. z.B. die Mundarten zwischen Tolbuchin und Varna in Ostbulgarien, in denen sich (mit Ausnahme des Punktes 1174) die Punkte 1175,1166,1171,1187,1190,1173,1946, $1192,1945,1949,1951,1953$ exakt aufteilen in solche mit *bbčva > b̧čva > běčva und parallel *brěgbts > bregbt > bregé, und solche mit *b̧čva > bbčva und parallel *brěģţ > bregí (BDA II, Nr. 1,169).

In den sehr seltenen Fällen, in denen ein bulg. Dialekt eine palatale und eine nichtpalatale Artikelform hat und beide mit dem generellen ProzeB von HV $b$, $b$ in Stammsilben übereinstimmen, ist die Annahme einer lokalen Entstehung der Artikelform gestattet. Dies gilt für die Mundart südlich von Krumovgrad an der bulg.-griech. Grenze (Rhodopen): *bbčva > bóčva (Punkte $4883,4884,4886,4887,4910) \cong$ brěgbts > bregòt; *tbnbko > tènko $\cong{ }^{*}$ pqtbtb $>$ pb̀tet. Schon die nächsten Nachbarpunkte $(4957,4888,4908)$ zeigen Durchbrechungen dieses Parallelismus. Da in diesen Punkten außerdem der dreigliedrige Artikel verwendet wird, der auf direkten frühalb.-slav. Kontakt zurückgeht (Kap. II.2.), ist hier anhand der guten Kartographierung die Feststellung einer primären Gegend der Artikelreplik gelungen.

Die innerbulg. Entlehnung der Artikelform findet ihre Parallele in der Entlehnung von Suffixformen ${ }^{509)}$, d.h. der 
Durchführung von HV $b>$ o in den Suffixen der mak. Mund-

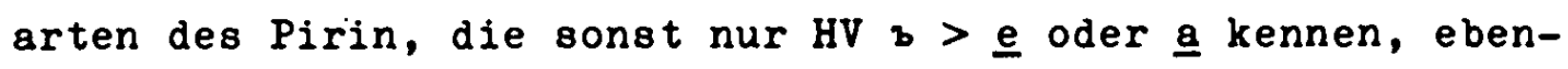
so in den nordmak. Mundarten, wo HV $b, b>\underline{a}$ gilt, jedoch petok, jarec, mrtovec ${ }^{510)}$, vgl. auch die Durchführung von HV $b>\underline{\theta}$ in Suffixen bei bulg. Dialekten, die sonst diesen ProzeB nur selten kennen 511$)$, - und in der Entlehnung von Lexemformen (ljubov) ${ }^{512)}$, sie konnte in den bulg. Mundarten der Sovjetunion $\underline{\text { im Prozeß }}$ von Bernštejn und Ceško ${ }^{513)}$ nachgewiesen werden.

SchlieBlich ist mit dem Tausch von $\underline{\text { und }}$ o im Artikelmorphem in denjenigen kundarten zu rechnen, die ein dreigliedriges Artikelsystem kennen oder kannten (vgl. Kap. II. 2.) : maž-ôv, maž-on führten zu maž-ot, oder maž- $\underline{t} t$ führte

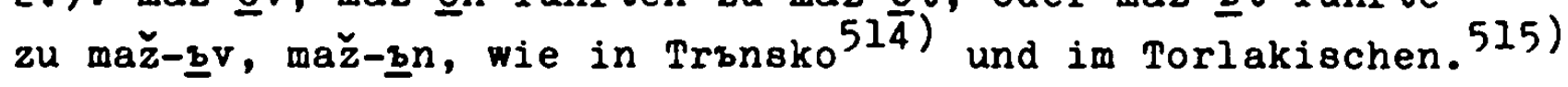

Zusammenfassend läßt sich sagen, daß die in den alten Texten spärlich reflektierte Verallgemeinerung eines der Allomorphe des Demonstrativpronomens zum Artikel in vielen bulg. Dialekten durch einen komplexen ProzeB wechselseitiger Beeinflussung erreicht wurde, der sich an der Verbreitung des Artikelmorphems -ot verfolgen läBt. Die Entlehnung des Artikelmorphems setzt dessen Isolierung von den übrigen fällen der Vollvokalisation voraus, und es ist dieselbe Isolierung des Artikelmorphems, die den innersystematischen Ersatz studen(e)cesb > studenecos' nach gradog' ermöglicht. Die seitens der rein identifizierenden Funktion unternommenen Maßnahmen zur formalen Aufteilung des Demonstrativpronomens beinhalten demnach drei Arten der Generalisierung des postpositiven Allomorphs:

1. -ot 'Artikel' gegenüber -st, -'bt/-et 'Demonstrativpronomen'

2. -bt, -ot 'Artikel' nach Palatalen gegenüber -'bt/-et 'Dempron.'

3. Entlehnung der generalisierten Form in andere Dialektsysteme. 
$\beta$. Generalisierung der unartikulierten Nominativform auch vor dem Artikel

Im Bulg.-Mak. gilt ausnahmslos die Regel, daB 'flüchtige' Vokale des Singulars eines Substantivs im Plural ausfallen, daB die unartikulierte Singularform jedoch auch vor den Artikel tritt:

den - dni (Singular unartikuliert - Plural unartikuliert) den - denjat bulg. (Sing. unartikuliert - Sing. artikuliert) den - denot mak.

Diese Generalisierung ist eingetreten aufgrund der Proportion žena : ženata $=$ pole $:$ poleto $=$ lovec : $\mathbf{x} ; \mathbf{x}=$ lovecot $/-b t$, gegenüber äl terem lovcot, lovcbt 'Demonstrativpronomen', sie wird reflektiert durch die obengenannte Form studenecosb < studenbcbsb (Dobrejšovo-Ev., 13. Jhd., Joh. 4,12). Jedoch finden sich in den Dialekten noch Archaismen vom Typ lovcot/ -st, vgl. bej den Siebenbürger Bulgaren p'äskot 'der Sand' < pěssksts. 516)

*. Ausgleich der Adjektivformen im Nominativ sing. masc.

Die Oppositionsglieder

dobrs : dobra : dobro

dobryjb-ts : dobraja-ta : dobroje-to

verändern sich in der mittelbulg. Periode durch den die fem. und neutr. Formen ergreifenden phonetischen ProzeB der Vokalkontraktion $z u$

(dobrъ, später: dobsr) : dobra : dobro

(dobryjb-ts, später: dobrij-bt) : dobra-ta : dobro-to.

$B e i$ den Banater Bulgaren sind die $Z w i s c h e n s t u f e n$ dobrajta (< dobrajata), dobrojto (< dobrojeto) belegt. 517 )

Die neue Bildungsweise der femininen und neutralen Formen (unartikuliertes Adjektiv + Artikel des Substantivs $\longrightarrow$ artikuliertes Adjektiv) konnte von der maskulinen Form nicht dadurch nachgeahmt werden, dab dobri (< dobryjb) für das unartikulierte maskuline Adjektiv generalisiert wurde (dobri : 
dobrij-st = dobra : dobra-ta), denn in der Periode vor der Kontraktion war die ehemalige zusammengesetzte Form des Adjektivs in nichtpostartikulierter Position durch die entsprechende Kurzform ersetzt worden ${ }^{518}$ ), der Typ dobri existierte nicht mehr außer im Vokativ (mili druže), in Archaismen (Svéti Ivan) und bei einer relativ geringen Zahl von Adjektiva (selski, boži, treti). 519) So besteht die Bildungsinkongruenz der artikulierten Adjektiva in den meisten bulg.-mak. Dialekten weiter, mit dem Ergebnis, daß synchronisch gesehen der Artikel des maskulinen Adjektivs im Singular bulg. -ijbt, mak. - ipt lautet:

$$
\text { nov : nov-ijat = nova : nova-ta = novo : novo-to }
$$

und sich rom entsprechenden Artikel des Substantivs -bt/ot unterscheidet. Die Allomorphe des Adjektivs (nov : novi-; nova : nova-ja > novaj-; novo : novoje > novoj-) werden damit beiseitigt.

In manchen Dialekten ist ein Ausgleich zwischen den beiden maskulinen Artikeln eingetreten: stàr'ạt (: star), màlk'ąn (: malsk) in den Rhodopen, mlad'ot, slep'ot (unterer Vardar), sogar selsk'at (in der Strandža, obwohl hier der Parallelismus selski - selskijat erhalten war), wo nur die Palatalität des auslautenden Konsonanten dem vollständigen Parallelismus mlad : mlad'ot = brat : bratot im Wege steht. ${ }^{520}$ ) Jedoch auch die Palatalität kann ausgeschaltet werden: starbt (: star), malkst (: malsk) in den Rhodopen. 52I) Vereinzelt erscheint auch pr\{łvnut, drúgut in Kulakija, drugựt, krajnut am unteren Vardar. ${ }^{522}$ Gblsbov schlägt eine phonetische Erklärung vor, die den vereinzelt (Solunsko, Verkovič) bezeugten Prozeb starbjb > staroj, nicht > staryjb, auf die Dialekte mit den genannten Ausgleichungen ausdehnt, also golěmb-jb- tb > golèmjsts. ${ }^{523)}$ Dies ist ganz unwahrscheinlich, da die artikulierten Formen im Solunsko selbst goljámojut, slépoju lauten, nicht "golěm'ot, *slěp'ot. Weil die artikulierte Form des Maskulinums im Solunsko und auch sonst in mak. Dialekten eine "Umgestaltung des Mask. -iju(t) nach dem Neutrum -otu"524) 
ist, d.h. golěmoto + golěmijot > goljamo-tu + goljamo-jut, darf das Bestehen eines Prozesses starbj > staroj im Solunsko überhaupt bezweifelt werden, eher hat die umgebildete artikulierte Adjektivform die nichtartikulierte beeinfluBt $>$ goljamoj. 525) DaB die Typen starst etc. auf Analogie zu den Substantiva beruhen, ist dagegen offensichtlich.

In seiner phonetischen Porm entspricht das Artikelmorphem des maskulinen Adjektivs im Singular im allgemeinen dem Artikelmorphem bei palatal auslautenden Substantiva: pìt'o - bèlijo, pàt's - bèlijb, píte - bèlije etc. (BDA I, Nr. 154, 157; BDA II, Nr. 172,175) Lehrreich sind hier Differenzen. In einigen ostbulg. Mundarten haben die adjektivischen Artikel die weitere Entwicklung von $s>a$ bei den Sub-

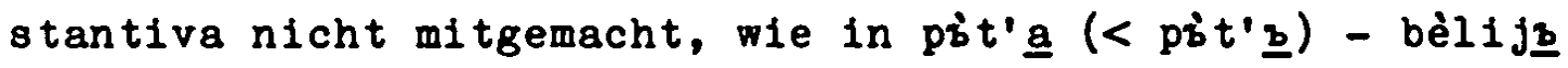
(BDA II, Nr. 172,175, Punkte 1166,1945,1951,1580,1630,1628, $1636,1639,2466,2467,1645)$. In anderen Pällen ist ein Reflex der palatalen Variante -bts beim Adjektiv erhalten geblieben und beim Substantiv unter Einflub des harten Substantivs zu

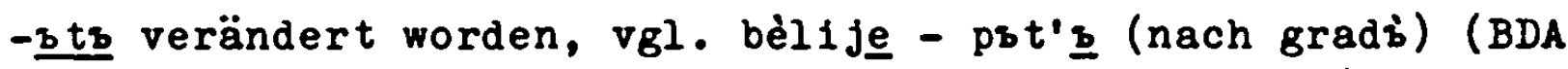
II, Nr. 172-175, Punkte 767,816,792,1535,1533); umgékehrt

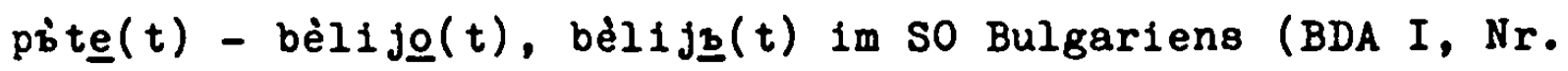
154,157 , Punkte 4217,3782,3780,3849,4220,4886,4883,4884,4910, 4754). Die schriftsprachliche Porm mladifa(t) stellt phonetisch ein mladifo(t) dar.

\section{Plurale -ta, -te, -to}

Zur Artikelform -ta im Plural Neutrum (selata 'die Dörfer'): Der Zusammenfall der Pluralformen der Adjektiva im Nominativ aller Genera, dem sich die Pronomina anschließen, ist für das 12.-13. Jhd. belegt (judejsky statt judejsci im Bologneser Psalter) ${ }^{526)}$, vgl. nbulg. tezi gradove, tezi ženi, tezi sela. DaB der Artikel nicht an dieser Neutralisierung teilnahm, zeigt, daB er zu dieser Zeit als ein vom Demonstrativpronomen getrenntes Morphem existierte.

Die Neuerung im Nominativ plur. masc. + fem. des De- 
monstrativpronomens ti und ty $>$ tẹ unter dem EinfluB der obliquen Kasus těchb, těmb, těmi hat der Artikel dagegen mitgemacht. Die Neutraliaierung von ti und ty > tě ist im Dobrejšovo-Ev. (13. Jhd.) belegt: Mth. 25,7. vsę děvy tě $-\pi \tilde{\alpha} \sigma a c$ ai

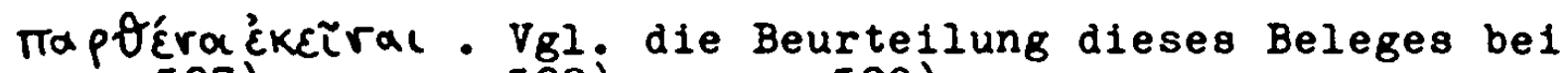
Svane ${ }^{527)}$, Koneski ${ }^{528)}$, Mirčev529).

Mit der Ausdehnung des Morphems - $(b j)$ e im Plural der maskulinen jo- und 1-Stämme ${ }^{530)}$, das mit dem Kollektivauffix - (bj)e zusammenfiel (schon im Suprasliensis kumirie statt kumiri, im Zusatz zum Zographensis voždie statt voždi), geriet der Artikel des neutralen Singulars in den Plural der

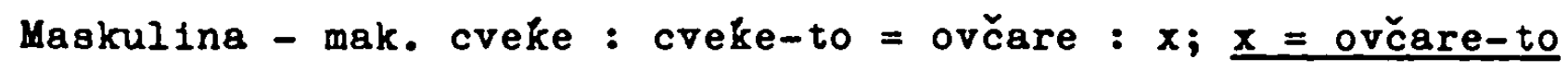
'die Schäfer'. Zu der weitverbreiteten Konkurrenz von bulg. mb̌̀ète - mbžèto, gradinàrite - gradinàrito, d.h. aurh mit Uberführung von - to in die durch - 1 gebildeten maskulinen Plurale, vgl. die Karten BDA I, Nr. 155, BDA II, Nr. 174. Erste Belege dieses Gebrauchs zeigen die Cergeder Texte: angeleto neben angel 1te. 531 )

b. Veränderung des Demonstrativpronomens in lokalisierender Punktion

Parallel mit dem formalen Ausbau des Demonstrativpronomens in rein identifizierender Funktion zum Artikel geht seine Umgestal tung in real lokalisierender Funktion. Letztere wird ebenfalls durch den Schwund der HV in schwacher Position ausgelöst. In vielen Positionen verlor der Nominativ sing. masc. der Pronomina tb und $s b$ seinen HV (tb sonb $>t_{-} s o n, t_{-} s b n$; sb dbnb $>8^{\prime}$ _ den, $s^{\prime} d^{\prime} b n$ ) und wurde deshalb in den einzelnen slavischen Sprachen durch verschiedene Morpheme erweitert, so im Russischen durch das Pronomen -jb (tsjb > toj) oder durch Doppelung (ts ts > tot).

Der Beginn der Angleichung der Demonstrativpronomina $\underline{s b}$ und $t b$ an die Plexion der zusammengesetzten Adjektiva im Nominativ, die im Süd- und 0stslavischen aufritt, läßt sich 
im Aksl. und im Altrussischen feststellen: Aksl. sii, sei $(<s b-j b)$ 'dieser', sije (statt se) 'dieses', sija 'diese' tsi 'dieser', tii 'diese' (masc.), tyje 'diese' (fem.).532) Für altrussisch sej, toj vgl. Jakubinskij. 533) Da die grammatisch lokalisierende Funktion des Demonstrativpronomens meist mit seiner Postposition und seine real lokalisierende Funktion meist mit seiner Präponierung verbunden sind, sind die suffigierten Formen vor allem in der Voranstellung zu beobachten. So unterscheidet sich in den Kiever Blättern das postponierte Demonstrativpronomen vom präponierten auch formal: $3 b i$ prinosb - prinosb $\underline{s b}^{534)}$, jedoch zeigen Fälle wie v dbnb tbj ${ }^{535)}$ im Bulgarisch-Kirchenslavischen, daB die ältere Stufe des Slavischen keine obligatorische Koppelung von real lokalisierender Punktion/Präponierung/Suffigierung kannte.

Die Suffigierung der Nominativformen des Demonstrativpronomens ist nicht infolge des HV-Verlustes entstanden, sie erhielt aber durch diesen ihre besondere Verbreitung. Der bulg. Reflex toj hat seinen Vokal den obliquen Kasus (togo, tomu) entnommen und ihn auf soj, (o)noj ausgedehnt, im Mak. ist ovoj, toj, soj (< sej nach toj) auch allein durch den phonetischen ProzeB s>0 erklärbar. 536) Die mak. Formen im Singular Femininum taa, ovaa, Plural tie, ovie gehen eher auf $t \bar{a}-(<$ taja)-ja, tî- $(<$ tije)-je denn auf einfaches taja, tije zurück.

Vom 12. Jhd. an 537) dringen neue Suffigierungen der Demonstrativpronomina auch in die Texte ein. Es sind dies zuerst $-\underline{z i}(z e)$, später $-j a(-j e),-\underline{-v a}(-v e),-\underline{k a}$ u.a.: tozi, toja, tova 'dieser', tomu-zi-ka 'diesem'. Inre Verbreitung erreicht mit dem Eintreten der Vokalkontraktion taja $>$ t $\bar{a}>$ ta, toje $>$ tō $>$ to (vollzogen bereits in den vlachobulgarischen Orkunden des 14. Jhd.) eine erhöhte Frequenz, um erneut Demonstrativpronomen und Artikel morphematisch zu differenzieren. Zur Entstehung und Verteilung der neuen Demonstrativsuffixe vgl. Beli(t53), Miletič539), Lamouche ${ }^{540)}$ und vor allem MazonVaillant $5 \dot{4 l}$ ). 
Zusammenfassend läBt sich die formale Trennung von real lokalisierender und grammatisch lokalisierender Funktion des Demonstrativpronomens im Bulg.-Mak. folgendermaßen skizzieren: Der HV-Verlust führt zur Entstehung von Allomorphen für die Präponierung und die Postponierung, die den beiden Funktionen zugeordnet werden. Erstes Differenzierungsglied ist der Nominativ sing. masc., durch Ausdehnung von $-j b$ auf andere Kasus (taja, toje, tii etc.) greift die Differenzierung um sich. Ihre Neutralisierung mit dem Artikel durch den später einsetzenden Proze $B$ der Vokalkontraktion intensiviert die Verbreitung einer zweiten Suffigierung des Demonstrativpronomens in real lokalisierender Funktion.

c. Entstehung des Artikelallomorphs -

Die nbulg. Schriftsprache unterscheidet bei den artikulierten Masculina einen Casus subiecti (Nominativ) narbdbt und einen Casus obiecti (Akkusativ) naroda. Zum einen ist für - $\underline{s}$ aus graphischen Gründen eingetreten, um in der alten Orthographie den unartikulierten Nominativ grádb vom artikulierten Akkusativ gradb zu unterscheiden. ${ }^{542)}$ Aber auch die systematische Trennung von Casus subiecti narbdst - Casus obiecti narbdb ist ein 'MiBverständnis.543), denn innerhalb eines Dialektsystems heiBt es narbdbt - na narbdbt angl1jskijbt (evtl. mit palatalen Varianten) oder naróds na narbdb - anglijokijb, oder die Formen mit erhal tenem -t sind mit den Pormen auf $-b$ austauschbar, jedoch in jeder syntaktischen Funktion, 80 dab narbdst und narbdb fakul tative Varianten sind.

Die syntaktisch bedingte Alternation von - $\underline{b t}$ und - $\underline{a}$ in der Schriftsprache muB daher noch einen anderen Grund haben. Dieser liegt im Gebrauch eines speziellen Objektmorphems bei Personennamen und Verwandtschaftsbezeichnungen in mehreren konservativen bulg. und mak. Mundarten: na Stojana, na sina (altbulg. Genitiv-Akkusativ syna), denn zwischen der alten 
Kasusform - $\underline{a}$ und dem Artikel -st/ot konnte es zu einer funktionellen Annäherung kommen. 544 )

Diese hängt mit der Veränderung des bulg. Kasussystems zusammen (vgl. Kap. III). Deshalb gehört die aksl. Verwendung von raba/rabs für das direkte Objekt, die Meillet545) als determiniert (raba) - Tòr Soṽ or und indeterminiert (rabs) Soṽfor unterscheidet, nicht hierher. Berneker ${ }^{546}$ ) bestreitet Meillets Ansicht über die Bedeutung von rabs-raba; Thomsen weist nach, dab für den Hechsel von rabb-raba im Objektkasus syntaktische Gründe bestehen: in den seltenen Fällen von rabs in der Funktion des Objektkasus war eine mibverständliche Auffassung dieser Form als Nominativ aus anderen Gründen nicht $z u$ befürchten, so 1. nach Präpositionen: vyiti za mǒ̌b, 2. mit Ergänzungen (svojb u.a.): otbcb vidě rabs svojb, 3. wenn durch Kontext oder Sprechsituation der Sinn klar ist: mati rodi syns, zovets brats pbss, oder wenn das Prädikat vorangeht: se privěsę čivks něms běsens (Marianus, Mth. 9,32).547)

Bei der Verwendung von raba für rabs im Objektkasus handelt es sich um eine nach der Neutralisierung von "gordos (Nominativ) und "gordom (Akkusativ) zu (aksl.) grads eingetretene Differenzierung von Subjekt- und Objektkasus bei Substantiva, die Lebewesen bezeichnen, die sich daraus erklärt, das das Subjekt (Agens) eines Satzes meist von Bezeichnungen für Lebewesen und besonders Personen gebildet wird, das direkte Objekt dagegen gleichermaßen von Bezeichnungen für Lebewesen und Sachen ${ }^{548)}$ und das die daraus resultierende assoziative Verbindung von Subjekt-Lebewesen eine besondere Unterscheidung von Subjekt- und Objektfall bei den Bezeichnungen für Lebewesen nötig macht, damit nicht jede Bezeichnung eines Lebewesens als Subjekt des Satzes mißverstanden wird (so schon frühindogermanisch: Neutrum mit einer Porm für den Subjekt- und Objektkasus; Genus animatum mit zwei Pormen). 549) Während sich der Differenzierungsproze $B$ in den anderen Slavinen fortgesetzt hat, mit. . dem Ergebnis, daß man in ihnen von einem Genus animatum (oder 
personale im Polnischen) sprechen kann, zu erkennen im Akkusativ sing. + plur.550), ist im Bulg-Mak. eine neuerliche Differenzierung des Akkusativs raba in den Akkusativ rab 'einen Sklaven' - raba 'den Sklaven' eingetreten.

Der Grund dafür ist in der Aufgabe der synthetischen Kasusmorpheme im Bulg.-Mak. zu sehen, die zu einer Neutralisierung aller Endungen in einer Porm führt. Diese Generalform des Substantivs wird entweder vom früheren Nominativ oder vom Akkusativ geliefert, vgl. žena (Nominativ) - ̌̌eng (Akkusativ) > žena oder ženb (Casus generalis), entsprechend im Neutrum und im Plural aller Genera. Die belebte Tesen bezeichnenden Substantiva der o-stämme schlossen sich diesem Prozeb an:

konb (Nominativ) - konja (Akkusativ) > konjoder konja (Casus generalis). Hier hat sich im Polgenden kon(i) allgemein durchgesetzt. Aber Fälle mit dem Morphem -a in Subjektfunktion sind in den Texten und der Volksdichtung des Bulg.-Mak. belegt: Chludov. Triod (13. Jhd.) proroka iona vbpijaše 551); in der Volksdichtung: mu veli cara Murat-bega .... konja Marku mu govoreše...552), pbpa du pitkl ${ }^{553)}$; daneben die neuen, feminin gebrauchten Nominative doma, roda, mrava, smea, skota im Mak., die Ortsnamen Bitol'a, Resna, Debra554); im Dialekt der bulg. Pomaken: v\&lkata vleze v košarata 555), bulg. Pamiliennamen wie Blàgoveca, Sumàra, Bliznàka, Pilip Bóžia 556) in den vlachobulg. Urkunden: što ju im e dal popa Makarie 557 ).

Dieser (ältere) Ausgleich von Nominativ und Akkusativ Ist ohne EinfluB auf das Artikelmorphem. Sein Resultat war aber, daß im Objektkasus der belebten o-stämme neben dem alten Akkusativ konja auch der alte Nominativ konj in objektfunktion gebräuchlich wurde, wobei es sich um keine Anknüpfung an die obengenannten aksl. Archaismen (otbcb vidè rabb svojb) handelt, sondern um eine Neublldung ${ }^{558)}$, die mit der Bildung des Casus generalis bei den bulg.-mak. Substantiva überhaupt im Einklang stand. Die Formen konj und konja standen sich als 
Allomorphe des Objektkasus gegenüber. In dieses Nebeneinander brachte eine bestimmte Gruppe von Substantiva eine Runktionsneuverteilung.

Verwandtschaftsnamen und Personennamen zeichnen sich in vielen Sprachen durch eine starke Resistenz gegen Neuerungen im System aus. Im Mak.-Bulg. bedeutet dies: 1. Sie bewahrten am längsten die synthetischen Kasusformen, 2. Sie nahmen ke1nen Artikel an (im Gegensatz zum Alb. und Rum.), da Eigennamen implizit identifiziert sind (inhärente Determination), vgl. Kap. II.1.559) Zur Bewahrung des Objektmorphems -a bei Personennamen $\nabla g 1$. Stojkov ${ }^{560)}$, Koneski 561 ) und BDA I, Nr. 158, 159 mit Kommentar. Im Gegensatz zum Einbruch des -a in den Nominativ setzt der Einbruch des -a in die Serie der Artikelmorpheme einen jüngeren Zustand voraus, in welchem die Verwendung des Morphems - $\underline{a}$ nur bei Personennamen und Verwandtschaftsbezeichnungen noch regelmäßig ist. Aus der Opposition eines Appellativs, für das inzwischen die Kategorie der nominalen Determination entwickelt worden ist, und eines Personennamens: viždam stol - viždam stolst / - viždam Petra ergibt sich für das Morphem - a die Information: 1. Objektkasus, 2. identifiziert. Die Identifikation wird also bei Appellativa durch den Artikel, bei o-stämmigen Personennamen durch das Morphem - $\underline{a}$ gekennzeichnet. Das gleiche Verhältnis besteht zwischen dem Artikel im Dativ (-tomu, jünger: na ${ }_{j}$ • -bt) und dem Morphem -u, -ove etc., z.B. daj tatkove mi $i^{562 j}=$

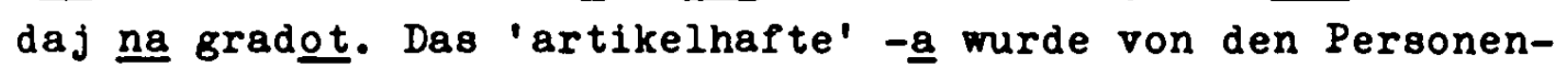
namen auf die belebten maskulinen Objektkasus rückübertragen, mit dem Ergebnis, daB sich z.B. In den vlachobulg. Urkunden vom 15. Jhd. $a n^{563)}$ die al ten Nominativ-Akkusativ-Pormen für die Wiedergabe des belebten maskulinen Substantivs im Objektkasus häufen: dadoše edin kon, za edin kon etc. ${ }^{564)}$, gegenüber: oni mu sut uzeli konè (= konja $)^{565)}$, weil nun die aksl. Nominativ-Akkusativform für den Ausdruck des indeterminierten Casus generalis gebraucht wird, die aksl. Genitiv-Akkusativ-Porm für den Ausdruck des determinierten Objektkasus. 
Pür den determinierten Subjektkasus steht die Artikelform $(-s t / o t)$ zur Verfügung. Das Ergebnis des Gesamtprozesses ist: Belebte Wesen (Maskulina)

\begin{tabular}{l|c|c} 
indeterminiert & kon & kon \\
\hline determiniert & $\begin{array}{c}\text { konjbt } \\
\text { Casus subiecti }\end{array}$ & kasja \\
& $\underbrace{\text { Casus obiecti }}_{\text {Casus obieneralis }}$
\end{tabular}

Damit tritt im Objektkasus konja neben stolbt, und ein Austausch der funktionsgleichen Morpheme -a und - st wird möglich. Vgl. die ähnliche Erklärung von Miletič, der jedoch die Schichten (aksl.) rabs-raba, bulg.-mak. pop-popa im Subjektkasus und bulg.-mak. konj-konja im Objektkasus nicht unterscheldet. 566 )

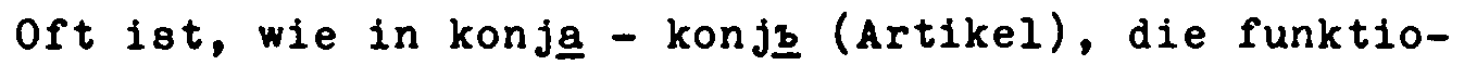
nelle Angleichung beider Morpheme durch ihre phonetische Ahnlichkeit intensiviert worden. ${ }^{567)}$ Dies gilt für die Mundarten mit dem Artikelmorphem $-s(t)$, welches in unbetonter Position eine a-Färbung annehmen kann oder generell (positionsunabhängig) zu a umgelautet worden ist. So ist ein Casus obiecti vòlz < vòls oder vòla möglich, z.B. in Tichomir (Rhodopen). In anderen b-Mundarten bleibt dagegen der Unterschled lautlich gewahrt: rekla na sinà $8 i$ - gegenüber $\frac{\text { ginb }}{569}$ im Subjektkasus und gradi im Subjekt- und Objektkasus. ${ }^{569}$ ) Ebenso in den o-Dialekten: sink $\underline{6}$ 'den Sohn' - vblko 'den Wolf'.

In den progressiven Dialekten des Bulg.-Mak. ist das Morphem -a als Kasusanzeiger (Objekt) bei Personennamen und Verwand tschaftsbezeichnungen geschwunden: mak. so Stojan_, bulg. Viždam Bogdan_570), dafür ist inm jedoch im Schriftbulg. der Einbruch in die Serie der Artikelmorpheme gelungen, und die Schriftsprache hat für seine Verbreitung auch bei unbelebten Substantiva im Objektkasus gesorgt. - Das neue Artikelallomorph -a kann zum Schwund des auslautenden -t des Artikels in vielen bulg.-mak. Dialekten beigetragen und (im 
Bulg.) den Vokal des Artikels (> - $\underline{a} t$ ) beeinfluBt haben.

Gblsbov hält die klaren Morphemgrenzen des bulg. Artikels: vol-bt, žena-ta, selo-to, volove-te, dobrij-st, gegenüber den mit den Kasusformen verschmelzenden Artikelmorphemen in den übrigen Balkansprachen: griech. $6 \tau_{0} \sigma \pi i \tau l<\varepsilon^{\prime} i s$ Tò $6 \pi \check{\tau l}$; rum. casă : casa, alb. vajzë : vajzą etc. für einen Beweis, daß der bulg. Artikel keine Replik zu der Artikelform anderer Balkansprachen darstellt und im Gegentell vom Rum. leicht zu kalkieren war. ${ }^{571)}$ Ahnlich urteilt Seidel beim Vergleich der balkanischen Possessivkonstruktionen: griech. ó

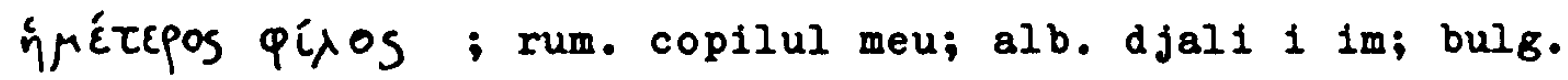
moeto dete. "Nur das Bulgarische zeigt durch die Nachstellung des Artikels, ohne Hypertrophie (wie im Albanischen), ohne Enklise des Artikels an das Substantiv (wie im Rumänischen), ohne formale Unsicherheit über die Zugehörigkeit des Artikels zum (adjektivischen) Possessivum, also zum Adjektiv, die balkanische Struktur in nuce'. "572) Und weiter: "Als nicht nur typische, sondern auch durch inre Vermittlerrolle aller balkanischen Einzelzüge (...) wichtigste Balkansprache stellt sich vielmehr das Bulg. dar. "573)

Dagegen läßt sich sagen: Die klare phonetische Form des bulg.-mak. Artikels spricht eher für seine relativ junge Entstehung, gegenüber den alb. und rum. Artikelmorphemen, die a. an alten phonetischen Verschmelzungsprozessen (alb. vajza < vajzë + ja/ea, rum. masa < męsa + éaya, domnul < dominu + ellu etc.) und $\underline{b}$. an der Deklinationsumgestaltung teilgenommen haben, daher der alb. Obliquus nuses < nusje-së, bregut < *bregi-të, Akkusativ nusen < snusăm tăm, bregun < *bregom-tom, rum. omului < omb-ellui, fetei < feate-ellei etc., vgl. Kap. III. Der bulg. Artikel nahm nur am HV-Verlust teil und entging der Beeinflussung durch Plexionsendungen wegen der stärkeren Vermeidung des Zusammenfalls von Kasusfunk- 
tion und Identifizierungsfunktion im bulg. Artikelmorphem. Die alb.-rum. 'Hypertrophie' des Artikels (Kap. II. 3.b.) hängt gleichfalls mit der Deklinationsumgestal tung zusammen, und die Zugehörigkeit des bulg. Artikels zum Adjektiv in dobro-to dete geht auf die slavische Adjektivvoranstellung zurück. Die echte Verbindung von Attribut und Artikel liegt eine ganze Epoche zurück, im Frühalb. *kal i-mirë und Prührum. "calu ellu-bunu. Die heutige Fusion von Artikel und Kasusendung im Rum. muB nicht für die Zeit gelten, als das Bulg. seine Artikelreplik bildete (also noch: "lupu-liu, featä-lla). Betrachtet man die Balkansprachen im Teilsystem des Nomens als ein Gesamtsystem, so sind gerade die fusionierten alb. und rum. Artikelformen für die interne Rekonstruktion viel aufschluBreicher als die klaren bulg. Artikelmorpheme.

In der Tat kommt das Bulg.-Mak. dem balkanischen Metamodell am nächsten, jedoch nur in synchronischer Hinsicht. Daraus läßt sich nicht auf eine historische Priorität des Bulg. gegenüber dem Alb.-Rum. im Artikelbereich schlieBen (vgl. Kap. I.l.), denn der Grad der Ausbildung eines Elementes in zwei vergleichbaren Sprachsystemen hat keinen Aussagewert darüber, welche der beiden Sprachen das Modell für die Replik der anderen abgegeben hat. Die heutige bulg. Progressivität ist das Resultat der systeminternen Weiterentwicklung entlehnter Elemente, während das Alb.-Rum. bei dem älteren Zustand der Koppelung von Kasus- und Identifizierungsfunktion in $\mathrm{e} i \mathrm{n} \mathrm{e} \mathrm{m}$ Morphem stehengeblieben ist. Die heutige Progressivität des Bulg.-Mak. beweist keine Progressivität gegenüber dem Alb. und Rum. in der Zeit um das 10. Jhd., wie am Aksl. abzulesen ist. Im Gegenteil spricht die rezente bulg. Entwicklungsdynamik im Nominalbereich für eine relativ junge Replikbildung, die zum bulg. Artikel führte, gemessen am $\mathrm{Alb}$. und Rum. - $Z u$ ähnlichen Ergebnissen führt der Vergleich der bulg.-mak. mit der rum. und alb. Umgestaltung der Kasusflexion, s. Kap. III. 
d. Chronologische Einordnung der Artikelevolution

Unterteilen wir die älteren alb.-rum.-bulg. Sprachkontakte aufgrund der in Kap. 1.2. angestellten Uberlegungen schematisch in

a. 1.-3. Jhd. Massenhafte Romanisierung der Balkanbevölkerung, Substratbildung des Prühalb. im Frührum.

b. 3.-6. Jhd. Abnehmende Romanisierung, Beginn der Eigenentwicklung von Alb. und Rum.

c. 6.-10. Jhd. Massenhafte Slavisierung von Rumänen und Albanern, Substratbildung des Rum. und Alb. im Bulg.-Mak.,

so ergeben sich aus der chronologischen Bewertung der vorgenommenen internen Rekonstruktion die Resultate:

Ein dreigliedriges Artikelsystem existierte im Alb. bereits in der Zeit vor der Romanisierung des Balkans, daneben war in attributhaltigen Syntagmata der Protoartikel erhalten. Das dreigliedrige Artikelsystem lag im Alb., wie die slavischen Repliken (domos - domot - domon) zeigen, noch nach dem 6. Jhd. und maximal bis zum 10. Jhd. vor. In diese leit fällt die Umsiedlung der Albaner in die Gebiete des heutigen Albaniens.

In der intensivaten alb.-rum. Kontaktzeit (1. - 3. Jhd.) bildete das Rum. Repliken $z u$ der im Alb. vorliegenden protoartikelhaltigen Konstruktion *kal i-mirë. Die rum. Replik - calu ellu-bunu lag bis zum 3. Jhd. vor. Bis zum 10. Jhd. hat das Rum. einen postpositiven Artikel ausgebildet, seine Evolution fällt daher zwischen das 3. - 10. Jhd.

Für das Rum. gestattet jedoch die slav. Artikelevolution durch Replikbildung eine Vorverlegung der unteren zeitlichen Grenze. Wenn gewisse bulg. Dialekte bis zum 10. Jhd. ein Artikelsystem herausgebildet haben, das durch den HVSchmund sichtbar gemacht wird, so müssen die vom Bulg. kal- 
kierten Muster im Rum. schon länger in festem, systemhaftem Gebrauch gewesen sein, und die Evolution von ersten spontanen Replikbildungen des Bulg. bis zum System des 10. Jhd. (s.u.) wird längere leit gedauert haben: Die slavische Replikbildung gestattet eine Vordatierung der Entstehung von primären Artikelmorphemen im Rum. bis maximal zum 6. Jhd. Vgl. balkanisch-rum. Toponymika mit postpositivem Artikel vom 9. Jhd. an bei Densusianu. 574) Das Auftreten des Artikels bei Eigennamen und Ortsnamen setzt seinen längeren Gebrauch bei den Appellativa voraus. Es hat somit den Anschein, als ob sich die wichtigsten linguistischen Prozesse, die zur Bildung eines Morphems mit primärer Artikelfunktion führten, im Rum. zwischen dem 3 . -6 . Jhd, abgespielt haben, d.h. zwischen der Räumung Daciens durch die Römer und dem Einfall der Slaven.

Piotrovskij575) versucht mit der Feststellung von Artikelformen $\underline{a}$. in balkanischen Ortsnamen, $\underline{b}$. in Entlehnungen der Balkaneprachen untereinander zu einer Datierung der balkanischen Artikelmorpheme zu gelangen. Seine Deutung ist miBlungen, da a. die Artikulierung von Ortsnamen in eine spätere Phase der Artikelentwicklung gehört, b. in den Zentren der balkanischen bilingualen Gruppen die Artikelmorpheme der Fremdsprache, auch bei etwaigen Ortsnamen, als solche erkannt und bei der Entlehnung von Substantiva ausgeschieden wurden (Skok).576) Pälle von Artikelentlehnungen sind im Balkanraum selten. 577) Zweifelhaft oder falsch sind ferner in Piotrovakijs Datierungsvoraussetzungen: daß der französische und der italienische Artikel, den die ersten Texte dieser Sprachen in 8. und 9. Jhd. zeigen ${ }^{578)}$, in progressiven romanischen Dialekten ausgebildet wurden, während Dacien von Bauernkolonien überzogen war, in denen konservative Dialekte gesprochen wurden, weshalb ein rum. Artikel vor dem 8./9. Jhd. a priori unmöglich se1. 579) Der alb.-rum. Bevölkerungs- und daraus folgend Sprachenkontakt bleibt hier gänzlich unberücksichtigt. - Das AR verwendet $\underline{1 u}$ und ali zur Deklination, diese 
Morpheme seien in den übrigen rum. Dialekten unbekannt (!, vgl. Kap. II.3.b.), deshalb habe es um das 10. Jhd. (Trennung von $A R$ und $D R$ ) noch keine gemeinsame Artikelform gegeben. 580) Der rum. Artikel habe sich um/nach dem 10. Jhd. herausgebildet, gleichzeitig mit dem bulgarischen, und der alb. Artikel schlieblich gehe auf bulg.-mak. EinfluB (im 13. Jhd.) zurück. - Die Ergebnisse der internen Rekonstruktion widersprechen dieser oberflächlichen Datierung in allen Punkten.

Bulg.-mak. Artikel: Hier gab es früher die extremen Standpunkte Miletič einerseits, der den bulg. Artikel in die urslav. Periode zurückdatierte, und vieler nichtbulg. Slavisten andererseits, die in Uberschätzung der bulg.-kirchenslav. Texte eine Artikelentstehung vor dem 15. - 16. Jhd. ablehnten. 581) Zur Kritik dieser späten Datierung vgl. Ilic. 582) Der urslav. Theorie Miletič hat sich Gblbbov angeschlossen, er geht wie Miletič von einem bulg.-russischen Artikelparallelismus und einer Existenz von Artikeln im Aksl. aus. Zur Kritik dieser Annahmen vgl. oben Kap. II.3.4., sowie Svane.583)

Insbesondere bezweifle ich, da die Artikulierung von Ortsnamen nicht in die frühe Phase der Artikelentwicklung gehört, daß der im 11. Jhd. südlich des Ohrid-Sees belegte Bergname Bpoxwiós tatsächlich ein slav. vrbch-ot 'der Berg' darstellt, wie Gslsbov meint. ${ }^{584}$ ) In der Chronik des Georgius Cedrenus Ioannis Scylitzo (mittelgriech.) heiBt es über die Ereignisse nach 1018: ... ó 'ß

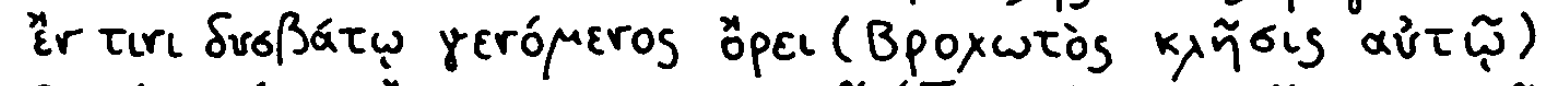

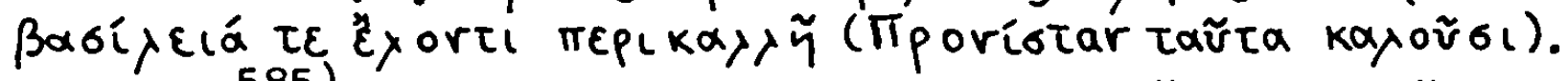
zlatarski 585$)$ übersetzt: ... Ivaca, kato izběgal i otišsl na edna nedosţpna planina (Vrochot e imeto 1) na kojato imalo prekrasen dvorec (Proništa go naričat), und er lokalisiert Vrochot und Proništa im Tomorgebirge (Mal i Tomorrit), südlich des Ohrid-Sees, nahe von Devol. Während Tporíta unzweifelhaft slav. Prọništa wiedergibt, möchte ich Bpoxwtós eher als griech. erklären, denn Bergnamen und Gewässernamen 
wechseln weniger schnell als Ortsnamen mit einer neuen $\mathrm{Be}-$ völkerung, und zu ( $(\hat{\eta}) \beta$ poyń 'Peuchtigkeit', 'Regen',

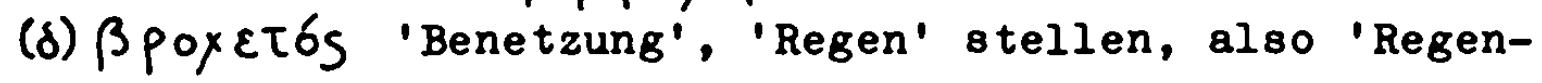
berg'. Vergleiche einen anderen Regenberg in Griechenland, den 0s8s, mittelgriech. Kísoapor ßourór, neugriech. Kíapog < slav. *kišavb zu kiša 'nasses Netter', 'Regen', der in der Volksdichtung als 'Regenberg' dem 'Schneeberg' 0lympos gegenübergestellt wird (Vasmer) ${ }^{586}$ ), und den Ortsnamen ( Bpóxol 587), sowie den modernen alb. Ortsnamen Moglicë < Moglica zu mbgla 'Nebel' am Devol-PluB. Von der Existenz eines so zweifelhaften Namens auf die Existenz eines Artikelsystems auch in den konservativen SW-Mundarten in jener Zeit schließen zu wollen 588), lst m.E. unzulässig.

Ansonsten tendiert die neuere Porschung zu einer Detierung der Artikelentstehung um das 10. Jhd., wobei sie sich auf den Unterschied zwischen progressiven ostbulg. und konservativen SW-bulg./mak. Dialekten (Aksl.) stützt, vgl. Mirčev 589), Trifonov 590), Svane 591). Dabei herracht Einhelligkeit darüber, daB das 13. Jhd. als Terminus ad quem zu gelten hat: 80 Koneski ${ }^{592)}$, Svane 593), Mirčev594). In folgenden ordne $1 \mathrm{ch}$ die aus meiner bisherigen Untersuchung sich ergebenden Indizien für eine Datierung in chronologischer Polge an:

Bis zum 10. Jhd.

1. Der bulg.-mak. Artikel lot in Auswahl und Position vom rum. und tellweise vom alb. Artikelsystem beeinflubt worden, diese Beeinflussung liegt zwischen dem 6. - 10. Jhd. 2. Aksl. kennt kein Artikeloystem, ist aber ein konservativer peripherer Dialekt.

3. Die synchronischen Prozesse stara> stara-ja (Urslav.Balt1sch) und žena > žena-ta sind voneinander getrennt. 4. Abhängigkeit des Artikelmorphems -ot/st vom HV-Verlust im 10. Jhd.

Bis zum 13. Jhd.

1. Artikelentstehung vor der Entnasalierung auslautender Na- 
salvokale (11. - 13. Jhd.), da in den Cergeder Texten: dete detento (< dětę). 595 )

2. Demonstrativpronomen mit dem Suffix -zi ab 12. Jhd. 3. Artikelformen - te, - ta im Plural, vor dem Genuszusammenfall bel den Adjektiva und Pronomina im Plural; zwisehen 12. 14. Jhd. 596)

4. Belege studenecosb, zlylotb rabb im 13. Jhd.

Daraus ergibt sich folgendes Bild: Bis zum 10. Jhd. war in den progresitien bulg.-mak. Dialekten der Gebrauch des Demonstrativpronomens in identifizierender Funktion nach dem alb.-rum. Muster so weit entwickelt, daB der HV-Verlust zum Entstehen des Artikelmorphems führte. Dieses ist durch einen langen zeitlichen $\mathrm{Zwischenraum} \mathrm{von} \mathrm{der} \mathrm{freien} \mathrm{Komposition} \mathrm{der}$ zusammengesetzten Adjektiva getrennt, seine Entstehung geht aber der Entnasalierung und dem Ausgleich der Genera im Plural der Adjektiva voraus und verläuft mit der Bildung des Demonstrativpronomens vom Typ tb-jb ungefähr parallel. Da die Demonstrativpronomina vom Typ tojbzi eine Reaktion auf die Vokalkontraktion der zusammengesetzten Adjektiva und Pronomina darstellt, liegt die Artikelbildung auch vor der Vokalkontraktion (ab 12. Jhd.).

Die Ausbreitung der neuen Kategorie durch die progressiven Dialekte auf die übrigen bulg.-mak. Dialekte vollzieht sich in der Periode vom 10. - 13. Jhd. Das Aksl., als peripherer konservativer Dialekt im 9. Jhd. zur Schriftoprache erstarrt, wird von der Ausbreitung nicht erfaBt. Dieses Bild bestätigt die Ansicht von Mirčev und Svane. - Der Ausbreitungoproze $B$ wird in der kirchenslavischen Iiteratur durch eine wachsende Verwendung des Demonstrativpronomens in sekundärer, grammatisch lokalisierender Funktion reflektiert: im Codex Suprasliensis (11. Jhd.), in den Schriften deg Exarchen Johann 597), im Praxapostolus ochridensis (12. Jhd.) 598), Im Dobrejšovo-Evangelium (13. Jhd.) ${ }^{599)}$, im Narodno žitie Ivana Rilbskago (12. Jhd.) 600), in den Erzählungen von Michail Voins (14. Jhd.) 601), vgl. zu weiteren einschlägigen Texten 


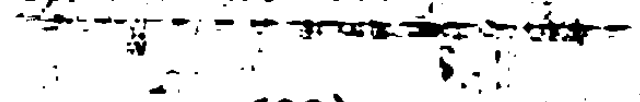

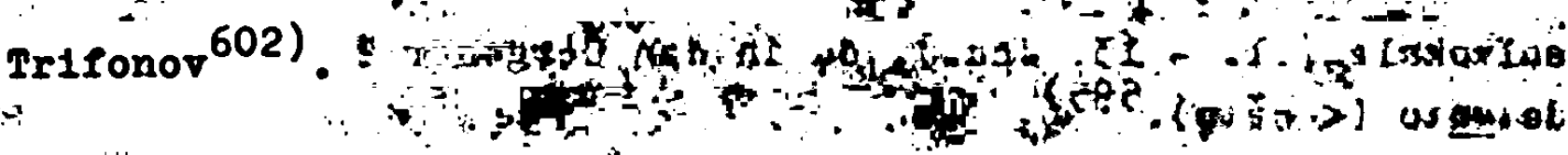

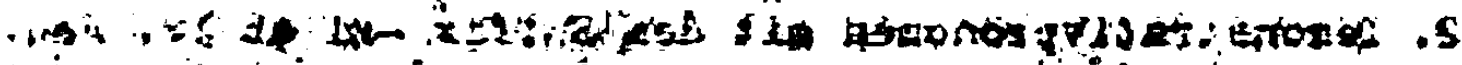

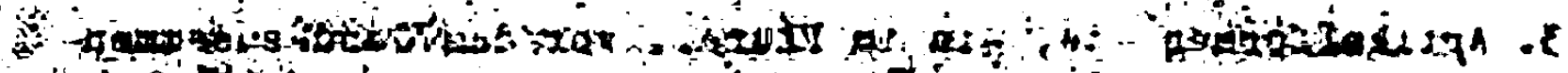

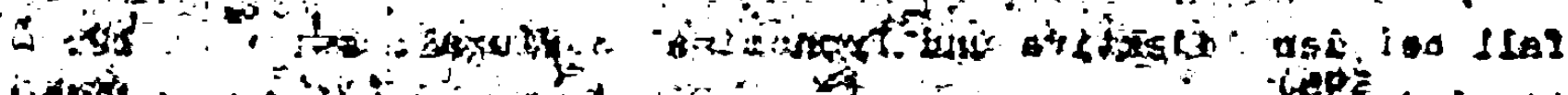

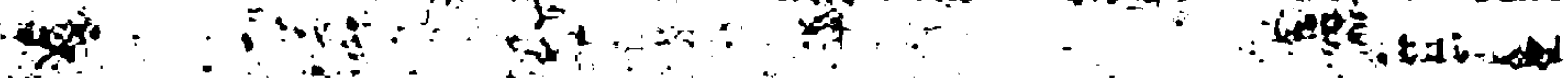
a

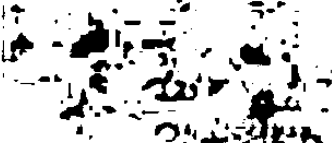
Ni

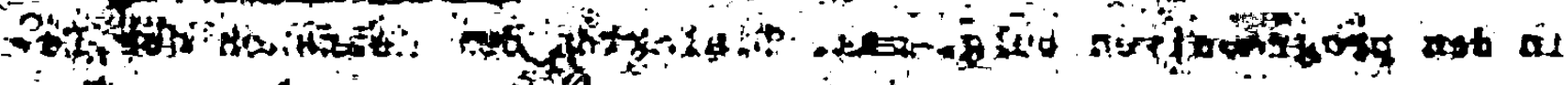

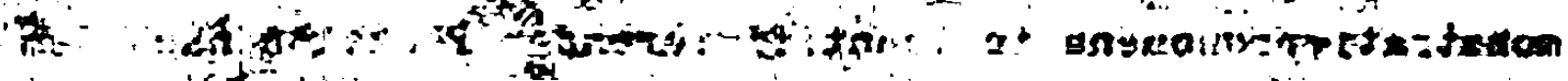

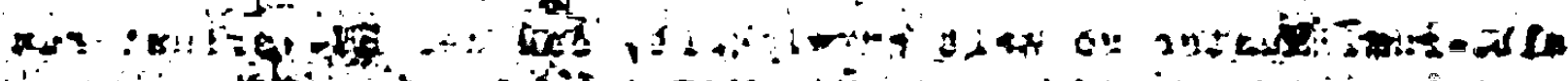

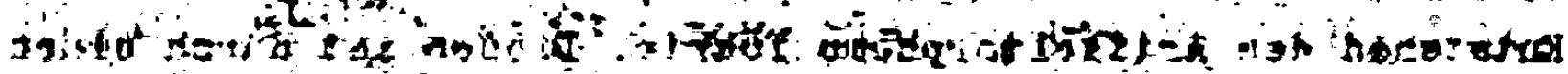

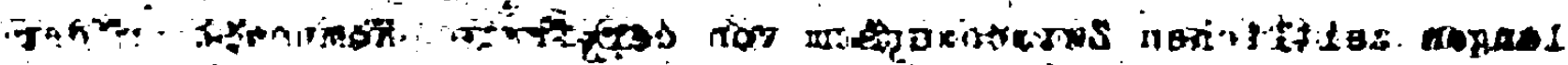

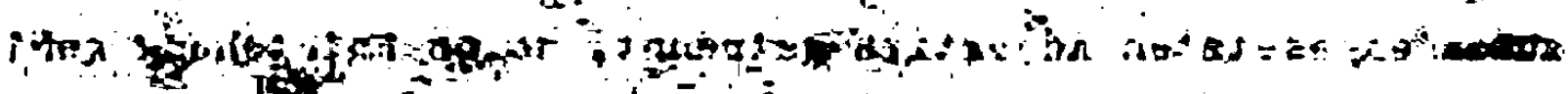
$\Rightarrow$ - -1 $x^{3}$

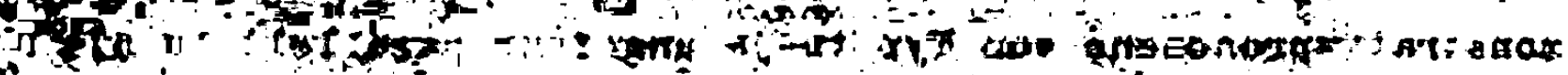
-

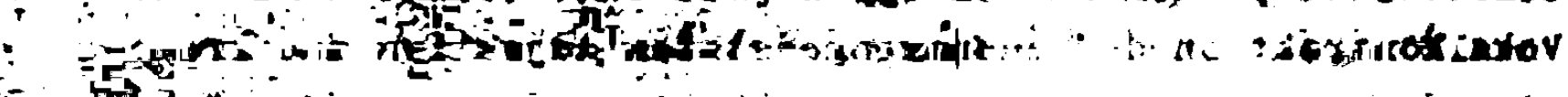
$\therefore-y_{0}$

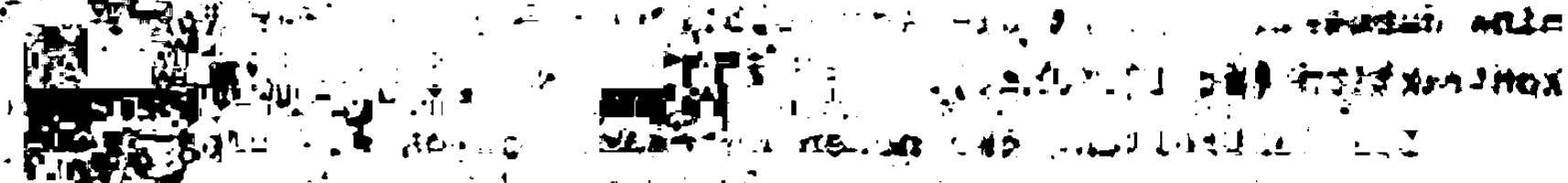

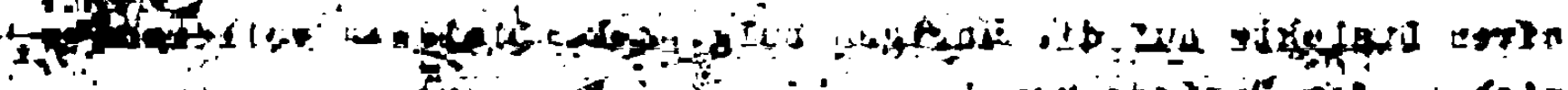

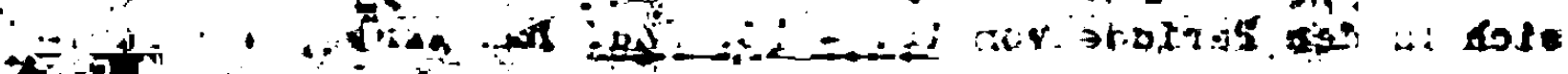

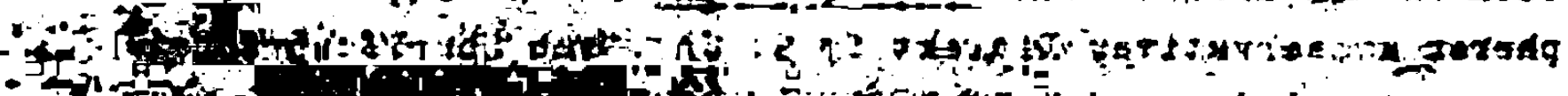

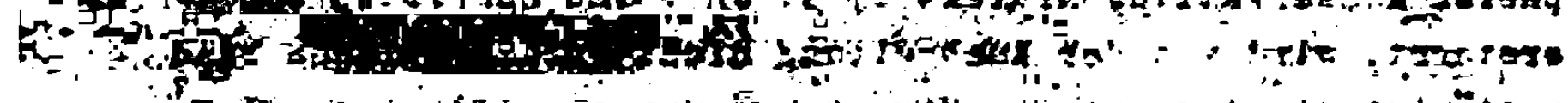

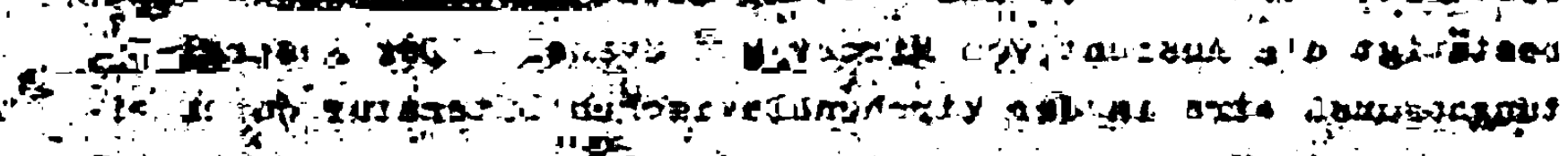

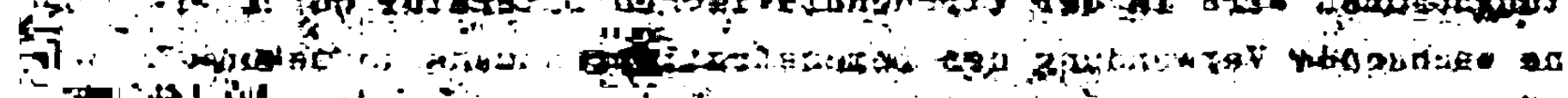

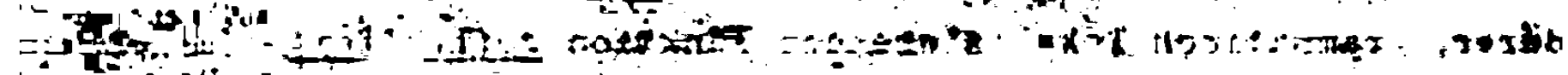

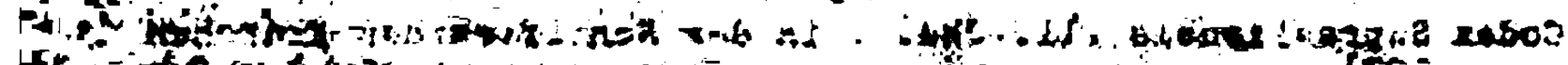

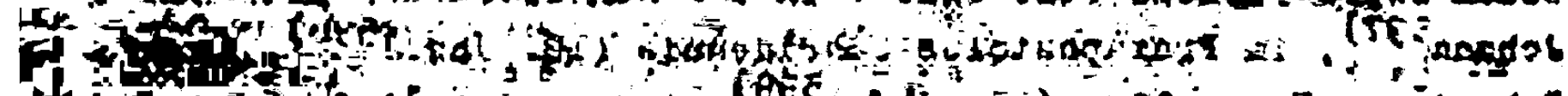

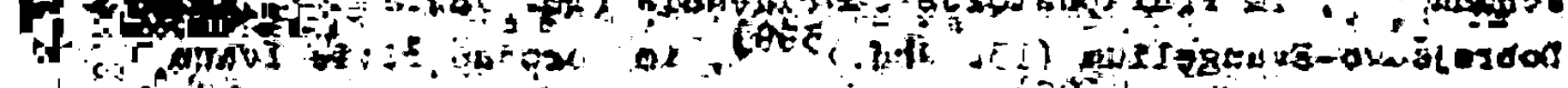

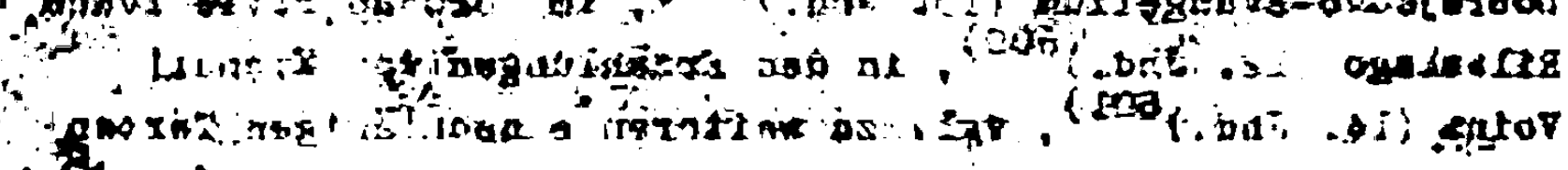

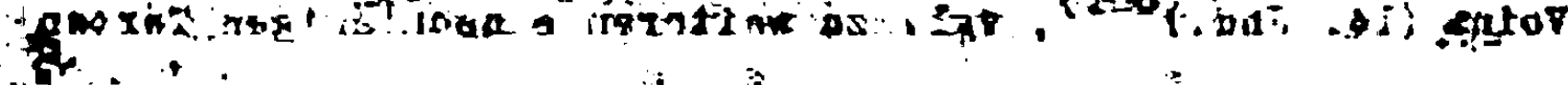

ar s.

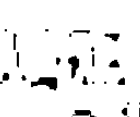

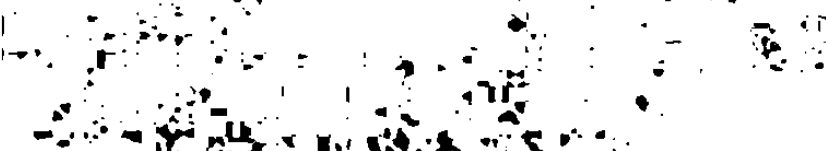


Die u.a. von Löfstedt $t^{603)}$, Racoviffá64), Seidel 605), Civ'jan606), Miletič607) angenommene Kausalverbindung 2wischen der Entstehung der Kategorie der nominalen Determination und der Umgestaltung der synthetischen Kasusflexion, derart, daB "entweder der Artikel als Konsequenz der Schwächung der Nominalflexion aufritt, oder daB sich umgekehrt die Nominalflexion aufgrund der Bildung und Entwicklung des Artikels vereinfacht, oder daB sowohl der Artikel wie die Plexionsschwächung einem dritten Paktor zuzuschreiben sind, der zu entdecken bleibt" (Coteanu) 608), ist zuletzt von Coteanu in seinem Aufsatz zur Artikeltheorie zurückgewiesen worden, und zwar anhand konkreter Analysen z.B. der nordgermanischen, griechischen, altfranzösischen, armenischen u.a. Sprachen. Die von Meillet ${ }^{609)}$ dargelegte Autonomie der Entstehung des (bel ihm: griechischen) Artikels bleibt somit bestehen. Auch aus der Entwicklung des Bulg.-Mak. läBt sich kein Zusammenhang in der Entstehung beider Prozesse, der Artikelevolution und der Umgestaltung der Kasusflexion, angeben: Am Beginn der bulg. Kasusumgeetaltung waren die Präpositionen beteiligt, nicht der Artikel. Als Entwicklungsschema beider Prozesse im Bulg.-Mak. stellt sich demnach eine getrennte Entstehung und eine im Laufe der späteren Entwicklung beider Prozesse eintretende Konvergenz dar, die Rückwirkungen auf die Weiterentwicklung beider Prozesse hat:

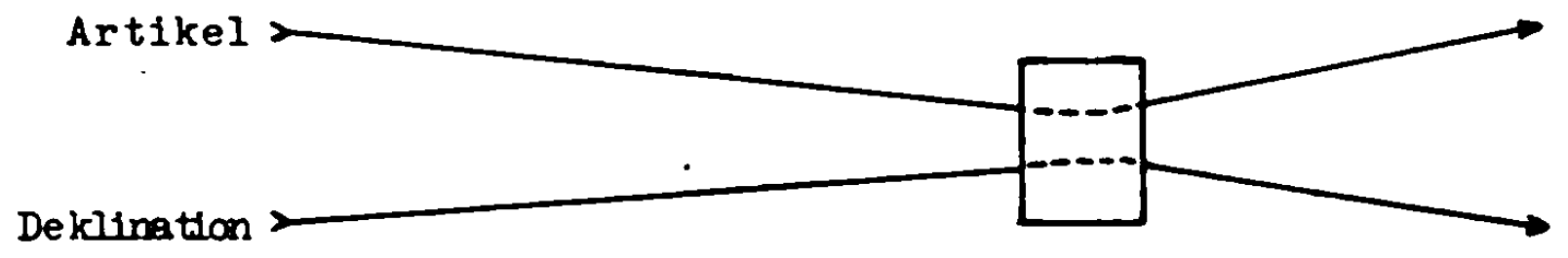

Der Artikel und der Individualisator sind ständige Begleitmorpheme 1hres Nomens, haben also eine höhere Frequenz beim Nomen als andere Attribute, wie das Adjektiv und das adjektivische Pronomen, deren Auftreten stärker semantisch bedingt 
1st. Stärker als Adjektiva und Pronomina nehmen deshalb Artikel und Individualisator Einflub auf die morphologischen Alternationen des mit innen $z u$ einer Einheit verbundenen Nomens, d.h. auf dessen Kasusflexion.

Auf einer frühen Entwicklungsstufe des bulg.-mak. Artikels (gleiches gilt für den Individualisator) wiederholt dieser, vom Demonstrativpronomen gebildet, die Kasus-NumerusInformation des Nomens nach der Konkordanzregel, was zu einem paradigmatischen Pleonasmug in der neuen Kategorie führt ${ }^{610)}, z . B$. bulg. kralju-tomu, mit der Angabe des obliquus sowohl beim Nomen wie beim Artikel. Die Kategorie 'Nominale Determination' ist auf dieser Stufe durch einen Kasusparallelismus gekennzeichnet, der es erlaubt, von einer einfachen (kralju - nicht-identifiziert) und einer zusammengesetzten Plexion (kralju-tomu - identifiziert) zu sprechen (složno sdonenie bel Miletič) 6ll). Jedoch kann in der Geschichte einer Sprache eine Verschiebung dieses Parallelismus eintreten, nach der die sekundäre Kasusinformation des Artikels nicht mehr pleonastisch ist. Bei Veränderungen in der Kasus-Numerusflexion kann die Kasus-Numerus-Information des Artikels Bedeutung für das ganze Syntagma erlangen als einzige formale Kasus-Numerus-Angabe für die Analyse des Hörers. 612) Polgende Typen im Verhältnis zwischen der Kasusflexion des Nomens und des Artikels sind möglich:

I. Artikel ミNomen (Das Kasus- und Numerussystem des Nomens und des Artikels sind annähernd parallel!)

II. Artikel > Nomen (Der Artikel hat ein stärker ausgebildetes Kasus- und Numerussystem als das Nomen.)

III. Artikel < Nomen (Der Artikel hat ein schwächer ausgebildetes Kasus- und Numerussystem als das Nomen.) 613)

Das Absterben der synthetischen Kasusformen des Nomens in den Balkansprachen steht deshalb in Verbindung mit einer erhöhten Prequenz des Artikels (und des Individualisators), der zur Kasusbezeichnung verwendet wird, auch wenn keine Identifizierung des Nomens beabsichtigt oder sinnvoll ist. 
DaB die Verbindung von Artikel + Nomen ein einheitliches Ganzes gegenüber dem isolierten Nomen und keine bloBe Addition von Artikel und Nomen darstellt, zeigt sich in der diachronischen Entwicklung, wo die Kasusflexion des determinierten Nomens eine vom nicht-determinierten Nomen abweichende Porm annehmen kann.

Bei der Betrachtung des bulg.-mak. Kasussystems in der Diachronie ergibt sich die Schwierigkeit der Definition des Terminus 'Kasus'. Warum betrachte ich bulg. na grada als Kasus ('der Stadt'), dagegen bulg. za grada ('für die stadt') als Präpositionalverbindung? Vgl. die Diskussion dieser Prage be1 Todorov614), Dilevski 615), Michajlov616), Ceško617), Andrejčin 618) und Mirčev 619). Hier kann das Kasuskriterium natürlich nicht aus der Ubersetzung in ein anderes Sprachsystem geliefert werden, etwa, daß na grada ein Kasus (Genitiv-Dativ) sei, weil er dem aksl. grada-gradu oder dem lat. urbis-urbi entspricht, dagegen za grada dem aksl. ks gradu (za grads) oder dem lat. pro urbe, d.h. einer Präpositionalfügung. Kasus nenne ich im Polgenden solche Morphemverbindungen, die in primärer Funktion eine oder mehrere syntaktische Beziehungen ausdrücken. Diese zugrundegelegten syntaktischen Beziehungen sind Subjekt, direktes Objekt, Attribut und zusätzlich als halb-semantische Beziehung das indirekte Objekt, auf denen die Satz-Transformationen der indogermanischen Sprachen beruhen: Aktivsatz zu Passivsatz wie in skr. hajduci su ubili konjanika > konjanik je ubijen hajducima (Beziehung Subjekt - direktes Objekt) und Aktiv(Passiv)-Satz zu einer Nominalform (Nominalphrase), d.h. Reduktion, wie in skr. hajduci su ubili konjanika bzw. konjanik je ubijen hajducima > ubijenje konjanika od hajduka (Beziehung Subjekt - Objekt - Attribut). Vgl. hierzu Kurylowicz. 620) Mit anderen Worten: es werden nur die sogenannten gramatischen Kasus behandelt. ${ }^{621)}$ Die diachronische Konstantheit dieser syntaktischen Punktionen erlaubt es, den Grad der Gebundenheit der Kasusmorpheme an das Nomen für die Kasusdefini- 
tion zu vernachlässigen. Nbulg. na grada stellt wie das altbulg. grada den Attributskasus dar, da jedes in seinem System an der Reduktion teilnimmt: altbulg. osvoboždenije grada nbulg. osvoboždenie na grada.

In der Gegenwart bestehen, wie Civ'jan feststellt, auf dem Balkan (im Bulg.-Mak., Torlak., Alb., Ngriech., Rum.) zwei prinzipiell verschiedene Kasussysteme nebeneinander ${ }^{622)}$ : I.

\begin{tabular}{|c|c|c|}
\hline Syntaktische Funktion & Pormans & Kasus \\
\hline direktes Objekt & $\varnothing+$ Grundform & Directus \\
\hline Attribut & \multirow{2}{*}{$\begin{array}{l}\text { Präposition + } \\
\text { Grundform }\end{array}$} & \multirow{2}{*}{ Obliquus } \\
\hline indirektes Objek & & \\
\hline
\end{tabular}

So im literarischen Nbulg. und literarischen Mak.: grad (Subjekt - direktes Objekt), na grad (Attribut - indirektes objekt)

II.

Syntaktische Punktion

$\left.\begin{array}{l|l}\text { Subjekt } & \begin{array}{l}\text { Grundform } \\ \text { Morphem A }\end{array}\end{array}\right\}$ Directus

So im literarischen DR: cas-a (Subjekt - direktes Objekt), cas-e (Attribut - indirektes objekt).

Das angestrebte balkanische Metamodell hätte demnach die Porm: 623$)^{3}$

$\frac{\text { Subjekt }}{\text { Kasus }_{1}} \frac{\text { direktes Objekt }}{\text { Kasus }_{1}} \frac{\text { Attribut }}{\text { Kasus }_{2} \text { oder }} \quad \frac{\text { indirektes Objekt }}{\text { Kasus }_{2} \text { Oder }}$ $\left(\right.$ Präpos. $\left._{1}+\mathrm{Kas}_{1}\right)\left(\right.$ Präpos $\left._{1}+\mathrm{Kas}_{1}\right)$

Inm entsprechen vollständig Schriftbulg. (I.), Schriftmak. (I.), Torlakisch (I.) und Schrift-DR (II.). Die Dialekte 
dieser Schriftsprachen sowie Alb. und Griech. differieren vom Metasystem durch zusätzliche Allomorphe (mak. na Stojana neben na Stojan).

Civ'jan sieht zwischen den beiden Grundtypen keinen historischen Zusammenhang und folgert: "Wesentlich erscheint nicht so sehr das Streben zum Analytismus (in I.), sondern vielmehr das Vorhandensein folgender Opposition: (...) auf der morphologischen oder morphosyntaktischen Ebene ein direkter (Dir.) und ein obliquer (Obl.) Kasus, mit Neutralisierung der Genitiv-Dativ-Funktion im letzteren."624) Civ'jan berückoichtigt nicht, daß diejenigen Sprachen, in denen heute System I. vorliegt, in ihrer Vergangenheit System II. kannten und $d a B$ in Sprachen, in denen heute System II. vorliegt, System I. in Dialekten und in der Umgangssprache vordringt. Wir haben es mit einer Konkurrenz beider Kasussysteme in der Diachronie der Balkansprachen zu tun, und jene Sprachen, die System I. vorziehen, sind nur progressiver als die anderen. Somit bleibt das Streben zum Analytismus neben der Zusammenfassung des Attributs und des indirekten objekts in $e i-$ $n$ e $m$ Kasus das Hauptcharakteristikum des Metamodells. Die Prage besteht darin, welche Paktoren zur Aufgabe des älteren Systems II geführt haben und führen. Ein Paktor ist sicher die Funktionsbelastung des Artikels in der Einheit 'Determiniertes Nomen', wenn dieses seine Kasus nach System II bildet (bulg. kralju-tomu, altrum. case-ei).

Für die in diesem Zusammenhang entscheidende Phase zwischen den aksl. und den nbulg.-mak. Nominalsystemen, für das sogenannte Mittelbulgarisch (12. - 15. Jhd.), fehlt es an volkssprachlichen Texten. Deshalb gewinne ich das zugrundezulegende linguistische Material aus neueren Dialekttexten, unter Anwendung der Internen Rekonstruktion.

Ein Sprachsystem läßt sich in Teilsysteme aufgliedern, wie die Phonologie, die Morphosyntaktik und die Lexik, diese wiederum eine Ebene tiefer in kleinere Teilsysteme, welche einander parallel zugeordnet sind. 625) Kann für ein gegebe- 
nes Teilsystem ein gleichbedeutendes Teilsystem eingesetzt werden (z.B. skr. Instrumental sing. fem. radosti neben radoš(u), so sind beide nicht nebeneinander, sondern übereinander angeordnet. Beide Systeme bilden dann Subsysteme eines einzigen Teilsystems, "stilistische Varianten eines Teilsys temsn. 626)

Bei diachronischer Betrachtung lassen sich die synchronischen Subsysteme häufig in ältere und sie ersetzende jüngere Konstruktionen auflösen. Beim Fehlen von Belegen für eine ältere Sprachperiode ist es zweckmäBig, aus mehreren Subsystemen bestehende Teilsysteme des jüngeren Sprachsystems in ihre einzelnen Schichten aufzulösen und diese als Demonstration der diachronischen Entwicklung aufzufassen (Interne Rekonstruktion). Aus der diachronischen Analyse des synchronischen Sprachsystems kann eine relative Chronologie nichtbelegter Entwicklungsstufen aufgestellt werden. 627)

Ebenso wie die Subsysteme eines synchronischen Sprachsystems lassen sich die verschiedenen Dialekte einer Sprache in diachronisch aufeinanderfolgende systeme umsetzen. Es ist dargelegt worden ${ }^{628}$ ), daB die räumliche Entfernung ebenso wie die Zeit an sich keine sprachliche Differenzierung schafft. Beide Dimensionen sind die Voraussetzungen für divergierende Entwicklungen und dialektale Aufspaltungen früher einheitlicher Mundarten. Sie können als 'Abstand zwischen Systemen' aufgefasst werden. Deshalb ist "die geographische Verschiedenheit durch temporale Verschiedenheit zu übersetzen" (de Saussure). 629) Die dialektale Entwicklung kennt zwei Richtungen: Der einzelne Dialekt entwickelt neue, weder in den übrigen Dialekten noch auf einer früheren Stufe seiner Entwicklung bekannte Formen; oder er bewahrt Pormen seiner früheren Entricklungsstufen. Im letzteren Pall kann ein dialektaler Zustand als Illustration einer Etappe in der Entwicklung der betreffenden Dialektgruppe interpretiert werden. 630)

Im folgenden kombiniere ich die Interne Rekonstruktion auf der Grundlage mehrerer Subsysteme eines Teilsystems mit 
der Internen Rekonstruktion auf der Grundlage mehrerer Dialekte einer sprache, d.h. ich betrachte die unterschiedlichen Subsysteme in unterschiedlichen Dialekten des Bulg.Mak. Ein Dialekt weist gewöhnlich mehr Schichten von Subsystemen auf, während in der Normsprache das System für die größere Anzahl der Sprechteilnehmer (kulturelle und soziale Funktionen) homogener zu sein hat. Der gemeinsame Nenner für das Verhältnis eines Subsystems zu einem anderen Subsystem desselben Teilsystems und für das Verhältnis eines Dialektsystems zu einem anderen Dialektsystem derselben Sprache ist der Systemabstand, der für die relative Chronologie der Sprachgeschichte ausgewertet wird. Das Schema für die Umsetzung synchronischer dialektaler Unterschiede in diachronische Evolutionsstufen hat die Form:

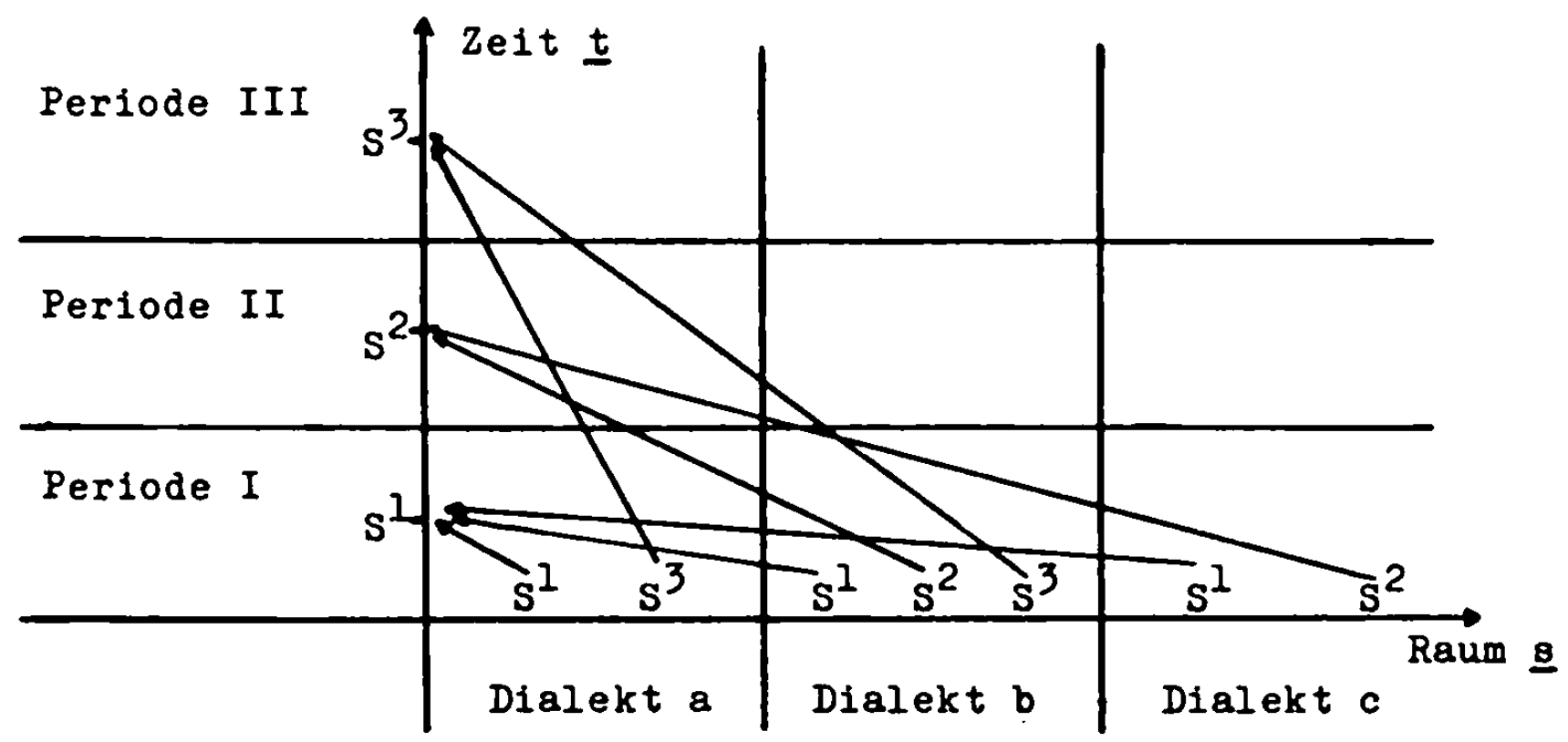

Gegeben sind die Dialekte a (mit den Subsystemen $s^{1}, s^{3}$ ), $\underline{b}\left(s^{1}, s^{2}, s^{3}\right), \underline{c}\left(s^{1}, s^{2}\right)$, den Subsystemen $s^{1}-s^{3}$ entspricht jeweils eine diachronische Periode in der Evolution. 
1. Plexionsparallelismus von Substantiv und Artikel a. Synthetisches Directus-Obliquus-Sys tem

Die im 16. Jhd. verfabten Texte der Siebenbürger Bulgaren, die sogenannten Cergeder Gebete, weisen folgendes Teilsystem für die Nominalflexion auf. Die Ziffern hinter den Belegen verweisen auf die Seiten in Miletič Ausgabe ${ }^{631}$ ), die Belege werden in der von Miletič rekonstruierten Porm (hier in lateinischer Transskription) gegeben.

\begin{tabular}{|c|c|c|c|}
\hline $\begin{array}{l}\text { m. } \operatorname{den}(90) \\
\text { f. } \operatorname{volja}(76) \\
\text { n. jume }(75)\end{array}$ & $\begin{array}{l}\text { svet-ot(102) } \\
\text { smbrt-ta(95) } \\
\text { pismo-to (136) }\end{array}$ & $\begin{array}{l}\text { dbne (124) } \\
\text { zvezd1 (107) } \\
\quad-\end{array}$ & $\begin{array}{l}\text { gresi-te (95) } \\
\text { čerkvi-te (106) } \\
\quad-\end{array}$ \\
\hline $\begin{array}{l}\text { Bina (76) } \\
\text { Iosef(120) } \\
\text { ljab(76) } \\
\text { vära (76) } \\
\text { - mäato(85) }\end{array}$ & $\begin{array}{l}\text { trupa-tago(100) } \\
\text { verni-ot širag(98) } \\
\text { zemja-ta }(96) \\
\text { nebe-to }(96)\end{array}$ & $\begin{array}{l}\text { gresi(93) } \\
\text { turci( } 92) \\
\text { zvezdi (85) } \\
\text { 1eca(135) }\end{array}$ & $\begin{array}{l}\text { grese-te(114) } \\
\text { se-te vernie(98) } \\
\text { se-te trevi( } 85) \\
\text { člet-ta(135) }\end{array}$ \\
\hline $\begin{array}{l}\text { giaula(76) } \\
\text { bogu(97) } \\
\text { na boga(118) } \\
\text { - vere(103) } \\
\text { na dus̆i(58) } \\
\text { - }\end{array}$ & $\begin{array}{l}\text { c'liaku-tumu(57) } \\
\text { kbrotu-tumu(133) } \\
\text { veri-tui (76) } \\
\text { - }\end{array}$ & $\begin{array}{r}\text { kbrotienem } \\
\text { (129) } \\
\text { roncem(81) } \\
\text { - }\end{array}$ & $\begin{array}{l}\text { židoven-tem } \\
(137) \\
\text { na dedi-te }(58) \\
\text { na vaš-tem } \\
\operatorname{gresim(58)} \\
- \\
\text { täf-tem obrcem } \\
(131)\end{array}$ \\
\hline 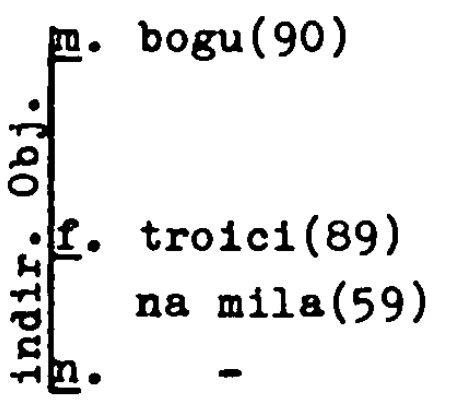 & $\begin{array}{l}\text { poganit tu-tumu (136) } \\
\text { vaš-tui duši }\end{array}$ & Iigiem(92) & $\begin{array}{l}\text { pastiren-tem (128 } \\
\text { vernien-tem } \\
\text { kbrstienem ( } 95) \\
\text { žechenien-tem } \\
\text { - (112) }\end{array}$ \\
\hline
\end{tabular}

Dieses Cergeder Tellsystem umfabt mehrere Subsysteme, die, 
diachronisch gesehen, einander ablösende Teilsysteme darstellen.

Für die bulg.-mak. Kasusentwicklung gilt allgemein, daß sich die jüngeren Systeme von den beiden Numeri gewöhnlich zuerst im Plural durchsetzen, von den drei Genera - zuerst im Neutrum, später im Femininum, zuletzt im Maskulinum, und be1 diesen zuerst bei Bezeichnungen für unbelebte Objekte, zuletzt bei Personennamen. 632) Deshalb findet sich das älteste Subsystem des Cergeder Teilsystems im Singular masc. belebter Objekte. Es hat folgende Form: A.

\begin{tabular}{l|l} 
Subjekt & Nominativ \\
\hline dir. Objekt & Akkusativ \\
\hline Attribut & Obliquus \\
indir. Objekt & Obla
\end{tabular}

Einem noch älteren System gehört Attribut - Genitiv (giaula) an, es bleibt hier unberücksichtigt.

Die Restitution dieses in Cerged nur im Singular masc. belebter Objekte erhaltenen Systems in allen Oppositionsgliedern führt zu dem Flexionsmuster:

\begin{tabular}{|c|c|c|c|}
\hline \begin{tabular}{l|l}
$\dot{3}$ & in \\
0 & $z v e z d a$ \\
3 & pismo
\end{tabular} & $\begin{array}{l}\text { sin-ot } \\
\text { zvezda-ta } \\
\text { pismo-to }\end{array}$ & $\begin{array}{l}\text { gresi } \\
\text { zvezdi } \\
\text { pisma }\end{array}$ & $\begin{array}{l}\text { gresi-te } \\
\text { zvezdi-te } \\
\text { plsma-ta }\end{array}$ \\
\hline 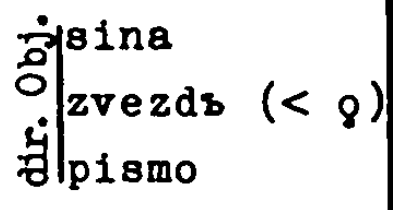 & $\begin{array}{l}\text { sina-tago } \\
\text { zvezds-ts } \\
\text { pismo-to }\end{array}$ & $\begin{array}{l}\text { (grěchy) } \\
\text { zvezdi } \\
\text { pisma }\end{array}$ & $\begin{array}{l}\text { (grěchy-ty) } \\
\text { zvezdi-te } \\
\text { pisma-ta }\end{array}$ \\
\hline 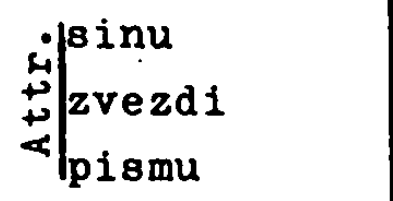 & $\begin{array}{l}\text { sinu-tumu } \\
\text { zvezdi-tui } \\
\text { pismu-tumu }\end{array}$ & \begin{tabular}{|l|} 
gresem \\
zvezdem \\
(pismom)
\end{tabular} & $\begin{array}{l}\text { gresem-tem } \\
\text { zvezdem-tem } \\
\text { (pismom-tem) }\end{array}$ \\
\hline 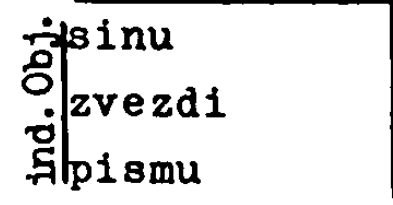 & $\begin{array}{l}\text { sinu-tumu } \\
\text { zvezdi-tui } \\
\text { pismu-tumu }\end{array}$ & \begin{tabular}{|l|} 
gresem \\
zvezdem \\
$($ pismom $)$
\end{tabular} & $\begin{array}{l}\text { gresem-tem } \\
\text { zvezdem-tem } \\
\text { (pismom-tem) }\end{array}$ \\
\hline
\end{tabular}

Dieses System ist gegenüber dem altbulg. durch die Zusammen- 
fassung des Attributs und des indirekten Objekts im Obliquus gekennzeichnet.

Eine Stufe jünger lst folgendes Cergeder Tellsystem, welches den im Aksl. Im Singular der a-Stämme und im Plural der o-Stämme bestehenden Unterschied von Nominativ und Akkusativ beseitigt hat $(-\mathrm{a} \longleftrightarrow-\mathrm{Q} ;-1 \longleftrightarrow-\mathrm{y})$ :

B.

\begin{tabular}{l|l} 
Subjekt & Directus \\
\hline dir. Objekt & \\
\hline Attribut & Obliquus \\
\hline indir. Objekt &
\end{tabular}

Dieses System existiert in Cerged nur bei den unartikulierten Substantiva und bei den artikulierten im Singular, seine Restitution in allen Oppositionsgliedern führt zu dem Flexionsmuster:

\begin{tabular}{|c|c|c|c|}
\hline \begin{tabular}{l|l}
$\dot{j}$ & den \\
$\dot{0}$ & $z v e z d a$ \\
$\tilde{s}$ & piamo
\end{tabular} & $\begin{array}{l}\text { den-ot } \\
\text { zvezda-ta } \\
\text { pismo-to }\end{array}$ & $\begin{array}{l}\text { done } \\
\text { zvezdi } \\
\text { pisma }\end{array}$ & $\begin{array}{l}\text { done-te } \\
\text { zvezdi-te } \\
\text { pisma-ta }\end{array}$ \\
\hline$\left.\right|_{\text {pismo }} ^{\text {den }}$ & $\begin{array}{l}\text { den-ot } \\
\text { zvezda-ta } \\
\text { piamo-to }\end{array}$ & $\begin{array}{l}\text { done } \\
\text { zvezdi } \\
\text { pisma }\end{array}$ & $\begin{array}{l}\text { done-te } \\
\text { zvezdi-te } \\
\text { pisma-ta }\end{array}$ \\
\hline $\begin{array}{l}\text { denu } \\
\text { zvezdi } \\
\text { pismu }\end{array}$ & $\begin{array}{l}\text { denu-tumu } \\
\text { zvezdi-tui } \\
\text { pismu-tumu }\end{array}$ & $\begin{array}{l}\text { donem } \\
\text { zvezdem } \\
\text { pismem }\end{array}$ & $\begin{array}{l}\text { drnem-tem } \\
\text { zvezdem-tem } \\
\text { pismem-tem }\end{array}$ \\
\hline$\left\{\begin{array}{l}\text { zenu } \\
\text { ovezdi smu }\end{array}\right.$ & $\begin{array}{l}\text { denu-tumu } \\
\text { zvezdi-tui } \\
\text { pismu-tumu }\end{array}$ & $\begin{array}{l}\text { donem } \\
\text { zvezdem } \\
\text { pismem }\end{array}$ & $\begin{array}{l}\text { dsnem-tem } \\
\text { zvezdem-tem } \\
\text { pismem-tem }\end{array}$ \\
\hline
\end{tabular}

Die Systeme Cerged $\underline{A}$ und $\underline{B}$ sind gekennzeichnet durch die Kasusoppositionen A: Nominativ - Akkusativ - Obliquus, B: Directus - Obliquus und durch die Kasusparallelität von Artikel und Substantiv: die Kasusinformation des Artikels ist pleonastisch. Koexistieren $A$ und $B$ als Subsysteme eines Teilsystems, wie in Cerged, so läßt sich der Akkusativ des Systems A als Variante des Directus von System B betrachten. Das äl tere Cergeder Subsystem $(A+B)$ hat demnach die Form: 
Nomen

\begin{tabular}{l|l} 
Subjekt & $\begin{array}{l}\text { Directus } \\
\text { (Allomorph) }\end{array}$ \\
\hline dir. Objekt & Obliquus \\
\hline Attribut &
\end{tabular}

Artikel

Directus

(Allomorph)

Obliquus

Damit stellt es nichts anderes dar als den balkanischen Haupttyp II $(8.0$.$) .$

Beim Ubergang vom altbulg. Kasussystem (Nominativ Genitiv-Dativ-Akkusativ) zum nbulg.-mak. ( $\phi$ + Grundform; Präposition + Grundform = Typ I.) haben alle bulg.-mak. Mundarten als 2 wischenstufe das in Cerged aufgezeigte system II $(A+B)$ gekannt. Für eine zentrifugale Wellenausbreitung der Kasusumgestaltung ${ }^{633)}$ spricht, daB sich das System II gerade an der bulg.-mak. Peripherie beobachten läßt, so

im Südtorlakischen (Prizren-Südmorava) ${ }^{634}$ ),

im Dialekt von Džakovac ${ }^{635)}$,

im mak. Dialekt von Boboščica in Südalbanien ${ }^{636)}$,

im Nordmak. (Skopska Crnogorija, Tetovsko) und Westmak. 637), in den bulg. Rhodopendialekten ${ }^{638)}$ sowie in den älteren Texten: den vlachobulg. Urkunden des 14.-15. Jhd. 639) und in den Damaskinen, z.B. von Koprivštica und von Svištov ${ }^{640)}$. Die Ausbreitung dieses Systems ist verschieden: häufig existiert es nur noch im Singular des Maskulinums (Stojan - Stojana Stojanu), seltener im Singular des Femininums (rukàta rukoto - rucltuchi in einigen Rhodopenmundarten ${ }^{641}$ ), , oder sogar im Plural (l'ud'i-te - l'ud'em-tem in Smoljan, Rhodopen $^{642)}$ ).

Hëufig hat das Allomorph den Ubergang von System II > System I (na Stojan) als Allomorph des Directus überdauert, hauptsächlich bei maskulinen o-Stämmen, die Lebewesen bezeichnen: Stojan - Stojana - na Stojana. ${ }^{643}$ Zur Geschichte der Neutralisierung von Nominativ und Akkusativ im Directus vgl. Duridanov ${ }^{644)}$, Mirčev ${ }^{645)}$, Koneski ${ }^{646)}$ ).

Nach der Feststeliung dieses vielen zeitlich und räum- 
lich getrennten Dialekten gemeinsamen Nominalsystems stellt sich die Prage, welcher chronologische Abschnitt der progressiven bulg.-mak. Dialekte durch dieses System charakterisiert wird, d.h. zu welcher leit es zuerst auftrat. Die Trennung von Nominativ und Akkusativ hielt sich mit Ausnahme der maskulinen o-Stämme in der Masse der bulg. Mundarten höchstens bis in die 1. Hälfte des 13. Jhd. 647) Die Ausbreitung der Dativform auf die Attributsfunktion, über den Dativus possessivus, beginnt mit dem 10. Jhd. 648) und ist spätestens im 15. Jhd. abgeschlossen. Sie ist die Voraussetzung für die folgende gomeinsame Form des Attributs und des indirekten Objekts mit na. 649) Nach Auskunft der Cergeder Texte, die nach der allgemeinen Ansicht den progressiven NO-bulg. Dialekt des 13 . Jhd. repräsentieren ${ }^{650}$ ), und der vlachobulg. Urkunden des 14.-15. Jhd., die neben System II schon system I (na carja) akzeptiert haben 65l), läBt sich die Herrschaft des Systems II in den progressiven bulg. Dialekten auf die Zeit zwischen dem 10./11. - 13. Jhd. (inklusive) datieren, vgl. Svane. 652) während im Zentrum der Neuerungen längst System I eingetreten ist, hat die Welle der formalen Dativausbreitung erst heute das östliche Serbisch erfaßt (kuca - kutu - kuci: kuća mojemu bratu 'das Haus meines Bruders'). 653) - Der archatsche bulg. Dialekt von Tichomir (Rhodopen) hat den Ausdruck des Possessivus (= Attribut) ausschlieblich durch eine Genitivform bis heute erhalten. ${ }^{654}$ ) Die Periode der Herrschaft von System II in den progressiven Dialekten fällt zusammen mit der Periode der Artikelausbreitung im Bulg.-Mak. (10. - 13. Jhd.), vgl. Kap. II.4.d.

Die Umgestaltung des bulg.-mak. Kasussystems vom aksl. Zustand zu System II wie auch weiter zu System I steht m.E. mit der Entwicklung des rum. und damit indirekt auch des alb. Kasussystems in Verbindung. Die Meinung Miletič', der die bulg. Kasusumgestaltung auf den lautlichen Zusammenfall vieler Kasusendungen infolge des Nasal zusammenfalls erklären wollte, ist durch die Hinweise auf das Cechische, in den ein 
ähnlicher Vokalzusammenfall $k$ e i $n$ e Umgestaltung des Kasussystems hervorgerufen hat ${ }^{655}$ ), und vor allem durch den Nachweis widerlegt worden, daß die Kasusumgestaltung vor diesem Lautwandel im Bulg. einsetzt (Nasalzusammenfall im 12. Jhd.), vgl. dazu Duridanov. 656) - Meistens nehmen die bulg. Linguisten eine balkanische Intensivierung der 'innerbulg. Entwicklungstendenzen' an 657), seltener die direkte Einwirkung des romanischen Substrats 658). Vgl. die Zusammenfassung der Diskussion bei Bernštejn. 659) Der rum.-bulg. Zusammenhang in diesem Teilsystem läBt sich m.E. durch die Feststellung des Systems II im Frührum. nachweisen, zu einer leit, als das Bulg.-Mak. noch dem aksl. Modell folgte, also vor dem 10. Jhd.

Das schriftsprachliche DR weist System II heutzutage nur bei den Feminina im Singular auf:

\begin{tabular}{l|ll} 
Subjekt & Directus & fatä - fata \\
\hline dir. Objekt & & fetribut \\
indir. Objekt & Obliquus & fetei
\end{tabular}

Diese DR Formen stellen Kontraktionen dar, im Frührum. wies das System einen Parallelismus von Nomen und Artikel auf:

$$
\text { fétā - feată-(1l)a / feate - feate-(1l)ei }
$$

Die Opposition von Directus und Obliquus galt im Frührum. auch für das Maskulinum. 660) Lat. locus (nom.) führte zu frührum. locā, was in den altrum. kyrillisch geschriebenen Texten durch locs, locb wiedergegeben wurde. Dagegen ergab lat. locō (dat.) im Rum. locu, kyrillisch geschrieben als lok-ou. Im Altrum. werden die beiden Formen bereits ohne syntaktischen Unterschied verwendet. - Auch der lat. Akkusativ locu(m) hatte im Rum. das Resultat locu, unterschied sich also nicht vom Obliquus. Die Differenzierung wurde jedoch durch die maskulinen Ṕronomina aufrechterhalten: z.B. (obl.) cărui, celui - (dir.) care, cel. Im Frührum. wurden die Maskulina wie folgt dekliniert: 


\begin{tabular}{|c|c|c|c|}
\hline Subjekt & Nominativ & $10 c a ̄ \quad(<10 c u s)$ & - locā-le \\
\hline$\overline{\text { dir. Objekt }}$ & Akkusativ & locu (< locum) & - $10 c u-1 u$ \\
\hline Attribut & Obliquus & locu (< locō) & - locu-12 \\
\hline
\end{tabular}

Später wurde locă durch den Akkusativ locu verdrängt und der Artikel le (< ille) auf Fälle wie nume-le, clne-le beschränkt, während die o-Stämme $\underline{\text { lu }}$ in den Subjektkasus einführten. Reichenkron, der die Verteilung von s, b und ou in den kyrillisch geschriebenen rum. Texten untersucht hat $660 \mathrm{a})$, sah in locã - locu lediglich eine Nominativ-Akkusativ-Differenzierung, wie sie im Altfranzösischen bis ins 13.-14. Jhd.661) galt. Jedoch zeigt das rum. Femininum casă - case (eine Unterscheidung, die bezeichnenderweise im Altfranzösischen fehlt), dab wir es auch und vor allem mit einer Nominativ-obliquusDifferenzierung zu tun haben. - Nicht überzeugend ist Şiadbeis Theorie vom Bestehen eines Casus generalis bei den maskulinen und femininen Substantiva (locu, casă) schon im Frührum. und seine Erklärung des femininen Obliquus (case) durch eine Analogiewirkung des Plurals.

Bei der Zusammenfassung der frührum. maskulinen und femininen Kasusflexion in ein System tritt der Akkusativ des Maskulinums als Allomorph des Directus auf. Im Frührum. ( 10 . Jhd.) existierte ein Kasussystem, welches mit dem im Bulg.Mak. des 10.-13. Jhd. festgestellten weitgehend parallel ist (Typ II):

\begin{tabular}{|c|c|}
\hline Subjekt & Directus (casä/locā - kravs/vslk) \\
\hline$\overline{\text { dir. Objekt }}$ & (Allomorph) (locu - vblka) \\
\hline Attribut & /locu - kravi, $\nabla$ blk \\
\hline
\end{tabular}

\begin{tabular}{l|l} 
Subjekt & $\begin{array}{l}\text { Directus (-a/-le }- \text {-ts/-st) } \\
\text { dir. Objekt }\end{array}$ \\
\hline Attribut & Obliquarorph (-ei/-lui $-1 u-t o i /-t o m u)$
\end{tabular}

Bei der Beurteilung dessen, ob das rum. System eine 
vulgärlat. Entwicklung darstellt oder auf balkanische Einflüsse zurückgeht, darf nicht übersehen werden, dab auch das Alb. nach Typ II flektiert und dieser im Alb. sehr alt zu sein scheint: gur 'Stein' - guri 'der Stein' (Subjekt), gurë - gurë-në (dir. Objekt), guri - guri-të (Attribut, indir. objekt). 663) Der Ausdruck des Attributs und des indirekten Objekts durch e in e $n$ Kasus (obliquus) findet sich gleichermaßen im Vulgärlat. wie im Alb., letzteres steht in Verbindung mit der gleichen Erscheinung im Armenischen und Iranischen, ist also vom Lat. unabhängig. Uber das Rum. ist dieses balk. Charakteristikum ins Bulg.-Mak. gelangt. Das alb. Modell macht es unwahrscheinlich, daB die Bewahrung des synthetischen lat. Dativs im Rum. (casae > case) auf den späten slavischen Einfluß zurückgeht ${ }^{664)}$, hier hat eher das alb. Substrat des Rum. gewirkt. ${ }^{665}$ Es ist mithin wahrscheinlich, daB sich das alb. Kasusmodell durch linguistischen Kontakt dem Rum. und über dieses dem Bulg.-Mak. mitgeteilt hat, daB der heutzutage festgestellte Typ II letzten Endes alb. Ursprungs ist. Dem entspricht die chronologische Abstufung: iranisch-armenisch-albanische Isoglosse für den Genitiv-Dativ-Zusammenfall, folglich der thrakischen Epoche angehörig $^{666)}$, der Obliquus im Frührum., die Ausbreitung des Dativs für das Attribut innerhalb des Typs II im Bulg.-Mak. zwischen dem 10.-13. Jhd..

b. Analytisches Directus-Obliquus-System

Mit einer geringen zeitlichen Verschiebung gegenüber dem ProzeB 'Aksl. Kasussystem > Typ II' setzt der ProzeB 'Aksl. Kasussystem > Präpositionalsystem' ein, d.h. die Verwendung von Präpositionen für den Ausdruck des Attributs und des indirekten Objekts. Dieser ProzeB, ausgehend von der Ersetzung des aksl. Genitivs und Dativs in deren konkreten (ablativischen bzw. zielgerichteten) Funktionen, beginnt in einigen bulg. Mundarten mit dem 10. Jhd. ${ }^{667)}$ Diese kleinere An- 
zahl von Mundarten steht der größeren Anzahl gegenüber, die den Typ II anstreben; es kann von zwei bulg.-mak. Mundartgruppen mit verschiedenen Entwicklungstendenzen gesprochen werden. 668) Die Trennung der 'analytischen' von den 'synthetischen' Mundarten beginnt im Ausdruck des Attributs: ots + Nomen in den 'analytischen', Dativus possessivus in den 'synthet1schen' Mundarten. 669) Vgl. im Zographensis: obětovanfje ots otca mojego, im Marianus: obětovanije otca mojego. 670) Die erste mundartliche Differenzierung hatte die Form:

\begin{tabular}{l|l|l} 
Attribut & otb + Nomen & Dativ \\
\hline indir. Objekt & $\begin{array}{l}\text { Dativ } \\
\text { 'analyt. Gruppe' }\end{array}$ & 'sativ \\
& 'synthet. Gruppe' -
\end{tabular}

Im 12.-13. Jhd. gibt es die ersten Anzeichen in den Texten für die Auflösung des Obliquus durch eine Präpositionalkonstruktion mit $\underline{n}^{671)}$, die wahrscheinlich die 'analytische' Dialektgruppe zuerst bildete, so daB die Differenzierung die Porm annahm:

\begin{tabular}{l|l|l} 
Attribut & ot + Nomen & Dativ \\
\hline Indir. Objekt & $\begin{array}{l}\text { na Nomen } \\
\text { 'analyt. Gruppe' }\end{array}$ & 'sativ \\
& 'synthet. Gruppe' -
\end{tabular}

Im 15. Jhd. hat sich die Präpositionalkonstruktion auch be 1 den Mundarten des Typs II durchgesetzt. 672) Jedoch wird in diesen Mundarten nicht ot, sondern nur na in grammatischer Funktion verwendet, da sie den Zusammenfall von Attribut und indirektem Objekt in $e i \mathrm{n} e \mathrm{~m}$ Kasus fortsetzen. Vor dem 14. Jhd. ist deshalb kein Attributsausdruck mit na + Nomen bezeugt, nur mit ot oder durch den Obliquus. 673) Die Konstruktionen mit ot für das Attribut "sind alt und gehen den Konstruktionen mit na voraus" (Koneski).674) - So stehen sich heute eine kleinere bulg.-mak. Dialektgruppe (die nicht territorial zusammenhängt) mit zweigliedrigem präpositionalen und eine größere mit eingliedrigem präpositionalen Kasusausdruck (Typ I) gegenüber: 


\begin{tabular}{l|l|l} 
Attribut & ot + Nomen & na + Nomen \\
\hline indir. Objekt & na + Nomen & na + Nomen,
\end{tabular}

der Typ I des Bulg.-Mak. ist aus einer Kontamination des

Typ II mit dem zweigliedrigen Präpositionalsystem entstanden. Die größere Gruppe wird vom Schriftbulg. und Schriftmak. repräsentiert (az davam knigata na učenika na učitelja), die kleinere von westmak. und einigen bulg. Dialekten. Zu den westmak. (krckanjeto od vratata, baranje od narodot, izvici od postarite učenici - also auch in der grammatischen Funktion eines Genitivus subiectivus und obiectivus ${ }^{675)}$ ) Mundarten vgl. Vidoevski ${ }^{676)}$, Seliščev ${ }^{677)}$, Mazon-Vaillant ${ }^{678)}$. Daß die Dialekte mit zweigliedrigem präpositionalen Kasusausdruck früher weiter verbreitet waren, zeigen die vlachobulg. Urkunden, in denen neben dem Typ II das System Attribut - ot, indirektes Objekt - na ${ }^{679)}$ besteht, heute gehören hierzu der Sofioter, einige zentrale und SW-bulg. Dialekte. 680) Zur Verwendung von ot und na im Schriftbulg. siehe Ceško681).

Der Zusammenhang des zweigliedrigen präpositionalen Kasusausdrucks im Bulg.-Mak. mit der analytischen Kasusbezeichnung des Vulgärlat. (ad und de), die im Rum. weiterexistierte, ist offensichtlich.

Parallel zum Bulg.-Mak., jedoch schon eine Epoche früher, seit dem Vulgärlat., kennt das Rum. das Nebeneinander von Typ II und einem zweigliedrigen Präpositionalsystem in Kasusfunktion (für das Attribut und das indirekte Objekt): "Es ist wahrscheinlich, daB das Altrumänische eine Tendenz zur Generalisierung der Genitivbildung mit de oder a gehabt hat, und vielleicht auch zur Dativbildung mit $\underline{a}$, wie in den anderen romanischen Sprachen" (Hansen).683) Tenn für Typ II sowohl eine alb. wie eine vulgärlat. Herkunft in Frage kommt, so ist das Präpositionalsystem mit de und ad, welche die Funktionsausweitung von bulg.-mak. ots und na durch Replikbildung bewirkt haben, unverkennbar romanischen Ursprungs.

Das Nebeneinander beider Systeme ist für das Vulgärlat. belegt: hic requiiscunt membra ad duus fratres Gallo et Fiden- 
cio, qui fuerunt fili Magno (7. Jhd., Gallien).684) Dabei besteht im analytischen system für den Ausdruck des Attributs eine Konkurrenz von de und ad. Das Eindringen von ad in die Attributsfunktion (ad duus fratres) erfolgte vom 4. Jhd. u.Z. an unter dem EinfluB des Typs II, in welchem der Obliquus das indirekte objekt und das Attribut ausdrückt ${ }^{685}$ ), ein Vorgang, den später das Bulg.-Mak. mit dem anfangs zum indirekten Objekt gehörigen na wiederholte. Zur Verteilung von obliquus, de und ad für den Ausdruck des Attributs vgl. die altfranzösischen Verhältnisse ${ }^{686)}$, in denen die Tendenz besteht, de zu verallgemeinern ( $>$ Neufranzösisch).

Ebenso koexistieren noch im Altrum. (16. Jhd.), wenn auch ungeregelt und reliktartig, die beiden Kasussysteme und im analytischen System für den Ausdruck des Attributs die Präpositionen a und de: Attribut calea četăţei, trestia cārtularĩului - cale de četate, casa de domnulb bzw. trestie a cärtularĭu, Impāratulb a toatá lumia, 687) turma de porci - turma porcilor, sat de olari, feate de oameni ${ }^{688)}$, indirektes Objekt děde (el) a lucrători, nimea nu poate a doi domni lucra neben tatālui, lucrătorilor etc. 689)

Schon im Altrum. ist die Präpositionalverwendung selten, auch in den heutigen großen Dialekten findet sie sich nur in Uberresten:

IR ocoli de foc, piţorle de om (DR picioarele omului), zidu de cåse (DR zidul casei) für das Attribut; für das indirekte Objekt ... \$i zis-a a l'ei, a l'ei aw Domnu dåt un fet.690) Reste des attributiven Gebrauchs von de finden sich auch im $A R^{691)}$ und im $M R^{692)}$. Im $D R$ erfüllt de neben der partitiven (wie ot im Schriftbulg.) die attributive Funktion vor einem nichtpostartikulierten Substantiv ${ }^{693)}$ : uz de graiuri diverse, accentul de intensitate. Diese Punktion verdankt de der weiteren Entwicklung des Typs II im DR, der auf einer späteren Stufe den Ausdruck der attributiven Funktion auf synthetischem Wege nicht mehr gewährleisten kann, wenn das attributive Nomen unartikuliert ist. Siehe dazu weiter unten. 
In der Funktion des indirekten Objekts sind auBer in den IR Resten (s.o.) die Präpositionen a und de völlig geschwunden. Im $A R$ ist a in attributiver Funktion dem Artikelsystem eingegliedert worden (a-li feată $\cong \underline{a}$ featăl'ei), Reste desselben Prozesses liegen im MR vor (al Chita, a lu Chita $\left.{ }^{694)}\right)$, im DR ist a für den attributiven Ausdruck schwer deklinierbarer Wortgruppen geblieben: adunare a tot satul, mamă a cinci copii.

Offensichtlich im Gegensatz zum Bulg.-Mak., in dem die Repliken na (und ot) zwischen dem 13. - 15. Jhd. den Typus II verdrängten, verlief im Gesamtrum. die Funktionseinengung von a und de und das Durchsetzen von Typ II noch in der Zeit vor den ersten Texten (16. Jhd.). Ich erkläre die rum. Entwicklung a. mit der balkanischen (alb. und rum.) Regel, nach der einer Präposition kein artikuliertes Nomen folgen kann. 696) Im Frührum. schlob die Präpositionalflexion die Kategorie der nominalen Determination in den obliquen Kasus aus, wodurch ein funktionelles Ubergewicht von Typ II gegeben war, bei dem diese Schwierigkeit nicht bestand. Noch im Altrum. vermeiden a und de gerne den folgenden Artikel: giudecaţi a sāracu giudecați säracului, turma de porci - turma porcilor. 697) Die Vereinbarkeit des (romanischen wie alb.) Typs II mit der (alb.) Postartikulierung hat die allmähliche Aufgabe des romanischen Präpositionalsystems für den Kasusausdruck bewirkt. b. mit der Interferenz des attributiv gebrauchten a mit dem Artikelsystem und der Eingliederung von a in letzteres, wie sie im $A R$ und $D R z u$ beobachten ist, als ein possessiver oder attributiver 'Artikel'. Dieser hat sich vor den ersten Texten des 16. Jhd. entwickelt, denn in ihnen tritt er ähnlich dem heutigen DR Gebrauch auf: calul a vecinului ミcalul al vecinului < *alu-lu a(d) vecinu + calu-lu ellu vecinu-lui. c. mit der Konkurrenz des proklitischen $1 u$, le, i für den Ausdruck des Obliquus schon im Frührum., vgl. Kap. II.3.b.D.

Erst die interne zersetzung des Typs II in den groben rum. Dialekten, die typologisch parallel zu der Zersetzung 
von Typ II im Bulg.-Mak. verläuft, hat zu einem neuen Aufblühen von Präpositionen für die Bezeichnung des Attributs und des indirekten Objekts im IR, MR und im umgangssprachlichen DR geführt ( $1 u$, ei, $1 a$, de $1 a$ ).

\section{Plexionsdifferenz von Substantiv und Artikel}

In der historischen Entwicklung des Bulg.-Mak. setzte sich das präpositionale Kasussystem (Typ I) durch, wohl aufgrund der Uberlegenheit von analytischen über synthetische Ausdrucksweisen, sofern sie in einem Sprachsystem infolge linguistischen Kontaktes koexistieren. 698) In Bulg.-Mak. bestanden für das präpositionale System nicht die Hindernisse, die sein Durchsetzen im älteren Rum. erschwerten. Prinzipiell war für die Ersetzung des synthetischen Obliquus im Bulg.Mak. durch den analytischen obliquus das störungsfreie Funktionieren des Typs II kein Hindernis, wie die bulg.-mak. Dialekte zeigen, in denen dem überwiegend herrschenden Typ I noch ein kleines Reservat des Typs II (meist bei Personennamen) gegenübersteht, ohne dab eine interne zersetzung von Typ II vorliegt. Vgl, den Dialekt von Tichomir (Rhodopen):

\begin{tabular}{|c|c|c|c|c|}
\hline Directus & žònạ (Akkusati & (v žènu) & žęnà-tạ & (ženùtu) \\
\hline obliquus & ženòj (Genitiv & žòny) & - ženòj-tẹ & \\
\hline Directus & žòny & - žòny-tę & & \\
\hline Obliquus & žẹnèm (žôn) & - ženềm- & & \\
\hline
\end{tabular}

In steigender Verwendung neben diesem Typ-II-System (in dem aur die Kürzung des Artikels - tem > té abweicht): dàdę

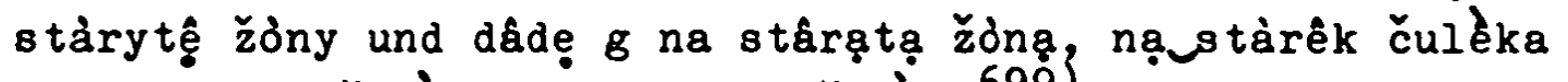
neben stàru čulềku und stàrọm čulếku ${ }^{699)}$; außerhalb dieses altertümlichen Dialekts meist mit weiterer Einengung des 
Typs II auf: sinu, bràtu, Ivànu, stujènu, babi, majci, sestri mit den entsprechenden artikulierten Formen. 700)

Jedoch lassen sich Fälle feststellen, in denen durch eine interne Funktionsschwächung von Typ II das Durchsetzen von Typ I erleichtert und beschleunigt wird. Diese Erscheinung ist im Bulg.-Mak. weniger stark ausgeprägt als im Rum., jedoch genügend belegt, um die Parallelität zum Rum. erkennen zu lassen. Sie beruht auf einer Flexionsdifferenz von Substantiv und Artikel in den Kasusoppositionen.

Eine solche Differenz kann nur im synthetischen Kasussystem (Typ II) auftreten, nicht im analytischen (Typ I). In dem letzteren bezieht sich das vorangestellte Kasusmorphem, die frühere Präposition, auf die folgenden kongruenten Nomina wie auch auf den folgenden Artikel: na bblgarsko-to osvoboždenie ist aufzulösen als: bblgarsko-Obliquus + to-Obliquus + osvoboždenie-Obliquus. Dadurch, daß der Kasusanzeiger für alle kongruenten Nomina und den Artikel als gemeinsamer Exponent gleichsam vor die Klammer gezogen wird: bblgarsko-Obliquus + to-Obliquus + osvoboždenie-obliquus > obliquus = na (brlgarsko-to osvoboždenie), ist eine diachronische Kasusparallelität von Substantiv und Artikel gewährleis tet.

Auf einer älteren Stufe, als der präpositionale Kasusausdruck noch durch redundante Kasusendungen des Nomens und des Artikels begleitet wird (na carją-togo, na carjü-tomu), lassen sich die Präposition und die Endungen des Nomens als ein komplexes Kasusmorphem betrachten (Chodova). 701) In diesem besteht die Tendenz, daß das Submorphem A (Präposition) das Submorphem B (Endung) völlig ersetzt > na-car-ot, bzw. daB das Submorphem $B$ seine Kasusfunktion ganz verliert und zur invariablen Grundform des Nomens nach Präpositionen (Casus generalis) wird, so im Torlakischen: na sestrú (Obliquus) wie bez sestrú 'ohne die Schwester'. Der Schwund der synthetischen Kasusendungen im Bulg.-Mak. ist deshalb zuerst in den präpositionellen Konstruktionen belegt. ${ }^{702)}$ Mit anderen Wor- 
ten: Im analytischen Kasussystem von Typ I ist es die Präposition als Hauptkasusmorphem, die den Funktionsverlust der synthetischen Kasusendungen des Nomens bewirkt. Der Funktionsverlust dieser Endungen verläuft beim Substantiv und beim Artikel parallel.

Im synthetischen Typ II ist die Flexionsendung des Substantivs im Gegensatz zu der gleichen Endung im Typ I (na carjü-tomu - carjü-tomu) das primäre Kasusmorphem. Die Existenz von Typ II hängt daher von der Funktionsfähigkeit der nominalen, synthetischen Kasusendung ab.

Um die Funktionsschwächung der nominalen Kasusendung durch den ebenfalls kasusindizierenden Artikel klar als interne Entwicklung des Typs II, ohne den kasusmorphemzersetzenden Einfluß des Präpositionalsystems, aufzeigen zu können, exemplifiziere ich diese Entwicklung am peripheren mak. Dialekt von Boboščlca und Drenovjúne, der, von gelegentlichem ot für den Possessivus abgesehen, kein mit dem Typ II konkurrierendes Präpositionalsystem kennt und dessen altertümliches Nominalsystem zum Zweck der Exemplifizierung des historischen Prozesses in Subsysteme zerlegt wird:

Alteste Stufe (funktionierender Typ II)

Singular fem.

\begin{tabular}{|c|c|c|}
\hline Directus & séstra & sestra-ta \\
\hline Obliquu: & (ene) séstre & sestr $j \dot{q}-t u j$ \\
\hline
\end{tabular}

Mittlere Stufe (Typ II nur beim artikulierten Nomen) Singular masc.

\begin{tabular}{c|cl} 
Directus & stárec & staréc-o \\
\hline obliquus & (enému) stárec & starcu-tbmu
\end{tabular}

Jüngste Stufe (indizierte Flexion) Singular neutr.

\begin{tabular}{l|ll} 
Directus & Ime & imjé-to \\
\hline Obliquus & (enemu) Ime & ime-tómu
\end{tabular}


Plural aller Genera

\begin{tabular}{|c|c|c|c|}
\hline Directus & & $m a j k^{\prime} e$ & majkjö̈-te \\
\hline Obliquus & (tram) & majk'e & majk jö tem \\
\hline
\end{tabular}

Der Wechsel von -'e > -jä hängt vom Akzent ab.

Eine Analyse der Rolle des Artikels in der Veränderung dieses Nominalsystems von der ältesten bis zur jüngsten Stufe kann die oft gestellte Frage ${ }^{704)}$ nach dem Anteil des Artikels am Ubergang des Bulg.-Mak. zum präpositionalen Kasussystem beantworten.

a. Aus dem synchronischen Nebeneinander von sestr $j_{a ̈}^{\prime}-t u j$ : séstre / starcu-tómu : stárec ist auf einen diachronischen Prozeb starcu-tómu : stércu $>$ starcu-tómu : stárec $z u$ schlieBen. Er ließe sich in der Weise deuten, daB der Artikel in den artikulierten Formen zur Aufrechterhal tung der synthetischen Deklination beigetragen hat, während die unartikulierten Substantiva dem Angriff des präpositionalen Typs I schutzlos ausgesetzt waren, d.h. daß der Artikel während einer längeren Periode die Lebensdauer des Typs II verlängert hat. So argumentieren Duridanov 705) und für die vergleichbaren rum. Pakten Budagov ${ }^{706)}$ und Coteanu ${ }^{707)}$. Jedoch zeigt der Dialekt von Boboščlca (und das DR), daB das Muster starcu ( $\equiv$ séstre) nicht $z u>\underline{\text { na stárec }}$ verändert worden ist; deshalb ist bei der Neutralisierung des obliquus des unartikulierten Nomens mit dem Directus nicht unbedingt mit einem Einflub des Präpositionalsystems zu rechnen, sondern mit einer Kasusaufgabe des Substantivs, wenn es ein kasusgleiches Attribut (Konkordanz!) bei sich hat. So entsteht für das unartikulierte Substantiv eine durch synthetisch flektierte Attribute indizierte Kasusflexion. ${ }^{708)}$ Ihre Spuren finden sich u.a. auch in den vlachobulgarischen Urkunden ${ }^{709)}$ : ovomu človek, na prěstolè roditelie našich, nevěrnik siemu povelěnie, tomu višepisannomu selo. Wo ist das Vorbild dieser Regelung zu suchen, nach der ein unartikuliertes Substantiv im Obliquus, das von synthetisch flektierten Pronomina und Adjek- 
tiva im Obliquus begleitet wird, in den Directus tritt?

Die Antwort geben solche altertümichen bulg.-mak. Nominalsysteme, die regelrecht nach Typ II flektieren, in dem Muster dobromu-tomu človeku aber die Tendenz zeigen, das dem Artikel folgende Substantiv > dobromu-tomu človek zu verändern. Vgl. folgenden Rhodopendialekt ${ }^{710)}$ :

\begin{tabular}{|c|c|c|}
\hline \multirow[t]{6}{*}{ obliquus } & masc. sing. & stárea tumu čileaku \\
\hline & fem. sing. & lošeâtuchi žéni \\
\hline & neutr. sing. & krotkutumu eagne \\
\hline & masc. plur. & $\begin{array}{l}\text { stareâmtêam čiléaci, } \\
\text { aber: čileácéamtéam }\end{array}$ \\
\hline & fem. plur. & $\begin{array}{l}\text { 16šếm têm } \underline{\text { žñni }} \\
\text { aber: žêneamteâm }\end{array}$ \\
\hline & neutr. plur. & $\begin{array}{l}\text { krotkémtêm êagneta } \\
\text { aber: éagneamtéam }\end{array}$ \\
\hline
\end{tabular}

Ebenso im Dialekt von Tichomir ${ }^{711)}$ als Ausnahmen vom sonst artikuliert und unartikuliert funktionierenden Typ II:

masc. plur. mlàdêmtę̂(m) sỳnąm - mlàdém sỳnąm fem. plur. mlàdêmtệ (m) žòny - mlàdêm ženém neutr. plur. mlàdệmtę̧(m) decà - mlàdẹm dẹcàm

Wie allgemein im Bulg.-Mak. gehen der Plural und der Singular neutrum mit den Neuerungen voran. 712)

Es muB demnach angenommen werden, daß das artikelhafte Syntagma Adjektiv-Artikel-Substantiv (Nomen 1 - Artikel Nomen $_{2}$ ) die Neutralisierung des nachgestellten Substantivs im Obliquus mit dem Directus initierte und $\mathrm{dab}$ in diesem Syntagma die generelle Tendenz entstand, jedes nichtpostartikulierte Substantiv im Obliquus mit dem Directus auszugleichen.

Nicht-postartikuliert sind außer den Substantiva, denen ein postartikuliertes Adjektiv vorausgeht (Adjektiv-Artikel-Substantiv), die van einem nicht-postartikulierten Adjektiv, vom Individualisator (dem 'unbestimmten Artikel'), vom Demonstrativ-, Interrogativ- und Indefinitpronomen begle1- 
teten Substantiva. Die Fälle, in denen ein Substantiv von einem konkordierenden Attribut (im gleichen Kasus wie das Substantiv) begleitet wird, unterteilen sich deshalb in:

$$
\begin{aligned}
& \text { 1. parvemu starcu } \\
& \text { 2. parvemu-temu starcu } \\
& \text { 3. e(d)nemu starcu } \\
& \text { 4. starcu-tomu }
\end{aligned}
$$

Die in der Konstruktion 2. entstehende Neutralisierung von Obliquus und Directus beim Substantiv dehnt sich auf die zu 1. und 3. gehörigen Konstruktionen aus. Vgl. oben das: višepisannomu selo und das Nebeneinander von nicht-neutralisierten und neutralisierten pronomenhaltigen Syntagmata in Tichomir: A ê kủpich nàšémtê bubàjk'u cigàrb, aber: sòzem

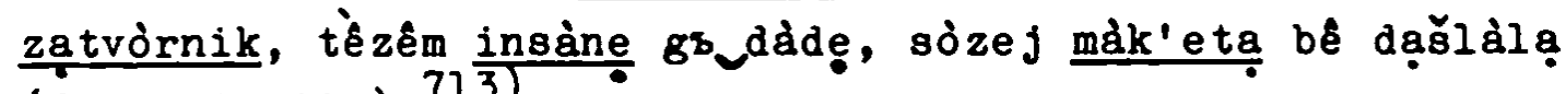
(demonstrativ).713)

Die hier vorgeschlagene Erklärung:

1. Phase parvemu starcu / parve(mu)temu starcu / e(d)nemu starcu / starcu-tomu >

parvemu starcu / parve(mu)temu starec / e(d)nemu starcu / starcu-tomu

2. Phase parvemu starcu / parve(mu)temu starec / e(d)nemu starcu / starcu-tomu >

parvemu starec / parve(mu)temu starec / e(d)nemu starec / starcu-tomu

erhellt, warum in den bulg.-mak. Dialekten die Reste von Typ II am ehesten in der Verbindung mit dem Artikel erhalten sind und nur schwach bei den unartikulierten Nomina - die Neutralisierung von Obliquus und Directus beim unartikulierten Nomen wurde, ausgehend vom Syntagma Adjektiv-Artikel-Substantiv, zu einer weiterverbreiteten Regel. Vgl. bei Miletic ${ }^{74}$ ): "Jetzt existieren in einigen Rhodopenmundarten, z.B. in der Mundart der Ropka, Formen des Dativ plur. gewöhnlich nur artikuliert (...) selten sind auch unartikulierte Dativformen zu hören." Vgl. die zahlreichen flektierten Artikelformen vom Typ caru-tomu, carem-tem im Mittelbulg. und in den Mundarten 
bei Miletič 715$)$ und Duridanov. 716) - Eine Ausnahme machen hier nur die traditionell unartikulierten und trotzdem z.T. noch synthetisch flektierten Verwandtschafts- und Personenbezeichnungen.

b. Muster starec: starcu-tómu > 1me : ime-tomu

Ebenso, wie der Artikel die Kasusneutralisierung des inm folgenden Substantivs bewirken kann, tendiert er dazu, das Kasusmorphem des ihm vorangehenden Nomens zu attrahieren, so daB das Kasusmorphem des Substantivs mit dem folgenden Artikel ein komplexes Kasus-Artikelmorphem bildet und das vorangehende Nomen eine konstante Form in allen Kasus einnimmt. Der gemeinsame Nenner für die Kasusneutralisierung des dem Artikel vorangehenden und des ihm folgenden Nomens ist die Reduktion der pleonastischen Kasusangabe im artikulierten Syntagma auf eine durch den Artikel ausgedrückte gesonderte determinierte Kasusflexion hin:
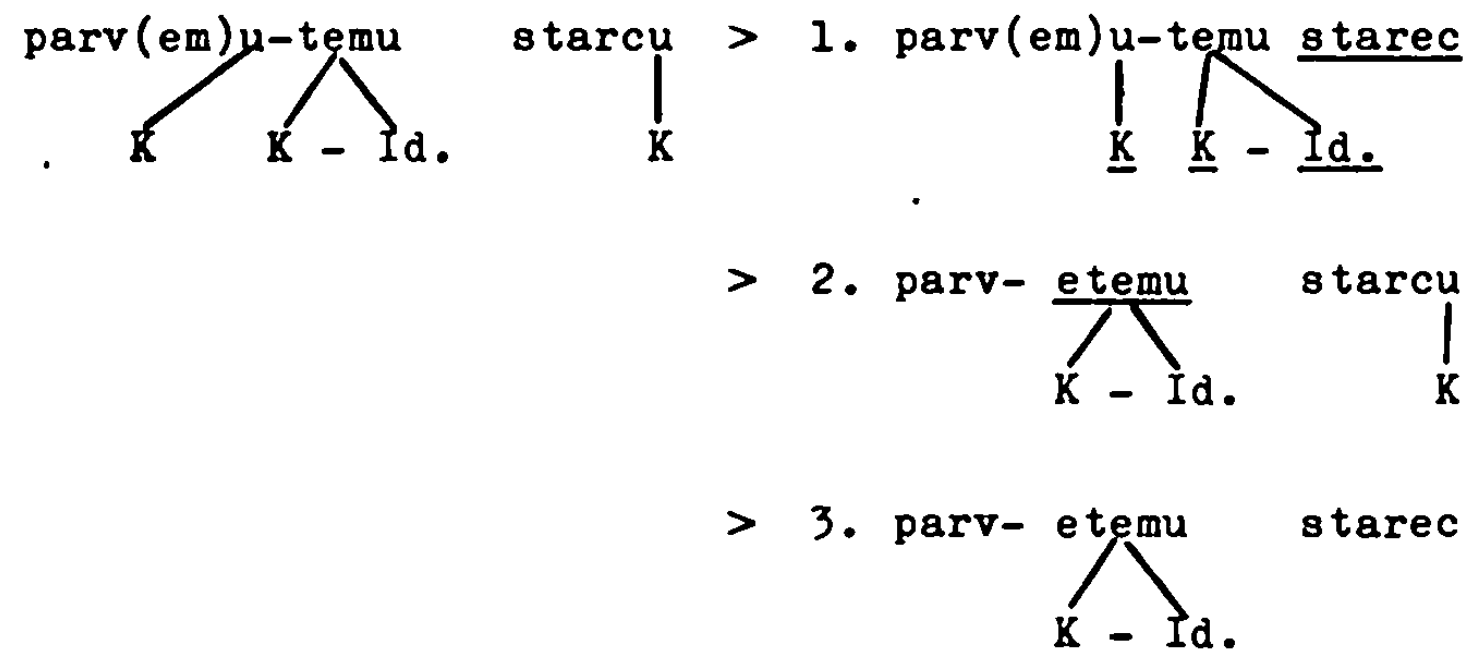

$K=$ Kasusangabe, Id. = Angabe der Identifizierung.

Dabei kann ProzeB 2 auch dem Proze $B \underline{1}$ vorausgehen oder ihre Kombination in 2 vom einzelnen Dialekt nicht erreicht werden. ProzeB $\underline{2}$ wird durch den Plural des Cergeder Systems belegt, welches einen regelmäBigen Typ II zeigt (s.0.), mit Ausnahme der Pormen des Obliquus plur. vor dem Artikel. 


\section{Obliquus}

Singular: ksrstu kbrstu-tumu Plural: ksrstem ksrstentem

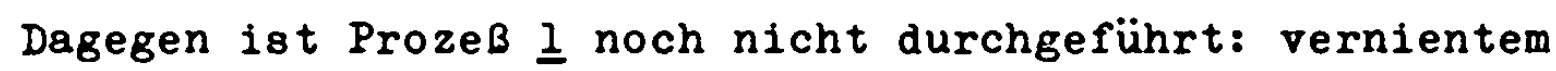
ksrstienem. Das Substantiv mit dem aus -em positionsbedingt entstandenen Allomorph -en: ksrsten- ist einer Analyse durch die entsprechende nichtartikulierte Kasusform ksrstem nicht zugänglich, was zu einer synchronischen Aufteilung in ksrst-entem und zu einer völligen Ubernahme der Kasusangabe durch diesen komplexen Artikel führt:

Obliquus

$\begin{array}{lll}\text { Singular: } & \text { kbrst-u (K) } & \text { kbrst-u (K) -tumu (Id.-K) } \\ \text { Plural: } & \text { kbrst-em (K) } & \text { kbrst-entem (Id. }-\underline{K} \text { ) }\end{array}$

Die Ausgangsform für den artikulierten obliquus plur. ist nicht mehr die entsprechende Form des unartikulierten Obliquus plur., wie im Singular, sondern eine konstante Nominalform, die mit dem Directus sing. nicht identisch ist, wie das Pemininum und das Neutrum zeigen: kbrst- zu kbrst (Directus sing.), aber zvezd- zu zvezda, şrc- zu sbrce. In Cerged hat dieser ProzeB auch den Singular der Adjektiva und Pronomina erfaßt:

* grěchovitago-tago > grechovit-ietago

* grěchovitomu-tomu > grechovit-itomu

*vašei-toi > vaš-tui, "našim-tem > naš-tem. 717)

Miletič bringt Belege für solche komplexen pluralischen Artikelformen in anderen Dialekten (Kumanovo: dobr-ientem) ${ }^{718}$ ), sie waren als frühe Stufe dieser Entwicklung wohl weiter verbreitet.

$\mathrm{DaB}$ sich eine besondere Kasusflexion des determinierten Nomens im Singular der Substantiva später bildete als im Plural, wird durch die zahlreicheren Relikte der determinierten Plexion des maskulinen Singulars in den bulg. und vor allem in den mak. Dialekten bezeugt: 
Directus člověk člověk-ot obliquus člověku člověku-tomu človek človek-ot Belege: carb́tomu, vlkótomu, zmajotoga, konjotoga in der Skopska Crnogorija 719 ), carotomu, popotogo im 19. Jhd. in Tetovo bzw. Polog 720 ), carotomu, drugotomu, popotogo, drugotogo, diavolotogo im 19. Jhd. bei Kiril Pejčinovik ${ }^{721)}$, in Ohrid: dulberbtomu, d'avolótomu, igumenótomu, kojnotogo ${ }^{722)}$, weitere Relikte bei Miletič ${ }^{723)}$. Einen vollständigen Reflex dieses Systems:

$\begin{array}{ll}\text { človek } & \text { človek-ot } \\ \text { človek-a } & \text { človek-otogo (dir. Objekt) } \\ \text { človek-u } & \text { človek-otomu }\end{array}$

zeigen Teile des Nordmak. mit den Formen človek, človekot, človeka, človekotogo, na človeka, na človekotogo, wo die analytische Form mit na für den synthetischen Obliquus eingetreten 1st, vgl. deren Nebeneinander in derselben Dialektgegend: ... rekla na ovčarótoga - carb́tomu mu rekal nekoj. 724)

Der Vokal -o-o-, der in diesen Pällen für -a-, -u- eintrat, geht offensichtlich auf das postartikulierte Adjektiv zurück, das seine obliquen Formen meist vom früheren zusammengesetzten Adjektiv bezog. Dies zeigt das Torlakische, wo nebeneinander mladógatoga und mladótoga bestehen, ebenso mojat - mbjetoga < mbjegatoga. ${ }^{725)}$ Die neugebildete komplexe Obliquusform des artikulierten Adjektivs wurde auf das Substantiv übertragen: mladomutomu > mladotomu > carotomu. Schlieblich ist in manchen Dialekten mit dem Artikel -o(t) auch dessen EinfluB möglich: carot - carútomu > carotomu, $\nabla g l$. die Interaktion zwischen dem Artikelmorphem und dem Obliquusmorphem im bulg. čileakąt, carjan, stoläs in Achbrčelebi (Rhodopen); die Miletič ausdrücklich aus čeleákg-tog(o) und in diesem Palle nicht aus dem phonetischen ProzeB - st > -at herleitet. 726 )

Aber es kann auch eine der alten Kasusendungen des Nomens generalisiert werden, so besonders bei Adjektiva: 
s tàrätumu čelàku < stàrätŏg(o)< 8 tarija-togo ${ }^{727)}$, stáreâtumu - stáréatug (Rhodopen) ${ }^{728}$ ), neben drugotogo, drugotomu im Mak. (Polog) ${ }^{729)}$, golemetégo, golemetému im Mak. (Bobošč1ca) ${ }^{730)}$, dobròtomu čovèku in den bulg.-serbischen Ubergangsmundarten.731)

Während die vor dem komplexen Artikel stehende konstante Form des maskulinen Nomens mit dem unartikulierten Directus übereinstimmt: kralj - kralj-otomu, ist die Ubereinstimmung des unartikulierten Directus mit der konstanten Form des Plurals prinzipiell nicht gegeben, wie das Pemininum und Neu-

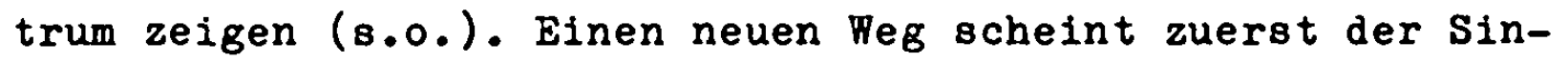
gular des Neutrums gegangen zu sein, indem es seine Nominalform im Obliquus mit dem Directus neutralisierte, ohne das Kasusmorphem an den Artikel abzugeben, so daB der Artikel die Doppelfunktion 'Kasusangabe' und 'Identifizierung' übernahm, ohne formal verändert zu werden:

městu-tomu > město-tomu, wie in Boboščlca.

Vgl. folgendes archaisches Nominalsystem aus den bulg. Rhodopenmundarten 732 ), das mit Ausnahme des neutralen Obliquus nach Typ II flektiert:

$\begin{array}{lll}\text { Subjekt } & \text { čileakat } & \text { čileacitê } \\ \text { Obliquus } & \text { čileakutumu } & \text { čileacêm tém } \\ \text { dir. objekt } & \text { čileakatug } & \text { čileacitea } \\ \text { Directus } & \text { žeankta } & \text { ženitea } \\ \text { Obliquus } & \text { žéneatuchi } & \text { ženeamtém } \\ \text { Directus } & \text { plletu } & \text { pilcétatea } \\ \text { Obliquus } & \text { plletumu } & \text { pilcémtém }\end{array}$

In solchen Mundarten, die zusätzlich den Obliquus sing. masc. mit dem unartikulierten Directus ausgeglichen haben, allerdings um den Preis eines komplexen Artikelmorphems, besteht nun folgende Relation zwischen dem artikulierten Obliquus masc. und neutr.: (Ohrid) dulber-btomu, d'avol-ótomu, aber det'é-tomu. 
Zu demselben Muster wie der Singular neutr. greift der artikulierte Plural aller Genera, wobei die Form mit Allomorph die $\mathrm{Zwischenstufe}$ bilden kann: stolovem-tem > stolov-entem $>$ stolovi-tem. ${ }^{734}$ ) Welches die Vorbedingungen für diese Generalisierung des Directus sind, zeigt der obenangeführte Rhodopendialekt, in welchem sich plletomu, ženeamtêm und 16šêmtêm ženi gegenüberstehen. Die unflektierte Obliquusform des Substantivs im Syntagma Adjektiv-Artikel-Substantiv wirkt auf die flektierte obliquusform des Substantivs im Syntagma Substantiv-Artikel oder des Adjektivs in Adjektiv-Artikel-Substantiv ein, und das Neutrum liefert das morphologische Modell für die neue Form: *žéni-têam, *I6̌si-team žéni. Dieser Rhodopendialekt kann als Illustration der unbelegten Vorstufe des Nominalsystems von Boboščlca gelten:

\begin{tabular}{|c|c|c|}
\hline $\begin{array}{l}\text { piletumu } \\
\text { pile-tomu }\end{array}$ & $\begin{array}{l}\text { ženêm team } \\
\text { majkjá-tem }\end{array}$ & $\begin{array}{l}\text { lǒseamteam žéni } \\
\text { parvjấ-tem májk'e }\end{array}$ \\
\hline
\end{tabular}

Mit parvjó-tem májk'e ist die Schlubstufe der Entwicklung des Syntagmas Adjektiv-Artikel-Substantiv erreicht: 1. "parvjám-tem majkam, 2. *parvjäm-tem májk'e, 3. parvjá-tem majk'e. In 3. wird die Identifizierung des Substantivs und dessen Kasus durch das Artikelmorphem allein ausgedrückt, ohne eine Doppelung der Kasusinformation durch das untergeordnete Adjektiv. Ubrigens weist auch der konsequente ProzeB des Syntagmas Adjektiv-Artikel-Substantiv von 1. bis 3. darauf hin, dab die Flexionsaufgabe des nicht-postartikulierten Substantivs in dem Entwicklungsstadium 2. des Syntagmas Adjektiv-Artikel-Substantiv das Vorbild für die Nachahmung durch somu starec, parvemu starec etc. war.

Das Muster stolovi-tem (3.) kann ebenso wie pile-tomu als im Bulg.-Mak. vor der Verdrëngung durch na stolovite (Typ I) weit verbreitet angesehen werden, während im Maskulinum stolútomu neben stolótomu weiterexistierte und mir Fälle von *stol-tomu nur beim Pronomen bekannt sind: naš-tumu 
caru in Cerged. 735) Auch den Typ ženz (oder -ą)-toi finde ich nicht belegt. Jedoch nahm die Formel artikulierter Obliquus $=$ Directus + Artikel im Obliquus mit dem Plural und dem Singular neutr. genügend Raum im Teilsystem der Kasusflexion ein, um einen schwachen Punkt im Typ II gegenüber dem Typ I zu bilden.

Die bulg. Tendenz, an einem Punkt der Entwicklung vom Altbulg. zum Nbulg. eine determinierte Plexion zu bilden, die den Kasusausdruck aller Teile des nominalen Syntagmas in den Artikel verlegt, hat Parallelen im Alb. und Rum. (sowie im Ngriech., worauf ich hier nicht eingehe, vgl. Civ' jan ${ }^{736)}$ ).

Im Alb. ist das nach einem Artikel folgende Nomen (wegen der Nachstellung des Adjektivs im Alb. meist ein Adjektiv) mit dem Directus ausgeglichen worden, vgl. Kap. II.3.b. B., und zwar so ausnahmslos, daB auf ein hohes Alter dieser Veränderung zu schließen ist. Vgl.

Nominativ

obliquus

Nominativ

obliquus

Nominativ

Obliquus

$$
\begin{aligned}
& \text { *vajzë e-mirë } \\
& \text { * vajze së-mire } \\
& \text { *vajzë-e-mirë } \\
& \text { "vajze-së-mirë }
\end{aligned}
$$$$
\text { modern als }
$$

Ebenso im Plural: Nominativ vajzat të mira, Obliquus vajzavet të mira und in der Inversion: së mirës vajzë, të mirit zot_.

Das Alb. bestätigt, daB die Aufgabe der Plexion des nicht-postartikulierten Nomens (im Alb. meist: Adjektiv) zuerst nach dem Artikel, nicht nach den Pronomina erfolgte. $\mathrm{Vgl}$. mit den obigen Mustern:

$$
\begin{aligned}
& \text { zot i-mirë } \\
& \text { zoti të-miri } \\
& \text { *zot-i-mirë } \\
& \text { *zoti-të-mirë }
\end{aligned}
$$

zot1 1 mirë zotit të mirẹ 
Nominetiv

ky djal

nji djal

em at

Ime bijë
Obliquus

këtij djali

njij djali

$t$ 'em et(i)

s'ime bije 'dieser Junge'

'ein Junge'

'mein Vater'

'meine Tochter'

neben (im Gegischen):

im bir

em' ámë

$$
\text { t'em bir }
$$

'mein Sohn'

'meine Mutter'. 737)

Wie die obengenannten modernen Formen zeigen, ist auch die Obliquusneutralisierung vor dem Artikel (alb. meist: Substantiv) durchgeführt, entsprechend dem bulg. stolovi-tem, 3., allerdings nur bei den Femina im Singular:

$\begin{array}{lll}\text { Nominativ } & \text { vajzë } & \text { *vajzë-a } \\ \text { Obliquus } & \text { vajze } & \text { *vajze-8̈̈ }\end{array}$

wird verändert zu

Nominativ

Obliquus

Nominativ

Obliquus
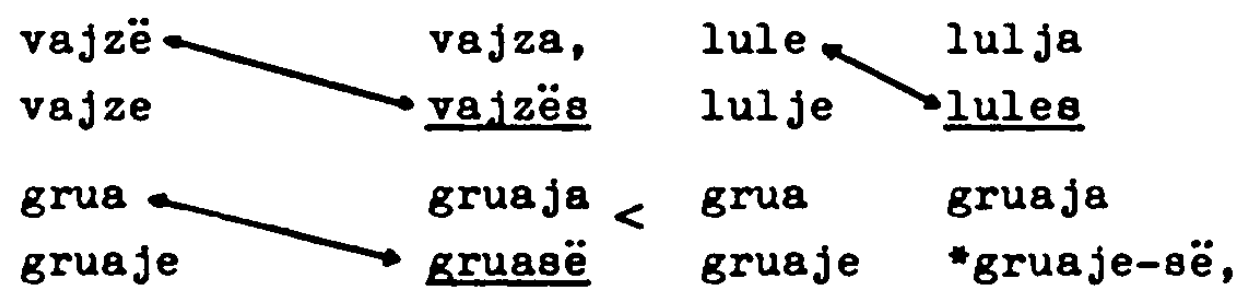

dagegen im Maskulinum mal 'Berg' - mali 'eines Berges, einem Berge' - malit'des, dem Berg(s)' mit unzerstörter Parallelität des unartikulierten und artikulierten obliquus, ebenso im Plural aller Genera.

Skok ${ }^{738}$ ) stellt alb. pune (unartikulierter femininer Obliquus) als entstanden aus dem Nominativ punë und dem Artikel e dar, ebenso djali (unartikulierter maskuliner obliquus) aus djal + Artikel $\underline{1}$, djelmve (unartikulierter Obliquus plur. im Toskischen) aus djelm + Artikel ve (<*(0)yos!) und muß nun erklären, warum der artikulierte Nominativ fem. punë + e > punge, aber der unartikulierte obliquus fem. punë $+e>$ pune. 
Skoks Analyse beruht auf dem falsch angesetzten Vergleich von alb. maleve, dem formal unartikulierten obliquus im Plural, der aber im Toskischen auch die identifizierende Punktion von malevet (so im Gegischen) ausübt, mit dem rum. domnilor, dem formal artikulierten Obliquus im Plural. Die richtige Entsprechung ist alb. maleve - rum. (a, de) domni, alb. malevet - rum. domnilor. Skok sucht in -ve, das er mit rum. -lor vergleicht, das Demonstrativpronomen *(0)yos, ebenso in djali 'eines Jungen', pune 'einer Arbeit', den Artikel, der in rum. copilului, lucrului vorliegt. - Dagegen stellt Barif zu Recht in den Endungen des unartikulierten Substantivs djali, zogu, vajze, maleve die indogermanischen Kasusendungen -oi/-ou, -i $\bar{a} s$, -öm fest. 739) Der Unterschied zwischen dem artikulierten Nominativ fem. puna und dem unartikulierten Obliquus fem. pune erklärt sich deshalb einwandfrei aus *(pun-)a-ja (Artikel) bzw. *(pun-) jās (Kasusendung).

Das alb. Syntagma vajzë-s së mirë entspricht also dem bulg.-mak. dobrí-tem starcí. Dieser alb.-slav. Parallelismus steht auBerhalb des Verdachts, auf linguistischen Kontakt zurückzugehen, dazu ist die Tendenz, auf die er im Bulg. zurückgeht, zu sehr in den bulg. Mundarten befestigt, die auf dieser Entwicklungsstufe (nach dem 10. Jhd.) keinen Kontakt mehr mit dem Alb. hatten. Es kann sich nur um eine Entwicklung handeln, deren Parallelismus auf der Ahnlichkeit der Ausgangsposition im Alb. und Bulg.-Mak. beruht, diese allerdings entstammen einem (zumeist mittelbaren) Kontakt.

Eine auf die alb. und bulg.-mak. Pakten gegründete Erklärung kommt zu dem SchluB, daß der Artikel in dem nominalen Syntagma nach vorn und nach hinten wirkend die Obliquusendungen der Nomina zu beseitigen bestrebt ist. In diesem ProzeB kann man das Wirken der Sprachökonomie beobachten, die es sich zunutze macht, daB der Artikel außer der Identifizierung des Substantivs auch den Kasus der kongruenten Nomina doubliert und nun diesen Kasusausdruck der Nomina allein in das Artikelmorphem verlegt. Diese Erklärung wird gestützt 
durch die Beobachtung der Civ'jan ${ }^{740)}$ : "(..) gerade der Artikel ist ein grundlegender grammatischer Anzeiger im Nominalsystem des balkanischen Sprachbundes. Im Lichte der Theorie linguistischer Kontakte läßt sich dies dadurch erklären, daB eine solche 'Plexion' dank inrer besonderen Porm auffälliger ist, leichter zu analysieren und zu erkennen."

Schwierigkeiten bereitet die Interpretation der rum. Pakten, weil diese den alb. und bulg.-mak. weitgehend ähneln und sich für sie dennoch eine andere Erklärung als die oben angebotene geben läßt.

Vom vulgärlat. Plural caballi (nom.) - caballos (obl.) 741) übernahm das Rum., hierin dem Italienischen gleichend, nur die Nominativform ( $>$ cai) und gab die Obliquusform auf. Dies bewirkt, daB im rum. Plural von Beginn an der dem Artikel vorangestellte wie auch der inm folgende obliquus mit dem Directus neutralisiert ist, ohne daß eine Einwirkung des Artikels als Erklärung herangezogen werden muB:

Directus case debile, oameni buni

Obliquus case debile, oameni buni

Directus casele debile, oamenii buni

Obliquus case-lor debile, oameni-lor buni

Derselbe zustand wurde im Singular masc. dadurch herbeigeführt, daß bei den o-Stämmen das mit dem Obliquusmorphem gleichlautende Akkusativmorphem zwecks Bildung eines einheitlichen Directus das Nominativmorphem verdrängte:

Directus *alā-le bună, calu-lu bunu

Obliquus calu-lu bunu

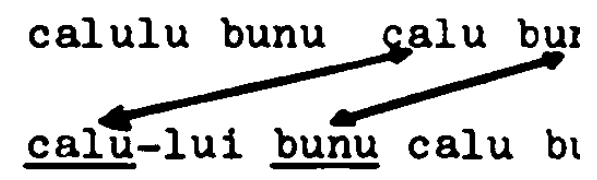

Die Resultate dieser Veränderungen, die vom Artikel unabhängig auftraten, entsprechen denen des Bulg.-Mak. und Alb. Im Syntagma Nomen-Artikel-Nomen übernimmt der Artikel neben der Identifizierung des Substantivs auch den Kasusausdruck.

Dagegen ist im rum. Pemininum kein Zusammenfall von Directus und Obliquus sing. gegeben; der Kasuspleonasmus aller 
Glieder des nominalen Syntagmas ist erhalten:

Directus casă nouă casa nouã

obliquus case noue case-ei noue (altrum.)

Entsprechend bel den adjektivischen Pronomina:

obliquus acestei case unei case

neben

acestul cal unui cal

Die Geschichte des Pemininums im Gesamtrum. ist in der Polgezeit durch das Bemühen gekennzeichnet, sich dem Vorbild des Plurals und des Singulars masc. anzugleichen und den Kasusausdruck in den Artikel zu verlegen. Diese Angleichung erfolgt auf zwei Wegen:

1. Der Artikel attrahiert das Kasusmorphem des vorangehenden Nomens: "Nachdem der enklitische Artikel zum Morphem des Casus obliquus geworden ist und einen gemeinsamen phonetischen Körper mit dem Nomen bildet, bewirkt er, daß die Endung des Casus obliquus an Bedeutung verliert und in vielen Fällen verschwinden kann." (Vasiliu) ${ }^{742)}$ Dieser ProzeB entspricht dem bulg.-mak. caru-tomu, carem-tem > car-otomu, car-entem.

Dieser ProzeB wird vom Singular masc. eingeleitet, das Pemininum kann sich ihm anschließen. Die Verstummung des auslautenden -ü im Rum., die schon im 13. Jhd. festgestellt werden kann 743 , verändert lupulu > lupul.

$\begin{array}{lll}\text { Directus } & \text { Iupu lupulu } & \text { lup lup-ul } \\ \text { Obliquus } & \text { Iupu lupului } & \text { lup lup-ului }\end{array}$

Die Analyse zu lup-ul, lup-ului beruht auf dem Vergleich mit der entsprechenden unartikulierten Form. - Das AR lup-lu, lup-lui geht auf lupulu, lupului zurück, die im 18. Jhd. für das AR und noch heute in einigen seiner Unterdialekte bezeugt sind. 744)

Die altrum. Texte zeigen noch nichtfusionierte und fusionierte Formen des Pemininums nebeneinander, $\nabla g l$. Tamare-e zu Tamara neben Topan-ej zu Topana (16. Jhd.), dosade-ei, nop $f \underline{1-e 1}$ neben modernem dosad-ei, nopt-1i ${ }^{745)}$ durch Kontrak- 
tion von -e-ei >-ei, -i-ei > ii. Die Kontraktion zerstört den synchronischen Parallelismus von unartikulierten und artikulierten Formen im Obliquus:

$\begin{array}{lll}\text { Directus } & \text { casā } & \text { casā-a } \\ \text { Obliquus } & \text { case } & \text { case-ei }\end{array} \quad \begin{array}{ll}\text { casā cas-a } \\ \text { case }\end{array}$

Die Kontraktion von *casā-a > casa 1 ist dagegen sehr alt. ${ }^{746)}$ Während die unartikulierte Form weiterhin case lautet, "hören wir in der gesprochenen Sprache niemals einen Genitiv-Dativ casei, sondern casai, casăi, casii." (Vasiliu) ${ }^{747)}$. Wie die Maskulina zeigen nun auch die Feminina eine determinierte Plexion mit komplexem Artikelmorphem vor einem konstanten Stamm:

$\begin{array}{lllll}\text { Directus } & \text { lup- } \varnothing & \text { lup-ul } & \text { cas-ā } & \text { cas-a } \\ \text { Obliquus } & \text { lup- } \varnothing & \text { lup-ului } & \text { cas-e } & \text { cas-i 748) }\end{array}$

Grammatikfehler in der Kongruenz des femininen Adjektivs im Obliquus zeigen, daß im DR auch das nachgestellte Nomen gelegentlich zur Neutralisierung mit dem Directus strebt, wie sie im Singular masc. und im Plural schon besteht. 749)

Dem Unterschied von parvjk-tuj májk'e - parv-etému

oterec in Boboščlca entspricht DR fete-ei bune - om-ului bun im 16. Jhd., während das moderne fet-i bune mit dem Cergeder vern-ientem ksrstienem zu vergleichen ist.

2. Der Obliquus vor dem Artikel verändert sich in den Directus wie beim slav. Singular neutr. und beim Plural aller Genera. Hier orientierte sich das Pemininum vor allem am Plural lupi - lupllor, case - caselor sowie, soweit es erhalten war, am Singular masc. lupu - lupului. Neben der Kontraktion von -e-ei > -el zeigt das Altrum. Fälle von Neutralisierung des Obliquus mit dem Directus: casă-i, fără-1, fărâ-i, Raveck-ei, Onä-ei 750) statt case-e1, nach dem unartikulierten Directus casā. Der Kasusausdruck erfolgt durch den nicht-komplexen Art1kel: 1. cas-i, aber 2. casă-1. In einigen DR Mundarten besteht die Tendenz zu 2. weiter. ${ }^{751}$ ) Sehr viel stärker ist sie 
im MR und AR. Im MR heiBt es allgemein im Obliquus: featăl'a < featel'à. Im AR konkurrieren das ältere Muster a casel'el und das jüngere a casạl'el im Obliquus. ${ }^{752)}$ Damit ist die Parallelität zwischen dem Plural, dem Singular masc. und fem. hergestellt: case (unartikulierter Directus) : caselor (artikulierter Obliquus) = bărbat (unartikulierter Directus): bărbatlui (artikulierter Obliquus) = casă (unartikulierter Directus) : casăl'el (artikulierter Obliquus). Die Unmöglichkeit einer inversen Erklärung: (älteres) casăl'el > (jüngerem) casel'ej ist von Densusianu753) und Rosetti ${ }^{754}$ ) festgestellt worden.

Sollen nun die frühzeitig entstandenen rum. Muster lupi-lor, lupu-lui, woraus lup-ului, als Ausgangspunkt für die Entwicklung auch im Alb. und Bulg.-Mak. gedient haben, wodurch die oben gegebene Erklärung durch die Artikeleinwirkung hinfällig würde? Eine eindeutige Entscheidung kann nicht getroffen werden. Jedoch halte ich die Einwirkung des Rum. auf das Alb. in diesem Punkt für unwahrscheinlich, weil in der früheitigen Neutralisierung von Directus und Obliquus beim nachgestellten Nomen und der sich daraus ergebenden Kasusübernahme des Protoartikels einer der Gründe für die lange Bewahrung des Protoartikels neben dem postpositiven Artikel im Alb. zu erblicken ist. Nicht wahrscheinlicher ist der Einflub des Rum. auf das bulg.-mak. Nominalsystem in der zeit nach dem 10. Jhd., denn die Ubermittlung des Artikels und der Deklinationstypen II und I rom Rum. ins Bulg.-Mak. liegt vor diesem Datum.

Jedenfalls gleichen sich die Ergebnisse des gesamten Prozesses im Alb., Rum. und Bulg.-Mak.: Der Typ II im Syntagma dobrem-tem starcem (obl.) ist in dem am weitesten fortgeschrittenen Palle zu dobri-tem starci verändert worden.

Die aus Gründen der Sprachökonomie initilerte Bildung einer besonderen determinierten Flexion (dobri-tem starci), mit Vereinigung der Kasus- und der Identifizierungsfunktion im Artikel, hat jedoch auch funktionelle Nachteile, weil sie, 
wie oben für das Bulg.-Mak. beschrieben, eine Obliquusneutralisierung aller Nomina nach sich zieht. Der Obliquusausdruck wird, außer vom Artikel, von flektierten Adjektiva, Pronomina und Zahlwörtern übernommen, eine indizierte Kasusflexion entsteht. Da in vielen Fällen semantische Gründe die Verwendung dieser Kasusanzeiger verhindern, wird der Artikel in zunehmendem Maße als Kasusmorphem verwendet, seine Identifizierungsfunktion wird nebensächlich. Diese Entwicklung und ihre Konsequenzen zeigen sich besonders klar im Rum.

Des DR, besonders die Schriftsprache, hat aufgrund ihres konservativen Charakters an dem Sieg festgehalten, den der synthetische Typ II im Altrum. über das zweipräpositionale Kasussystem errungen hatte, und deshalb den Typ II zuungunsten des Präpositionalausdrucks beibehalten. Das führt dazu, daB der Artikel neben anderen Hilfawörtern zur stützung der grobenteils aufgegebenen nominalen Kasusmorpheme verwendet wird und damit seine Identifizierungsfunktion verblaßt. 755) Zur Obliquusbildung von unartikulierten Nomina können Demonstrativ-, Interrogativ- und Indefinitpronomina dienen, die noch eine synthetische Obliquusform aufweisen: acestui om bun, acelui om bun, acelor oameni buni. Wird für das betreffende Nomen keine zusätzliche semantische Information gewïscht, wie sie diese Pronomina vermitteln, so weicht das DR auf den Artikel, den Individualisator und die Präposition de im partitiven Sinne aus. So entsprechen einander: frunzele de brad oint veril = frunzele unui brad sint verzi, frunzele bradului oint verzi. 756) Am häufigsten ist die Verwendung des Artikels in dieser Punktion. Die Bedeutungsgleichheit von de brad, unui brad, bradului im obigen Beispiel beweist die Neutralisierung der primären Funktion des Artikels, den Identifizierungsverlust. Die Prequenz des Artikels als reines Kasusmorphem ist sehr hoch, so sehr, das "Personen mit beschränkter grammatischer Bildung meinen, der Genitiv von pom sei pomului, nicht (unui) pom, und durch Analogie wird als Genitiv von casā - casei betrachtet anstelle von (unei) case 
(...)n (Coteanu). 757) $\mathrm{Zu}$ den sich zwischen dem Obliquusausdruck mit de, un, Artikel einstellenden Bedeutunganuancen (camera deputafilor - camera de deputafi, directorul băncil directorul de bancā) vgl. Hansen. ${ }^{758)}$ Dadurch, daß $\underline{1 u}$ nur vor postartikulierten Nomina für den Obliquusausdruck verwendet wird: 1 -am spus lu omu astă = omului ${ }^{759)}$ und la für den Ausdruck des indirekten Objekts vermieden wird, unterscheidet sich die Schriftsprache von den DR Dialekten: hier gilt auch lu, $\underline{\text { la }}$, de la neben de für das Attribut und la für das indirekte Objekt: se infātişấ la oameni und sogar: Cui ai dat vaca? - La un vecin (für unui vecin). 760) In den DR Dialekten ist ein ein- oder zweigliedriges Präpositionalsystem im Vormarsch gegen die indizierte Flexion der Schriftsprache, welche die Ruine von Typ II stützt.

Im $A R$, $M R$ und IR ist ein ausschliebliches Eintreten von Präpositionen für die Kennzelchnung des unartikulierten Obliquus und von dort sich ausbreitend auch für den artikulierten obliquus festzustellen, $d . h$. die eingetretene Neutralisierung des unartikulierten Obliquus mit dem Directus wirkt nun auf die determinierte Kasusflexion zurück und zerstört sie.

Im AR koexistieren noch die obligatorisch gewordene Präposition a und die tellweise erhal tene synthetische Fle$x i o n$ des Nomens: a unei feate neben a un bărbat in der zu

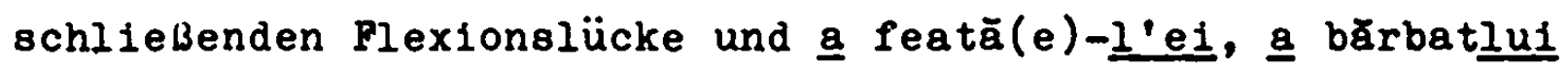
in der Ausdehnung auf die Flexion der artikulierten Substantiva. Daneben (selten) 1a für den Dativ. ${ }^{761)}$ Weiter fortgeschritten ist der AR Pärgeroten-Dialekt, in welchem der oblique Artikel nach der Präposition seine sekundäre Kasusinformation aufgegeben hat: unartikulierter Directus bärbat, unartikulierter Obliquus a un bărbat, artikulierter Directus bărbat-lu (bărbat-u), artikulierter Obliquus a bărbat-lu (a bărbat-u). ${ }^{762)}$ Damit ist die eindeutige Punktion des Artikels als Identifikator wiederhergestellt:

Directus bărbat - (Kas. $\varnothing)$-u (Id.)

Obliquus a (Kas.)- bărbat-u (Id.) 
und der Flexionstyp I erreicht.

Denselben Endpunkt der Entwicklung zeigen MR und IR, wobei MR die Funktionen des Attributs (mit $\underline{\text { lu}}$ ) und des indirekten Objekts (mit 1 a) erneut reinlich trennt, wie in $D R$ Mundarten als Tendenz bemerkbar. ${ }^{763)}$ Das IR Muster lautet artikuliert:

$\begin{array}{lllll}\text { Directus fil'u } & \text { fil'i } & \text { fęta } & \text { fętele } \\ \text { Obliquus } & \text { lu fil'u } & \text { lu fil'i } & \text { lu fęta } & \text { lu fętele }\end{array}$

das MR Muster lautet artikuliert:

Directus ampirātu

Genitiv lu ąmirätu

(neben: ampirātuluj)

$\underline{\text { Dativ }}$ featili

lu featili

la featili

Die Schließung der Obliquus-lücke, von der die Ersetzung der determinierten Kasusflexion ausging, hat MR (entsprechend IR) die Form: lu unā featã, la ună feată, lu frał 'von Brüdern', la fraf 'Brüdern'. 765)

Zu dem Zustand im DR vgl. einige alb. Dialekte, wie das Gegische von Shkodër ${ }^{766)}$, den Dialekt von Dushmani ${ }^{767)}$, von Zadar in Dalmatien ${ }^{768)}$, wo das Verhältnis vajzë (unartikulierter Nominativ) - vajzës (artikulierter obliquus) analog zum DR zur Verwendung der Form vajzës auch für den nicht-identifizierten obliquus geführt hat, übertragen vom Femininum auf das Maskulinum: (i) gurit 'des Steines', 'von Stein'. Selten tritt im Alb. eine Präposition für den Ausdruck des Obliquus ein: te dielli 'der Sonne' = 'bei' + artikulierter Nominativ, tek juga 'dem Südwind 769), denn dem Alb. fehlt das romanische präpositionale Kasussystem als Ausweichmöglichkeit. Unter italienischem EinfluB wächst im Italoalb. von Acquaformosa der Ausdruck des Attributs durch $\underline{k a+N o m i n a t i v}$, entsprechend dem italienischen da. ${ }^{770)}$ Der Ubergang des Artikels von der Identifizierungsfunktion zu einer reinen Kasusfunktion ist sogar im Armenischen zu beobachten. 771 ) 
Der Prozeß dobrem-tem starcem $>$ dobri-tem starci, den ich oben an einigen altertümlichen bulg.-mak. Dialekten und hier vor allem im Bereich der Personenbezeichnungen feststellte, muB sich in den progressiven Mundarten und vor allem im Bereich der Sachbezeichnungen in der Zeit bis zum 15. Jhd. abgespielt haben, von dieser Zeit an herrschte in ihnen der Typus I, und II erhielt immer kleiner werdende Reservate bei Personenbezeichnungen zugewiesen. Typ II ist in den Damaskinen, vor allem bei Personenbezeichnungen, bis ins 17 . 18. Jhd. bewahrt. 772) Das Resultat dobri-tem starci, krotk-otomu pile zeigt die Fehlerhaftigkeit der Ansicht, die Artikelform stände im Bulg. in keinem Zusammenhang mit der Aufgabe der synthetischen Kasusformen 773), sie hat im Gegenteil auf diese Aufgabe hingewirkt, wenn auch in geringerem MaBe als das präpositionelle Kasussystem selbst: "(...) je mehr sich die Homonymie von Kasusendungen in einem gegebenen Flexionstyp ausbreitet, um so mehr verhilft dies zu einer zewissen Schwächung des Synthetismus im Nominalsystem dieser Sprache" (Duridanov). 774) Die Kasusfunktion des Artikels kann, in ähnlicher Weise wie im Rum. und Alb., seine uneigentliche Verwendung gefördert haben: "Der Artikel gewann mit dem Verluste der Declinationsformen an Verbreitung, er wurde allgemeiner. Deshalb finden wir mehr Beispiele desselben erst aus dem 14. Jahrhundert, wo die Zerrüttung der Declination bereits begonnen hatte" (Oblak). 775) Zur Aufgabe der Identifizierungsfunktion des Artikels kam es jedoch nicht, da in den meisten Mundarten das Ausweichen auf das Präpositionalsystem mit seiner funktionellen Priorität möglich war. DaB eine Aufgabe dieser primären Funktion des Artikels überhaupt unmöglich ist, wie Kurz 776) meint, kann nach den vorgelegten Fakten des Rum. und Alb. nicht mehr behauptet werden.

Der Dialekt von Boboščlca zeigt eine dem DR überraschend ähnliche indizierte Flexion, weil er wie dieses nicht auf das präpositionale Kasussystem auswich. In Boboščlca ist die Kasusangabe durch synthetisch flektierte Pronomina und 
Adjektiva zum System ausgebaut worden. Die Notwendigkeit einer Kasusindikation des unartikulierten Substantips hat besonders zur Ausbildung eines regulären Individualisators éden (en), éna, éno geführt, dessen "Gebrauch ebenso konstant 1st wie im Französischen der von un und im Deutschen von ein: éden čbvek imjéše dva sinovin" (Mazon) ${ }^{777)}$, während sonst im Bulg.-Mak. ein Individualisator noch sehr sporadisch und unregelmäßig auftritt (kein System bildet). Als Plural von éden gilt in Boboščlca tra (Obliquus tram): tram ludi 'einigen Leuten', welches dem DR neşti entspricint. Vgl. folgende Aufstellung:

Boboščica

Directus

stárec

s taréc-o

obliquus

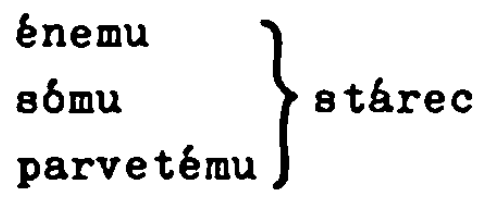

starcu-tómu

Attribut auch:

ot stárec

ot starca-tbgo

DR

Directus bărbat

Obliquus

$$
\left.\begin{array}{l}
\text { unuí } \\
\text { acestui } \\
\text { bunului }
\end{array}\right\} \text { bārbat }
$$

Attribut auch:

de bärbat

Boboščica

$\begin{array}{ll}\text { Directus } & \text { stáci } \\ \text { Obliquus } & \text { starc1-ti } \\ & \left.\begin{array}{l}\text { sijam } \\ \text { parvitim }\end{array}\right\} \text { starc1-tim }\end{array}$

Attribut

auch:

ot stárci

ot $8 \operatorname{tarc} 1-t i$ 
DR

\begin{tabular}{|c|c|c|}
\hline Directus & bārbaţi & bārbati-i \\
\hline Obliquus & unor & bărbaţi-lor \\
\hline & $\begin{array}{l}\text { acestor } \\
\text { bunilor }\end{array}$ & \\
\hline
\end{tabular}

Attribut

auch: de bärbaţi

Sogar die erhaltene Obliquusform in unartikulierten singular des Femininums ist beiden gemeinsam:

éne májk'e - unei mame éne çupe - unei fete

Diese Parallelität beruht nicht auf linguistischem Kontakt, sondern auf typologisch ähnlichen Polgerungen, welche aus der Bewahrung von Typ II und aus der Ablehnung des präpositionellen Kasussystems fließen. In diesem Sinne repräsentiert die induzierte Plexion von Boboščlca kein früher im Mak. weitverbreitetes System 778), sondern eine originelle Sonderentwicklung.

Den entgegengesetzten ProzeB: Nomen + Kasus + Artikel + Kasus > Nomen + Kasus + Artikel, also Artikel < Nomen, zeigt, allerdings in sehr junger Entwicklung, der Rhodopendialekt von Tichomir: "Charakteristisch für die Kasusformen, die mit einem Artikel verbunden sind, ist, daB die Artikelform gewöhnlich nicht dekliniert wird"779): stàrạtế (Obliquus plur.), stàrsj-sệ (Obliquus sing. fem.), čulêku-tẹ (Obliquus sing. masc.), stàrom-tẹ čulềku, mlàdêmtệ(m) žòny neben ženêmte, čulèku-sề neben seltenerem čulềku-su.

Mit der Aufgabe von Typ II ist das Bulg.-Mak. in der Entwicklung weiter fortgeschritten als die übrigen balkanischen Schriftsprachen ${ }^{780)}$, indem es das romanische präpositionelle Kasussystem, z.T. mit Verwendung nur einer Präposition (Typ I), ausnahmslos durchgesetzt hat: "In dieser Beziehung theilte daher das Bulgarische eher den Standpunkt der übrigen romanischen Sprachen als das Rumänischen (Jagić).78l) Während 
das DR, wie die progressiven rum. Dialekte zeigen, aus Kcnservativismus den Ubergang zu Typ I noch nicht vollzogen hat, konnte das Alb. auf kein vom Romanischen übernommenes prépositionales Kasussystem zurückgreifen, für seinen intern $\varepsilon$ schwächten Typ II gibt es keine Konkurrenz im eigenen System. Wie die bulg.-mak. und die rum. Dialekte zeigen, besteht und bestand in beiden Sprachen ein ständiges Nebentinander von Typ I und Typ II, und in ihre Auswahl für die Veiterentwicklung der Kasusflexion hat zweimal der Artikel, wenn nicht immer entscheidend, so doch beeinflussend eingegriffen: einmal förderte er den Typ II gegenüber dem Typ I im Frürrum., zum andern' trug er zur Durchsetzung von Typ I im Bulg.-Mrk. und in den rum. Dialekten dadurch bei, daB er den synthe;ischen Typ II durch die Bildung einer besonderen determin:erten Kasusflexion zersetzte. 
IV. PROTOARTIKEL IN SIAVISCHEN UND ALBANISCHEN 782)

Bereits in Kap. II.3.b. war der erschlossene alb. Prototyp *kal i-mirë 'das gute Pferd' mit der slav. Konstruktion dobrb-ib konb zusammengestellt worden. Im folgenden sollen einerseits die funktionelle und die formale Parallelität zwischen der alb. und der slav. Konstruktion hervorgehoben und andererseits die divergierende Feiterentwicklung beider Konstruktionen erklärt werden: Während im Alb. ein kal-i 'das Pferd' entstand, ist es im Slav. $2 u$ einem *jb-konb nicht gekommen. Die Postulierung eines jb otbcb 'der Vater' für das Urslav. durch tos ${ }^{783)}$ hat meines Wissens keine weiteren Befürworter gefunden.

Die alb. Konstruktion ist gekennzeichnet durch a. die indirekte Identifizierung eines Substantivs durch einen zum Attribut gehörigen und nur in Verbindung mit diesem auftretenden Protoartikel,

b. das Auftreten des idg. Relativpronomens *ios im Morphem des Protoartikels.

Die slav. Konstruktion ist in Verbindung mit der parallelen baltischen zu untersuchen. Im Slav. und Baltischen (hier: Iitauischen) lautet das Oppositionssystem des Nomens:
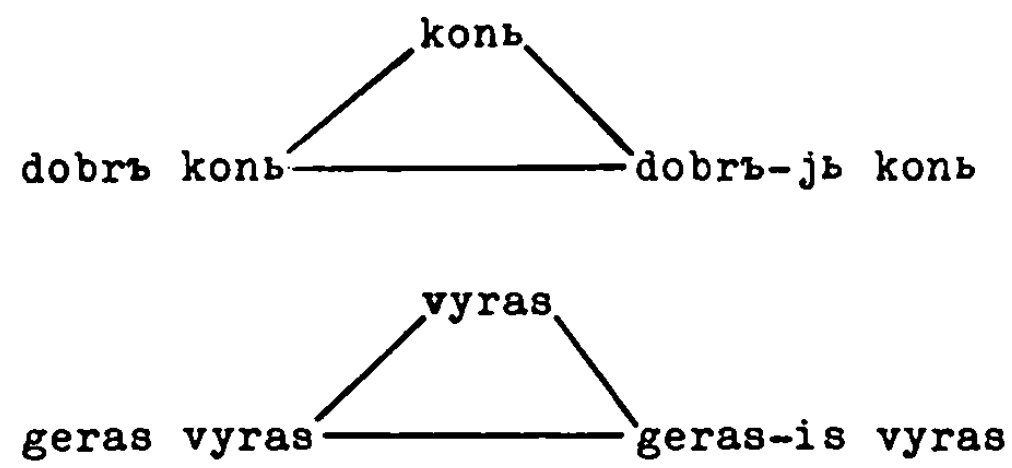

(vyras 'Mann', geras 'gut')

entsprechend dem frühalb.

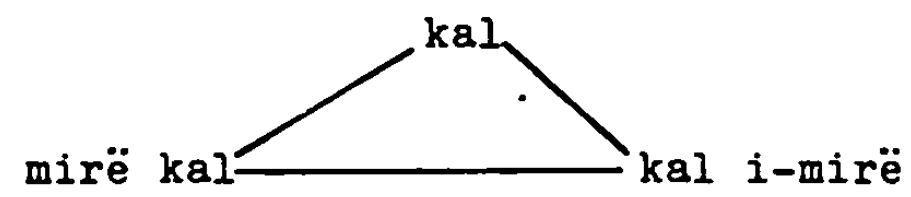


Während aksl. dobrb-jb konb mit 'das gute Pferd' zu übersetzen ist, gleich dem alb. kal i-mirë, bedeutet das 11t. gerasis vyras nicht nur 'der gute Mann'. Zu der Diskussion über die Bedeutungen der Pronominalform des Adjektivs im Lit. vgl. die Zusammenstellung der verschiedenen Ansichten bei Kurz ${ }^{784}$ ) und L. Baldauf ${ }^{785)}$. Auf die von der letztgenannten Autorin durch Substitutionsversuche festgestellten Bedeutungen der Pronominalform des lit. Adjektivs stütze ich mich in der folgenden Ubersicht, die klarmachen soll, daB die neben der Identifizierung festgestell te emotionale Funktion des pronominalen Elementes im Syntagma Adjektiv-Substantiv nicht gegen die funktionelle Parallelität des alb. und des balto-slav. Protoartikels spricht.

Die Aufgabe des pronominalen Elementes besteht im Lit. generell darin, das von ihm begleitete Adjektiv hervorzuheben.

1. Die Klarstellung des intendierten Gegenstandes durch eine Identifizierung mit dem inn bezeichnenden Substantiv wird nicht angestrebt, da das Substantiv als immer nur einen bestimmten Gegenstand bezeichnend aufgefaßt wird, das Appellativ also wie ein Name verwendet ist. Die Hervorhebung durch das pronominale Element führt hier zur Emotionalisierung des Adjektivs: gerasis tévelis 'guter Vater', mielimofi sesuté 'liebes Schwesterlein', viešnia šviesioji 'heller Gast'. "Jeder hat doch nur einen Vater, und nicht einen guten und einen schlechten; man will mit diesem Ausdruck 'gerasis tẽvelis' (wo gerasis eine Pronominalform ist) eben nur seine Achtung und Liebe inm gegenüber zum Ausdruck bringen. (...) Wenn meine Schwester in ihren Briefen mir schreibt 'mylimoji sesuté, so gebraucht sie die Pronominalform gewib nicht in der Funktion der Determination; denn sie hat noch eine Schwester, und sie will gewiB nicht auf die Frage antworten, welche von uns zwei sie lieber hat. Sie gebraucht hier die Pronominalform in der Punktion zum Ausdruck der Emotion (...)" (Baldauf). ${ }^{786)}$ 
2. Den Ubergang zwischen 1. und 3. bildet die Verwendung einer Pronominalform, die die Aufgabe hat, "einen Gegenstand von anderen gleichartigen Gegenständen zu unterscheiden, indem sie diesen Gegenstand durch den Besitz eines nur ihm gehörigen Merkmals, das für die übrigen Gegenstände dieser Art nicht charakteristisch ist, unterscheidet (...)" (Baldauf) 787) Vgl. Daržininkas pasiūlè man mèlynuju alyvy - 'Der Gärtner bot mir blauen Flieder an', Ant stalo stovi puokstè mélynuiu grazdiky - 'Auf dem Tisch steht ein StrauB blauer Nelken', Me̊lynoji rožè graži - 'Die blaue Rose ist schön!'. In diesen Fällen kann das Substantiv zwar mehrere Gegenstände bezeichnen, aber die Pronominalform führt hier weniger zu einer Identifizierung des intendierten Gegenstandes als zur Schaffung einer besonderen Untergruppe der Gruppe aller durch das Substantiv bezeichneten Gegenstände. Die Gegenstände der Untergruppe können, wie die deutsche Ubersetzung zeigt, als identifiziert oder nicht-identifiziert aufgefaBt werden.

3. "Die Pronominalform des Adjektivs in der Punktion der Determination unterscheidet einen Gegenstand von anderen gleichartigen Gegenständen, indem sie diesem ein auch den anderen Gegenständen eigenes Merkmal in höherem Maße zubilligt: 'Paduok man astruif peili', 'Reiche mir das scharfe Messer' (Das heibt: auf dem Tisch liegen mehrere scharfe Messer; eines ist aber ganz besonders scharf und dieses muBt du mir geben.)" (Baldauf) ${ }^{788}$ ) Eine Ausweitung dieses Gebrauchs führt dazu, ein Merkmal zu verwenden, das die anderen gleichartigen Gegenstände in diesem Falle nur in geringem Maße oder gar nicht haben, wichtig ist nur, daß das genannte Merkmal den intendierten Gegenstand von anderen Gegenständen abhebt: Aš pamečiau savo kambario raktą, turèjau pirkti naują. 0 dabar atradau ir senaij. - 'Ich habe meinen 2 immerschlüssel verloren und muBte jetzt einen neuen kaufen; und jetzt habe ich auch den alten gefunden.' - In der Verwendung 3. kann ein Substantiv mehrere Gegenstände bezeichnen (wird als Appellativ verwendet), die Identifizierung des intendierten Ge- 
genstands erfolgt durch die Hervorhebung eines seiner Nerkmale.

4. "Wenn wir sagen: 'geras vyras', 'ein guter Mann', geben wir zu verstehen, daß wir über einen Mann sprechen, den wir von allen 'negery̆jy', 'nicht guten' zu unterscheiden haben; doch 'gery̧h', 'gute' Männer gibt es viele, deshalb, wenn wir sagen wollen, daB wir über einen bestimmten, uns bekannten 'gérą výrą', 'guten Mann' sprechen, sagen wir 'gerásys vŷras', 'der gute Mann'." (K. Jaunius, Lietuviy kalbos gramatika) 789) In diesem Pall ist der intendierte Gegenstand durch die Sprechsituation bekannt, im folgenden durch den Kontext: "Buvo du broliu gudriu, trečias kvailas. Ir einančiu gudriuoju vienu keliu, o kvailys vienas pats kitu keliu', 'Es lebten einmal zwei kluge Brüder und der dritte war dumm. Die zwei klugen gingen einen Weg miteinander, der Dumme aber einen anderen allein." (Baldauf) 790) - In der Verwendung 4. ist der, intendierte Gegenstand zusamen mit einem seiner Merkmale durch die Sprechsituation oder den Kontext bereits bekannt und wird durch die Hervorhebung des bereits bekannten Merkmals mit dem als Appellativ gebrauchten Substantiv formal 1.dentifiziert. Der Unterschied zwischen der Verwendung 1 . und 4. besteht darin, $d a B$ in 1. das Substantiv als Name verwendet und dadurch die Emotionalisierung ermöglicht wird, während in 4. der (ebenfalls bekannte) intendierte Gegenstand durch ein appellativisch gebrauchtes Substantiv bezeichnet und deshalb eine Identifizierung sinnvoll wird. Ein nach 4. verwendetes gerasis vyras läßt sich jedoch auch so interpretieren, daB das Adjektiv nur deshalb in der Pronominalform erscheint, weil 'vyras' bereits bekannt ist. Der Akzent verlagert sich von der Betonung eines bekannten Merkmals (welche die Identifizierung des Gegenstandes ermöglicht) auf die Betonung der Bekanntheit des intendierten Gegenstandes selbst.

5. Die Pronominalform gibt die Bekanntheit des intendierten 
Gegenstandes an, sein durch das Adjektiv bezeichnetes Merkmal muB nicht mehr vorher bekannt sein. "Die Bestimmtheitsformen der Adjektiva passen $z u$ den Substantiva, die im Gesagten schon erwähnt worden waren, oder, die uns auf irgendeine andere Art und Weise wohl bekannt sind. Wir gebrauchen die Bestimmtheitsformen dann, wenn wir diese, uns wohl bekannte Sachen oder Personen, von den anderen, innen aber ähnlichen Sachen oder Personen, herausheben wollen, d.h., dort wo die Prage 'welcher, welche' und nicht die Prage 'was für ein, was für eine' gestellt werden muB (...)" (A. Baranauskas, Kalbamokslis lëtuviszkos kalbos, 1896) 791) $\mathrm{vgl}_{\text {. : Kiekvieng }}$ rytą senasis Salteikis traukdavo iš burteliy̧ po vieną lapą patsai, o paskui traukdavo ir Martynukas. - 'Jeden Morgen 208 der alte Salteikis aus den Zauberkarten eine Karte, und dann pflegte auch Martynukas eine zu ziehen.' In einem derart verwendeten gerasis vyras 'der gute Mann' steht die Pronominalform des Adjektivs, weil der intendierte Gegenstand bereits aus dem Kontext oder der Sprechsituation bekannt ist; anstelle von 'gut' könnte er auch 'schlecht', 'groß' oder 'klein' sein, in jedem Fall würde die Pronominalform des Adjektivs gebraucht.

Wie die Ubersicht zeigt, haben wir es in den Punkten 1.4. mit einer konstanten Grundfunktion des pronominalen Elementes zu tun, der Hervorhebung (Emphase) des Adjektivs. Diese Emphase steht immer in Verbindung mit dem semantischen Gehalt des verwendeten Adjektivs. In Punkt 5. jedoch hat sich die Identifizierung durch die Pronominalform vom semantischen Gehalt des Adjektivs gelöst, aus der semantischen ist eine grammatische Regelung geworden:

$$
\begin{array}{ll}
\text { vyras }(\text { nicht-identifiziert) } & + \text { geras } \longrightarrow \text { geras vyras } \\
\text { vyras (identifiziert) } & + \text { geras } \longrightarrow \text { geras-is vyras }
\end{array}
$$

Die Verwendung der Pronominalform nach Punkt 5. ist so breit, daB die Verwendung nach den Punkten 3. und 4. in sie eingeht. Punkt 5. konkurriert deshalb im Lit. mit Punkt 3. und 4., 
wird aber noch nicht regelmäBig zum Kriterium für die Verwendung der Pronominalform gemacht. Nicht jedem deutschen Syntagma Artikel + Adjektiv + Substantiv entspricht deshalb ein 11t. Syntagma Pronominalform des Adjektivs + Substantiv, wie Kurschat, J. Otregbski u.a. 792) irrigerweise angenommen hatten. Im Lettischen ist die grammatische Regelung (Punkt 5.) durchgeführt worden, und regelmäßig bedeutet

labs cilvę̈ks '(ein) guter Mensch'

laba-18 cilvę̄ks 'der gute Mensch' neben

cilvę̃ks ' (ein) Mensch', 'der Mensch'

Wie das Lettische verhält sich das Slav., bereits im Aksl. und heute noch in der skr. Schriftsprache. Die Verwendung nach Punkt 3. und 4. ist in der Verwendung nach Punkt 5. aufgegangen. Der emotionale Gebrauch der Pronominalform des Adjektivs im Iit. kann vom Slav. nicht mehr nachvollzogen werden, weil das nach der grammatischen Regelung verwendete pronominale Element das Adjektiv nicht mehr hervorhebt.

Der Unterschied zwischen dem Gebrauch der Pronominalform des Adjektivs im Slav. und Lettischen einerseits und im Iit. andererseits läßt sich diachronisch interpretieren: "Im Iitauischen ist die Verwendung der Bestimmtheitsformen noch nicht so streng geregelt wie im Slavischen. Das Iitauische repräsentiert auch hier einen älteren Zustand des BaltischSlavischen; im Iitauischen hat die Bestimmtheitsform ihren ursprünglichen emotionalen Charakter im allgemeinen beibehalten und hat sich noch nicht zu einem morphologisch-formalen System entwickelt wie im Slavischen." (Arumar) ${ }^{793)}$ Das Bestehen eines solchen morphologisch-formalen Systems im Slav. und Prühalb. einerseits und das diachronische Verhältnis zwischen dem strikten System im Slav. und der freieren Verwendung im Iit. andererseits gestatten den RückschluB, daB auch das Alb. einst einen in seiner Anwendung semantisch orientierten, das Adjektiv hervorhebenden und damit zwischen Emotionalisierung 
und Identifizierung wechselnden Protoartikel gekannt hat, wie er heute noch im lit. existiert.

Soll nun angenommen werden, daB die ursprüngliche Punktion des pronominalen Elementes (slav. 迆, lit. jig, alb. 1) im Syntagma Adjektiv-Substantiv in einer Emotionalisierung, wie sie in Punkt 1. für das Lit, beschrieben wurde, lag, zu der in jüngerer zeit je nach semantischem Kontext auch die Identifizierung hinzutreten konnte? Daß eine Entwicklung von Emotionalisierung $2 u$ Identifizierung funktionell möglich ist, beweisen die Diminutiva und Koseformen des Iit., welche, anfangs in emotionaler Verwendung mit den Pronominalformen der Adjektiva gleichgesetzt, heute in fast einem Drittel des lit. Sprachgebiets die Pronominalform auch in identifizierender Verwendung ersetzt haben. ${ }^{794)}$ Es ist jedoch nicht erklärbar, warum zur Bildung eines emotionalen 'guter Vater' gerade ein Pronomen ('dieser', wenn < is, 'welcher', wenn < *108) verwendet worden sein soll; hier wāre eher eine Koseform des Adjektivs zu erwarten. Die Verwendung eines Pronomens spricht gegen die Möglichkeit, daB aksl. dobrb-jb konb, alb. *kal 1-mirë 'das gute Pferd' ursprünglich nur in der Bedeutung 'gutes Pferd', mit emotionaler Emphase auftraten. Das Pronomen kann lediglich durch Vermittlung der Identifizlerungsfunktion für die emotionale Verwendung herangezogen worden sein.

Wenn das Pronomen (slav.) jb über die Punktion der Identifizierung in das Syntagma Adjektiv-Substantiv eingeführt wurde und dabei bald auch die Emotionalisierung übernahm (denn diese Verwendung ist nach Ausweis des Iit. sehr alt), dann muB die Identifizierung eines Substantivs ursprünglich durch die Hervorhebung des begleitenden Adjektivs erfolgt sein: diese Hervorhebung ermöglichte eine Identifizierung bei appellativem Gebrauch des Substantivs; sie murde zum Selbstrweck in der Begleitung eines als Namen gebrauchten Substantivs und wirkte daher als emotionale Emphase. Wenn das Pronomen (slav.) jb.ursprünglich im Slav., Baltischen, Alb. in Verwendungen auftrat, die für das lit. durch die 
Punkte 1. - 4. beschrieben worden sind, so war dazu der Ausgangspunkt die Verwendung des Pronomens nach den Punkten 3. und 4. (Identifizierung), die emotionale Emphase ergab sich bei einem besonderen, eingeengten Gebrauch des Substantivs. Ein (slav.) dobrb-jb konb hatte die primäre Bedeutung:

(nach Punkt 3.) 'das gute Pferd' - in Abgrenzung von weniger guten oder schlechten Pferden

(nach Punkt 4.) 'das gute Pferd' - in Abgrenzung von anderen gleichguten Pferden

Wie kam es zu der (indirekt) identifizierenden Punktion des pronominalen Elements in slav. dobrb-jb konb, alb. "kal i-mirë, welche gegenüber der Emotionalisierung als historisch primär festgestellt wurde? Die Beantwortung dieser Prage hängt davon $a b$, ob dieses pronominale Element auf ein Demonstrativpronomen oder auf ein Relativpronomen zurückgeht. Vgl. hierzu die ausführliche Diskussion in der Zusammenstellung von L. Baldauf. 795) wir suchen zunächst AufschluB in der Punktion des pronominalen Elementes auBerhalb des identifizierten Syntagmas.

Das slav. 迆, lit. jis hat, hierin dem Prühalb. entsprechend, die Pormen und Funktionen des idg. Demonstrativpronomens 18 und des idg. Relativpronomens 108 in éinem Morphem vereinigt. Die Trennung in $i b$ 'Demonstrativ' und

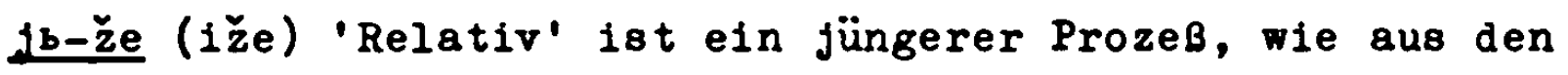
Reliktfällen auf den älteren slav. Sprachstufen zu erkennen 1st. $\nabla g l$, alť̌echisch jen und jenž(e) in demonstrativer Punktion ${ }^{796)}$, ebenso ib im Zogr., Marian., Ass. Mth. 7.14; Marian., As8. Joh. 19.37 sowie jb ohne die Partikel že in relativischer Funktion 797), auch in zane, pone 'für mas' und

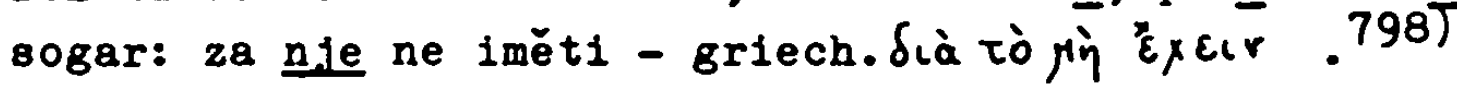

Das Paradigma des slav. jb, lit. jis ist suppletiv aus den Pormen des früheren Demonstrativpronomens *is, "eīa, *id und des früheren Relativpronomens $108, \ldots \bar{z}$, \#od > jb, ja, je (11t. jis, j1) gebildet. Dabei kommt ein phone- 
tischer Zusammenfall für das lit. nicht und für das slav. nicht in allen Pormen in Frage. Für die Pormen jego, jemu, (j)imb, jemb, je (<*jod, nicht<*id) ist auf den Relativstamm zurückzugehen ${ }^{799}$ ), dabei weist das Lit. in einigen Fällen andere Suppletionen auf als das Slav.: slav. ja $<{ }^{*} \bar{z}$ zu *jos - lit. ji<*i zu *is (neben $\left.{ }^{2} j \bar{a}\right) .800$ ) Wegen des funktionellen und formalen Zusammenfalls des idg. Demonstrativpronomens und des idg. Relativpronomens außerhalb des identifizierten Syntagmas zu slav. jb 'dieser', 'welcher' bleibt die Herkunft des pronominalen Elementes im identifizierten Syntagma weiterhin unentschieden.

V. Wijk ${ }^{801)}$ vertrat die Ansicht, daB man es im aksl. $j_{b}(z ̌ e)$ mit einer Portsetzung nur des Demonstrativpronomens * is zu tun habe, welches sekundär auch die Relativfunktion übernahm. Folglich sei *jos im Slav. nie verwendet worden. Er stützt seine Argumentation darauf, daB die Bildung eines Relativpronomens aus einem Demonstrativ- oder Interrogativpronomen eine in den idg. Sprachen regelmäbige Erscheinung ist, und vergleicht das Gotische. ${ }^{802}$ ) während diese Auffassung für das außerhalb des identifizierten Syntagmas gebrauchte jb prinzipiell möglich ist, weist das identifizierte Syntagma darauf hin, daB in inm ein Demonstrativpronomen is zumindest historisch sekundär und die Ablösung eines älteren *jos ist.

Gegen die ursprüngliche Verwendung des Demonstrativpronomens *is im Syntagma dobrb-jb konb 'das gute Pferd' sprechen die Position und die Funktion des pronominalen Elementes. Die unbedingte Enklise des Pronomens beim Adjektiv (dobrb-jb konb, konb dobrb-jb) kann von einem Demonstrativpronomen nicht erwartet werden, und wenn man schon, wie v. Wijk es tut ${ }^{803)}$, mit der 'Bedeutungsschwächung' des Demonstrativpronomens dessen Postponierung verbindet, dann wären jedenfalls auch die Sequenzen *dobrb konb jb, konb ib dobrb, *konb dobrb tb zulässig, von denen jedoch jede spur fehlt. - Wenn dobrb-jb konb 'das gute Pferd' funktionell auf ein zunächst grammatisch lokalisierendes dobrb-( is) konb 'dieses gute 
Pferd' zurückgeht, dann ist nicht einzusehen, warum nicht parallel dazu aus konb-(*is) oder (*is)-konb 'dieses Pferd' ein primäres Artikelmorphem: 'das Pferd' entwickelt wurde. Die Identifizierung eines Substantivs mit Hilfe der Hervorhebung seines Adjektivs, wie sie oben für das Balto-slav. und das Prühalb. festgestellt wurde, wäre in einem solchen Pall überflüssig gewesen.

Im Folgenden unternehme ich eine funktionelle Ableitung des slav. dobrs-jb konb 'das gute Pferd' (entsprechend im Iit. und Frühalb.) aus einer relativischen Konstruktion dobrs-(*jos) konb. Dies wird durch die Pakten des Iranischen gestützt, aus denen viele Iinguisten eine baltoslav.-iranische Isoglosse im Bereich des zusamengesetzten Adjektivs ableiten. 804) Gebräuchlich ist eine Identifizierung durch Hervorhebung des Adjektivs im Avesta, am häufigsten wohl im Al tpersischen 805$)$ : avestisch kharem jim-ašavanem $\cong$ slav. ovęts-jb 0sbls 'den heiligen Esel' (acc.), altpersisch avam kāram tyam Mādam 'jenes medische Heer' (acc.).805.a.) Diese Konstruktion taucht auch vor nicht-adjektivischen Attributen auf: avestisch raōcēbǐs yēiš ahurahę mazdă 'mit den Lichtern des A.M. ${ }^{806)}$ und steht damit dem Alb. nahe: kal i-fqini. Entsprechendes liegt in baltischen und slav. Archaismen vor: bez-čina-je 'le sans ordre', bes-posaga-ja 'la sans mariage', altlit. dangu(ję)-jis 'le dans le ciel' zu dangujè (loc.) 'dans le ciel'.807) Im Avesta und Altpersischen handelt es sich feweils un das Relativpronomen des betreffenden Sprachsyotems in identifizierender Punktion:avestisch ya- < jos; Altpersisch verwendet einen früheren Demonstrativstamm als Relativpronomen: hya, hyā, tya. ${ }^{808)}$ Das Iranische zeigt durch die Verwendung eindeutig relativischer Pronomina in den dem Balto-Slav. und Alb. parallelen identifizierenden Konotruktionen, daß auch in dobrb-jb konb, kal i-mirë uroprünglich ein Relativpronomen verwendet wird.

Slav. dobrb-jb konb, alb. *kal 1-mirë, die ich im weiteren mit der metasprachlichen Formel (lat.) equus qui bonus 
wiedergebe, können als Verkürzung des vollständigeren equus qui bonus est betrachtet werden. Die Auslassung der Kopula 'est' ist in den älteren Perioden der idg. Sprachen eine häufige Erscheinung. Sie führt jedoch im Palle von equus qui bonus est $>$ equus qui bonus zu einer neuen Bedeutung der verkürzten Konstruktion.

In equus qui bonus est wird das Relativpronomen 'qui' substantivisch gebraucht, es verweist auf das übergeordnete Substantiv 'equus':

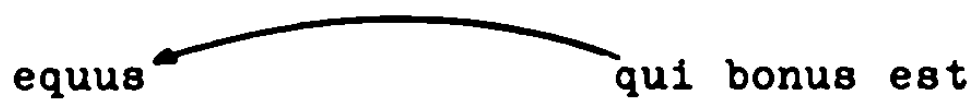

Die Wiederaufnahme des übergeordneten Substantivo durch das Relativpronomen dient zur Einführung einer Ergänzung durch einen ganzen (Neben-)Satz.

In adjektivischer Verwendung kann das Relativpronomen mit dem Demonstrativpronomen (in grammatisch lokalisierender Funktion) wechseln:

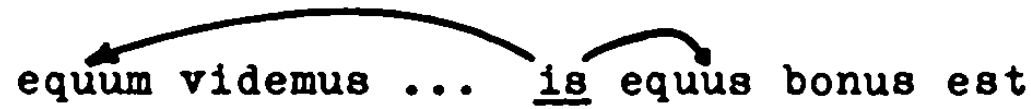

(II)

(I)

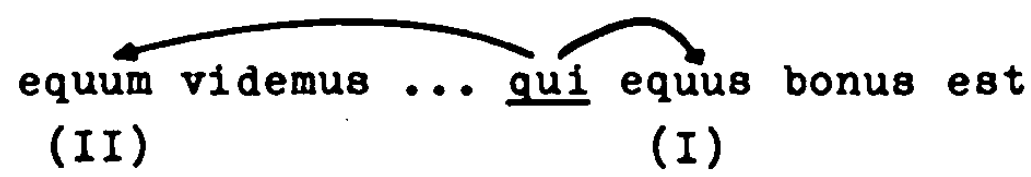

In diesem sogenannten relativischen AnschluB leitet das Relativpronomen keinen Nebensatz ein. Die Bedingung für das Auftreten des adjektivischen Relativpronomens im relativischen AnschluB ist die gleiche wie für das Demonstrativpronomen in sekundärer Funktion: das Vorhandensein einer vorausgehenden oder nachfolgenden Erwähnung des gemeinten Gegenstandes (II) im Kontext, zusätzlich zu dem vom Pronomen begleiteten Substantiv (I).

Aus der Vertauschbarke1t des adjektivischen Relativpronomens mit dem Demonstrativpronomen in sekundärer Funktion ergibt sich, daß das adjektivische Relativpronomen das von inm begleitete Substantiv (I) mit dem intendierten Ge- 
genstand identifiziert, indem es auf eine vorausgehende oder folgende Erwähnung dieses Gegenstandes im Kontext (II) verweist. Daraus läßt sich für das substantivische Relativpronomen ableiten: Das substantivische Relativpronomen identifiziert sich selbst mit dem intendierten Gegenstand, indem es auf eine vorausgehende oder folgende Erwähnung dieses Gegenstandes im Kontext (equus) verweist.

Durch Auslassung der Kopula nimmt die Konstruktion mit substantivischem Relativpronomen die Form equus qui bonus und damit die Form der Konstruktion mit adjektivischem Relativpronomen qui equus bonus an. Die Sequenz der Elemente bietet hier keine Differenzierung, da das adjektivische Relativpronomen wie das Demonstrativpronomen verschiedene Positionen einzunehmen imstande ist: equus is bonus $\cong$ equus qui bonus. Ein verkürztes equus qui bonus kann folglich sowohl als substantivisches wie auch als adjektivisches Relativpronomen aufgefaßt werden. Nach der substantivischen Interpretation ist 'equus' die kontextuelle Vorerwähnung, auf welches 'qui' verweist, um sich selbst mit dem intendierten Gegenstand zu identifizieren; nach der adjektivischen Interpretation ist 'equus' das begleitete Substantiv (I), das von 'qui' durch Verweis auf den Kontext identifiziert wird.

Die formale Gleichheit beider Konstruktionen kann vom Sprecher dazu benützt werden, die Funktion des adjektivischen Relativpronomens durch die Konstruktion mit dem substantivischen Relativpronomen, welche un die Kopula verkürzt wurde, zu imitieren. Daß es sich im Grunde um eine verkürzte Konstruktion mit substantivischem Relativpronomen handelt, zeigt der Kontext. Das substantivische equus qui bonus est hängt in seiner Verwendung nicht von einer zusätzlichen Erwähnung des 'equus' im Kontext ab, im Gegensatz zum adjektivischen qui equus bonus. Wird nun ein aus equus qui bonus est hervorgegangenes equus qui bonus in einem Kontext, der keine weitere Erwähnung von 'equus' zeigt, trotzdem adjektivisch interpretiert, so findet das adjektivische 'qui' 
für seine grammatische Lokalisierung keinen Bezugspunkt im Kontext. Dieser Effekt läßt sich für die Fälle ausnutzen, in denen ein Substantiv identifiziert werden soll, dessen intendierter Gegenstand nicht durch den Kontext, sondern durch die Sprechsituation bekannt ist oder dessen Bekanntheit postuliert wird. Das adjektivische Relativpronomen in kontextuell nicht gerechtfertigter Verwendung bezeichnet die reine Identifizierung: equus qui bonus - 'das gute Pferd'.

Um ein Substantiv formal zu identifizieren, genügt es demnach - sofern es ein Attribut bei sich hat -, das Syntagma Substantiv-Attribut in einen verkürzten Relativsatz umzuformen: equus bonus $\longrightarrow$ equus qui bonus, was bei zusätzlicher Erwähnung von 'equus' im Kontext (equus .... equus qui bonus) als eine durch den Kontext motivierte Identifizierung, bei fehlender Erwähnung (equus qui bonus) als eine durch die Sprechsituation gegebene Identifizierung erscheint. Das Substantiv muß für seine Identifizierung ein Attribut bei sich haben, weil die dabei verwendete Konstruktion auf einen verkürzten Relativsatz zurückgeht, der das adjektivische Relativpronomen imitiert. - Während 'equus ... equus qui bonus' auch vom Demonstrativpronomen in sekundärer Funktion geleistet werden kann (equus ... equus is bonus), kann dieses für 'equus qui bonus' nicht eintreten: ohne eine vorausgehende Erwähnung des 'equus' bedeutet equus is bonus 'dieses gute Pferd', mit realer Lokalisierung.

Dieselbe Prozedur läßt sich auch mit einem ein Attribut enthal tenden Relativsatz vornehmen, dessen übergeordnetes Substantiv im Kontext nicht genannt wird. In qui bonus est identifiziert sich 'qui' mit dem intendierten Gegenstand und spricht inm Merkmale (bonus) zu; der Verzicht auf eine kontextuelle Anknüpfung bedeutet, daB dieser Gegenstand aus der Sprechsituation bekannt ist oder dab die Bekanntschaft mit inm postuliert wird. Eine originäre adjektivische Verwendung des Relativpronomens gibt es in diesem Fall nicht, denn per definitionem ist die adjektivische Verwendung von einer kon- 
textuellen Erwähnung des intendierten Gegenstandes abhängig. Jedoch kann nach dem Vorbild equus qui bonus est $\longrightarrow$ equus qui bonus aus qui bonus est ein qui bonus gebildet werden. Die postulierte Identifizierung ist darin dieselbe wie in qui bonus est; nun bezieht sie sich jedoch nicht mehr auf das Pronomen, sondern auf das folgende Attribut, welches dadurch 'substantiviert' wird. Das 'substantivierte Attribut' wird dann formal mit dem intendierten Gegenstand identifiziert. Sachlich ist dies so zu verstehen, dab einzelne, durch das Attribut bezeichnete Merkmale mit dem intendierten Gegenstand verbunden werden. Wenn equus qui bonus 'das gute Pferd; so bezeichnet qui bonus 'das Gute'. Darunter ist ein bestimmter Gegenstand zu verstehen, wenn er aus der Sprechsituation bekannt ist; wird dagegen die Bekanntschaft postuliert, so sind darunter alle möglicherweise für das genannte Merkmal infragekommenden Gegenstände gemeint, das Relativpronomen wirkt generalisierend.

Das Nebeneinander von equus qui bonus 'das gute Pferd' und qui bonus 'das Gute' führt schlieblich zu der Regel, daB ein Substantiv dann als formal identifiziert $z u$ betrachten 1st, wenn es ein durch das Relativpronomen identifiziertes 'substantiviertes Attribut' bei sich hat. Da das Relativpronomen nur zusammen mit dem Attribut auftritt, handelt es sich bei der Identifizierung stets um eine indirekte Identifizierung. Wir hatten dies bereits bei der Untersuchung des Verhältnisses von elliptischem i mirë, *ellu bunu zum vollständigen kal i mirë, calu ellu bunu im Alb. und Rum. Festgestellt.

Die Verwendung des Relativpronomens für die Bezeichnung der Identifizierung ist auch auBerhalb des Iranischen, BaltoSlav. und Alb. bekannt, 80 im Griech., Lat., Altindischen, Hethitischen. 809)

Lateinisch. Qui patres qui conscripti 'die versammelten Patres' ist eine alte Pormel im Lat. ${ }^{810)}$, in der dieser Gebrauch erhalten ist, er findet sich noch in anderen Archais- 
men. Erneuert wurde er vor allem in den volkslat. Ubersetzun-

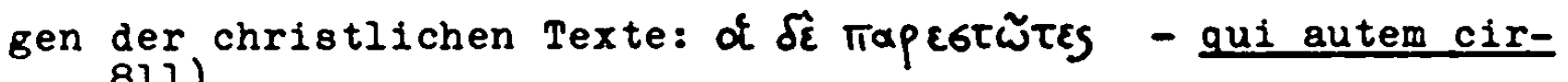
cum. 811)

Griechisch. Der griech. Artikel setzt die Stämme to-, *sos und *0s fort. 812) Das Relativpronomen "jos nahm am Pormensynkretismus teil, weil das nach der Formel qui bonus gebildete ó ExVpós (aus: 'welcher feindlich ist') in der Bedeutung 'der Feindliche' mit dem sich aus dem Demonstrativpronomen bildenden Artikel (ćexVpós < sos .... eigentlich: 'dieser Peind') zusammenfiel. 813) Das alte Relativpronomen liegt auch in dem nach der Formel equus qui bonus gebildeten

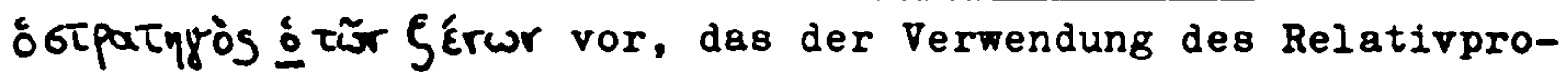
nomens vor substantivischen Attributen im Alb. und Iranischen entspricht und die Hervorhebung des Attributs zum Zwecke der Identifizierung des übergeordneten Substantivs zeigt ${ }^{814}$ ), welches später auch noch den präpositiven Artikel angenomen hat. - Erneuert wurde die identifizierende Verwendung des Re-

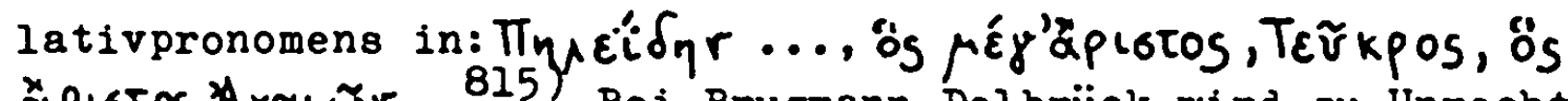

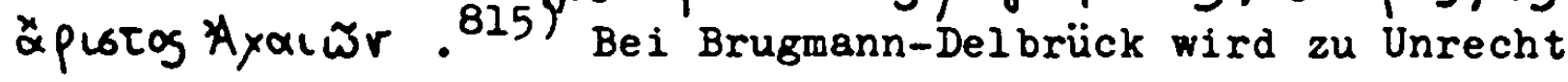
ein al tes *sos für diesen Gebrauch bemüht.

Hethitisch. Das Relativpronomen lautet kuiš und ist ursprünglich interrogativ wie lat. qui: Sallayaš-kan DINGIR láS-aš kuiš šallǐs - '(parmi) les grands dieux le grand'. '816

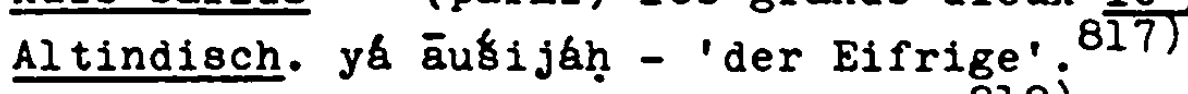

$$
\text { Nach Benvenistes Feststellung }{ }^{818)} \text { : "Der Relativsatz }
$$

(...) verhält sich wie ein determiniertes 'syntaktisches Adjektiv', ebenso wie das Relativpronomen die Rolle eines determinierten 'syntaktischen Artikels' spielt." kann man sagen, daß die oben beschriebene Verwendung eines equus qui bonus (< equus qui bonus est) eine Ausnützung der Determination des Relativsatzes für die Determinierung des übergeordneten Substantivs und damit die Uberführung des 'syntaktischen Artikels' (Relativpronomen) in einen 'morphologischen Artikel' darstellt. Die Ansicht L. Hjelmslevs: " - die Artikelbedeutung von einer relativen Bedeutung abgeleitet, das 
wäre eine einmalige Sachen ${ }^{819)}$ ist damit widerlegt. Die formale Ubereinstimmung

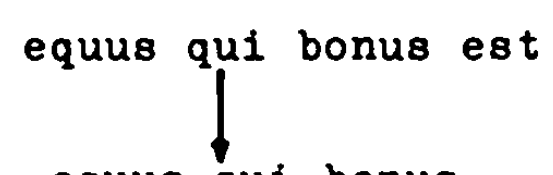

equus qui bonus equus... qui equus bonus
$=$

equus qui bonus

auf der die Verwendung von equus qui bonus für die reine Identifizierung, bei fehlender kontextueller Erwähnung des intendierten Gegenstandes, beruht, stellt sich nur dann ein, wenn das übergeordnete Substantiv im Nominativ steht:

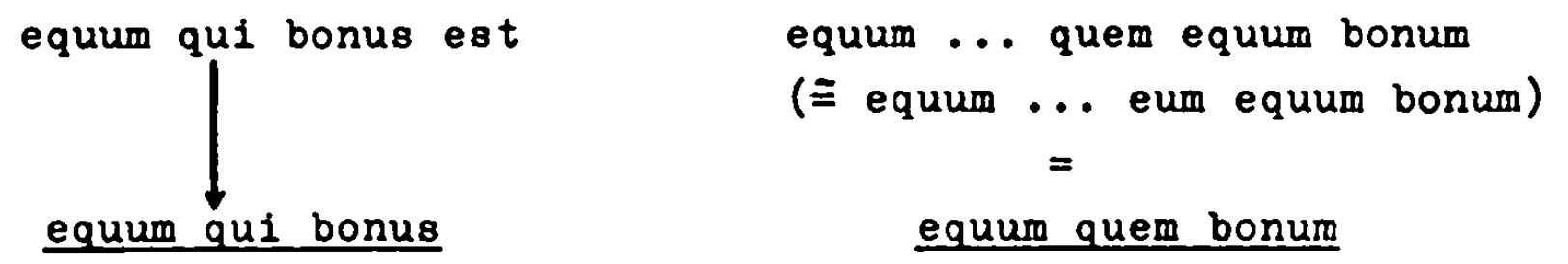

Die reine Identifizierung (mit postuliertem oder schon bekanntem intendierten Gegenstand) ist durch equus qui bonus daher nur im Nominativ möglich, während die Identifizierung durch grammatische Lokalisierung durch equus qui bonus in alIen Kasus möglich ist. Im Lat., Griech., Hethitischen und Altindischen, die die Identifizierung durch equus qui bonus nicht zu einem System ausbauten, ist sein Auftreten auf den Nominativ beschränkt geblieben, wenn ihm im Kontext keine Erwähnung des intendierten 'equus' vorausging.

Dagegen zeigen das Balto-Slav., Alb. und Iranische eine Angleichung von equum qui bonus an equum quem bonum $819 a)$, d. h. die Kongruenz des übergeordneten Substantivs mit dem Relativpronomen und dem Attribut (je nach dessen Motionsfähigkeit) auch in den Fällen, in denen die Identifizierung nicht durch den Kontext ermöglicht wird. Im Avesta und Altperischen erscheinen selten noch nominativische Anschlüsse des verrürzten Relativsatzes: tąm daēnąm y $\bar{a}$ hātąm vahištā - 'diese Religion (acc.), die beste (nom.) für die Lebenden'.820) Der ProzeB der Angleichung ist im Avesta nachweisbar: Während im (älteren) Gāva-Avesta die Kongruenz auBerhalb des Nominativs 
auf den Akkusativ und den Instrumental beschränkt ist, nehmen im jüngeren Avesta alle Kasus an ihr teil. ${ }^{821)} \mathrm{Vgl}$. avestisch čaratąm yąm daragąm (acc.) - 'la longue piste.822), frühalb. * pyllë tën-bukurë (acc.) - 'den schönen Wald' gegenüber dem Nominativ *pyll i-bukur, wo später die Kasusflexion des nachgestellten Adjektivs, jedoch nicht die des Artikels (< Relativpronomen) aufgegeben wurde; slav. dobra-jego mǫ̌a (gen.acc.).

Der Grund für die formale Durchführung des adjektivischen Relativpronomens in allen Positionen ist darin zu sehen, daB im Balto-Slav., Alb. und Iranischen die Formel equus qui bonus systematisch dem als nicht-identifiziert zu betrachtenden equus bonus gegenübergestellt wurde. Nach der Proportion equus bonus : equus qui bonus = equum bonum : $\underline{\mathbf{x}}$ setzte sich für die identifizierte Konstruktion $x=$ equum quem bonum durch. Das Ergebnis war eine vollkommene Parallelität des Syntagmas nicht-identifiziertes Substantiv + Attribut mit dem Syntagma identifiziertes Substantiv + Attribut:

$\begin{array}{lll}\text { (slav.) } & \text { dobrb mǧ̌b } & \text { dobrb-jb mǧ̌b } \\ \text { dobra mǧa } & \text { dobra-jego moža (gen.-acc.) } \\ \text { entsprechend im 'substantivierten' Gebrauch: } & \\ \text { dobrb } & \text { dobrb-jb } \\ \text { dobra } & \text { dobra-jego (gen.-acc.) }\end{array}$

Allerdings zeigt das Iit., daB die Formel equus qui bonus (equum quem bonum etc.) lange Zeit nur in solchen Fällen für die Identifizierung verwendet murde, in denen das Attribut 'bonus' herausragende Merkmale des intendierten Gegenstandes bezeichnete und dadurch die Identifizierung ermöglichte (im lit. Punkt 3.). Hieraus ergab sich als nächster Schritt in der Entwicklung die Regel, dab 'qui' (die Pronominalform) selber Attribute hervorhebt (im Lit. Punkt 4.). In bestimmten semantischen Umgebungen führte dies zu einem emotionalisierenden Effekt von 'qui' (im Lit. Punkt 1.). Der AbschluB der Entwicklung wird von der im Aksl., Alb. und Neu- 
persischen allein gültigen Regel gebildet, daß das Relativpronomen 'qui' nicht mehr ein zur Identifizierung führendes Attribut, sondern diese Identifizierung selbst anzeigt (im Lit. Punkt 5.).

Die Verwendung eines mit einem Relativpronomen versehenen Attributs (qui bonus) für die formale Identifizierung des übergeordneten Substantivs (equus) ist also in den genannten Sprachen durch semantische Gründe mitverursacht worden, durch das Vorhandensein von den intendierten Gegenstand kennzeichnenden Attributen.

Dieses ist nicht mehr der Fall in der unter griech. Einfluß im Aksl. entstandenen Neuerung konb jbže dobrb (equus qui bonus). Die Verwendung des Relativpronomens iže zur Wiedergabe des griech. Artikels vor komplexen Attributen im Aksl. wird als 'mechanische Lehnübersetzung'823), 'sklavische Nachahmung ${ }^{824)}$ des Griech. beurteilt, dessen Artikel o < *jos/ 808. Dafür spricht, daß sich die Konstruktionen mit iže stark an das griech. Original anlehnen, vor allem bei der Wiedergabe von griech. $\delta \tau o \tilde{r}$, of Präpositionalausdruck, von substantivierten Infinitiven, und daB sie sich auBerhalb des Kirchenslavischen in keiner anderen slavine finden.

Be1 der aksl. Konstruktion konb iže dobrs handelt es sich um eine durch fremdsprachlichen EinfluB hervorgerufene Aktivierung der in allen idg. Sprachen vorhandenen strukturellen Möglichkeiten des Relativpronomens. Sie kommt fast ausschlieblich im Nominativ vor, beschränkt sich also auf die Reduktion equus qui bonus est $z u$ equus qui bonus und vermeidet die Kongruenz equum quem bonum. Daher stellt sie, im Gegensatz zu der Pronominalform des Adjektivs, nichts für die 1dg. Untergruppe Balto-Slav., Alb., Iranisch Spezifisches dar und ist $z$ den obengenannten lat., griech., altindischen und hethitischen Beispielen zu stellen. Sie wurde bei der Ubersetzung der christlichen griech. Texte notwendig, weil im Balto-Slav., im Gegensatz zum Alb. und Iranischen, die Anwendung der Pronominalform (des Relativpronomens *jos) auf ad- 
jektivische Attribute eingeschränkt worden ist. Relikte, wie bez-čina-je, bes-posaga-ja, na-božijg-jb člověkb $\cong$ ó kaてà $\Theta$ Eöräripwiog 825$)$, weisen darauf hin, dab es einst auch im Balto-slav. heißen konnte: "sgsěda-jb konb - 'das Pferd des Nachbarn'.

Die aksl. Konstruktion konb iže dobrs bestätigt durch ihre häufige Parallelität zum zusammengesetzten Adjektiv (der Pronominalform), daB dieses aus einer Relativkonstruktion hervorgegangen ist:

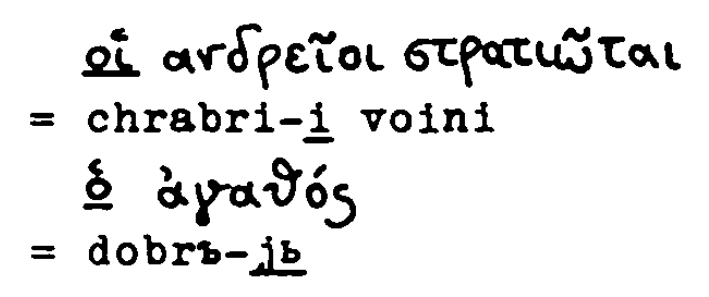

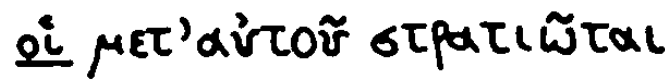

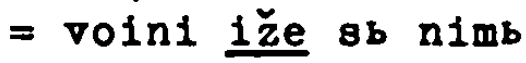

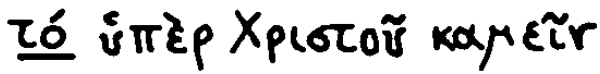 $=$ ježe za cha truditi se

(supr. 98.30)

Vaillant ${ }^{826)}:$ "(...) die Mendungen člověkū jǐ̌e blagū und blagü-ji člověkū sind identisch, nur daß die zweite allein im Falle des attributiven Adjektivs gebräuchlich ist und daB die erstere für die komplexeren Fälle von Apposition wie otIcI

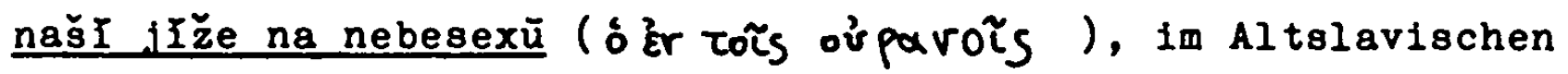
vor allem in den Lehnübersetzungen aus dem Griechischen erscheint." Vgl. auch die Parallelität des zusammengesetzten Adjektivs und der Relativkonstruktion bei Bischof Konstantin

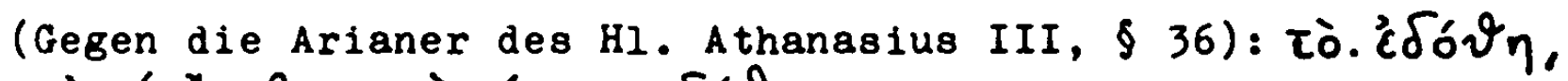

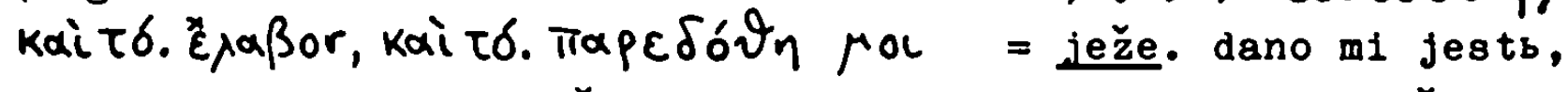
1. prijęls jesmb, 1 prědano-je mi jestb, wo einander ježe dano - prědano-je vollkommen entsprechen: 'das Gegebene'.827) Sodann im Harianus: ěže na duchs chula (12.31), dagegen im Savva-Ev.: duchovbno-je chulenije. ${ }^{828)}$ Auch im Altlit. findet sich ein syntaktischer Parallelismus zwischen dem geneuerten Relativpronomen kuris und der Pronominalform des Adjektivs (Morkunas Postilie 11 b) 829)

Aus einer relativischen Konstruktion (equus qui bonus et audax) erklärt es sich schlieblich auch, daß, wenn mehrere Attribute auf einen intendierten Gegenstand bezogen werden, 
nur das erste von ihnen in der Pronominalform steht: (Narian. 23.37) Ierusalime izbiv-y proroky 1 kameniems pobivaje, (10.28) ne uboite sę ubivajo̧šti-ichs tělo a dušę ne mogăšstb ubit1. 830) Ebenso verhält es sich im Avesta, wo die Verwendung eines Relativpronomens offensichtlich ist: havra... yazataēibyō yat aməšā̄ibyō spantā̄ibyō 'mit den unsterblichen, heiligen Yazatas'.831)

Es bleibt zu fragen, warum das Balto-Slav. und das Alb. von vergleichbaren Konstruktionen (dobrb-jb konb, *kal i-mirë), in denen die Bedeutung 'das gute Pferd' auf die Verwendung eines Relativpronomens zurückgeht, zu den unterschiedlichen Resultaten alb. kall 'das Pferd' - slav. konb '(ein) Pferd', 'das Pferd' gelangt sind, m.a. W. warum das Balto-Slav. keinen kontextunabhängigen Artikel gleich dem Alb. herausgebildet hat.

Der Grund ist in der unterschiedlichen Position des verwendeten Relativpronomens in den betreffenden Sprachen zu sehen. In dem slav. Syntagma dobrb-jb konb, konb dobrb-jb stand das Morphem jb hinter dem Adjektiv und geriet mit dessen Plexionsendungen in Kontakt. Dieser Kontakt setzt im Slav. den vorherigen Verlust der Auslautkonsonanten voraus: novyj < novsjb < novos 108.832 )

Die weitere Fusion ist ein Zeichen dafür, daß das Formans jb aufgrund seiner adjektivenklitischen Position in den ProzeB der Nominaldifferenzierung mit dem Ziel der Bildung einer besonderen Adjektivflexion einbezogen wurde. Ausgangspunkt ist die Differenzierung derjenigen Nomina, die zugleich als Substantiva wie auch als Adjektiva verwendet wurden. Das

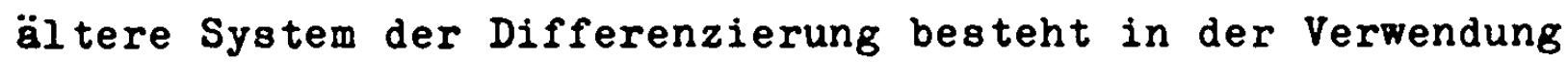
von Nominalouffixen: stars > starbcb (Substantiv) und stars (Adjektiv), desna > desnica (Substantiv) und desna (Adjektiv), voins > voiniks (Substantiv) und voins (Adjektiv). 833) Das jüngere Differenzlerungssystem durch die obligatorische Verwendung der Pronominalform des Adjektivs zeigt seinen Anfang im Aksl.: drugb > drugb (Substantiv) und drugyjb (Ad- 
jektiv). Vgl. Kurz.

834)

Anders als im Balto-Slav. stand im Alb. das Morphem 1 hinter dem übergeordneten Substantiv (*kal 1-mirë) und kam mit dessen Plexionsendungen in Kontakt, woraus der postpositive Artikel entstand. Dagegen blieb in der elliptischen Konstruktion das $\underline{i}$ als freies Morphem erhalten und führte zum präpositiven 'Artikel' des Attributs.

Eine Parallele zur alb. Entwicklung bietet das Persische. Dort ist unter Verwendung des durch ein Relativpronomen identifizierten Syntagmas das folgende System entstanden:

$$
\text { asp '(ein) Pferd', 'das Pferd' }
$$

aspI hū̄b 'das gute Pferd' - asp hūu 'ein gutes Pferd' Die Einführung eines Individualisators (' $\bar{i}$ der Ein-heit') veränderte das System zu:

$$
\begin{aligned}
& \text { asp 'das Pferd' - aspī 'ein Pferd' } \\
& \text { aspi hūb 'das gute Pferd' - aspī nūb 'ein gutes Pferd' } \\
& \text { und sekundër: } \\
& \text { aspi hūbi 'ein gutes Pferd' }
\end{aligned}
$$

Das ältere System entspricht in Etymologie, Position und Funktion des Protoartikels genau dem rekonstruierten alb. System vor der Evolution des attributunabhängigen postpositiven Artikels. Aber sogar ein solcher findet sich in der persischen Umgangssprache: aspI (aspē) 'das Pferd', entwickelt aus aspI hūb. - Die Ubertragung des $-I$ in das nicht-identifizierte aspi h hūbĩ (neben aspĩ hūb) entspricht dem alb. nji kal mirë > nji kal $\underline{i}$ mirë. Die Parallelentwicklung des seit dem Al tertum miteinander nicht in Kontakt stehenden Iranischen und Albanischen von einem equus qui-bonus zu equus-qui bonus und schließlich equus-qui 'das Pferd' ist eine Bestätigung dafür, daB die Ausgangskonstruktion equus qui bonus selber die Weiterentwicklung in eine bestimmte Richtung zwang, wie auch im Rum., als es das alb. "kal i-mirë durch *calu ellu-bunu kalkierte. 
Bei dieser Gelegenheit ist auf das iranische Westossetisch hinzuweisen, das von dem altiranischen equus qui bonus zu qui equus 'das Pferd' gekommen ist, allerdings in unregel-

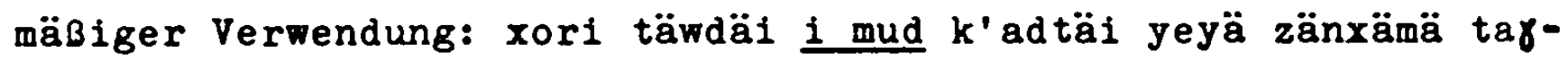
däi 'infolge der Sonnenhitze floB der Honig, der (da) war, auf die Erde nieder'. ${ }^{835)}$ Es handelt sich hier um eine Einführung von Substantiva in die 'substantivierende' Konstruktion des Attributs: avestisch yām angram 'den Feindlichen' (acc.) > 'den Peind', yā dragvā 'der Druggenosse (Adjektiv!)' erlaubten später auch ein aēša yā kaine '(dieses) das Mädchen', wobei kaine Substantiv ist. Gestützt wurde dieser Gebrauch durch solche Pälle, in denen das übergeordnete Nomen in die Relativkonstruktion gezogen wurde (qui bonus equus): aoi yogm astvaitīm gaē mäßige ahmi anhvō yat astvainti 'in diesem irdischen Leben'. 836; Eine ähnliche Möglichkeit mag im Frühalb. bestanden haben, denn es finden sich rum. Repliken (selten und nur al trum.): In čelb dělu svăntu al tău $\cong$ vo svętuju goru tvoju, spuse

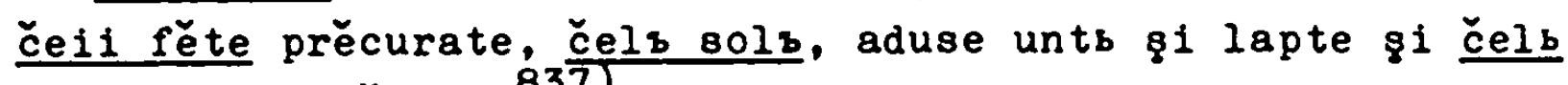
vitelb Inaintě lor. ${ }^{837)}$ Diese Repliken fassen das alb. í ebenso demonstrativ auf wie in *kal i-mirë > calu ellu-bunu > calul cel bun.

Wie erklärt sich die vom Alb. und Iranischen abweichende Position des Relativpronomens in slav. dobrb-jb konb, durch welche die Entstehung eines *konb-jb oder *jb-konb verhindert wurde?

Ein Relativsatz kann dem übergeordneten Substantiv vorausgehen oder folgen, im Relativsatz selbst kann das Pronomen am Anfang oder am Ende stehen. Für den verkürzten Relativsatz in attributivem Gebrauch sind deshalb die folgenden Sequenzen möglich:

1. a. equus qui-bonus $(S-\operatorname{Pr}-A)$ b. qui-bonus equus $(\operatorname{Pr}-A-S)$

2. a. equus bonus-qui $(S-A-P r)$ b. bonus-qui equus $(A-P r-S)$. 838$)$

Gegen die Möglichkeit, daß das Balto-Slav. die konsequente 
Endstellung des Pronomens im Relativsatz, unabhängig von dessen Sequenz zum übergeordneten Substantiv (2.a.b.), von Anfang an für sein identifiziertes Syntagma verwendete, spricht:

1. Keine andere idg. Sprache zeigt die Position des Relativpronomens hinter dem Attribut (S-A-Pr, A-Pr-S) in einer solchen Starrheit wie das Balto-Slav. Im Altindischen, wo die Sequenz S-A-Pr ebenfalls vorkommt: śa rátr ȳ 'cette nuit, la décroissante ${ }^{839)}$, findet man auch die Sequenz S-Pr-A. 840) so entspricht z.B. lit. dangujejiis, žemèjęjis, kalnęjis (A-Pr) einem altindischen yá diví, yá prọthivyám, yâ párvateǫu (Pr-A).841)

Bei einer Ubereinstimmung des Balto-Slav. mit dem Altindischen in der Behandlung des adjektivischen Relativpronomens, die von einigen Iinguisten angenommen wird, ist die konsequente Nachstellung des Relativpronomens beim Attribut für das Balto-slav. nicht zu erwarten.

2. Die Sequenz S-A-Pr (konb dobrb-jb), die im Aksl. 'sehr häufig', im Iit. dagegen 'erheblich seltener' ist ${ }^{842)}$, ist gegenüber der Sequenz (dobrb-jb konb) A-Pr-S historisch sekundär. Das Charakteristische der Position des Pronomens im Balto-slav. besteht anscheinend nicht nur in seiner Nachstellung zum Attribut, sondern auch in der Binnenstellung des Pronomens zwischen dem Attribut und dem übergeordneten Substantiv.

3. Die im Aksl. neuaufgelegte identifizierte Relativkonstruktion (otbcb našb iže na nebesechb) erscheint in der vom Alb. und Iranischen $z u$ erwartenden Sequenz S-Pr-A.

4. Die zu erwartende Sequenz S-Pr-A der balto-slav. Pronominalform läßt sich in altlit. Relikten aufzeigen. 843) Dort kann das Pronomen jis bei einem Partizip zwischen das Verbalpräfix und das Simplex treten: zu paprastàs-is 'der gewöhnliche' vom Verb pa-piràsi 'gewöhnt sein' findet sich der Genitiv žaisla pa-jo-prasta 'des gewöhnlichen Spielzeugs', 
auBerdem: visi su-ji-espaust1 'alle Bedrückten', pra-jis-puolegs 'der Zugrundegegangene'.844) Auch nach Negationen ist diese Stellung im Altit. erhalten, z.T. mit Doppelung des Pronomens: ne-iam turinč-iam ${ }^{845)}$, walgit Awinela ne 10-kalto-ia (d.1. ne-io-kalto-10) ' $2 u$ essen das unschuldige Lamm'. 846) - Die moderne Entsprechung zu pa-jo-prasta lautet paprasto-jo. Die lit. Relikte bezeugen die frühere Existenz der Sequenz S-Pr-A (konb jb-dobrb) im Balto-Slav.. Nimmt man an, daB einst im Balto-Slav. ein kkonb jb-dobrs 'das gute Pferd' existierte, entsprechend dew alb. "kal 1-mirë und dem persischen asp-I hüb, so wird klar, daB alle drei Sprachgruppen von der gebräuchlichsten Sequenz des Relativeatzes, von equus qui-bonus (1.a.) ausgegangen sind. Die spätere Umstellung der Elemente zu dobrb-jb konb im BaltoSlav. 18t nicht als Rückkehr zu einer der übrigen Sequenzen (2.a. oder 2.b.), sondern als Angleichung des Syntagmas mit identifiziertem Substantiv an das syntagma mit nicht-identifiziertem Substantiv (dobrb konb 'ein gutes Pferd') zu werten. Für die Identifizierung von Gegenständen, die vorher nicht im Kontext erwähnt worden sind, wurde die Sequenz equus qui bonus verwendet, die eine Verkürzung von equus qui bonus est darstellt, gebildet, um die funktionellen Möglichkeiten des adjektivischen Relativpronomens nachzuahmen. Bei kontextueller Vorerwähnung des intendierten Gegenstandes konnte dagegen die Identifizierung auch durch das ursprüngliche adjektivische Relativpronomen bezeichnet werden, das in dieser grammatioch lokalisierenden Funktion die verschiedenen Positionen des Demonstrativpronomens einnahm: equus qui bonus, bonus qui equus, bonus equus qui, equus bonus qui, qui equus bonus, qui bonus equus. Für die Häufigkeit einzelner dieser Sequenzen Im Balto-Slav. war, ebenso wie für die Sequenz der Gileder eines Syntagmas mit nicht-identifiziertem Substantiv, de Tatsache ausschlaggebend, daB das qualifikative Adjektiv Im Slav. gewöhnlich $\nabla$ o seinem Substantiv steht. 847) Damit existierten im (Balto-)Slav. die folgenden Sequenzen ne- 
beneinander:

\begin{tabular}{c|l|l} 
nicht-identifiziert & $\begin{array}{l}\text { anknüpfend } \\
\text { identifiziert }\end{array}$ & $\begin{array}{l}\text { einführend } \\
\text { identifiziert }\end{array}$ \\
\hline dobrb konb & $\begin{array}{l}\text { dobrb jb }<\text { jos konb konb jb dobrb } \\
\text { jb dobrb konb } \\
\text { dobrb konb jb }\end{array}$ & kobs
\end{tabular}

Die Polge war ein Ausgleich zwischen den Sequenzen der anknüpfenden und der einführenden Identifizierung. Die anknüpfende (kontextbedingte) Identifizierung lieferte die gebräuchliche Sequenz Adjektiv + Sübstantiv, die einführende Identifizierung die Binnenstellung des Pronomens zur Kennzeichnung seiner rein identifizierenden Punktion, unabhängig rom Vorhandensein oder Fehlen einer zusätzlichen Erwähnung des intendierten Gegenstandes im Kontext. Die Bildung einer einheitlichen Konstruktion für den Ausdruck aller Möglichkeiten der Identifizierung führte zu einer weitgehenden Parallelität zwischen dem identifizierten und dem nicht-identifizierten Syntagma:

$$
\text { dobrb konb } \longleftrightarrow \text { dobrb-jb konb }
$$

Im identifizierten Syntagma erinnert nur noch die Binnenstellung des Pronomens an die frühere relativische Konstruktion konb fb dobrb (festb). - Die altlit. Relikte sind als Uberbleibsel der Sequenz in der einführenden Identifizierung zu betrachten. - Die Position des Pronomens im elliptischen jb-dobrs ist unter dem Einflub des neugebildeten dobrb-jb konb zu dobrs-jb verändert worden.

In das Syntagma dobrb-jb konb, mit jb $<$ j0s, erhielt schlieblich das Demonstrativpronomen $i b<$ is Zugang, als es das Relativpronomen, ausgehend von dessen Verwendung auBerhalb des identifizierten Syntagmas, zu ersetzen begann. Der Grund für diese Ersetzung ist darin zu sehen, dab jb $<{ }^{*}$ is immer mehr durch das Demonstrativpronomen ons (1it. anàs) aus der realen Lokalisierung verdrängt und die grammatische Loka- 
lisierung seine primäre Punktion wurde. Es ist anzunehmen, daß $j b<$ is für das identifizierende $j b<* j 0 s$ zuerst in der anknüpfenden Identifizierung auftrat.

Die vollkommene Koppelung des Pronomens mit dem vorausgehenden Adjektiv wird in dem Augenblick offenbar, da neben dobrb-jb konb auch die Inversion konb dobrb-jb möglich wird. Das Kriterium der Binnenstellung des Pronomens ist aufgegeben worden, weil das Pronomen gar nicht mehr als selbständiges Wort erkannt wird. Im Aksl. ist diese Fusion von Adjektiv und Pronomen $z u$ einer 'Langform' des Adjektivs weit fortgeschritten, die Inversion wird häufig verwendet, die Identifizierung durch die Langform des Adjektivs ist bereits grammatisch geregelt; dagegen bewahrt das Pronomen im Altlit. noch einen Rest seiner Unabhängigkeit vom Adjektiv ${ }^{848)}$, die Inversion wird selten gebraucht, und die Identifizierung durch die Pronominalform unterliegt noch der semantischen Umgebung und der Willkür des Sprechers. Aus dem Vergleich des Aksl. mit dem Lit. konstruiert Wissemann ${ }^{849)}$ eine Verbindung zwischen der Häufigkeit der Inversion und der grammatischen Regelung der Identifizierung im Aksl. und der Seltenheit der Inversion und der emphatischen Verwendung der Pronominalform im Lit. Es handelt sich hier wahrscheinlich weniger um eine funktionelle Interdependenz als um die Gleichzeitigkeit einer formalen und einer funktionellen Entwicklung.

Es bleibt zu fragen, warum eine vergleichbare Umstellung der Glieder des identifizierten Syntagmas im Alb., wo Relikte auf die einstige Voranstellung des Adjektivs (mirë kal) verweisen, nicht eingetreten ist: von kal i-mirë etwa zu*mirë-i kal, entsprechend dem slav. konb jb-dobrs zu dobrb-jb konb. Der Grund liegt darin, daB das Alb. über die anknüpfende Identifizierung (grammatische Lokalisierung) sein gesamtes lokalistisches Zeigesystem in die einführende (kontextunabhängige) Identifizierung eingebracht hat: neben kal 1.-mirë (< *jos) entstanden durch den Ausgleich der Konstruktionen mit anknüpfender und einführender Identifizierung auch 


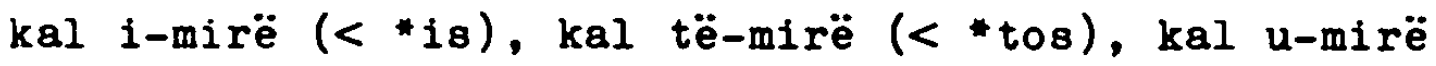
(<*oyos), die heute suppletiv im Paradigma des eingliedrig gewordenen Artikels verteilt sind: kal-i (nom. sing.), kali-t (obl. sing.), zog-u (nom. sing.). Vgl. Kap. II.3.b. Da die Stämme $\underline{i}$, $\underline{\text {, }}$ të im Prühalb. fortfuhren, als Demonstrativpronomina real zu lokalisieren, muBten sie die relativische Sequenz von kal 1 -mirë (<*ios) vollkommen imitieren, wenn sie als kontextfrei identifizierend verstanden werden wollten.- Die Ersetzung von *jos durch *is im identifizierten Syntagma des Balto-Slav. kann mit der Einführung des gesamten alb. Zeigesystems in das System des Protoartikels nicht verglichen werden: Während im Alb. dadurch ein dreigliedriges Artikelsystem entstand, blieb das System des balto-slav. Protoartikels auch nach der Einführung von is eingliedrig. Das Pronomen is hat im Balto-Slav. und im Alb. unterschiedliche Werte, im Alb. steht es für den Zeigebereich der 3. Person, im Balto-Slav. steht es auBerhalb des lokalistischen Zeigesystems.

Ich fasse zusammen: Slav. dobrb-jb und konb_, alb. i-mirë und kal-í gehen auf ein vergleichbares Syntagma konb ib-dobrb / kal i-mirë zurück, in dem ein Relativpronomen das Substantiv durch Hervorhebung des Attributs identifizierte. Diese Konstruktion konnte im Alb. zur Ausbildung eines kontextunabhängigen Artikels führen, weil die Position des Pronomens hinter dem Substantiv erhalten blieb. Dagegen begab sich das Balto-Slav. der Möglichkeit zur Weiterentwicklung des Protoartikels, weil es die Sequenz der Elemente im identifizierten Syntagma mit der Sequenz der Elemente im nicht-identifizierten Syntagma ausglich. Dadurch geriet der Protoartikel mit dem Auslaut des vorangehenden Adjektivs in Kontakt und wurde später für den Aufbau einer gesonderten Adjektivflexion verwendet. 
Den alb. Artikel -í, das Pronomen - ib des zusammengesetzten Adjektivs im Balto-Slav. und die Partikel I der iranischen Izāfet-Verbindung haben schon andere Iinguisten zusammengestellt, so Georgiev ${ }^{850)}$ und Pisani ${ }^{851}$ ). Jedoch erst die funktionelle Ableitung aller drei Morpheme aus einem diesen Sprachen früher eigenen identifizierten Syntagma, wie sie oben durchgeführt wurde, macht ihren genetischen Zusammenhang wahrscheinlich. Eine jüngere Isoglosse verbindet das Alb. mit dem Armenischen, in beiden Sprachen entstand durch den Einbruch des dreigliedrigen Zeigesystems in das identifizierte Syntagma ein dreigliedriges Artikelsystem. 852)

Diese Isoglossen im Artikelbereich zwischen dem BaltoSlav., Iranischen, Alb. und Armenischen werden von anderen Ubereinstimmungen begleitet: "Das Slavische gehört zu einer bestinmten Dialektgruppe des Indogermanischen" (Meillet) ${ }^{853)}$, diese umschliebt das Baltische, Slavische, Albanische, IndoIranische und ist gekennzeichnet durch die parallele Behandlung der Gutturale, Labio-Velare, des indogermanischen . $^{854)}$ Weitere Isoglossen umfassen nicht a $l 1$ e Teilnehmer dieser ostindogermanischen Gruppe. $\mathrm{Zu}$

Albanisch - Balto-Slavisch siehe: den Ablaut 855 ) Nasalierung ${ }^{856)}$, sigmatische Imperfektbildung, Lexik ${ }^{857}$.

Iranisch-Slavisch: "Diese lexikalischen Ubereinstimmungen zwischen dem Slavischen und dem Iranischen weisen auf eine Nähe der beiden Dialekte in der indogermanischen Einheit hin. Aber die Beziehungen zwischen den slavischen Stämmen und den nordwestlichen Stämmen des iranischen Bereichs haben lange fortgedauert, und die Pakten der slavischen Prähistorie bezeugen einen Kontakt und sogar eine gewisse Mischung der Bevölkerung mit den Skythen (...)n (Meillet). 858)

Albanisch-Armenisch. Siehe die Aufzählung der Isoglossen bei Pisani ${ }^{859)}$, Pedersen ${ }^{860)}$, Seliščev ${ }^{861)}$, Barić(862), bei letzterem auch zu den albanisch-iranischen Isoglossen. Wichtig ist, daB die thrakischen Sprachreste besonders nahe zum Balto-Slav. gestellt werden (Jokl, Dečev, Pisani, 
Mladenov) ${ }^{863)}$. Unter Berücksichtigung der bal toslav.-alb. Isoglossen wird dadurch bestätigt, daB das Alb. als Nachfolgesprache des Thrakischen zu werten ist. ${ }^{864}$ )

Eine bedeutsame Isoglosse des Iranischen-Indischen-Armenischen-Albanischen, die auch das Phrygische in Kleinasien umfaBt ${ }^{865)}$, ist der Ausdruck des indirekten 0 bjekts und des Attributs durch e in e n paradigmatischen Kasus ${ }^{866)}$ : "Die Fusion des Genitivs und des Dativs umfaBt das vom Albanischen, Thrakischen, Armenischen und Iranischen gebildete Gebiet, d.h. dasjenige, welches durch die Isoglosse des postponierten Artikels plus Iranisch gekennzeichnet ist." (Pisani) 867$)$

Die Wechselbeziehungen unter den Gliedern der ostindogermanischen Sprachgruppe legen es nahe, dab es sich bei dem Protoartikel um eine 'gemeinsame Neuerung', um eine 'Dialekterscheinung von indogermanischem Datum , 868) handelt, die folglich auch das Thrakische, als Bindeglied zwischen dem Alb. und Slavisch-Baltischen, dem Albanischen, Armenischen und Phrygischen, dem Alb. und dem Iranischen aufwies. Gamillschegs Einwand, das stilistisch nicht ausgebildete Thrakisch habe eine Feinheit, wie der Artikel sie darstelle, nicht kennen können ${ }^{869)}$, ist schon angesichts der artikellosen modernen slav. Sprachen nicht haltbar, zudem gehört die Ausbildung eines primären Artikelmorphems den vergleichsweise jungen Perioden des Alb., Armenischen, Ossetischen an, und für das ältere Thrakisch genügt es, ein identifiziertes Syntagma anzunehmen. Dasselbe gilt für die phrygischen Sprachreste, die keinen primären Artikel aufweisen. 870 )

Eine Berührung des Slavischen, Iranischen, Thrakischen, Phrygischen, Armenischen, die an der Bildung des identifizierten Syntagmas teilnahmen, hat sich auf dem Balkan bis in die Epoche vor der Hellenisierung bzw. Romanisierung abgespielt. Wenn in den diesbezüglichen Darlegungen Vl. Georgievs auch manche unsichere Paktoren bleiben müssen, so entsprechen sie doch am besten den antiken Nachrichten und den festgestellten 
sprachlichen Beziehungen.

Das sogenannte 'Thrakisch' stellt eine Mischung des Dakomysischen (Vorläufer des Alb.) und des Echtthrakischen dar871), die im 2. Jahrtausend v.u.z. eintrat.872) AuBerdem hatte 'Thrakisch' eine phrygische Komponente, denn "die Phrygier hatten vor ihrer Auswanderung nach Kleinasien ihre Wohnsitze im heutigen Bulgarien" (Giese). 873) Ein Teil der Phrygier, deren Sprache auch eine thrakische Schicht aufwies, die Protoarmenier, wanderte im 2. Jahrtausend v.u.Z. nach Armenien $a b^{874)}: "(\ldots)$ das sogenannte thrakische linguistische Material gehört $z u$ drei verschiedenen indogermanischen Sprachen: (Echt)Thrakisch, Dakisch oder Dako-Mysisch (...) und Phrygisch" (Georgiev). 875) Im Schema:

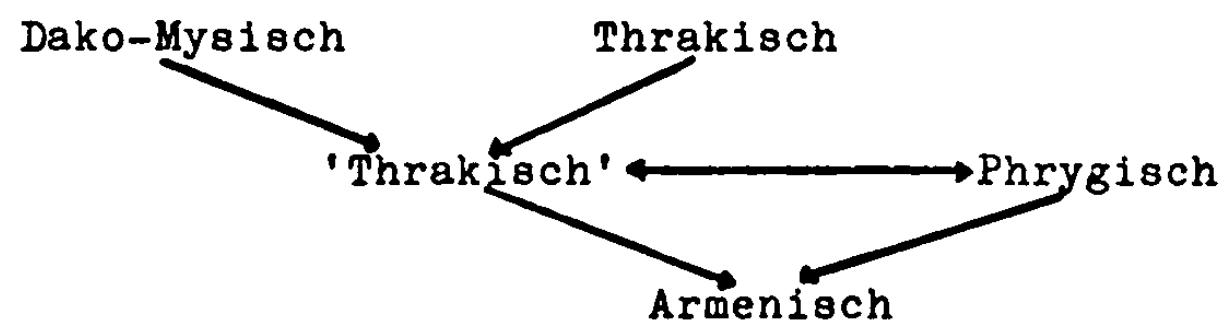

Am Rande dieser Sprachmischung (an der außerdem das Altmakedonische, Griech. und Keltische teilnahmen), die sehr wohl als altbalkanischer Sprachbund bezeichnet werden kann, bewegten sich das Iranische und das Slavische, ersteres von südrussland bis zur Donau, letzteres im Kontakt mit dem Iranischen in Südrussland. Thrakische Namen im skythisch-sarmatischen Gebiet und iranische Namen in Dakien sind belegt. 876) Eines der linguistischen Elemente, durch die der al tbalkan18che Sprachbund und die im Norden angrenzenden Sprachen gekennzeichnet waren, ist das identifizierte Syntagma (Substantiv-Protoartikel-Attribut) gewesen.

Uber das Alb. hat der postpositive Artikel des Balkanslavischen, der als Replik zum rum. postpositiven Artikel zu werten ist, welche im jüngeren balkanischen sprachbund entstand, eine mittelbare Verbindung zum identifizier- 
ten Syntagma des altbalkanischen Sprachbundes, welches, auch im Balto-Slavischen existierend, dort eine vom Alb., Iranischen und Armenischen abweichende Entwicklung nahm, deren Endprodukt das 'lange' Adjektiv ist. Mit anderen Worten: Die vom Gemeinslavischen verpaßte Möglichkeit, einen primären Artikel auszubilden, wurde im Balkanslavischen dadurch nachgeholt, daß es die aus derselben Möglichkeit im Albanischen entwickelten Resultate, gröBtenteils durch rumänische Vermittlung, entsprechend den Bedingungen des eigenen Zeigesystems nachbildete. Die aufällige Ubereinstimmung zwischen dem dreigliedrigen bulgarisch-makedonischen und dem al tarmenischen dreigliedrigen Artikelsystem ${ }^{877}$ ), die man durch ein phrygisches Substrat im Bulgarischen erklären wollte $\mathrm{e}^{878)}$, was chronologisch nicht möglich ist, beruht deshalb auf einem nur mittelbaren 'Kontakt', dessen Bindeglied das frühalbanische dreigliedrige Artikelsystem darstellt. 


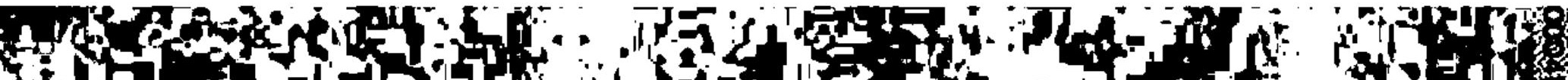

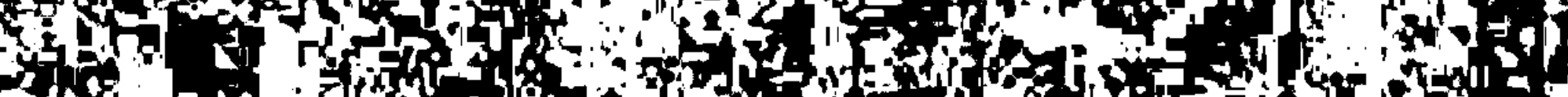

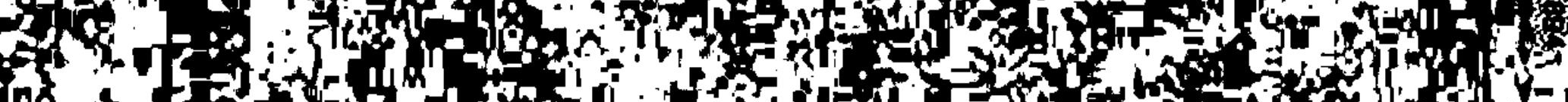

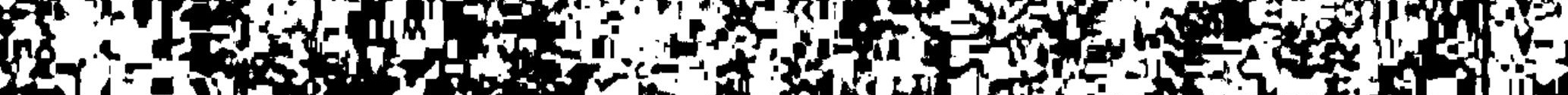

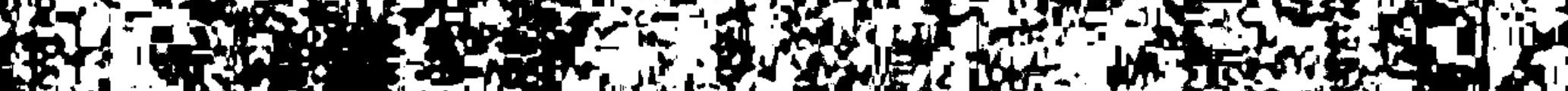

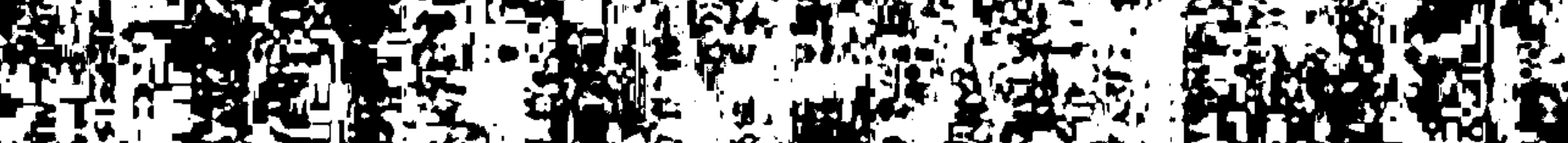

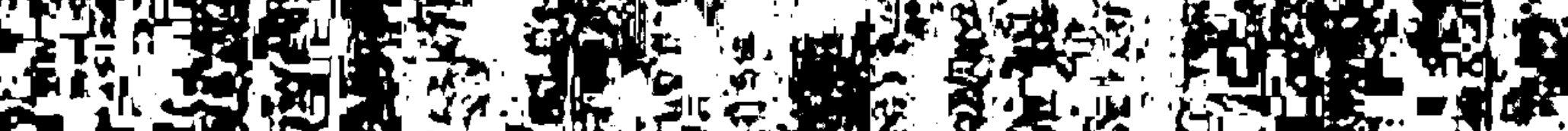

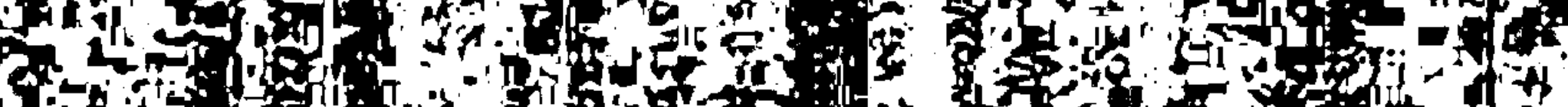

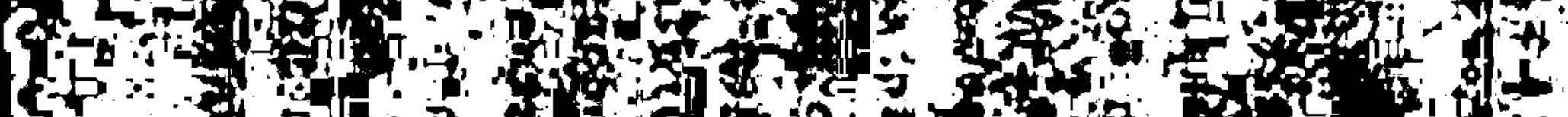

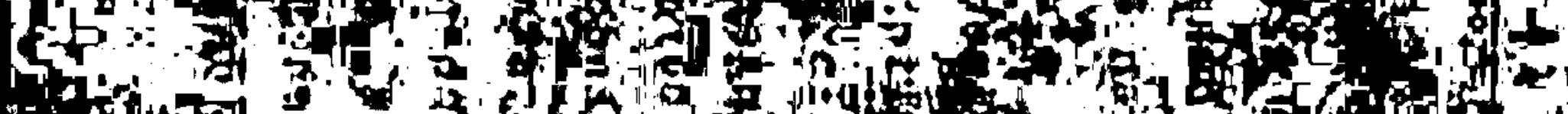

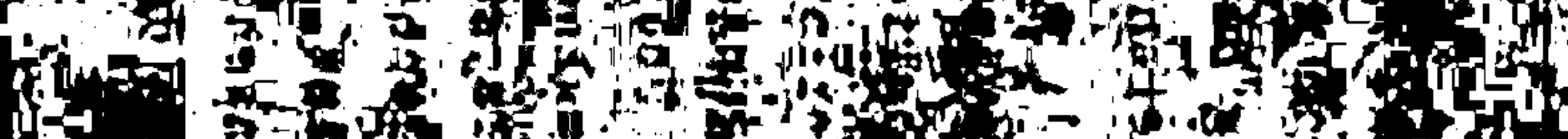

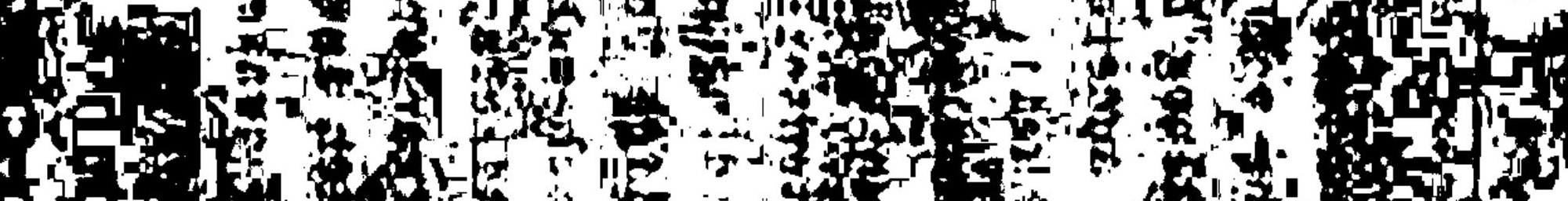

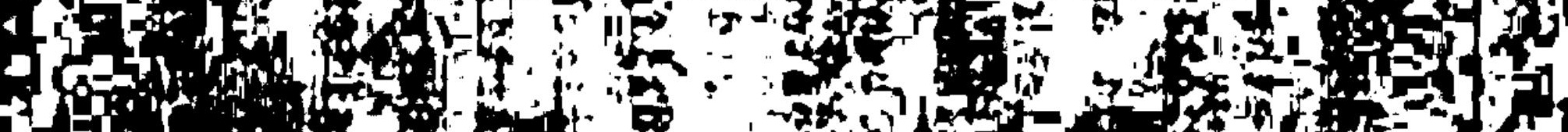

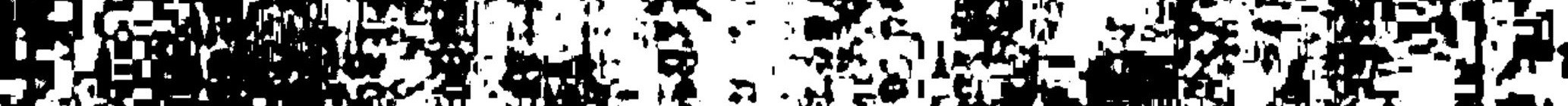
-

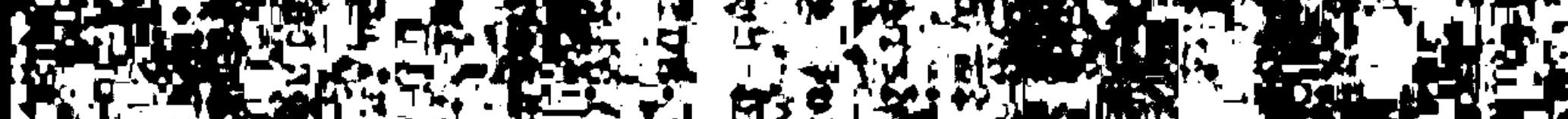

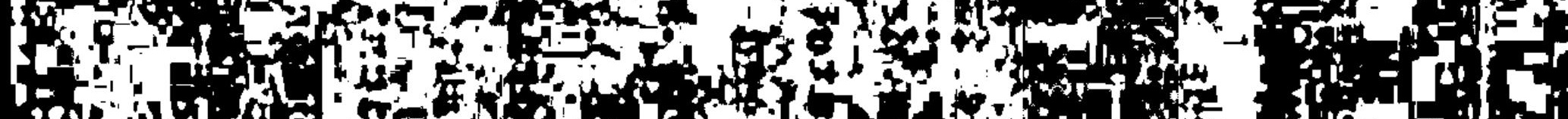

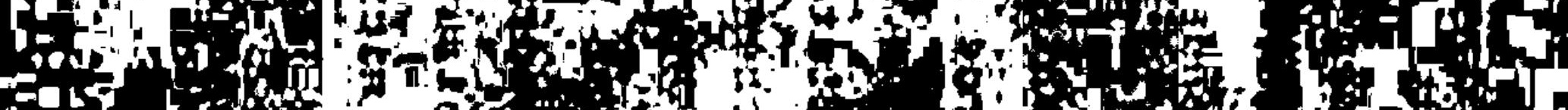
-

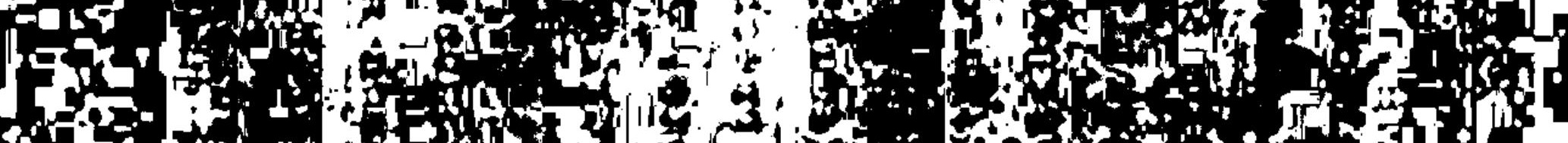

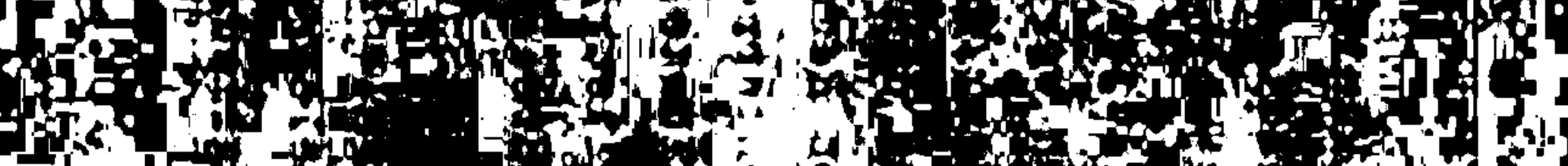
1. T. The

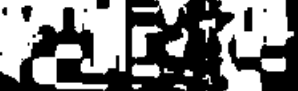
fofto is

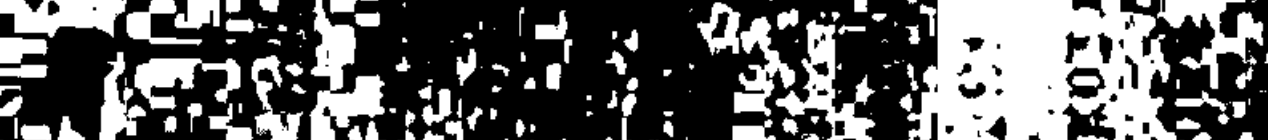

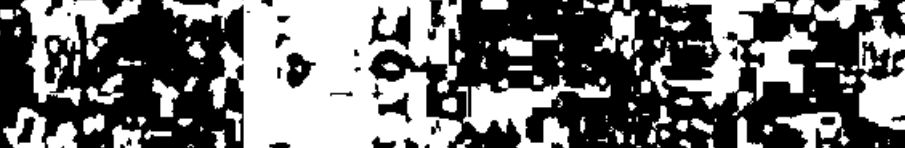
1 ld ofe

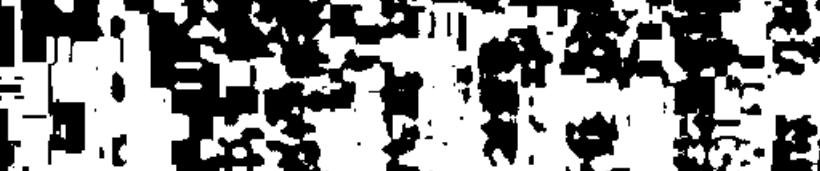

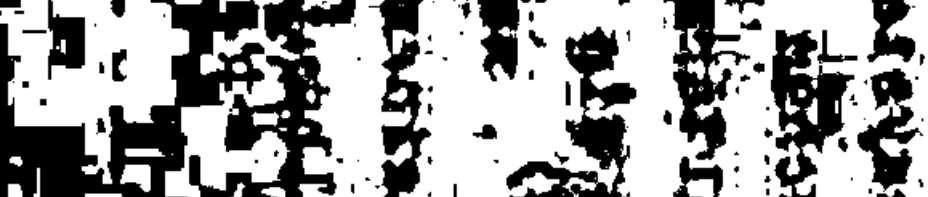

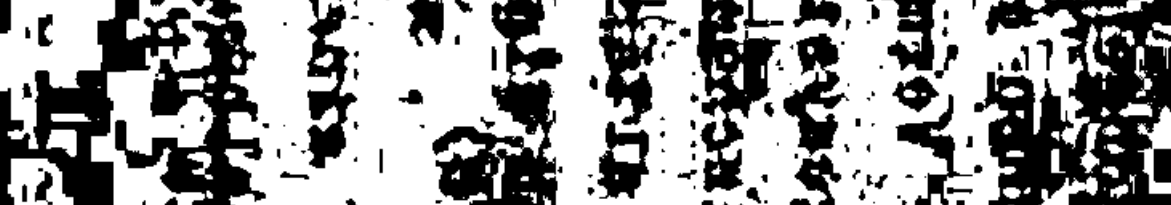




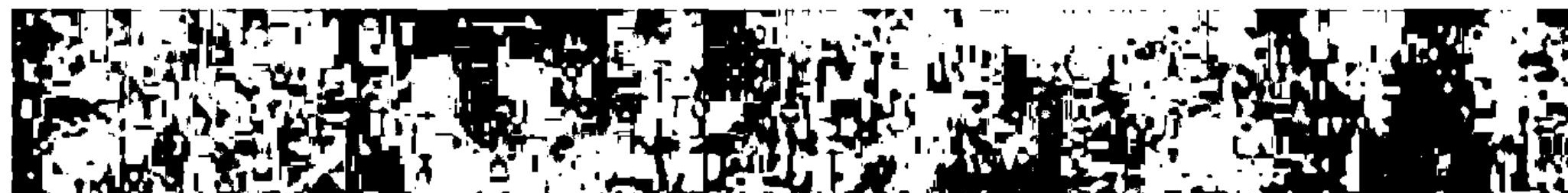
ind ind

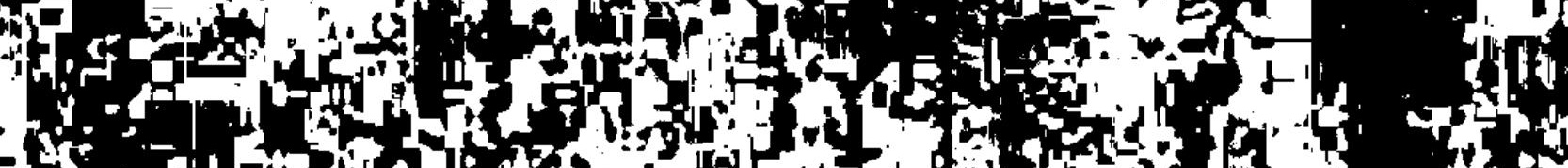

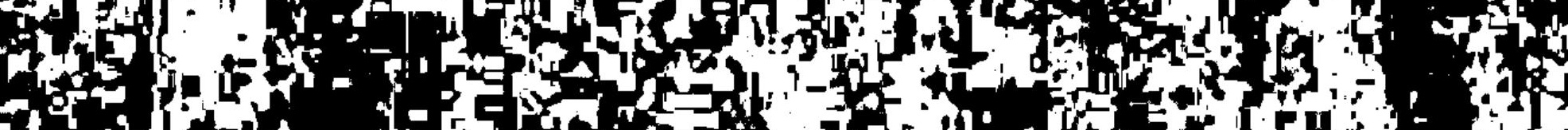

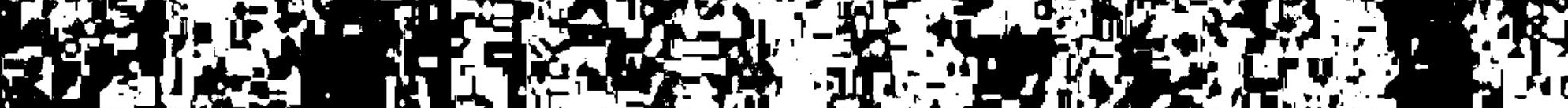

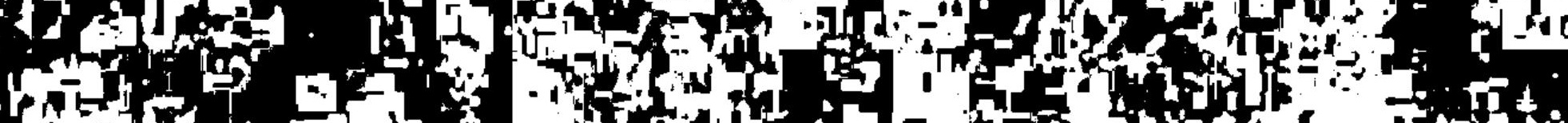
H

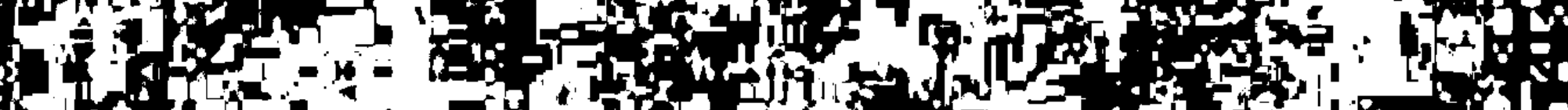

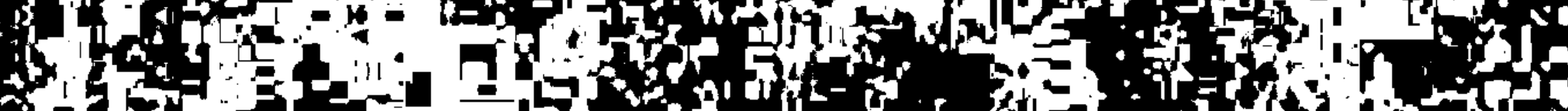

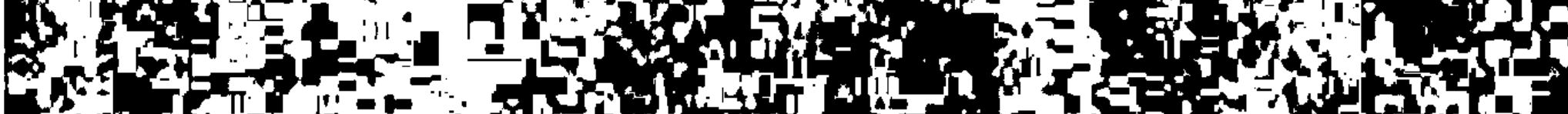

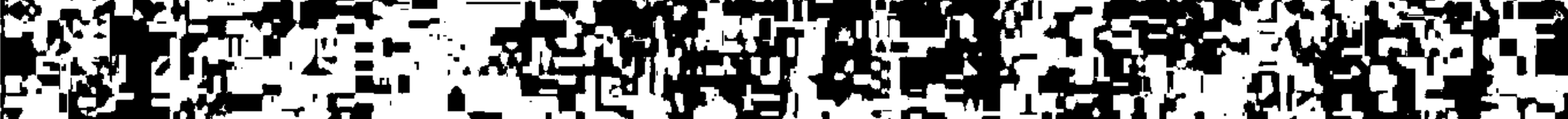

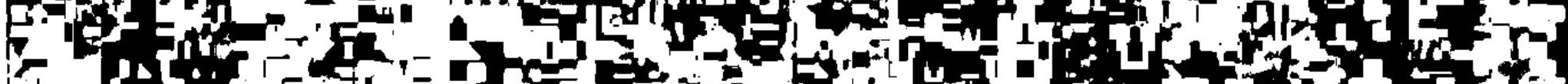
Fif

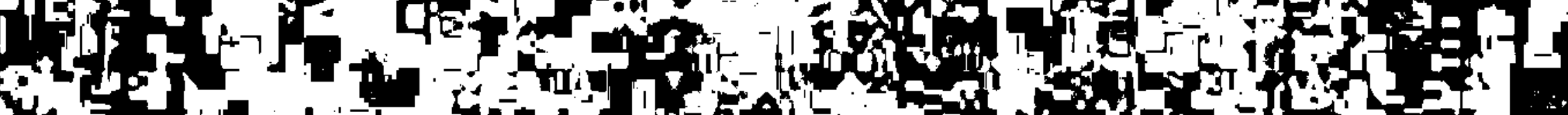

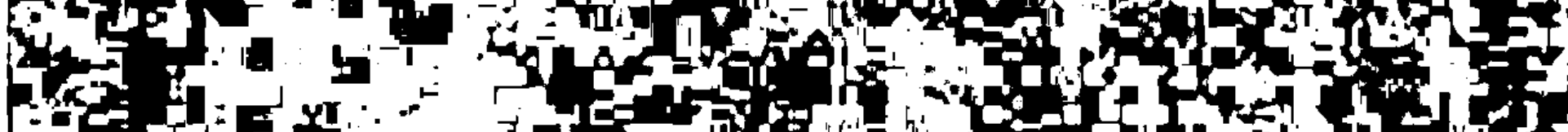

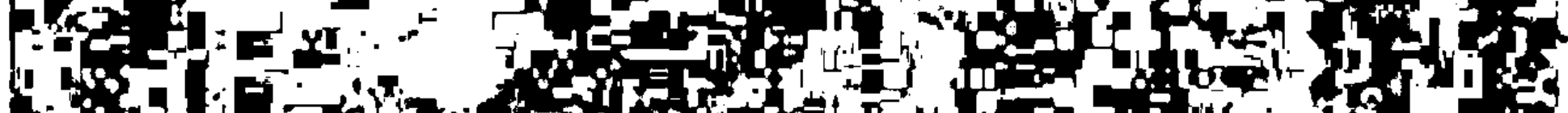
-

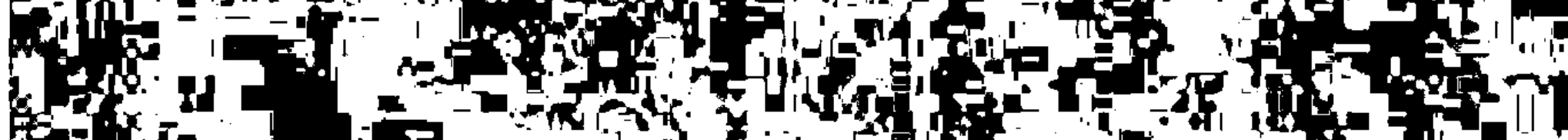

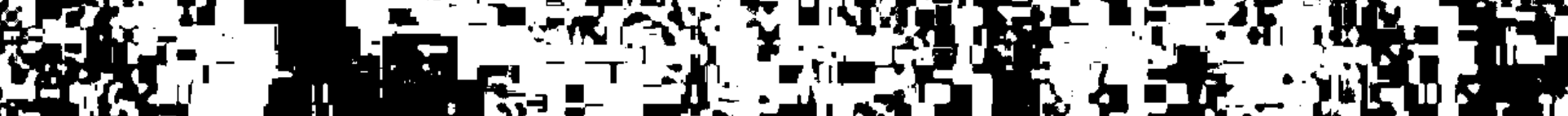

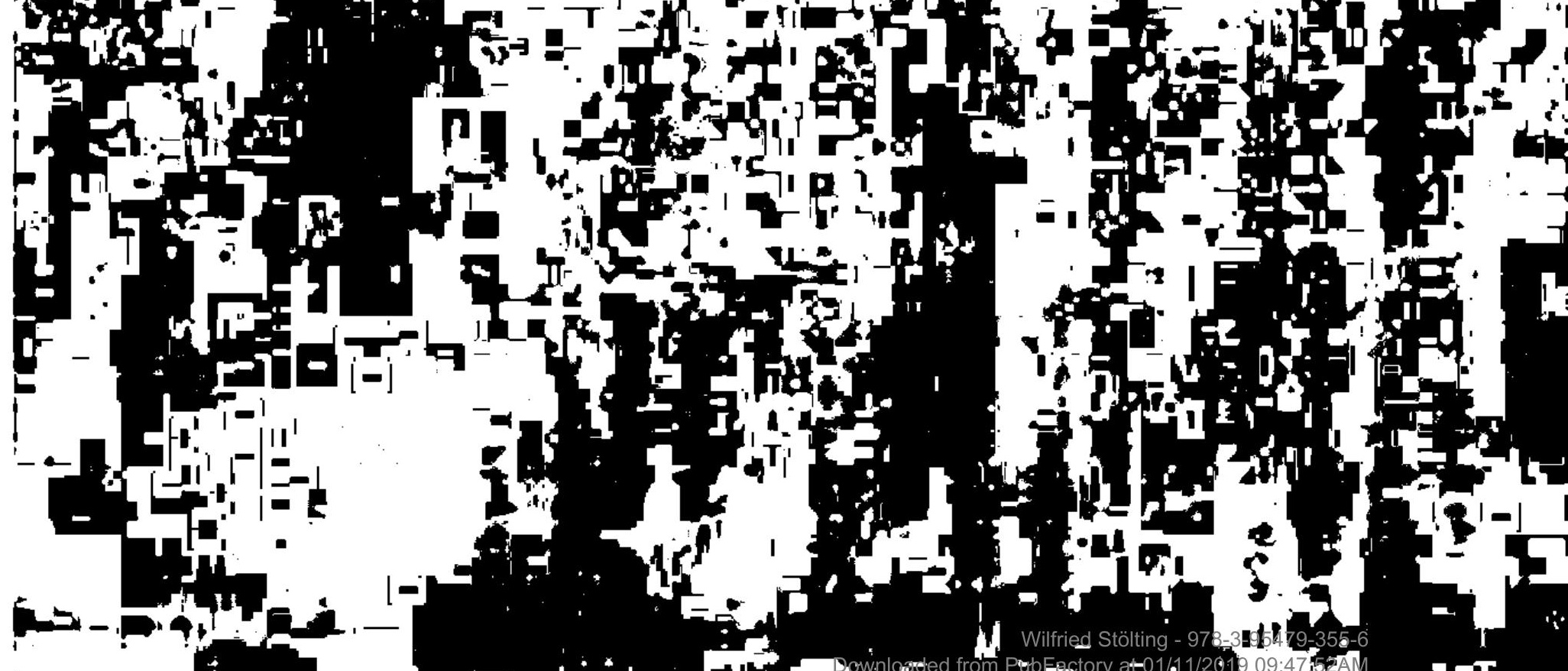




\section{R E S Ü M E E}

Einleitend wird der historische Kontakt von Sprechern des Slavisch-Bulgarischen mit Sprechern des Rumänischen und des Albanischen auf der Balkanhalbinsel in der Zeit bis zum

10. Jhd. analysiert. Durch diese linguistischen Kontakte werden die Grundlagen für das heute im Nominalbereich des Bulgarischen, Rumänischen und Albanischen feststellbare Metasystem gelegt. Wichtig erscheint es für die Charakterisierung und Datierung der diesbezüglichen Neuerungen des Bulgarischen, zu denen auch der Artikel gehört, im 9. Jhd. zwischen dem belegten konservativen Altkirchenslavischen und dem nicht belegten Altbulgarischen der Kontaktgebiete zu unterscheiden (Kap. I).

Das heutige bulgarische Artikelsystem wird auf die Entstehung seiner Charakteristika hin untersucht. Das Nebeneinander von dreigliedrigen und eingliedrigen Artikelsystemen im modernen Bulgarisch-Makedonischen (volos-volot-volon / volot) verweist auf eine Anregung des bulgarischen Artikels durch das erschlossene dreigliedrige System des Frühalbanischen und das eingliedrige System des Rumänischen. Die Postposition des bulgarischen Artikels kommt den innerslavischen Tendenzen entgegen, wird zu einer obligaten Regelung jedoch durch die parallele Position des rumänischen Substrats erhoben. Bei dieser Gelegenheit werden die rumänischen und albanischen Artikel aus dem Protoartikel eines identifizierten Syntagmas (alb. *kal i-mirë 'das gute Pferd') abgeleitet, wie es einst auch im Gemeinslavischen bestanden haben muß. Die Existenz eines morphematisch und positionell festgelegten Artikels im Bulgarischen wird durch den Verlust der Halbvokale evident. Die Folge ist eine Neubildung der Demonstrativpronomina, deren ältere Formen zu Artikeln werden. Das Artikelallomorph des heutigen Bulgarischen, - $\underline{a}$, läßt sich Eus dem Genitiv-Akkusativ-Morphem der o-stämme ableiten. Für die Datierung ergibt sich, daß der in den fortschrittlichen 
bulgarischen Dialekten um das 10. Jhd. vorliegende Artikel bis zum 13. Jhd. in alle anderen Dialekte verbreitet worden ist (Kap. II).

An der vom rumänischen Substrat ausgelösten Kasusumgestaltung des Bulgarischen wirkte der Artikel mit, er trug durch die Bildung einer gesonderten Determinierten Kasusflexion zur Zersetzung des synthetischen Kasustyps bei (Kap. III).

Das im Prühalbanischen erschlossene, durch einen Protoartikel identifizierte nominale Syntagma entspricht morphematisch und funktionell der gemeinslavisch-baltischen Vorform des späteren 'zusammengesetzten Adjektivs', die positionelle Parallelität zwischen der albanischen und der slavischen Konstruktion läBt sich erschließen. An der Bildung eines identifizierten Syntagmas nimmt das Iranische teil. Während das Albanische aus dem Protoartikel einen zum Substantiv postpositiven Artikel entwickelte, verpaßte das Slavische diese Möglichkeit, weil es die Position des Protoartikels im Syntagma veränderte. Erst das Bulgarische übernahm durch rumänische Vermittlung die Resultate des albanischen Prozesses. Das durch einen Protoartikel identifizierte Syntagma (alb. *kal i-mirë, slav. konb jb-dobrb 'das gute Pferd') kann als Kennzeichen des Altbalkanischen Sprachbundes (Thrakisch u.a.) und der ihm benachbarten Sprachen (Balto-Slavisch, Iranisch) betrachtet werden (Kap. IV). 
In den folgenden Anmerkungen werden Kurztitel der zitierten Arbeiten verwendet. Die vollständigen bibliographischen Angaben finden sich im Literaturverzeichnis. Der Kurztitel besteht aus dem Namen des Autors oder, falls dieser mit mehreren Arbeiten im Literaturverzeichnis vertreten ist, aus dem Namen des Autors und dem verkürzten Titel der zitierten Arbeit. - Die Angabe a.a.0. bezieht sich jeweils auf die unmittelbar vorausgehende Anmerkung; falls in dieser Anmerkung mehrere Arbeiten erwähnt sind, so bezieht sich die Angabe a.a.0. auf die dort zuletzt erwähnte Arbeit. Das Gleiche gilt für die Angabe ebda..

Im Text angefürte fremdsprachliche Zitate sind vom Verfasser ins Deutsche übersetzt worden. 
1) Mirčev, Istoričeska gramatika, S. 176

2) Belić, Dijalekti Srbije, S. 442

3) Civ'jan, S. 11

4) Svane, K voprosu proischoždenii, S. 165

5) Civ'jan, S. 3-14

6) Actes du 1-er Congrès International des linguistes 1928, S. 18

7) Weinre1ch, S. I

8) Vogt, S. 34

9) vgl. Weinreich, S. I

10) a.a.0., S. 8-9

1I) Haugen, S. 772 , S. 777

12) Vogt, S. 34

13) vgl. Weinreich, S. 30

$14)$ a.8.0., S. 38-40

15) a.8.0., S. 11

16) Seidel, Elemente sintactice, S. 120

17) Weinreich, S. 40-4l

18) Koneski, Istorija, S. 132-133

19) Birnbaum, Balkanslavisch, S. 30 Anm. 36, S. 61; Vogt, s. 36

20) Goląb, Some Arumanian-Macedonian isogrammatisms, S. 415

21) ebda.

22) a.a.0., S. 434-435

23) nach Weinreich, S. 9-10

24) ebda.

25) V.V. Ivanov, in: Proceedings of the 8 th International Congress of Linguists, Oslo 1958, S. 26

26) Birnbaum, Balkanslavisch, S. 16

27) Ivic, Dijalektologija, S. 12l, vgl. Birnbaum, Balkanslavisch, S. 45 Anm. 62

28) Birnbaum, Balkanslavisch, S. 15

29) a.a.0., S. 21

30) Civ'Jan, S. 160-161, S. 188

31) Vogt, S. 37

32) Desnickaja, S. 71

33) Birnbaum, Balkanslavisch, S. 29

34 Popov1e, S. 79-85, S. 157-166, S. 188-189

35) ebda., S. 79-85

36) Rosetti, Influenta limbilor slave, S. 15 
37) ebda., Rosett1, La situation du roumsin, S. 171 , S. 177-178, Rosett1, Istoria I, S. 39-40

38) a.8.0., S. $47-49$, Selirxev, S. 42

39) Rosetti, Influenta limbilor slave, S. 14

40) siehe Popovid, S. 80-81, Iiteraturangaben S. 85

4l) vgl. Bernztejn, K voprosu o periodizacil, S. 112, Georgiev, Opit za periodizacija, S. 81,

Mir Zev, Is toriCeska gramatika, S. 265, Popovit, S. 75-77 mit Iiteraturangaben

$42)$ a.a.0., S. 75-77; V1. Georgiev, Probleme substratului balcanic in lericul limbii bulgare, in: Omagiu lui

Iorgu Iordan, Bucuregt1 1958, S. 325-331;

v. Berevliev, Die Thraker im ausgehenden Al tertum, in:

Studil clasice, Bucuregti, III, 1961; J. Zaimov, Quelques particularités des noms thraces en Bulgarie, in: Balkansko ezikoznanie, Sofija, VI, 1963

43) Miletix, Die Rhodopemundarten, S. 3-4

44 ) Selizter, S. 38

45) Ivic, Die serbokroatischen Dialekte, S. 39

46) siehe Bernztejn, K voprosu o periodizacil, S. 110

47) vgl. Rosetti, Influenta limbilor slave, S. 17

48) ebda.

$49)$ S. Puģcariu, Pe marginea cărtilor, in: DR 8, S. 357

$50)$ Popovit, S. 59-64 mit Iiteraturangaben

51) vgl. Miȟ̈escu, S. 37

52) Bernłtejn, Razyskanija, S. 97

53 Rosetti, Influenta limbilor slave, S. 15

54 a.a.0.. S. 18, Bernłtejn, Razyskanija, S. 55-57

55) Capidan, Raporturile lingvistice, S. 237

56) Bernitejn, K voprosu o periodizaci1, S. 115, Gblsbov, Problembt za riena, S. 36, S. 45

57) Bernztejn, Razyskanij8, S. 58-62

58) a.a.0., S. $77 \mathrm{ff}$.

59) vgl. Rosetti, Influenfe limbilor slave, S. 19-20

60) Vaillant, A., Vieux bulgare et roman de Bulgarie, in: BL $14,1946, \mathrm{~S}$. II, vgl. N. Iorga, Histoire des Roumains II, S. 379

61) Vaillant, vieux bulgare et roman, s. 6-11

62) Puģcariu, Pe marginea cärţilor, DR 8, S. 333

63) Ivic, Znataj lingvisticke geografije, S. 302 , Capidan, Raporturile lingvistice, S. 145 Anm. 2

64) Golab, Some Arumanian-Macedonian isogrammatisms, S. 418 , S. 424

65) Selirtev, S. 40

66) Popovic, s. 238-241

67) Mirtev, Istoriteska gramatika, S. 265

68 Gslsbov, Problemst za Elena, S. 9-22

69 vgl. Georgiev, Opit za periodizacija, S. 95

70) M.A. Gabinskij, Vozniknovenie infinitiva kak vtoričnyj balkanskif jazykovoj process, Leningrad 1967, S. 50

71) Pugcariu, Pe marginea cätilor, S. 342, Popovit, S. 200

72) a.8.0., S. 199 
73) Capidan, Raporturile lingvistice, S. 176-234

74) a.a.0., S. 237-238

75) Bernztejn, Razyskanija, S. lo0ff.

76) Duridanov, Za nacenkite na unalitizma, S. 25

77) ebda.

78) Svane, K voprosu o proischožden11, S. 157-158

79) Georgiev, Opit za periodizacija, S. 105

80) a.a.0., S. 96-97

81) siehe Gblbbov, Problembt za člena, s. 73

$82)$ Mirter, Istoríeska gramatika, S. 182

83) Georgiev, Opit za periodizacija, S. 97

84 St. S tojkov, Li teraturen ezik 1 dialekti, in: I zv. IBE, kn. $2,1952, \mathrm{~S} .142-143$

85) Stawsk1, Zarys dialektologi1, S. 139

86) Goląb, Some Arumanian-Macedonian isogrammatisms, S. $434-435$

87) Weinreich, S. 56

88) ebda.

89) Seidel, Probleme und Methoden, S. 788

90) Gblsbov, Problembt za Xlena, S. 29 Anm. 5

91) Capidan, Raporturile lingvistice, S. 235

92) ebda.

93) K. Mirčev, Za periodizacijata na istorijata na bblgarski ezik, in: Iz.v. IBE, kn. 2, 1952, S. 200

94 ) Rosetti, Influenta limbilor slave, S. 16

95) vgl. Slawsk1, Zarys dialektologi1, S. 126-127

96) Svane, K voprosu o proischozdeni1, S. 153

97) Mladenov, S. 346 , Conev, Koi novobblgarski govori, S. 4

98) Conev, Is torija A.1., S. 83

99) Skok, o bugarskom jeziku, S. 88-89

100) Lamanskij, Zurnal ministerstva narodnago prosvěščnija, I896, Januar, S. 125

101) Srepkin, Bolonskaja paal tyr', Sankt-Peterburg 1906, S. IV

102 V. Oblak, Njakolko belezk1 vsrchu otaroslavenskite pametnici, in: SbNU 9, 1893, S. 3 Anm.

103) Bernłtejn, Razyskanija, S. 353

104 Svane, X voprosu o proischozdenif, S. 157-158

105) Mirð̌ev, IstoriČeska gramatika, S. 265

106) Birnbaum, Balkanslavisch, S. 36-37

107) Sedlkxek, S. 387

108) H. Birnbaum, Zum periphrastischen Futurum im Gotischen und Altkirchenslavischen, in: BSI 18, 1957, s. $77 \mathrm{ff}$.

109) Vaillant, Vieux bulgare et roman, BL 14, S. 8

110) Gerov, B., Latinsko-grbcki leksikalni vzaimootnošenija v nadpisite ot balkanskite zem1, in: GSU, 43, 1947, S. 114

111) Gslsbov, Ksm vrprosa za Xlena, S. 358

112 Georgiev, Opit za periodizacija, s. 86

113 Kurz, Problematika 18sledovanija, S. 12

114 ) Broendal, S. 204

115) Bally, Ch. und Sechehaye, A., Antworten auf: Quelles sont les méthodes les mieux appropríes à un exposé complet et pratique de la grammaire d'une langue 
quelconque? in: Actes du 1-er Congrès International des linguistes à la Haye 1928, Leiden 1930, S. 45

116) Georgiev, Opit za periodizacija, S. 89

117) vgl. Kurz, Problematika issledovanija, S. 13

118) a.a.0., S. 12

119) Georgiev, Opit za periodizacija, S. 96-97

120) Bernstejn, K voprosu o periodizacii, S. 116

121) Slawski, Zarys dialektologii, S. 135

122) Stojkov, S. 51-52

123) ebda.

124) Mladenov, S. 214-216

125) MiletiC, Edinstvo na bslgarski ezik, S. 6

126) Duridanov, Ksm problemata za razvoja, S. 255-256

127) Meillet, Le slave commun, S. 2

128) siehe im Text S. 4-5

129) Mirtev, Koga voznikva Clennata forma, S. 45

130) ebda.

131) A. Schaff, Einführung in die Semantik, Berlin 1966, S. 271

132) ebda.

$133)$ a.a.0., S. 272

$134)$ de Saussure, S. $177 \mathrm{ff}$.

135) ebda., Meier, in: Zeichen und System der Sprache, 2. Bd., Berlin 1962, S. 257

136) Koschmieder, S. 20

137) Kurylowicz, On the methods, S. 16

138) Chodova, s. 21-22

139) Kurylovicz, Inflectional categories, S. 245

140) Kurz, K otázce Xlenu BSI 7, S. 244-246

141) Schaff, Einführung in die Semantik, S. 272

142) Kamlah-Lorenzen, S. 32-33

143) Wackernagel, II, S. 84, Jakubinskij, S. 195

144) Kamlah-Lorenzen, S. 33-34

145) Jakubinskij, S. 195

146) siehe Reichenkron, Anfänge einer Artikelausbildung, S. 343

147) siehe a.a.0., S. 342 , mit weiteren Beispielen

148) Kamlah-Lorenzen, S. 34

149) Reichenkron, Anfänge einer Artikelausbildung, S. 338-339

150) Kurz, K otf́zce Clenu BSI 7, S. 246-249

151) Hansen, S. 12

152) Svane, Cergedskie teksty, S. 238

153 Guillaume, S. $305 \mathrm{ff}$.

154) siehe Koschmieder, S. 199

155) siehe Diaconescu, Un mod de descriere, S. 169

156) Brugmann, Die Demonstrativpronomina, S. 13, Kurz, Problema

157) Schwyzer, S. 150

158) a.a.0., S. is7, S. 162

159) Seidel, Zu den Funktionen, S. 80

160) Schwyzer, S. 159

161) Koschmieder, S. 199-204

162) Reiter, Der Artikel, S. 111-112 
163) Reichenkron, Anfänge einer Artikelausbildung, S. 345

164 Gblsbov, Problemst za Zlena, S. 51

165 Belic, Dijalekti Srbije, S. 447-453

166) siehe vidoevski, Osnovni dijalektni grupi, s.22, Isogl. 16, Lamouche, S. 48, Vidoevski, Makedonskite di jalekti, S. 89, Isogl. 9 und 10, Karte I

167) Stojkov, S. Ill, Vaillant, Grammaire comparée 2, S. 401

168) Stojkov, S. 82

169) Lamouche, S. 44

170) ebda.

171) Vidoevski, Osnovni dijalektni grupi, S. 24, Isogl. 16, Karte II, SXawski, Zarys dialektologii, S. 122-123, S. 129

172) Mazon, Documents, S. 73-74

173) Stojkov, S. 87, S. 89, Stawski, Zarys dialektologii, S. 143, Miletiz, Rhodopemundarten, S. 215

174 ) Koneski, Trojniot tlen, S. 26

175 Svane, Cergedskie teksty, S. 236

176) Gblsbov, Problemst za VIena, S. 112-113

177) si ehe BDA I, Nr. I und $\mathrm{Nr}$. 152, BDA II, Nr. I und $\mathrm{Nr} .169$

178) Skok, 0 bugarskom jeziku, S. 117-118

179) Stojkov, S. 111

$180)$ Belic, Dijalekti Srbije, S. 444

181) Skok, 0 bugarskom jeziku, S. 117-118

182) Vidoevski, Makodonskite dijalekti, S. 89-90, Isogl. 14, Mazon-Vaillant, I'évangéliaire, S. 129, Oblak, S. 96

183) Miletic, Rhodopemundarten, S. 56-58, Lamouche, S. 49-50

184 ) siehe Jakubinskij, S. $189 \mathrm{ff}$, anders Netteberg, S. $187 f$.

185) Jakubinskij, S. 194

186) Vaillant, Grammaire comparée 2, S. 379, vgl. Lamouche, S. 57

187) Kurylowicz, Inflectional categories, S. 148

188) a.8.0., S. 149

189) a.a.0., S. 148

190) a.a.0., S. 148

$191)$ Jakubinskij, S. 194

192 Netteberg, S. 180

193) VelCeva-Bojadそieva, S. 136-137

194 ) Netteberg, S. 197, vgl. Lamouche, S. 44

195 ) siehe Jakubinskij, S. 194

196) KuryXowicz, Inflectional categories, S. 148-149

197) vgl. dazu Mazon-Vaillant, L'évangéliaire, S. 129

198) BDA I, Nr. I69-170, Kurz, K otkzce XIenu BSI 7, S. 259, Lavrov, Obzor, S. 185, Mazon-Vaillant, L'évangéliaire, S. 129

199) Belić, Galitki dijalekat, S. 193

200) Jensen, M.H. Die Entwicklung des sprachlichen Ausdrucks für Raumverhältnisse, in: Actes du l-er Congrès International des linguistes à la Haye 1928, Leiden 1930, S. 179, Koneski, Is torija, S. 129-130, Skok, 0 bugarskom jeziku, S. 119, Gslsbov, Kbm vbprosa za Clena, S. 365 
201) Belic, Dijalekti Srbije, S. 444

202) Kabasanov, S. 49, Ilic, S. 151-152, Netteberg, S. 199, Belic, Dijalekti Srbije, S. 444

Ausnahmen siehe Miletic, Rhodopemundarten, S. 130-131, Lamouche, S. 59

203) Mazon-Vaillant, L'évangéliaire, S. 129

204 siehe Unbegaun, B.0., Des Alter von russisch étot, in: ZfsIPh 23, 1954 , S. 322-325

205) VelXeva-BojadXieva, S. 131

206) Mazon, Documents, S. 66

207) Miletic, Sedmogradskite bslgari, S. 43

208) Mazon-Vaillant, I'évangéliaire, S. 129,

Mazon, Documents, S. 66

209) Vidoevski, Makedonskite dijalekti, S. 95, Isogl. 82-83, Karte III

210) BDA I, Nr. 169, BDA II, Nr. 184

211) Mazon-Vailiant, I'évangéliaire, S. 129,

Mazon, Documents, S. 66

212 ) Svane, K voprosu o proischoždenii, S. 157-158, Cergedskie teksty, S. 235-236, S. 250, Duridanov, Kom problemata za razvoja, S. 104, Bernitejn, $\mathrm{K}$ voprosu o periodizacii, S. 115

213 ) Bernstejn, Razyskanija, S. 291, Anm. 2

214) Grlsbov, Problembt za k̇lena, S. 64

215) a.a.0., S. 80-81, S. 93, Miletix, Kbm istorijata na trojnija clen, s. 2

216) ebde.

217) Skok, o bugarskom jeziku, S. 119

218) Piotrovakij, Pormirovanie artiklja, s. 25

219) a.8.0., S. 8, Väänänen, S. 128

220) Väänänen, S. 129, Piotrovskij, Pormirovanie artiklja, S. $36 \mathrm{Anm}$. $17 \mathrm{mit}$ Iiteraturangaben, vgl. auch Meader, C.I., The latin pronouns is:hic:iste:ipse:ilie, New York, ig02, E. Löfetedt, Syntactica

221) Piotrovekij, Formirovanie artiklja, S. 8

222 vgl. BDA I Nr. 162, BDA II Nr. 177, Vidoevski, Makedonskite dijalekti, S. 92-93, Isogl. 5I, Karte II, S. 96, IsogI. 85, Karte III, Osnovni dijalektni grupi, S. 22, Isogl. 17, Karte II, S. 24

223) Belie, Dijalekti Srbije, S. 406, 419-423, 447-453

$224)$ Jakubinskij, S. 204

225) Mazon-Vailiant, L'évangéliaire, S. 128, S. 142-144

226) Jakubinskij, S. 204

227) Kurz, K otkzce doby vaniku, S. 212

228) Kurz, K otkzce nominativu, S. 47, S. 49

229) a.a.0., S. 53-54 mit Belegen

230) Vaillant, Grammaire comparée 2, S. 433-434

231) Netteber8, S. 180

232) Kurz, K otazce nominativu, S. 53-54

233) Kurz, Problema Elena, S. I81, K otkzce nominativu, S. 54

234) Barnstejn, Razyskanija, s. 337-338

235) Netteberg, S. 198

236) Ilie, S. 150 
237) Belic, Dijalekti Srbije, S. 444-445

238 Baric, Istorija, S. 25

239) vgl. G. Meyer, Albanesische Studien II, 1884, S. 79, K. Brugmann, GrundriB I, S. 94 , Die Demonstrativpronomina, S. 51, S. 83, Camaj, S. 129f., S. 132-134

240) Piotrovakij, Pormirovanie artikl ja, S. 103

241) Skok, Considérations générales, S. 173

242) Barić, Istorija, S. 25, so auch Georgiev, Le problère, S. 18

243) Baric, Istorija, S. 25-28

244 Brugmann, Die Demonstrativpronomina, S. 45, dazu auch Georgiev, Le problème, $S$. 17-18

245) Giese, S. 44, Tumjanan, Artikli v sovremennom armjar.skom jazyke, Erivan 1963

246) so Camaj, S. 103, anders Pekmezi, S. 145

247) siehe Barić, Istorija, S. 11

248) vgl. Skok, Considérations générales, S. 173-174

249) a.8.0., S. 175

250) Barik, Istorija, S. 25

25I) G. Weigand, im 17.-18. Jahresbericht des Instituts für rumänische Sprache (Rumänisches Seminar) zu Leipzig, S. 192

252) C. Tagliavini, L'albanese di Dalmazia, Firenze 193? XV, S. 35

253) Barik, Istorija, S. 25

254 N. Jokl, Zur Geschichte des alb. Diphthongs -ua-, -ue-, In: IP 50 (1932), S. $42 f f$.

255) vgl. Popovic, S. 75-77 mit literaturhinweisen

256) Miletid, Die Rhodopemundarten, S. 3-4

257) Poporic, S. $258 f$.

258) vgl. ähnlich bei Gblsbov, Problembt za člena, S. 112-113

259) Miletic, Die Rhodopemundarten, S. 45-46

260) Miletit, Clenst $v$ bslgarski i ruski ezik, S. 10

261 a.a.0., S. 30

262) Gslsbov, Problemst za člena, S. 109, Mladenov in: SBNU 18, 1901,

263) vgl. Svane, K' voprosu o proischoždenil, S. 153

Gslsbov, Problemst za Clena, S. 108

264) Mazon-Vaillant, L'évangéliaire, S. 117

265) a.a.0., S. 117, S. 172

266) a.a.0.S. S 5

267) Svane, ' Cergedskie teksty, S. 237

268) Mirtev, IstoriCeska gramatika, S. 178, so auch Gblsoov, Problemst za Clena, S. 53, SXawski, Miejace enklityisi, S. 8lff., Miletit, Clenst v bslgarski i ruski ezik

269) Jakubinskif, S. 195

270) Kurz, Problema Xlena, S. 169-170

271) a.8.0., S. 169 Anm. 2

272) Radorevie, S. 150

273) Mazon, DocumentB, S. 73

274) Berneksr, Die Wortfolge, S. 147, Svane, K voprosu o proischozdeni1, S. 156 . 
275) Reichenkron, Anfänge einer Artikelausbildung, S. 344

276) ebda.

277) a.a.0., S. 347 Anm. 10

278) Väänänen, S. 130

279) Vondrak, S. 356-357

280) J. Jedvaj, Bednjansk1 govor, in: Hrvatski dijalektološk1 zbornik, knj. 1, Zagreb 1956, s. 323, N. Majnarlk, Jedno rovtarsko narjecjje u Gorskom Kotaru, in: JP 17, 1938-39

281) Reichenkron, Anfânge einer Artikelausbildung

282) Jakubinskij, S. 195

283) J. Wackernagel, Uber ein Gesetz der indogermanischen Wortstellung, IF 1,1892, E. Nilsson, Mackernagel's Gesetz im Slavischen, in: KZ 37, 1904

284 ) Berneker, Die Wortfolge, S. 60, Jakobson, Les enclitiques slaves, S. 384-385

285) a.a.0., S. 384

286) Stawski, Miejoce enklityki, S. 81

287) a.a.0., s. 79

288) a.a.0., S. 70

289) Reiter, Zur Stellung der Enklitika, S. 378

290) Gslsbov, Zur Prage der bulgariachen Enklitika

291) Slawsk1, Mie jace enklityki, S. 87

292) Kurz, Problematika issledovanija, S. 12, Gblbbov, Kbm vъprosa za Clena, S. 358, vgl. Broendal, S. 204

293) Grlsbov, Problembt za Clena, S. 97, 8 gl. S. 92, S. 98

294) Miletid, $\mathrm{K}_{b m}$ istorijata na trojnija Xlen, S. 8

295) Miletic, Clenst $v$ bølgarski i ruski ezlk, S. 12

296) Slawski, Miejsce enklityki, S. 86f.

297) Svane, K voprosu o proischozdeni1, S. 154

298) Kurz, Problema Clena, S. 181

299) Wackernagel, II, S. 147-148

300) Schwyzer, S. 158

301 S.K. Saumjan, Strukturnaja lingvistika, Moskva 1965 (AN SSSR), S. $11-12$

302) siehe Kurz, K otłzce členu BSI 8, S. 262

303) Mircev, Koga vbznikva Clennata forma, S. 48

304 ) Mir Xev, Istorileska gramatika, S. 180-181, Lavrov, S. 186 Anm.

305) Kurz, Problema Elena, S. 181

306) vgl. Kurz, Problematika is8ledovanija, S. 10, Vyznam s tudia jazyka staroslovénského, S. 241-242, Trifonov, S. 18

307) Muller, S. 6-7, S. 19,21 , S. $26 \mathrm{ff}$.

308) T. Maretic, Gramatika hrvatskoga ill sppokoga knjlževnog jezlka, 3. Aufl., Zagreb 1963, S. 506, Kurz, K otkzce Xlenu BSI 7, S. 219-220

309) Radorevic, S. 145-146

$310)$ Muller, S. 13

311 Kurz, Problema člena

312) Kurz, Problema Clena, S. 152

313 Radosević, S. 148-149

314 Trifonov, S. 21 
315) Kurz, Problema člena, S. 177-178, vgl. K otáce členu BS1 7, S. 267

316) Mirtev, Za chronologijata, S. 292-293

317) Svane, Dobrejłovo evangelie

318) a.a.0., S. 229-230

319) Kurz, Problema Clena, S. 168, vgl. zu diesem Abschnitt Kurz, K otázce Elenu und Problema Elena

320) Kurz, Problema Xiena, S. 172

321) a.a.0., S. 173-174

322) a.a.0., S. 172-173

323) a.a.0., S. 175

$324)$ a.a.0., S. 168

325 a.a.0., S. 179

326) a.a.0., S. 171

327) a.a.0., S. 179

328) a.a.0., S. 174 , S. 179

329) Marguliés, S. 122-123

330) Kurz, Problema Clena, S. 174

331) vgl. Doroszewski, Neskol'ko slov o ponjatil 'sistemy' $\checkmark$ jazyke, S. 126-127

332) Vaillant, Grammaire comparée 2, S. 432

333 Seidel, Elemente sintactice, S. 22 Anm. 1

334 ) Georgiev, Opit za periodizacija, S. 83 Anm. 1

335 Piotrovskij, Pormirovanie artiklja, S. 142

336 Svane, K voprosu o proischozdeni1, S. 160-161

337 Coteanu, Despre poziţia articolului, S. 70

338) Gslsbov, Problemst za Clena, S. 115

339) siehe A.B. Desnickaja, Dva tipa prilagatel'nych v sovremennom albanskom jazyke, in: Voprosy grammatiki, Sbornik statej k 75-letiju ak. I.I. Mercaninova, Moskra-Leningrad 1960

340) Graur, Autour de l'article postposé, S. 207, Seidel, $2 u$ den Punktionen, S. 15, S. 51

341) Civ'jan, S. 176

342) Piotrovakij, Pormirovanie artiklja, S. 63, S. 85-86, S. $56-58$

343) a.a.0., S. 64

344) Gamilischeg, Zum romanischen Artikel, S. 16

345) Pugcariu, Zur Nachstellung, S. 262-265, Gamillscheg, Zum romanischen Artikel und Possessivpronomen, vgl. Reichenkron, Die Bedeutung des Griechischen für die Entstehung des balkanischen Typus, in: Beiträge zur SüdosteuropaPorschung, München 1966, S. 10-11

346) Giese, S. 42

347 Coteanu, Despre poziţia articolului, S. 64-65

348 Piotrovikij, Pormirovanie artiklja, S. 110-118

349 Tanase, S. 37

350) Coteanu, Despre pozitia articolului, S. 65-70

351) Graur, Questions latino-roumaines, Notes sur l'article postposé en roumain, Autour de l'article postposé

352) Pugcariu, Zur Nachstellung, S. 246 
353) Gblbbov, Problemst za člena, S. 116

354 a.a.0., S. 123

355) Stölting, Das Artikelsystem im Albanischen und Rumänischen

356) z.B. Hą̧deu, S. 428 , S. 435 , Çabe j, S. $513 \mathrm{ff.,}$ Rosett1, Istoria II, S. 92-93

357) Graur, Questions latino-roumaines, S. 478-479

358) a.a.0., S. 478

359) a.a.0., s. 477

360) a.a.0., s. 479

361) Graur, Notes sur l'article postposé, S. 234

362) Graur, Questions latino-roumaines, S. 478

363) ebda.

364) vgl. zur Lautentwicklung Pugcariu, Zur Nachstellung, S. 248 , S. 252

365) vgl. Al. Rosett1 + Al. Graur, Sur le traitement du lat. 1 double en roumain, in: $B L$ IV, 1936 , S. 43

366) Puscariu, Zur Nachstellung, S. 246 Anm. 3

367) Schürr, S. 135, Piotrovskij, Pormirovanie artikl ja, S. 61-62, Gamilischeg, Zum romanischen Artikel, S. 21

368) N. Dräganu, Rezengion von A. Graur, Autour de i'article postpose, in: DR 9, 1938, S. 277

369) Puscariu, Zur Nachstellung, S. 246 Anm. 3

370) Piotrovskij, Pormirovanie artiklja, S. 60-61

371) Puģcariu, Zur Nachstellung, S. 247

372) Piotrovakij, Pormirovanie artikl ja, s. 60

373) Vgl. Puşcariu, Der lu-Genttiv; Procopovic1, S. 322, S. 339

374 ) Coteanu, Despre pozifia articolului, S. 58, mit Iiteraturhinweisen

375) N. Jokl, IP 50 , S. 47

376) Tiktin, S. 144

377) Pedersen, s. 310-311

378) Pugcariu, Zur Nachstellung, S. 267

379) Rosett1, Istoria VI, S. 278

380) Procopovic1, S. 328

381 Pugcariu, Zur Nachstellung, S. 248, S. 252

382 Gäzdaru, S. 161f.

383) Camaj, S. 130-131

384 ) Procopovic1, S. 327 .

385) a.a.0., s. 335

386) Michov, S. 13

387) Tagliavin1, Rumänische Konversationggrammatik, Heidelberg 1938, S. 367

388) Cabej, S. 533

389) a.a.0., S. 547

390) a.a.0., s. 546

391) Piotrovekij, Pormirovanie artiklja, S. 132

392) siehe auch Capidan, DR 1, S. 551-552

393 vgl. Verfasser, S. $72 f f$.

$394)$ Çabej, S. 550

395 Rosett1, Istoria IV, S. 42

396) Pekme21, S. 117 
397) Haşdeu, S. 430

398) Seidel, Zu den Funktionen, S. 12

399) Civ'jan, S. 173

400) Diaconescu, Un mod de descriere, S. 167

401) Capidan, Meglenoromani1 I, S. 150

402) Rosett1, Istoria VI, S. 280-281

403) ebda.

404) vgl. Verfasser, S. 64

405) siehe Çabej, S. 539, S. 544

406) $\nabla$ gl. Seidel, Zur Rolle des Bulgarischen, S. 910

407) Coteanu, Despre pozifia articolului, S. 69, vgl. Graur, Questions latino-roumaines, S. 479, Budagov, S. 82-83

408) Plotrovskij, Formirovanie artiklja, S. 121-122

409) Çabej, Unele probleme

410 Coteanu, Despre pozifia articolului, S. 68

411) Gamillscheg, Zum romanischen Artikel, S. 15

412) a.a.0., S. 20

413) Lerch, Besprechung von Gamillscheg, Zum romanischen Artikel, in ZfrPh 60, 1940 , S. 190

414) Giese, S. 45

415) Piotrovikif, Formirovanie artiklja, S. 27, S. 118-119

416) Coteanu, Despre pozifia articolului, S. 64

417) Hansen, S. 152-155

418) Hasdeu, S. 427, Diaconescu, Un mod de descriere, S. 167, Coteanu, Despre pozifia articolului, S. 67-68

419) Tiktin, S. 125

420) Gäzdaru, S. 119, Puģcariu, Zur Nachstellung, S. 247, vgl. Schürr, S. 137

421) siehe Verfasser, S. 67, Rosett1, Istoria I, S. 120

422) Pugcariu, Zur Nachsteliung, S. 254, vgl. Gamillscheg, Zum romanischen Artikel, S. 22

423) so Găzdaru, S. 136-137

424 Çabe J, S. 540

425 siehe Civijan, S. 140-141

426) Coteanu, Despre pozifia articolului, S. 67-69

427 Densusianu, II, S. 113

428) Drăganu, Besprechung von A. Graur, Autour de l'article postposé, in: DR 9, 1938, S. 311

429) Pugcariu, Der lu-Genitiv, S. 80

430) Gäzdaru, S. 110-117

431) Graur, Autour de l'article postposé, S. 214

432 ) Plotrovikif, 0 oravnitel'noj chronologil, s. 9

433 Coteanu, Despre pozitia articolului, S. 57 und Anm. 5

434) Gblbbov, Problembt za Clena, S. 134

435) a.8.0., S. 117

436) vgl. Budagov, S. 32

437) vgl. Găzdaru, S. 113-117, C. Lacia, Genitive Peminine formate cu articolul prepozitiv, in: DR 3, Pugcariu, Zur Nachs tellung

438) Coteanu, Despre pozifia articolului, S. 59-60

439) ebda.

440) Weigand, S. 26 
441) Popovici, I, S. 64

442) Capidan, Meglenoromanii I, S. 145-149, Weigand, S. 25

Civ'jan, S. 126, Coteanu, Schitã a declinăril, S. 428

443) Capidan, Meglenoromanii I, S. 145, Civ' jan, S. 130

444 ) Grlbbov, Problembt za ellena, S. 130, S. 133 Anm. 4

445) Vasiliu, S. 139

446) Coteanu, Schif̧a a declinării, S. 414

447) Coteanu, Despre pozitia articolului, S. 59, Drăganu, S. 308

448) Coteanu, Despre poziţia articolului, S. 58

449) Pugcariu, Zur Nachstellung, S. 249, S. 250 Anm. 2

$450)$ a.a.o., S. 272

$451)$ a.a.0., S. 249 , S. 250 Anm. 2

452) vgl. Gäzdaru, S. 55-57, Coteanu, Despre pozitia articolului, S. 58

453) Gamillscheg, Zum romanischen Artikel, S. 23 Anm. 1, Meyer-Lübke, Rumänisch und Romanisch, S. 9-10

454) Densusianu, II, S. 111-113, gegen Coteanu, Schitã a declinäri1, S. 453

455) Densusianu, II, S. 113

456) Pugcariu, Zur Nachstellung, S. 249

457) Coteanu, Despre pozitia articolului, S. 70

458) Popovici, II, S. 23, S. 32, Gblbbov, Problembt za člena, S. 134

459) Piotrovakij, Pormirovanie artiklja, S. 121

$460)$ Seidel, Zu den Funktionen, S. 34

461) Coteanu, Despre pozitia articolului, S. 61-62

462) Brugmann, Die Demonstrativpronomina, S. 32

$463)$ a.a.0., S. 37, H. Krahe, Indogermanische Sprachwissenschaft, II Formenlehre, Berlin 1959 (Sammlung Göschen), S. 45

464) Georgiev, Le problème, S. 18 Anm. 2

$465) 0$. Grünenthal, Die Ubersetzungstechnik der al tkirchenslavischen Evangelienübersetzung, in: Afsi Ph 31, 1910,

466) Hans Reichelt, Awestisches Elementarbuch ${ }^{2}$, Darmstadt
Hans 1967 (Indogermanische Bibliothek. Erste Abteilung, erste Reihe, fünter Band), S. 371

467) ISandfeld, S. 134

468) Svane, K voprosu o proischoždenii, S. 165

469) so bei Ilić, S. 150 , Miletix, Prilagatelni členni formi, S. 3, Georgiev, Le problème, S. 17

470) Svane, K voprosu o proischożdenif, S. 162

471) Skok, 0 bugarekom jeziku, S. 130-131, siehe Pisani, S. 106, Georgiev, Le problème, S. 18, S. 20-21, gegen Rosetti, Istoria II, S. 96-97

472) Jakubinskij, S. 196-197

473) J. Rozwadowski Przyczynki do historycznej fonetyki języków slowianskich, in: RSI 7, Kraków 1914-15, S. 14-18

474) Gslbbov, Problembt.za Clena, S. 65 Anm. 2

475) Skok, 0 bugarskom jeziku, S. 117 
476) Vondrak, S. 356, Jagic, Afsl Ph 20, S. 604-605, gegen Miletix, Gblbbov, mit Reserve Mirtev, Koga vbznikva..., S. 47

477) Kurz, Problema člena, S. 181-182

$478)$ Svane, Dobrej8ovo evangelie, S. 234

479) vgl. Mircev, Za Elennite formi, S. 224

480 gegen Gblsbov, Problemst za Clena, S. 79

481) Wissemann, Die Syntax der nominalen Determination, Racovifă, Koduchov, Kurz, K otáce Klenu BSI 7, S. 222, Chalanskij, Iz zametok po istorii russkago literaturnago jazyka, II. O Clene $v$ russkom jazyke, in: Izv. otdel. russk. jaz. i slov. Imp. Akad. Nauk, 1901, VI, 3 , s. $127-169$

482) A. Stender-Petersen, Kritičeskie zametki po teorii o suffigirovannom tlene $v$ russkom jazyke, in: In memoriam $\mathrm{Kr}$. Sandfeld, Kobenhavn 1943 (in dänischer Sprache)

483) Jakubinskij, s. 194-197

484) Piotrovskij, Formirovanie artikl ja, S. 106 Anm. 11

485) Selizとev, KritiCeskie zametki po istoril russkogo jazyka, in: UCenye zapiski MGPI, 5, Moskva 1941, S. 185

486) Bernstejn, Razyskanija, S. 291 Anm. I

487) Jakubinskij, S. 197

488 Gslsbov, Problembt za člena, S. 68-69

489 Mir Xev, $2 a$ Xlennite formi, S. $233 \mathrm{ff}$., Svane, Dobrejŏovo evangelie, S. 227-228, Gblsbov, Problemst za Clena, S. 66, Miletix, Prilagatelni Cienni formi, s. 6

490) Mirtev, Za Xlennite formi, S. 224

491 Kurz, Problema Klena, S. 176

$492)$ vgl. Gslsbov, Problemst za Clena, S. 105

493 a.a.0., S. 100

494 vgl. a.a.0., s. 73

495 S tojkov, S. 123

$496)$ a.a.0., S. 104

497 a.a.0., s. 105

498 vgl. a.a.0., S. 140

499) Koneski, Istorija, S. 130

500) a.a.0., S. 129

501) Belic, Dijalekte Srbije, S. 447

502) a.a.0., S. 78-81

503) Mir Zev, IstoriČeska gramatika, S. 103

504) a.a.0., S. 113

505) vgl.a.a.0., S. 112, Stojkov, S. 123

506) Miletix, Das 0stbulgarische, S. 71

507) Bernðtejn, Razyskanija, S. 144-147

508) vgl. Stojkov, S. 95

509) Slawski, Zarys dialektologi1, S. 128-129

510) Koneski, Istorija, S. 31

5II Mirłev, Is toriXeska gramatika, S. 122, Bernštejn, Razyskanija, S. 148

512) vgl. Gblsbov, Problemst za člena, S. 65 Anm. 2

513) Berņtejn-Cesko, Opyt klassifikacii, S. 329, 333, 338, S. 341 
514) Stojkov, S. 141

$515)$ Belić, Dijalekti Srbije, S. 444

$516)$ Miletic, Sedmogradskite Bbigari, S. 19, Gblbbov, Problemst za Clena, S. 55

517) Mirtev, Istoriłeska gramatika, S. 159

$518)$ a.a.0., s. 159-160, Bernłtejn, Razyskanija, s. 355

519) vgl. Vondrák, S. 32l, Mirtev, Istoriłeska gramatika, S. 160, Koneski, Istorija, S. 120, Gblbbov, Problembt za Xlena, s. 59-61

520) a.a.0., S. 67

521) Miletix, Die Rhodopemundarten, S. 50

522) Mazon-Vaillant, L'évangéliaire, S. 107

523) Gslbbov, Problembt za Clena, S. 62, S. 67

524) Mazon-Vaillant, L'évangéliaire, S. 107

525) vgl. a.a.0., Anm. I

526) vgl. Mirtev, Koga vaznikva člennata forma, S. 49

527) Svane, Dobre jłovo evangelie, S. 228-229

528) Koneski, Istorija, S. 129

529) Mir Xev, IstoriCeska gramatika, S. 181

530 ) vgl. a.a.0., S. 149 , Koneski, Istorija, S. 116

531 vgl. Svane, Cergedskie teksty, S. 243

532) Belegstellen bei Diels, I, S. 207, S. 209, Vaillant, Manuel du Vieux Slave, 1964, I, S. 140

533) Jakubinskij, S. 194-195

$534)$ a.a.0., S. 195

535) Biletič, Edinstvo na bslgarskija ezik, S. 17

536) Lamouche, S. 49

537) Mirtev, IstoriCeska gramatika, S. 164

538) Belić, Dijalekti Srbije, S. 420

539) Miletix, Dako-rombnite SbNU 13, S. 112

540) Lamouche, S. 50-51

541) Mazon-Vaillant, L'évangéliaire, S. 130-131, mit Anmerkungen

542) St. Stojanov, Clenuvane na imenata v bblgarskija ezik, Sofija 1965, S. 13

543) Gblsbov, Problembt za člena, S. 54, vgl. St. Stojkov, Clenuvane na imenata ot mbzki rod, edinstveno Zislo, $v$ bblgarskija knižoven ezik, in: GSU 46, 1949-50, kn. 4

$544)$ vgl. hierzu Miletic, Das Ostbulgarische, S. I01, Dako-rombnite SbNU 13, S. 109, 115-117, 132-133, Ivanov, G., S. 34-35, Bernstejn, Razyskanija, S. 288-291, S. 365, Koneski, Istorija, S. 135-136, Georgiev, Preosmisl jane

545) Meillet, Recherches sur l'emploi du génitif-accusatif en vieux slave, Paris 1897, Le Slave commun, S. 407

546) Berneker, Der genitiv-accusativ

547) nach Vondrák, S. 253

548) A. Thomsen, Beiträge zur Kasuslehre, in: IF 24, S. 305

549) vgl. Vaillant, Grammaire comparée l, S. 11

550) Meillet, Le slave commun, S. 463

551) Koneski, Istorija, S. 135

$552)$ ebda.

553 0. Broch, Die Dialekte des südlichen Serbiens (Südslavische Dialektstudien III. Schriften der Balkancommission, 
Linguistische Abteilung 1.3) Wien 1903, S. 294

554) Mazon-Vaillant, L'évangéliaire, S. 102-103

555 Koneski, Istorija, S. 136, Miletid, Die Rhodopemundarten, S. 5l, Staroto sklonenie, S. 248-249

556) Ivanov, G., S. 150

557) Bern§tejn, Razyskan1ja, S. 291

558) a.a.0., S. 289

559) Conev, Istorija 2, S. 473-474

560) Stojkov, S. 62 , S. 138

561) Koneski, Istorija, S. 114-115

562) Belic, Galitki dijalekat, S. 65, S. 166, Ilić, S. 157

563) Bernztejn, Razyskanija, S. 290, S. 365

564) a.a.0., S. 289

565) a.a.0., S. 290

566 Miletix, Das Ostbulgarische, S. 101

567) ebda.

568) Kabasanov, S. 50

569) Stojkov, S. 70

570) a.a.0., S. 138, Koneski, Istorija, S. 115

571) Gslsbov, Problemst za Clena, S. 54, S. 63

572) Seidel, Zur Rolle des Bulgarischen, S. 913

573) a.a.0., S. 915

574 Densusianu, Histoire de la langue roumaine I, S. 393-394

575 Piotrovskij, 0 sravnitel'noj chronologii

576) Skok, 0 bugarskom jeziku, S. 116

577) a.a.0., S. 115

578) Piotrovskij, Formirovanie artiklja, S. 87, 94, 95, Tackernagel, II, S. 150

579) Piotrovskij, 0 sravnitel'noj chronologii, S. 10

580 a.8.0., S. 15

58I Miř̌ev, Istoričeska gramatika, S. 178-179, Sandfeld, S. 170

582) Ilic, S. 145-146

583 Svane, $\mathrm{K}$ voprosu o proischoždenil, S. 153

584 Grlsbov, Problemst za Kiena, S. 72-73

585) Zlatarski, Istorija na bslgarskata dsržava prez srednite vekove I, 2, Sof 1 ja 1927 , S. 780

586) M. Vasmer, Zur Ortsnamenkunde der Balkanländer, in: ZfslPh 18, 1942, S. 384-385

587) T. Pape, Wörterbuch der griechischen Eigennamen, 3. Aufl., Braunschweig 1884 , S. 230

588) Grlsbov, Problemst za člena, S. 72-73

589) Mirtev, Istoriteska gramatika, S. 178-179, S. 182

590) Trifonov, S. 22

591 Svane, $\mathbb{K}$ voprosu o proischoždenii, S. 157

592) Koneski, Istorija, S. 129

593) Svane, Cergedskie teksty, S. 233-234

594 ) Mirtev, Is torileska gramatika, S. 182, Za člennite formi, S. 223-228, Koga vbznikva elennata forma, S. 45-50

595) Gslsbov, Problemst za Clena, S. 76

596) Mirtev, IstoriCeska gramatika, S. 181-182

597) vgl. Trifonov, Kam istorijata na Xlennite formi 
598) vgl. Svane, Dobrejšovo evangelie, S. 237

599) vgl. Mirtev, Za Clennite formi

600) vgl. Mirtev, IstoriCeska gramatika, S. 183, Koga vbznikva Clennata forma, S. 50

601) Vgl. Miræev, Istoriteska gramatika, S. $183 f$.

602) Trifonov, S. 7-16

603) Löfstedt, 1,1942

604 ) Racovifā, S. 130

605) Seidel, Zu den Funktionen, S. $5 f f$., Der gegenwärtige Stand der rumänischen und allgemeinen Artikel probleme, in: BL 9, 1941

606) Civ'jan, S. 60

607) Miletic, 0 Clanu, S. 4-5, vgl. Kurz, K otázce členu BS1 7, S. 215

608) Coteanu, Contributil, S. 21

609) A. Meillet, Aperçu d'une histoire de la langue grecque, ed. IV, Paris 1935, S. 189

610) vgl. Civ'jan, S. 89

611) Miletix, Clenst $\nabla$ bolgarski 1 ruski ezik, S. 9

612) Kurz, K otazce Xlenu BSl 7, S. 251

613) nach Cir'jan, S. 88

614) Cv. Todorov, Po voprosa $z a$ sklonenieto na imenata $v$ sbvremennija bslgarski knizoven ezik, in: BE V, kn. 2, 1955

615) Dilerski, Ssztestrurat li padezi

616) G. Michajlov, Ksm viprosa za sðstestruvaneto na padežl $\nabla$ bslgarski ezik, in: BE V, kn. 4, 1955

617) E.V. Ceško, ob izu飞enil funkc11 predlogov $v$ bolgarskom jazyke, in: Kratkie soobrcenija instituta slavjanovedenija Akad. Nauk SSSR, vyp. 10, Moskva 1953,

Padezi 1 predlogi $\nabla$ oovremennom bolgarakom jazyke

618) I. Andrejxin, Kbm vbprosa za analitidnija charakter na sovremennija bslgarski ezik, in: BE II, 1952

619) Mirðev, Po viprosa za sklonenieto

620) Kurytowicz, Inflectional categories, S. 245-246, S. 32, S. 188

621) vgl. Kurglowicz, on the methods, S. 10, Inflectional categories, S. 179, Chodova, S. 23-25

622) Civ'jan, S. 165

623) a.a.0., S. 188

624) 8.8.0., S. 192

625) P. Danes, in: Zeichen und System der Sprache, II. Bd., Berlin 1962, S. 62

626) R. Rǔžizka, in: Zeichen und System der Sprache, S. 6

627) Kurytowicz, on the methods, S. 9

628) de Saussure, S. 277-278, W. Doroszewski, Le structural isme Iinguistique, S. 540

629) de Saussure, S. 277

630) Stojkov, S. 9-13

631) Miletid, Sedmogradskite bslgari

632) Stojkov, S. 12

633) Civijan, S. 157, Ivik, Die serbokroatischen Dialekte, S. 35 , Znataj lingristicke geografije, S. 185, Birn- 
baum, Balkanslavisch, S. 47

634) a.a.0., S. 50

635) Civijan, S. 63-64

636) Mazon, Documents, S. $54,60,62$

637) Koneski, Istorija, S. $114-115$, S. 131

638) Stojkov, S. 84, slawski, Zarys dialektologii, S. 143-144

639) Bernłtejn, Razyskanija, S. 225-313, Georgiev, Opit za periodizacija, S. 102-103

640) Duridanov, Ksm problemata za razvoja, S. 152

641) Miletit, Die Rhodopemundarten, S. 217-218

642) Sxawski, Zarys dialektologii, S. 143-144, Stojkov, S. 84

643) vgl. a.a.0., S. 62, 69, 70, Miletic, Die Rhodopemundarten, S. 217-218, Civ'jan, S. 42, Vidoevski, Makedonskite dijalekti, S. 91, Osnovni dijalektni grupi, S. 16, 22, 24

644 ) Duridanov, Kbm problemata za razvoja, S. $239 \mathrm{ff}$.

645) MirZev, IstoriCeska gramatika, S. 153-154, S. 262-263

646) Koneski, Istorija, S. 135

647) Duridanov, Kъm problemata za razvoja, S. 238-239

648) Mirtev, Is toriłeska gramatika, S. 245, vgl. Vondrák, S. 264 , S. 296 , K.H. Meyer, S. 52-55

649) Duridanov, Kbm problemata za razvoja, S. 218, Koneski, Is torija, S. 140, Mircev, Istoriteska gramatika, S. 253

650) Svane, $\mathrm{K}$ voprosu o proischozdeni1, S. 157-158, Cergedskie teksty, S. 235-236, S. 250

651) Miržev, Istoričeska gramatika, S. 145

652) Svane, K voprosu o proischozdenii, S. 157-158

653) Ivić, Die serbokroatischen Dialekte, S. 125

654) Kabasanov, S. 54,56

655) Duridanov, Kbm problemata za razvoja, S. 95, Mirčev, Istoriteska gramatika, S. 264

656) Duridanov, Kbm problemata za razvoja, S. 97, S. 163-165, siehe Koneski, Istorija, S. 131-133, Georgiev, Opit za periodizacija, S. 83, Vaillant, Gramalre comparee 2, S. 23, S. 50

657) Mircev, Is toričeska gramatika, S. 58, Duridanov, Kbm problemata za razvoja, S. 174-175

658) Georgiev, Opit za periodizacija, S. 84 , S. 95, Koneski, Istorija, S. 132-133

659) Bernztejn, Razyskanija, S. 357-362

660) Coteanu, Schita a declinärii, S. 445-446, Georgiev, Opit za periodizacija, S. 84

660a) Reichenkron, Zur Geschichte des auslautenden - $\underline{u}$

661) Coteanu, Schitã a declinärii, S. 446

662) Siadbei, S. 232-235

663) vgl. Verfasser, S. 5l-53

664) so Seidel, Elemente sintactice, S. 92-93, Rosetti, Influenfa limbilor slave, S. 33, Coteanu, Epocile de evolutie, S. 150-151

665) vgl. zum Genitiv-Dativ: Giese, S. 52-53, Schröpfer, S. 143, Coteanu, Schiţă a declinării, S. 448, Pisani, S. 104, Sandfeld, S. 187, Gamillscheg, Historische franzö- 
666) Giese, S. 52

667 Duridanov, Za načenkite na analitizma, S. 25, Kbm problemata za razvoja, S. 204, Mirlev, Istorileska gramatika, S. 254-255

668) Duridanov, Ksm problemata za razvoja, S. 219-220, S. 255 , Goląb, Dva makedonski govora I, S. 130

669) Mirčev, Istoriceska gramatika, S. 254-255, Duridanov, Kbm problemata za razvoja, S. 219-220

670) Koneski, Istorija, S. 139

671) MirXev, Istoriceska gramatika, S. 257, Duridanov, Ksm problemata za razvoja, S. 238

672) Mirtev, Is toriceska gramatika, S. 248, S. 259-260

673 Duridanov, Krm problemata za razvoja, $s .218$

674 ) Koneski, Istorija, S. 139, vgl. Bernitejn, Razyskanija, S. 308

675) Korubin, s. 58-59

676) Vidoevski, Osnovni dijalektni grupi, s. 23, 25, 30, Makedonskite dijalekti, S. 89-90

677 ) A.M. SelizCev, Makedonskaja dialektologija 1 serbskie lingvisty, in: MP $9, \mathrm{kn} .2, \mathrm{~S} .78$

678) Mazon-Vailiant, I'évangéliaire, S. 174-175, Belic, Galicki dijalekat, $S$. 176-177, Koneski, Za padezite, $S$. 170, Istorija, S. 139, Dimitrovski, S. 29-30, Civ'jan, S. 36, Teodorov-Balan, Bblgarsko sklonenie, in: $B E 4$, 1954 , S. 48

679) Miletic, Novi vlachobblgarski gramoti, S. 119-120, Bernztejn, Razyskanija, S. 305-309, S. 292-298

680) Duridanov, Kam problemata za razvoja, S. 218-219

681) Cerko, Padezi 1 predlogi, S. 22-23, S. 62-73

682) Georgiev, Opit za periodizacija, S. 113, Skok, 0

bugarskom jeziku, S. 133, Koneski, Istorija, S. 139,

Sedlacek, S. 394, Duridanov, Kom problemata za razvoja, S. 219-220

683) Hangen, S. 166

684 Uihăescu, S. 172, Coteanu, Schiţā a declināri1, S. 448449

685) a.8.0., S. 448-449

686) Gamilischeg, Historische französische Syntax, S. 16-19

687 Vasiliu, S. 14I, Rosetti, Istoria IV, S. 7I, VI, S. 271272, Densusianu, I, S. 120, II, S. 255-256

688) Meyer-lübke, Rumänisch und Romanisch, S. 11

689) Rosetti, Istoria VI, S. 272, Slama-Cazacu, S. 216

690) Coteanu, Schiţă a declinärii, S. 458, Popovici, I, S. 109, S. 67-68

691) Rosetti, Istoria I, S. 148

692 Capidan, Meglenorománi I, S. 149-150, S. 181

693) Coteanu, Schiţa a declinärii, S. 463-464, S. 468

694) Capidan, Meglenoromanii I, S. 149-150

695) Coteanu, Schiț a declinärii, S. 448, S. 450, Gamillscheg, Zum romanischen Artikel, S. 22 
696) Hansen, S. 13

697) siehe Densusianu, II, S. 93-94, Rosetti, Istoria VI, S. 272, Vasiliu, S. 139

698) vgl. Weinreich, S. 42, Georgiev, Opit za periodizacija, S. 95, B. Havránek, 3 medjunarodni kongres slavista 1939, Beograd, Dopune (knj. 3), S. 42

699) Kabasanov, S. 51-53, S. 54, S. 56

700) Stojkov, S. 138

701 Chodova, S. 16, mit literaturhinweisen

702) Mirtev, Istoriceska gramatika, S. 249-250, Koneski, Is tori ja, S. 135

703) Mazon, Documents, S. 54, 60,62

704 ) Ilik, S. 157-160, Trifonov, S. 23, Oblak, S. 100, Miletix, 0 rlanu, s. 9, Madenov, s. 215, Belic, Galitki di jalekat, S. 165

705) Duridanov, Kim problemata za razvoja, S. 149-153, S. 252

706) Budagov, S. 14

707 Coteanu, Contribufii, S. 29

708) vgl. Mazon, Documents, S. 57-58, Koneski, Istorija, S. 140

709) Miletič, Dako-romsnite SbNU 9, S. 306-307

710) Konstantinov, S. 141 Anm. 14

7il) Kabasanov, S. 5i-53

712) Stojkov, S. 12

713) Kabasanov, S. 62,64

714) Miletix, Sedmogradskite bslgari, S. 39, vgl. Slawski, Zarys dialektologi1, S. 143-144

715) Miletix, Edinstro na bslgarskija ezik, S. 17-20

716) Duridanov, Ksm problemata za razvoja, s. 153

717) vgl. a.a.0., S. 152

718 Miletil, 0 zlanu, S. 23

719) Vidoevski, Severnite makedonski govori, S. 170-171

720) Ilit, S. 154, Seliztev, A.M., Polog 1 ego bolgarskoe naselenie: Istoriceskie, étnografiCeskie i dialektologireskie oterki severo-zapadnoj Makedoni1, Sofija 1929,

721) Sire, S. 153-154

722) ebda.

723) Miletič, Staroto sklonenie, S. 258

724 ) Vidoevski, Severnite makedonski govori, S. 170-171

725) Belit, Dijalekti Srbije, S. 448, S. 454-455

726) Miletic, Staroto sklonenie, S. 243

727) Miletic, Die Rhodopemundarten, S. 138

728) Konstantinov, S. 141 Anm. 14

729) Mazon-Vaillant, L'évangéliaire, S. 110

730) ebda.

731) Stojkov, S. 109

732) Konstantinov, S. 141 Anm. 14

733) Ilić, S. 153-154

734 ) Miletix, o Xlanu, S. 23

735) Miletic, Sedmogradskite bslgari, S. 32

736) Civ'jan, S. 40 ff. 
737) siehe Verfasser, S. 73

738) Skok, Considérations générales, S. 170-173

739) Baric, Istorija, S. 26

740) Civ'jan, S. 173

741) Meyer-Lübke, Grammatik der Romanischen Sprachen, S. 13l132

742) Vasiliu, S. 145

743) Rosetti, Istoria VI, S. 167, S. 228

744 ) Rosett1, Istoria IV, S. 68

745) Rosetti, Istoria VI, S. 268-269

746) Rosetti, Istoria I, S. 98, S. 120

747) Vasiliu, S. 143

748) a.a.0., S. 145, Diaconescu, Aspecte ale declinärii, S. $156-157$

749) Budagov, S. 56-57

750) Vasiliu, S. 143, Popovici, I, S. 70

751) Vasiliu, S. 143-144, Budagov, S. 56-57

752) Caragiu-Marioteanu, Plexiunea, S. 238-246, vgl. Civ'jan, S. 25

753) Densusianu, II, S. 107, mit Literaturangaben

754 ) Rosetti, Istoria I, S. 116

755) Coteanu, Schiță a declinării, S. 446, Guţu-Romalo, Unele valori, S. 366-369, Articolul şi categoria determinării, S. 232-235

756) Diaconescu, Un mod de descriere, S. 175 Anm. 2

757 Coteanu, Contributil, S. 29

758 Hansen, S. 120-123

759) Vasiliu, S. 139, Slama-Cazacu, S. 220 Anm. I

760) Seidel, Elemente sintactice, S. 64 , Civ'jan, S. 130 , Slama-Cazacu, S. 216-217, S. 221, Sffrlea, S. 151, Coteanu, Schiţă a declinärii, S. 464, Sandfeld, S. 185 Anm. 2, Vasiliu, S. 138 Anm. I und 2

761) Caragiu-Mariofeanu, In legaturä cu articolul, s. 97 Anm. I

762 a.a.0., S. 95-99, Civ' jan, S. 126-127

763) a.a.0., S. 130

764) Popovici, I, S. 64

765) Capidan, Meglenorománi1 I, S. 147-148

766) Vaientini, S. 99

767) Civ'jan, S. 151

768) I. Ajeti, Istorijski razvitak gegijskog govora kod Zadra, S. 121-124

769) Sandfeld, S. 185 Anm. 2

770) R. Rohr, Zur Plexion der Substantive des Albanischen in Acquaformosa, in: Beiträge zur Südosteuropa-Porschung, München 1966, S. 90

771) Coteanu, Contributil, S. 24

772) Duridanov, Kbm problemata za razvoja, S. 153, Miletič, Clenst $\nabla$ bblgarski i ruski ezik, S. $15-16$

773) so Trifonov, S. 22

774 ) Duridanov, Kom problemata za razvoja, S. 120

775) Oblak, S. 100 
776) Kurz, K otázce členu BSl 7, S. 262 Anm. 111

777) Mazon, Documents, S. 73

778) a.a.0., S. 57

$779)$ Kabasanov, S. 57

780 Koneski, Istorija, S. 132-133, Civ'jan, S. 34

781 Jagić, Rezension von P.A. Lavrov, Obzor, S. 283-284

782) vgl. zum Folgenden: J. Kurz, K otkzce Clenu, Pr. Pastrnek, Die griechischen Artikelkonstruktionen, H. Wissemann, Zur nominalen Determination sowie die dort S. 61 Anm. 2 und S. $63 \mathrm{Anm} .8$ angeführte Iiteratur

783) J. Lob, Gramatyka staros Lowiahska, Lwow-Tarszawa-Krakbw 1922 , S. 97

784) Kurz, K otkzce doby vaniku, S. 213, S. 218-219, Anm. 18 mit weiterer Iiteratur

785) Baldauf, S. 21-31

$786)$ a.a.0., S. 79

787 a.a.0., S. 54

788 a.a.0., s. 51

789 a.a.0., S. $25-26$

790 a.a.0., s. 55

791 a.a.0., s. 25

$792)$ a.a.0., s. 22, s. 27

793) a.a.0., S. 81-82

794 a.a.0., s. 83

795 a.a.0., s. 16-21

796) Gebauer-Trkvnlðek, Historicka mluvnice jazyka českého, d11 IV, Prahe 1929, S. 231-232, S. 251f., Vondrak, S. 478

797) Meillet, Besprechung von: W. Vondrak, Altkirchenslavische Grammatik, 2. Aufl., Berlin 1912, in: RSl 6, 1913, S. 141, v. Wijk, S. 22 , Kurz, K otkzce nominativi, S. 46

798) Hermann, S. 23

799) $\nabla$. Wijk, S. 28

800) a.a.0., S. 26, 28, Vaillant, Grammaire comparée 2, S. 423, S. 425, Vondrkk, S. 85

$801)$ v. Wijk, Eine syntaktische Parallele

$802)$ ähnlich bei Vondrak, S. 477-478

803 vgl. hierzu Diels, S. 192, Tissemann, Zur nominalen Determination, S. 61

804 ) vgl. Vondrák, S. 96 Anm. 1, Pisani, S. 106, Georgiev, Le problème, $S .16$, Meillet, Le slave commun, $S .446$, Vaillant, L'article en vieux slave, S. $5 \mathrm{ff}$., Wissemann, Zur nominalen Determination, S. 6l, mit weiterer Literatur

805) Hermann, S. 23

805a vgl. Brugmann-Delbrück, GrundriB, S. 304-314

806) a.a.0., S. 309

807) Vaillant, Grammaire comparée 2, S. 430, Praenkel, S. 83, Specht, S. 269-276

808) vgl. Brugmann-Delbrück, GrundriB, S. 295, S. 311

$809)$ vgl. Benveniste, La phrase relative

810) a.a.0., s. 51 
811) Piotrovskij, Formirovanie artiklja, S. 6 Anm. 1, mit weiterer Iiteratur

812) Vaillant, Grammaire comparée 2, S. 429

813) Brugmann-Delbrück, GrundriB, S. 318

814) Valentini, S. 93

815 Benveniste, S. 48, Brugmann-Delbrück, GrundriB, S. 311

816) Benveniste, S. 50

817) Brugmann-Delbrück, GrundriB, S. 304

818) Benveniste, S. 53-54

819) I. Hjelmslev, Principes de grammaire générale, Kóbenhavn 1928, S. 7l, vgl. Kurz, K otazce doby vaniku, S. 211

819a) Schwyzer, S. 151, Benveniste, S. 48, Brugmann-Delbrück, GrundriB, S. 307-308, Specht, S. 276

820) Benveniste, S. 47-48

821) H. Reichelt, Awestisches Elementarbuch, Indogermanische Bibliothek, Erste Abteilung, erste Reihe, fünfter Band, 2. Aufl., Darmstadt 1967, S. 370

822) Georgiev, Le problème, S. 16

823) Birnbaum, Zur Aussonderung der syntaktischen Gräzismen, S. $244-245$

824 ) Marguliés, S. 125

825) Vaillant, I'article en vieux slave, S. 6-10

826) a.a.0., S. 5

$827)$ a.a.0.. S. 8-9

828) 0. Grünenthal, Die Ubersetzungstechnik der al tkirchenslavischen Evangelienübersetzung. In: AfslPh 31, 1910, S. 343

829) Specht, S. 272

830) Grünenthal (vgl. Anm. 828), S. 338

831) Reichelt (vgl. Anm. 821), S. 371

832) Duridanov, Kom problemata za razvoja, S. 112

833) Vaillant, Grammaire comparée 2, S. 526

834) Kurz, K otazce doby vaniku, S. 217-218, mit Iiteratur

835) Ws. Miller, Die Sprache der Osseten (Grundrib der iranischen Philologie I, Anhang), Strabburg 1903, S. 43

836) Reichelt (vgl. Anm. 821), S. 371

837 Rosetti, Istoria VI, S. 280

838) vgl. Meillet, Introduction à l'étude comparatif des langues indo-européennes, Paris 1924, 6. Aufl., S. 337

839) Benveniste, S. 49

840) Brugmann-Delbrück, GrundriB, S. 297-308, vgl. Specht, S. $273 f$.

841) a.a.0., S. 276

$842)$ Wissemann, Zur nominalen Determination, s. 77

843) a.a.0., S. 76-77

844) Praenkel, S. 82-83, vgl. Ergänzungs-Heft zu K2 14, 15 mit Anm. 2

845) Specht, S. 273

846) Baldauf, S. 5

847 ) Vondrak, S. 56l, Vaillant, Grammaire comparée 2, S. 496

848) Baldauf, S. 3-4 
849) Tissemann, Zur nominalen Determination, S. 77-78

850) Georgiev, Le problème, S. 18

851) Pisani, S. 106

852 Brugmann, Die Demonstrativpronomina, S. 43, Barit, Istorija, S. 25

853) Meillet, Le slave commun, S. 9-10

854 ebda.

855 Camaj, S. 138

856) Popovic, S. 82

857 G. Svane, Slovensko-arbanaške izoglose, in: Gjurmime albanologjike, 2, 1965, Prishtinë. - Weitere Literaturangaben bei Popovic, S. 84

858) Meillet, Le slave commun, S. 507, siehe RES 6, S. 165174

859) Pisani, S. 108

860 Pedersen, Albanesisch und Armenisch

861) Seliztev, S. 51

862) Barit, Istorija, S. 19-32, N. Jokl, Albanisch-iranische Berührungen, in: Wiener Zeitschrift für die Kunde des Morgenlandes, 24, 1927, S. 30-50

863) vgl. die Iiteratur bei Popovic, S. 77

$864)$ a.a.0., S. 82

865 0. Haas, Die phrygischen Denkmäler, Sofija 1966, S. 5I, S. 220

866) Georgiev, Le problème, S. 9, Schröpfer, S. 142-143

$867)$ Pisani, S. III

868) Meillet, Le slave commun, S. 9-10

869) Gamillscheg, Zum romanischen Artikel, S. 4

870) Schwyzer, S. 149

$871)$ Georgiev, Trakijskijat ezik, S. 72-74

$872)$ a.a.0., S. 82-83

873) Giese, S. 44, mit Iiteraturangaben

874 Georgiev, Trakijskijat ezik, S. 77, S. 82

875) Georgiev, On the Present State, S. 738, Trakijakijat ezik, S. 8l-83

876) siehe Popovie, S. 89, mit Iiteraturhinweisen, Vasmer, M., Untersuchungen über die ältesten Wohnsitze der Slaven. I. Die Iranier in Südrußland. (Veröffentlichung des baltischen und slavischen Instituts der Universitât Leipzig. Bd. 3), Leipzig 1923

877) Georgiev, Le problème, s. 17

878) siehe E. Lewy, Orientalistische Literaturzeitung, 25, 1922, S. 145ff., V. Bogrea, DR 2, S. 662-664 


\section{A B K U R Z U N G EN}

$\begin{array}{ll}\text { acc. } & \text { Akkusativ } \\ \text { aksl. } & \text { altkirchenslavisch } \\ \text { alb. } & \text { albanisch } \\ \text { AR } & \text { arumunisch } \\ \text { balk. } & \text { balkanisch } \\ \text { bulg. } & \text { bulgarisch } \\ \text { dat. } & \text { Dativ } \\ \text { dir. } & \text { Directus } \\ \text { DR } & \text { dakorumänisch } \\ \text { fem. } & \text { feminin } \\ \text { frz. } & \text { französisch } \\ \text { gen. } & \text { Genitiv } \\ \text { griech. } & \text { griechisch } \\ \text { HV } & \text { Halbvokal } \\ \text { idg. } & \text { indogermanisch } \\ \text { IR } & \text { istrorumänisch } \\ \text { ksl. } & \text { kirchenslavisch } \\ \text { lat. } & \text { lateinisch } \\ \text { lit. } & \text { litauisch } \\ \text { masc. } & \text { masculin } \\ \text { MR } & \text { meglenorumänisch } \\ \text { nbulg. } & \text { neubulgarisch } \\ \text { ngriech. } & \text { neugriechisch } \\ \text { nom. } & \text { Nominativ } \\ \text { obl. } & \text { Obliquus } \\ \text { ON(N) } & \text { Ortsname(n) } \\ \text { PE } & \text { paradigmatische Ebene } \\ \text { plur. } & \text { Plural } \\ \text { rum. } & \text { rumänisch } \\ \text { russ. } & \text { russisch } \\ \text { SE } & \text { syntagmatische Ebene } \\ \text { sing. } & \text { Singular } \\ \text { skr. } & \text { serbokroatisch } \\ & \end{array}$


$\begin{array}{ll}\text { slav. } & \text { slavisch } \\ \text { torlak. } & \text { torlakisch } \\ \text { v.u.z. } & \text { vor unserer Zeitrechnung }\end{array}$

Afslph Archiv für slavische Philologie, Berlin ab 1876 BDA

$B E$ Bblgarski dialekten atlas $v$ četiri toma. Hrsg. Stojkov, St. - Bernštejn, S.B. (BAN. Institut za bblgarski ezik. AN SSSR. Institut slavjanovedenija) Sof1ja, t. I 1964, t. II 1966 BL Bblgarski ezik, Sofija (BAN) ab 1951 Bulletin linguistique, Paris (später: Copenhague) ab 1933

BP

BS1

$\mathrm{DR}$

GSI

GSU

IP

Izv. IBE

JP

K2

MJ

MP

RES

RP

RLR

RSI

SbNU
Bblgarsk1 pregled, Sofija ab 1929

Byzantinoslavica, Prague ab 1929

Dacoromania, Cluj (später: Bucurest1) ab 1920

Germanoslavica, Brünn, Prag, Leipzig, Wien ab 1931 Godišnik na Sofijskija Universitet, Sofija ab 1905 Indogermanische Forschungen, Straßburg (später: Berlin) ab 1892

Izvestija na Instituta za bblgarski ezik, Sofija ab 1952

Južnoslovenski filolog, Beograd ab 1913

Zeitschrift für vergleichende Sprachforschung auf dem Gebiete des Deutschen, Griechischen und Lateinfschen (Kuhn's Zeitschrift), Berlin (später: Gütersloh, Göttingen) ab 1852

Makedonski jazik, Skopje ab 1950

Makedonski pregled, Sofija ab 1924/25

Revue des études slaves, Paris ab 1921

Revista fillologică, Cernāuţ ab 1928

Revue des langues romanes, Montpellier ab 1870 Rocznik slawistyczny, Krakow ab 1908

Sbornik za narodni umotvorenija, nauka 1 knižnina 
(BAN), Sofija ab 1889

SC Studii §i cercetări, Bucureşti (Academia románă) ab 1919

SCL Studii §i cercetări lingvistice, Bucurę̧ti ab 1950

ScS1 Scando-Slavica, Kopenhagen ab 1954

Spis. BAN Spisanie na Bblgarskata Akademija na naukite, klon istoriko-filologičen i filosofsko-obštestven, Sofija ab 1911

$2 f B$ Zeitschrift für Balkanologie, Wiesbaden ab 1962

$2 f r P h$ Zeitschrift für romanische Philologie, Tübingen ab 1878

$2 f S I$ Zeitschrift für Slawistik, Berlin ab 1956

$2 f s I P h$ Zeitschrift für slavische Philologie, Leipzig (später: Heidelberg) ab 1925 

Baldauf, I.: Der Gebrauch der Pronominalform des Adjektivs im Litauischen. (Slavistische Beiträge, Bd. 26) Hünchen 1967.

Barić, H.: Iingvističke studije. Sarajevo 1954. (Naučno dru\}tvo NR Bosne i Hercegovine, Djela, 1. odjeljenje istorijsko-filol. nauka, l.)

Ders.: Istorija arbanaškog jezika. Sarajevo 1959. (Naučno drustvo NR Bosne $i$ Hercegovine, Djela, knj. 12, Balkanoloski institut, knj. 1)

Belić, A.: Dijalekti istočne i južne Srbije. Beograd 1905. (Sipski dijalektolołki zbornik, knj. I)

Ders.: Galički dijalekat. Beograd 1935. (Srpski dijalektološki zbornik, $\mathrm{knj}$. 7)

Benveniste, E.: La phrase relative. Problème de syntaxe générale. In: Bulletin de la Société de linguistique de Paris, 53, Fasc. 1, 1958.

Berneker, E.: Die Wortfolge in den slavischen Sprachen. Berlin 1900.

Ders.: Der genitiv-accusativ bei belebten wesen im Slavischen. In: KZ 37,1904 .

Bernštejn, S.B.: Akademija Nauk SSSR. Institut slavjanovedenija. Razyskanija v oblasti bolgarskoj istoriCeskoj dialektologil. Tom 1 . Jazyk valarskich gramot 14 - 15 vekov. Moskva - Ieningrad 1948.

Ders.: $\mathrm{K}$ voprosu o periodizacil istorii bolgarskogo jazyka. In: Izvest1ja Akademii Nauk SSSR, otdelenie literatury i jazyka, tom 9, vypusk 2, 1950.

Ders. und Ceško, E.V.: Opyt klassifikacii bolgarskich govorov SSSR. In: UCenye zapiski Instituta slavjanovedenija, 4, 1951.

Birnbaum, H.: Zur Aussonderung der syntaktischen Gräzismen im Altkirchenslavischen. Einige methodische Bemerkungen. In: ScSl 4, 1958 .

Ders.: Balkanslavisch und südslavisch. In: ZfB 3, 1965.

Bogrea, $\nabla_{.}:$In chestia postpunerii articolului. In: DR 2, $1921 / 22$. 
Bojadžlev, S.: Upotreba na predloga 'na' $v$ obvremennija bslgarski ezik. In: Izv. IBE I, 1952.

Broendal, $V_{.}$: Substrat et emprunt en roman et en germanique. Etude sur l'histoire des sons et des mots. Kopenhagen 1948. (Société Roumaine de Iinguistique, sér. I, mémoires 6)

Brugmann, K., Die Demonstrativpronomina der indogermanischen Sprachen. Leipzig 1904. (Abhandlungen der KöniglichSächsischen Gesellschaft der Wissenschaften, phil.-hist. $\mathrm{KI} ., \mathrm{Bd} .22, \mathrm{Nr} .6$ )

Ders.und Delbrück, B.: Grundriß der vergleichenden Grammatik der indogermanischen Sprachen. Bd. 5. Vergleichende Syntax der indogermanischen Sprachen. 3. Straßburg 1900.

Brunot, $P_{.}:$Histoire de la langue française dès origines à 1900. Paris 1905. I.

Budagov, R.A.: Étjudy po rumynskomu sintaksisu. Moskva 1957.

Çabej, E.: Unele probleme ale istoriei limb1i albaneze. In: SCL 10, nr. 4, 1959.

Camaj, M.: Albanische Wortbildung. Wiesbaden 1966. (Albanische Porschungen, $\mathrm{Bd} .6$ )

Capidan, T.: Raporturile lingristice slavo-romine. I. Influenţa romlnă asupra limbii bulgare. In: DR 3, 1924 .

Ders.: Meglenorománif. I. Istoria gi graiul lor. II. Literatura popularā la meglenoromén11. Bucurę̧t1 1925, 1928. (Academia Romană, studii gl cercetëri, 7)

Caragiu-Mariofeanu, M.: In legaturä cu articolul enclitic al masculinelor In aromină. In: Ponetică gi dialectologie 4, Bucureg̨t1 1962.

Dies.: Flexiunea substantivelor in arominā. In: SCL 15, nr. 2, 1964 .

Ceško, E.V.: Padeži 1 predlogi $\nabla$ sovremennom bolgarskom jazyke. In: Voprosy gramatiki bolgarskogo literaturnogo jazyka. Moskva 1959.

Chodova, K.I.: Sistema padežej staroslavjanskogo jazyka. Moskva 1963.

Civ'jan, T.V.: Imja suščestritel'noe v balkanskich jazykach. $\mathbb{R}$ strukturno-tipologiceskoj charakteristike balkanskogo jazykovogo sojuza. Moskva 1965. 
Conev, B.: Koi novobslgarski govori stojat naj-blizo do starobslgarski ezik $v$ leksikalno otnosenie. In: Spis. BAN 11,1915 .

Ders.: Istorija na bslgarski ezik. Tom l. A. Obšta čast. Sofija 1919. - Tom 2. A. Obłta Cast. B. Specialni Casti. Posmbrtno izdanie. Sofija 1934.

Coteanu, I.: Despre pozitia articolului in limba romină. In: SCL 7, 1956.

Ders.: Contribufii la teoria articolului. In: SCL 9, $\mathrm{nr} .1$, 1958.

Ders.: Epocile de evolutie a limbii romine. In: SCL 9, nr. 2, 1958.

Ders.: Schif̧ă a declinării numelui in romina comunā Declinarea articulatā. In: SCL 15, nr. 4, 1964.

Densusianu, 0.: Istoria limbii romine. Vol. I und II. Bucureşti 196I.

Desnickaja, A.V.: K voprosu o vzaimodejstvii jazykov. In: Doklady $i$ soobscenija Instituta jazykoznanija Akademii Nauk SSSR 9, 1956.

Diaconescu, P.: Un mod de descriere a flexiunil nominale, cu aplicafie la limba romină contemporană. In SCL 12, $\mathrm{nr} .2$, 1961.

Dies.: Le système casuel du roumain. In: Cahiers de linguistique theorique et appliquée 1. Bucuregti 1962.

Dies.: Aspecte ale declinării cu articol definit in limba románā. In: SCL 16, nr. $1,1965$.

Diels, P.: Altkirchenslavische Grammatik I, Heidelberg 1932.

Dilevski, N.M.: Sšštestvuvat li padeži v şvremennija bslgarski ezik? In: BE 5, kn. 1, 1955.

Dimitrovski, T.I.: Značenja i upotreba na predlozite vo makedonskiot literaturen jazik. Skopje 1956.

Doroszewski, W.: Neskol'ko slov o ponjatii 'sistemy' $v$ jazyke. In: PSP-Vinogradov-Pestschrift 1965.

Ders.: Le structuralisme linguistique et les études de géographie dialectale. In: Proceedings of the Eighth International Congress of Linguists, 0slo 1958. 
Dräganu, N.: Etimologii - formele de dativ gi genitiv cu Ali gi Al in dacorominä. In: RP 2, 1928.

Duridanov, I.: Ksm problemata za razvoja na bolgarskija ezik ot sintetizsm ksm analitizsm. In: GSU 51, 1955.

Ders.: Za načenkite na analitizma $v$ bolgarski ezik. In: RSI 20, 1958.

Fraenkel, E.: Die baltischen Sprachen. Heidelberg 1950.

Gälābov, I.: Zur Prage der bulgarischen Enklitika. In: ZfslPh 20, 1950.

Dere. (= Gslsbov, I.): Ksm vsprosa $2 a$ člena v slavjanskite ezici s osoben ogled kъm bslgarski ezik. In: Izv. IBE 3 , 1957.

Ders.: Problemst za člena $v$ bslgarski 1 rumsnski ezik. Sofija 1962.

Gamillscheg, E.: Zum romanischen Artikel und Possessivpronomen. Berlin 1936. (Sitzungsberichte der PreuBischen Akademie der Wissenschaften, Phil.-hist. KI. 1936, 27.)

Ders.: Historische französische Syntax. Tübingen 1957.

Gäzdaru, D.: Descendenţu demonstrativului latin Ille in limba romină. Iaşi, Viaţa romanească 1929.

Georgiev, Vl.: Opit za periodizacija na ietorijata na bslgarskija ezik. In: Izv. IBE 2, 1952.

Ders.: Preosmisl jane na padežno okončanie $v$ členna forma. In: $\mathrm{BE} 5, \mathrm{kn} .3,1955$.

Ders.: Trakijskijat ezik. Sofija (BAN) 1957.

Ders.: On the Present State of Indo-European Linguistics. In: Proceedings of the 9 th International Congress of Linguists, Den Haag 1964.

Ders.: Lo problème de l'union linguistique balkanique. In: 1-e congrès des Etudes balkaniques, Rapport pour la séance plénière. Sofija 1966.

Giese, T.: Balkansyntax oder thrakisches Substrat?

In: Studia neophilologica 24, Uppsala 1952.

Golab, Z.: Some Arumanian-Macedonian Isogrammatisms and the Social Background of their Development. In: Ford (Journal of the Iinguistic Circle of Nen York), 15, New York 1959. 
Ders.: Dva makedonski govora (na Sucho 1 Visoka vo Solunsko).

In: (I) MJ 11-12, kn. 1-2, 1960/61

(II) MJ 13-14, kn. 1-2, 1962/63.

Ders.: Syntactic Redundance. In: The Slavic and East European Journal $8(: 1)$, Bloomington, Ind. 1964.

Graur, A.: Questions latino-roumaines (A propos de l'article postposé). In: Romania 55, Paris 1929.

Ders.: Notes sur l'article postposé en roumain. In: Romania 60, Paris 1934.

Ders.: Autour de l'article postposé. In: BL 5, 1937.

Guillaume, G.: Le problème de l'article et sa solution dans la langue française. Paris 1919.

Gufu-Romalo, V.: Unele valori ale articolului In limba rominā actualā. In: Omagiu lui Iorgu Iordan. Bucuregti 1958.

Dies.: Articolul gi categoria determinărij in limba româna actuală. In: Elemente de lingvistică structursiă, Bucureg̨ti 1967.

Hansen, A.R.: Artikelsystemet 1 rumaensk. Dissertation. Kobenhavn 1952.

Hądeu, B.P.: Le type syntactique Homo-ille ille-bonus et $8 a$ parentèle. In: Archivio glottologico italiano Bd. 3, Roma 1878.

Haugen, E.: Language contact. In: Proceedings of the Eighth International Congress of Iinguists, 0slo 1958.

Hermann, E.: Das Pronomen 108 als Adjektivum. In: Einladungsschrift des Gymnasium Casimirianum zu Coburg 1897.

Hjelmslev, L.: La catégorie des cas. In: Acta Jutlandica 7, 1. Aarhus 1935.

Ilić, V.: Pitanje porekla zameničke članske postpozicije u juznoslovenskoj jezixnoj arei. In: Godiznjak filozofskog fakul te ta u Novom Sadu 5, 1960.

Ivanov, G.: Orchanifskijat govor. In: SbNU 38, 1930.

Ivanov, V.V.: Lingulstika kak teorija otnošenif meždu jazykovymi sistemami 1 ee sovremennye prakticeskie priloženija. In: Lingristiðeskie issledovanija po małinnomu perevodu, vypusk 2, Moskva 1961. 
Ivić, P.: Dijalektologija srpskohrvatskog jezika. Uvod 1 tokavako naređje. Matica Srpska. (Novi Sad 1956)

Ders.: Značaj lingvističke geografije za uporedno 1 istorijsko prouravanje juznoslovenskih jezika i njihovih odnosa prema ostalim slovenskim jezicima. In: JP 22, $1957 / 58$.

Ders.: Die serbokroatischen Dialekte - ihre Struktur und Entwicklung. 1. Allgemeines und die $\gamma$ tokavische Dialektgruppe. ' 'Gravenhage 1958. (Slavistic Printings and Reprintings, Leiden Univ. XVIII)

Jagic, V.: Rezension von P.A. Lavrov, Obzor zvukovych 1 formal'nych osobennostej bolgarskago jazyka. In: Afsl Ph 16,1894 .

Jakobson, R.: Les enclitiques slaves. In: Att1 del III congresso internazionale dei Iinguisti, Roma 1933.

Ders.: Beitrag zur allgemeinen Kasuslehre. Prague 1936. (Travaux du Cercle linguistique de Prague, 6.)

Jakubinskij, I.P.: Istorija drevnerusskogo jazyka. Moskva 1953.

Jungmann, P.: L'emplo1 de l'article défini avec le substantif en arménien classique. In: Revue des études arméniennes, Tome 1, Paris 1964 .

Kabasanov, St.: Edin starinen bslgarski govor (Tichomirokijat govor). Sofija 1963.

Kamlah, W.und Lorenzen, P.: Logische Propädeutik oder Vorschule des vernünftigen Redens. (B.I.-Hochschul taschenbücher 227) 227a) Mannheim 1967.

Koduchov, V.I.: K voprosu o 'postpozitivnom člene' $v$ russkom jazyke. In: Utenye zapiski Leningradskogo gosudarstrennogo pedagogiCeskogo instituta 1meni A.I. Gercena. Kafedra russkogo jazyka. Tom 92, 1953.

Koneski, B.: Za padežite. In: MJ l, kn. 8, 1950.

Ders.: Trojniot člen. In: MJ 8, kn. 1, 1957.

Ders.: Istorija na makedonskiot jazik. Skopje 1965.

Konstantinov, Chr.P.: Materijal za izučvanie rodopakoto nare $1 \mathrm{e}$. In: SbNU 1, kn. 1, 1889.

Korubin, B.: Upotrebata 1 značenjata na predlogot na vo sovremeniot makedonski jazik. In: MJ $5, \mathrm{kn} .1,1954$. 
Koschmieder, E.: Beiträge zur allgemeinen Syntax. Heidelberg 1965.

Kurylowicz, J.: On the Methods of Internal Reconstruction. In: Preprints of Papers for the Ninth International Congress of Linguists. Cambridge (Mass.) 1962.

Ders.: The Inflectional Categories of Indoeuropean. Heidelberg 1964 .

Kurz, J.: K otázce členu v jazyclch slovanskfch se zvláštnim złetelem $k$ starosloventine. In: BSI 7, 1937/38 und BSI $8,1939 / 46$.

Ders.: Význam studia jazyka staroslověnského pro historickogrovnávac1 zkoumán1 slovanskfch jazykú. In: SIavia. Casopis pro slovanskou filologi1, 21, Praha 1952.

Ders.: K otázce doby vaniku slovanskfch adjektiv složenf́ch a jejich púvodniho víznamu. In: Studie ze slovanské jazykovedy. Praha 1958.

Ders.: K otḱzce nominativu zájmena třet1 osoby $v$ slovanštině. In: Slavica Pragensia 2, 1960.

Ders. (= Kurc, I.): Problema člena v staroslavjanskom jazyke (Konstrukcil surcestvitel'nogo s mestoimeniem ukazatel'nym 1 s dal'nej子im atributom). In: Issledovanija po sintaksisu s taroslavjanskogo jazyka. Praga (CAN) 1963.

Ders. (= Kurc, I.): Problematika issledovanija sintaksisa staroslavjanskogo jazyka. In: Isgledovanija po olntaksisu ataroslavjanskogo jazyka. Praga (

Lamouche, L.: Les déterminatifs dans les langues slaves du sud. In: Mémoires de la société de linguistique de Paris $12,1903$.

Lavrov, P.A.: Obzor zrukovych 1 formal'nych osobennostej bolgarskago jazyka. Moskva 1893.

Löfstedt, E.: Syntactica. 2. erw. Auflage. 1. Lund 1942 2. Lund 1933. Neudruck Iund 1956.

Lunt, H.G.: On the Loss of Declension in Bulgarian and Macedonian. In: Die Welt der Slaven 10, 1965.

Marguliés, A.: Der altkirchenslavische Codex Suprasliensis. Heidelberg 1927.

Mazon, A.: Documents, contes et chansons slaves de l'Albanie du Sud. Paris 1936. (Bibliothèque d'Etudes Balkaniques - V) 
Ders. und Valllant, A.: L'évangéliaire de Kulakia. Un parler slave du Bas-Vardar. Paris 1938. (Bibliothèque d'Etudes Balkaniques - VI)

Meillet, A.: Les formes nominales en slave. In: RES 3, 1923.

Ders.: Le slave commun. 2. éd., revue et augmentée. Paris 1934 .

Ders.: Les dialectes indo-européens. Paris 1950.

Meyer, K.H.: Der Untergang der Deklination im Bulgarischen. Heidelberg 1920. (Slavica. 3.)

Meyer-Lübke, W.: Grammatik der romanischen Sprachen. 2. Bd. Formenlehre. Leipzig 1894 .

Ders.: Rumänisch und Romanisch. In: Academia Românā, Memorile sectiunii literare, Seria III, Tomul V. Bucuregti 1930/31.

Michov, D.M.: Die Anwendung des bestimmten Artikels im Rumänischen, verglichen mit der im Albanesischen und Bulgarischen. Dissertation. Leipzig 1908.

Mihăescu, H.: Limba latină in provincille dunărene ale imperiului roman. Bucureşti 1960.

Miletič, L.: 0 članu u bugarskom jeziku. Disgertation. Zagreb 1889

Ders.: Staroto sklonenie $v$ dnešnite bblgarski narečija. In: SbNU 2, 1890.

Ders.: Dako-rombnite 1 tjachnata slavjanska pismenost. In: SbNU 9, 1893.

Ders.: Novi vlachobslgarski gramoti ot Brašov. In: SBNU 13, 1896.

Ders.: Clenbt $\vee$ bblgarski 1 ruski ezik. In: SbNU 18, 1901.

Ders.: Das Ostbulgarische. Tien 1903. (Schriften der Balkancommission. Linguistische Abtheilung II)

Ders.: Kbm gramotite ot Brašovakata sbirka. In: SbNU 25, 1909.

Ders.: Die Rhodopemundarten der bulgarischen Sprache. Wien 1912. (Schriften der Balkankommission. Linguistische Abtellung $X$ )

Ders.: Zur Geschichte der bulgarischen Nominalflexion. In: AfslPh 39, 1925. 
Ders.: Sedmogradskite bblgari i technijat ezik. In:

Spis. BAN, kn. 33, nr. 18, 1926.

Ders.: Pokazatelnite mestoimenija $v$ postpozitivna služba.

In: Symbolae grammaticae in honorem loannis Rozwadowski,

2, Kraków 1927.

Ders.: Edinstvo na b̧lgarskija ezik $v$ negovite narečija. In: BP l, kn. 1, 1929.

Ders.: Prilagatelni členni formi v starobßlgarskija ezik. In: MP $8, \mathrm{kn} .2,1932$.

Ders.: Kъm istorijata na trojnija člen $v$ bblgarskija ezik. In: BP 2, kn. 1, 1933.

Ders.: Krm istorijata na bslgarskoto analitično sklonenie. In: MP 9, kn. 3-4, 1935 .

Mirčev, K.: Koga vъznikva člennata forma $v$ bъlgarski ezik? In: $\mathrm{BE} 3,1953$.

Ders.: Po vbprosa za sklonenieto v bblgarski ezik. In: BE 4, kn. 1, 1954 .

Ders.: Za člennite formi $v$ Dobrejšovo evangelie. In: BE 6 , 1956.

Ders.: Istoričeska gramatika na bblgarskija ezik. 2. Aufl., Sofija 1963.

Ders.: 2a chronologijata na osnovnite balkanizmi $v$ bblgarski ezik. In: BE 16, kn. 4, 1966.

Mladenov, St.: Geschichte der bulgarischen Sprache. Berlin 1929. (GrundriB der slavischen Philologie und Kulturgeschichte. 6)

Muller, F.: Zur Geschichte des Artikels und zur Wortfolge besonders in den italischen sprachen. In: IF 42, 1924.

Netteberg, Kristine: 0 formacjach od rdzeni zaimkowych. In: ScSl 4, 1958.

Nilsson, E.: Wackernagel's Gesetz im Slavischen. In: KZ 37, 1904 .

Oblak, V.: Macedonische Studien. Wien 1896. (Sitzungsberichte der Kaiserlichen Akademie der Wissenschaften, Phil.-hist. KI., Bd. 134, Jahrgang 1895, VIII. Abhandlung) 
Pastrnek, Fr.: Die griechischen Artikelkonstruktionen in der altkirchenslavischen Psalter- und Evangelienübersetzung.

I. In der Psalterübersetzung. In: AfslPh 25, 1903.

Pavlović, M.: L'elemento romanzo e non romanzo nella posposizione dell'articolo nelle lingue balchaniche. In:

Studia romanica $l=N r .1 / 2$. Zagreb 1956 .

Ders.: Perspektive i zone balkanističkih jezičkih procesa.

In: JP 22, $1957 / 58$.

Ders.: Tragovi prastarog jezičkog supstrata Sredozemlja na Balkanu 1 Pirinejima. In: Godiznjak filozofskog fakulteta u Novom Sadu 3, 1958.

Pedersen, H.: Albanesisch und Armenisch. In: K2 36, 1900.

Pekmezi, G.: Grammatik der albanesischen Sprache (Laut- und Pormenlehre). Wien 1908.

Piotrovskij, R.G.: 0 sravnitel'noj chronologil postpozicil opredelennogo artiklja $v$ tak nazyvaemych balkanskich jazykach. In: Voprosy slavjanskogo jazykoznanija 4, Moskva 1959.

Ders.: Pormirovanie artikl ja $v$ romanskich jazykach. Moskva-Leningrad 1960.

Pisani, V.: Saggi di linguistica storica. Torino 1959.

Popovik, I.: Geschichte der serbokroatischen Sprache. Wiesbaden I960. (Bibliotheca Slavica)

Popovic1, Io.: Dialectele Románe, 9. Dialectele románe din Istria. Partea I: Gramatica. Partea II: Texte gi glosar. Halle 1914 .

Procopovici, A.: Din 1storia pronumelui in limba románeascã. 4. Articolul antepus gi articolul demonstrativ, pronumele determinative ăl, äst gl variantele lor; cuculi = cucului. In: RP 2, 1928.

Puşcariu, S.: Zur Rekonstruktion des Urrumänischen. In: Beihefte zur ZfrPh, Nr. 26, Halle 1910.

Ders.: Der lu-Genitiv im Rumänischen. In: ZfrPh 4l, 1922.

Ders.: Raporturile slavo-romine. In: DR 6, 1929/30.

Ders.: Zur Nachstellung des rumänischen Artikels. In: 2 frPh 57, 1937. 
Racoviţā, C.: I'article en russe. In: BI 7, 1939.

Radoševic, N.: Prilog pitanju člana u staroslovenskim spomenicima. In: JP 16, 1937.

Reichenkron, G.: Zur Geschichte des auslautenden -ụ im Rumänischen. In: Cahiers Sextil Puø̧cariu, Vol. I, Pasc. 2, Roma - Valle Hermoso 1952.

Ders.: Anfänge einer Artikelausbildung im Serbokroatischen?

In: Die Welt derSlaven 11, Heft 4. Wiesbaden 1966.

Reiter, N.: Zur Stellung der Enklitika im Serbokroatischen. In: $2 f 8 I \mathrm{Ph} \mathrm{27,} 1959$.

Ders.: Der Artikel in den Balkansprachen. In: ZfB 5, Heft 1 , 1967.

Rosetti, A.: Influenta limbilor slave meridionale asupra

limbii romine. (sec. VI - XII). Bucuresti 1954.

Ders.: Balcanica. Consideratii asupra 'uniunii Iingristice' balcanice. In: SCI 9, ar. 3, 1958.

Ders.: Ia situation du roumain parmi les langues balkaniques.

In: Slarjanska filologija 3. Sofija 1963.

Ders.: Istoria limbii románe. I. 4. Aufl. 1964.

$$
\begin{aligned}
& \text { II. 4. Aufl. } 1964 . \\
& \text { III. 5. Aufl. } 19644^{\circ} \\
& \text { IV. V. VI. } 1966 \text { Bucuresti. }
\end{aligned}
$$

Rưžička, R.: Griechische Lehnsyntax im Altslavischen. In: ZfSI 3, 1958.

Sandfeld-Jensen, K.: Iinguistique balkanique. Problèmes et résultats. Paris 1930 .

de Saussure, P.: Cours de linguistique generale. Lausanne-Paris 1916.

Schröpfer, J.: Zur inneren Sprachform der Balkanvölker. In: ZfSI $1(: 4), 1956$.

Schürr, Pr.: Zum rumänischen Artikel. In: Romanische Por8chungen 55,1941 .

Schwyzer, E.: Die nominale Determination in den indogermanischen Sprachen. In: KZ 63, 1936. 
Sedláček, J.: Sintaksis staroslavjanskogo jazyka $v$ svete balkanistiki. In: Slavia $32(: 3), 1963$.

Seidel, E.: Zu den Funktionen des Artikels. In: BL 8, 1940.

Ders.: Gibt es ein Genus Personale? In: BL 15, 1947.

Ders.: Elemente sintactice slave in limba romină (Materiale gi cercetări lingvistice III). Bucureşti 1958.

Ders.: Probleme und Methoden der Balkanlinguistik. In: Omagiu lui Iorgu Iordan. Bucuregti 1958.

Ders.: Zur Rolle des Bulgarischen in der Balkanlinguistik. In: ZfSI $8(: 6), 1963$.

Seliščev, A.: Des traits linguistiques communs aux langues balkaniques. In: RES 5, 1925.

Senn, A.: Kleine litauische Sprachlehre. Heidelberg 1929.

Sfirlea, L.: Coexistenta mai multor sisteme morfologice in acelą̧i grai regional (Valea Sebeģului). In: Cercetāri de lingvistică 2 , Cluj 1957.

Şiadbei, I.: Persistenţa cazurilor latine in Romania orientalä. In: Mélanges de linguistique et de littérature romanes offerts à Mario Roques, IV, Paris 1952.

Skok, P.: Considérations générales sur la déclinaison nominale roumaine-albanaise. In: Arhiv za arbanasku starinu 3, 1926.

Ders.: 0 bugarskom jeziku u svjetlosti balkanistike. In: JP 22, 1933.

Slama-Cazacu, T.: Cazurile oblice in evolutia limbajului copilului. In: SCL 12, $\mathrm{nr} .2,1961$.

sławski, P.: Miejsce enklityki odmiennej $w$ dziejach języka buX garskiego. Kraków 2946.

Ders.: Zarys dialektologii poludniowo-słowiańskiej. Warszawa 1962.

Specht, F.: Die Flexion der n-Stämme im Baltisch-Slavischen und Verwandtes. In: KZ 59.

Stölting, W.: Das Artikelsystem im Albanischen und Rumänischen. In: Beiträge zur Südosteuropa-Porschung, anläBlich des 1. In ternationalen Balkanologenkongresses in Sofia 1966, München 1966. 
Stojkov, St.: Bblgarska dialektologija. Sofija 1962.

Svane, G.: K voprosu o prolschoždenii člena v vostočnoj gruppe južnoslavjanskich jazykov. In: ScSl 4, 1958.

Ders.: 0 sintaksičeskom primenenil bolgarskogo člena $v$ XIII veke. A. Cergedskie teksty. In: ScSl 7 (1961).

Ders.: B. Dobrejšovo evangelie. In: ScS1 8, 1962.

Tanase, E.: La postposition de l'article défini en roumain. In: Revue des langues romanes $75,1962$.

Tiktin, H.: Rumänisches Elementarbuch. Heidelberg 1905.

Togeby, $K_{.}:$Le problème de l'article en roumain (à propos de A. Hansen, Artikelsystemet i rumaensk, thèse Copenhague 1952). In: Cahiers Sextil Puşcariu, Vol. 1, Roma - Valle Hermoso 1952.

Trifonov, J.: Kъr istorijata na člennite formi $v$ bslgarski ezik. In: MP 7, kn. l, 1931.

Trubetzkoy, N.S., in: Actes du 1-er Congrès International des linguistes ì la Haye 1928. Leiden 1928.

Väänänen, V.: Introduction au latin vulgaire. Paris 1963. (Bibliothèque Prançaise et Romane. Série $A$ : Manuels et études linguistiques)

Vaillant, A.: L'article en vieux slave. In: RES 20, 1942.

Ders.: Grammaire comparée des langues slaves, Bd. 2, 1958 Lyon.

Valentini, G.: La declinazione determinata e indeterminata in Albanese. In: Ricerche linguistiche, 2, Roma 1951.

Vasiliu, E.: Observaţi asupra flexiunii nominale in limba romină. In: SCL $4,1953$.

Velčeva-Bojadžieva: Kъm vъprosa za izčezvaneto na tričlennata pokazatelna sistema $\checkmark$ bolgarski ezik. In: Slavistiten sbornik (BAN). Sofija 1963.

Vidoevski, B.: Severnite makedonski govori. In: MJ 5 , $\mathrm{kn} .1,2,1954$.

Ders.: Osnovni dijalektni grupi vo Makedonija. In: MJ 11-12, kn. 1-2, 1960/61. 
Ders.: Makedonskite dijalekti vo svetlinata na lingvističkata geografija. In: MJ 13-14, kn. 1-2, 1962/63.

Vogt, H.: Dans quelles conditions peut $s^{\prime}$ exercer sur le système morphologique d'une langue l'action du système morphologique d'une autre langue? In: Actes du 6-ième Congrès International des linguistes, Paris 1948.

Vondrák, T.: Vergleichende slavische Grammatik. 2. Bd. Formenlehre und Syntax. 2. Aufl. Göttingen 1928.

Tackernagel, J.: Vorlesungen über Syntax, mit besonderer Berücksichtigung von Griechisch, Lateinisch und Deutsch. Reihe I, II. Basel (1950) 1928.

Weigand, G.: Vlacho-Meglen - eine ethnographisch-philologische Untersuchung. Leipzig 1892.

Weinreich, U.: Languages in Contact. New York 1953.

v. Tijk, N.: Eine slavisch-germanische syntaktische Parallele. In: GSI 3, Heft 1-4, 1935.

Tissemann, H.: Die Sytax der nominalen Determination im Großrussischen. (Veröffentlichungen des Slavischen Instituts an der Priedrich-Tilhelms-Universität Berlin, Heft 25) Leipzig 1939.

Ders.: Zur nominalen Determination. I. Die Grundfunktion des bestimmten Adjektivs im Bal tischen und Slavischen. In: IP $63,1957 / 58$. 